\title{
UICN
}

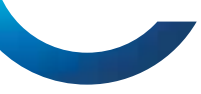

\section{La Conservación en una Nueva Era}

Jeffrey A. McNeely y Susan A. Mainka

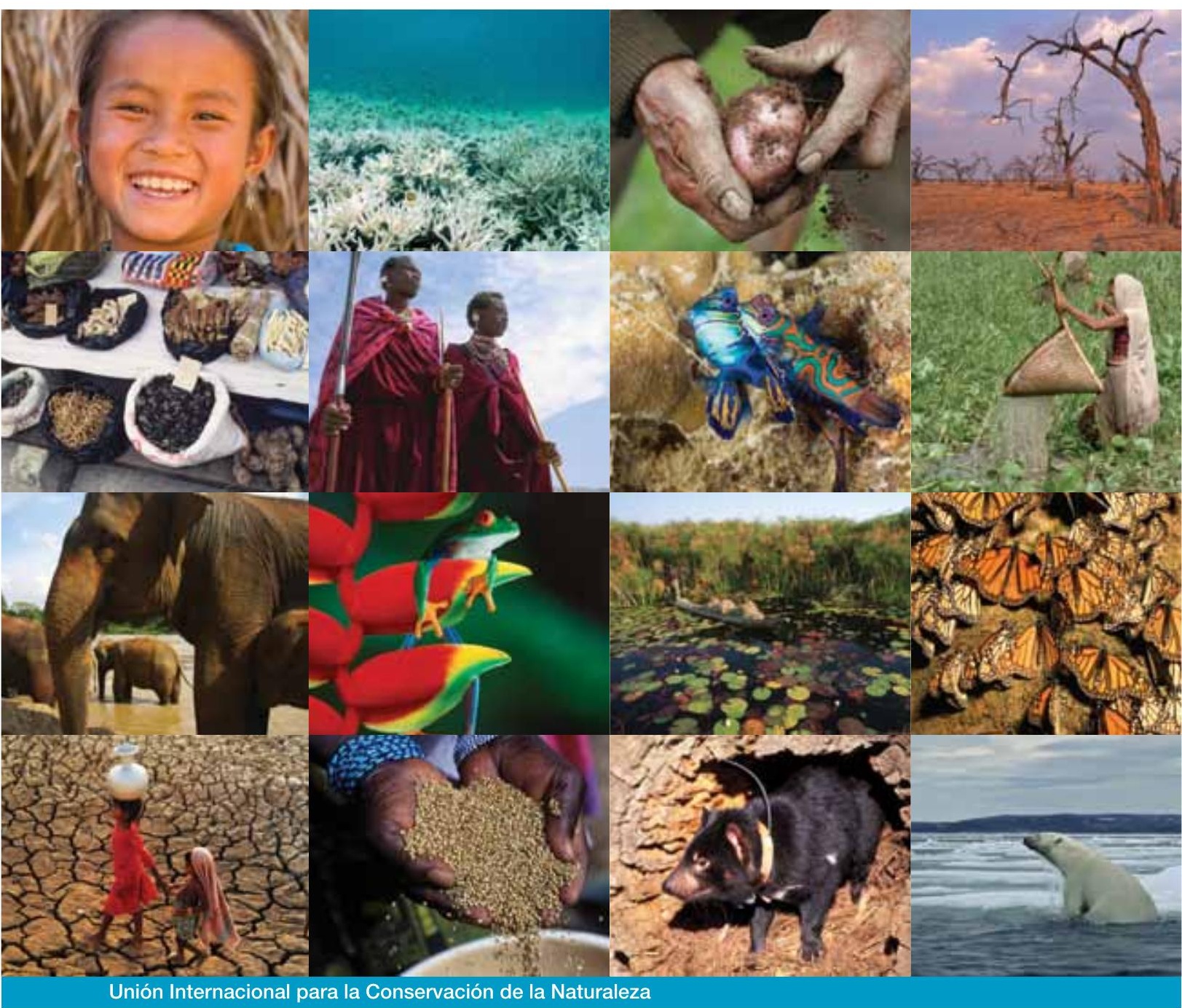

零 Ajuntament de Barcelona 


\section{La Conservación en una Nueva Era}

Jeffrey A. McNeely y Susan A. Mainka 
Traducción:

Patricia Odio-Iglesias

Diagramado por:

Charlescannon

Impreso por: abp project

Disponible en:

UICN (Unión Internacional para la Conservación de la

Naturaleza)

Servicio de publicaciones

Rue Mauverney 28

1196 Gland, Suiza

Tel +41 229990000

Telefax +41229990020

books@iucn.org

www.iucn.org/publications

También existe a disposición un catálogo de las publicaciones de la UICN.

El texto de este libro fue impreso en papel FSC.
La designación de entidades geográficas y la presentación del material en este libro no implican la expresión de ninguna opinión por parte de la UICN respecto a la condición jurídica de ningún país, territorio o área, o de sus autoridades, o referente a la delimitación de sus fronteras y límites.

Los puntos de vista que se expresan en esa publicación no reflejan necesariamente los de la UICN.

La UICN y las organizaciones participantes declinan cualquier error u omisión en la traducción de este documento de la versión original en ingles al español.

Publicado por: UICN, Gland, Suiza

Derechos reservados: (C) 2009 Unión Internacional para la Conservación de la Naturaleza y de los Recursos Naturales

Se autoriza la reproducción de esta publicación con fines educativos y otros fines no comerciales sin permiso escrito previo de parte de quien detenta los derechos de autor con tal de que se mencione la fuente.

Se prohibe reproducir esta publicación para la venta o para otros fines comerciales sin permiso escrito previo de quien detenta los derechos de autor.

Citación: McNeely, J.A. y S.A. Mainka (2009). La Conservación en una Nueva Era.

UICN, Gland, Suiza. 232 pp. 


\section{Tabla de Contenido}

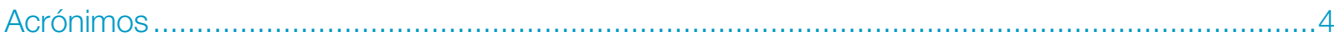

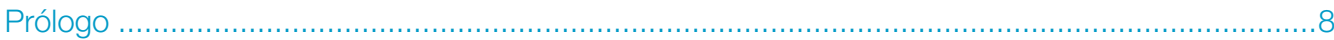

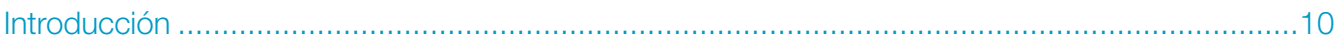

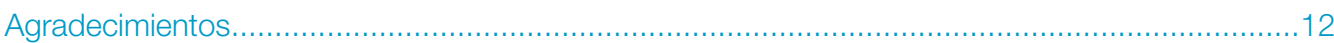

1. El Foro de Barcelona: Un Mundo Diverso y Sostenible.................................................................14

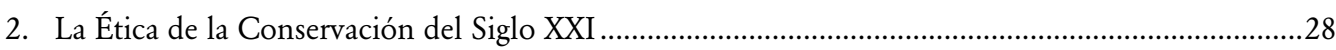

3. El Papel Central de las Personas ...................................................................................................

4. Servicios de los Ecosistemas: Los Beneficios que la Naturaleza Ofrece a las Personas ......................42

5. Cambio Climático y Biodiversidad...................................................................................................

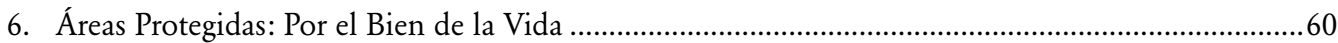

7. Conservación de las Especies: Los Retos del Mundo Actual.............................................................68

8. Un Futuro Post Petróleo: ¿Qué Significa para la Conservación?...........................................................78

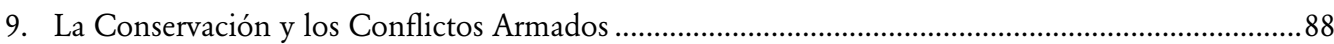

10. Afrontando el Desastre: Consideraciones sobre los Ecosistemas para la Recuperación Post Desastre .......................................................................................................96

11. Salud Humana y Biodiversidad: Cómo Puede Contribuir la Conservación ....................................102

12. Desarrollo de una Economía "Verde" ........................................................................................110

13. Tecnología y Conservación.......................................................................................................

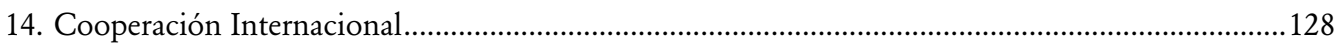

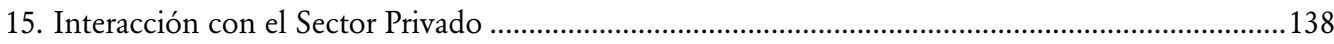

16. Sistemas Forestales: Percibiendo los Bosques y los Árboles ............................................................146

17. Sistemas Marinos: Encauzando la Conservación hacia el Mar .......................................................154

18. Sistemas de Tierras Secas: Se Trata del Agua ..........................................................................162

19. Sistemas de Agua Dulce: Gestión de Caudales para Beneficio de las Personas y la Naturaleza ......170

20. Sistemas Agrícolas: La Biodiversidad en Paisajes Domesticados ........................................................178

21. Sistemas Urbanos: La Conservación en las Ciudades ..................................................................186

22. Puntos Centrales para la Conservación en una Nueva Era................................................................194

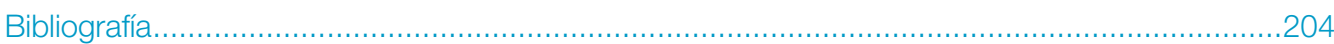

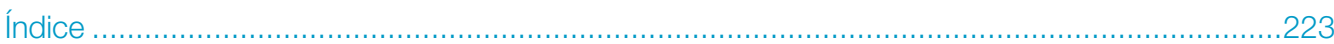




\section{Acrónimos}

\begin{tabular}{|c|c|c|c|}
\hline ACR & Acuerdos comerciales regionales & CITES & Convención sobre el comercio \\
\hline $\mathrm{ADB}$ & Banco Asiático de Desarrollo & & internacional de especies amenazadas \\
\hline \multirow[t]{2}{*}{ ALCA } & Área de Libre Comercio de las & & \\
\hline & Américas & CMAP & Comisión Mundial de Áreas Protegidas \\
\hline \multirow{2}{*}{ AMMA } & Acuerdo multilateral sobre el medio & CMn & Compañías multinacionales \\
\hline & ambiente & $\mathrm{CMN}$ & Congreso Mundial de la Naturaleza \\
\hline AMP & Áreas marinas protegidas & CMS & Convención sobre las Especies \\
\hline $\mathrm{AP}$ & Áreas protegidas & & Migratorias \\
\hline \multirow[t]{2}{*}{$\mathrm{APB}$} & Acceso y participación en los & COP & Conferencia de las Partes \\
\hline & beneficios & CPAES & Comisión de Política Ambiental, \\
\hline \multirow[t]{2}{*}{ BBOP } & Programa de Compensaciones de & & Económica y Social de la UICN \\
\hline & Negocios y Biodiversidad & $\mathrm{CPF}$ & Asociación de Colaboración en \\
\hline \multirow[t]{2}{*}{ BIP } & Alianza sobre Indicadores de & & Materia de Bosques \\
\hline & Biodiversidad & CSD & Comisión sobre el Desarrollo Sostenible \\
\hline BM & Banco Mundial & CSE & Comisión de Supervivencia de Especies \\
\hline BOD & Demanda biológica de oxígeno & & de la UICN \\
\hline CCAD & $\begin{array}{l}\text { Comisión Centroamericana de } \\
\text { Ambiente y Desarrollo }\end{array}$ & $\mathrm{DAC}$ & $\begin{array}{l}\text { Comité de Asistencia al Desarrollo (de } \\
\text { OCDE) }\end{array}$ \\
\hline CCS & $\begin{array}{l}\text { Captura y almacenamiento del } \\
\text { carbono }\end{array}$ & DAES & $\begin{array}{l}\text { Departamento de Asuntos Económicos } \\
\text { y Sociales de las Naciones Unidas }\end{array}$ \\
\hline CDA & Centro de Derecho Ambiental & DALY & Años de vida perdidos por incapacidad \\
\hline \multirow[t]{2}{*}{ CDA } & Comisión de Derecho Ambiental de la & $\mathrm{EbA}$ & Adaptación basada en el ecosistema \\
\hline & UICN & EIA & Evaluación de Impacto Ambiental \\
\hline CDB & Convenio sobre la Diversidad Biológica & EM & Evaluación de los Ecosistemas del \\
\hline \multirow[t]{2}{*}{ CEC } & Comisión de Educación y & & Milenio \\
\hline & Comunicación de la UICN & EPANDB & Estrategias y planes de acción \\
\hline \multirow[t]{2}{*}{ CEFDHAC } & $\begin{array}{l}\text { Conférence sur les Ecosystèmes de } \\
\text { Forêts Denses et Humides d'Afrique }\end{array}$ & & $\begin{array}{l}\text { nacionales en materia de diversidad } \\
\text { biológica }\end{array}$ \\
\hline & Centrale & FAO & Organización de las Naciones \\
\hline CGE & $\begin{array}{l}\text { Comisión de Gestión de Ecosistemas } \\
\text { de la UICN }\end{array}$ & & $\begin{array}{l}\text { Unidas para la Agricultura y la } \\
\text { Alimentación }\end{array}$ \\
\hline CIFOR & $\begin{array}{l}\text { Centro Internacional de Investigación } \\
\text { Forestal }\end{array}$ & FLEG & $\begin{array}{l}\text { Aplicación de las leyes y gobernanza } \\
\text { sobre los bosques }\end{array}$ \\
\hline
\end{tabular}




\begin{tabular}{|c|c|c|c|}
\hline FLEGT & $\begin{array}{l}\text { Plan de Acción para la aplicación de las } \\
\text { leyes, gobernanza y comercio forestales }\end{array}$ & IRC & $\begin{array}{l}\text { Centro Internacional de Agua Potable } \\
\text { y Saneamiento }\end{array}$ \\
\hline FMAM & $\begin{array}{l}\text { Fondo para el Medio Ambiente } \\
\text { Mundial }\end{array}$ & ISSC-MAP & $\begin{array}{l}\text { Estándar Internacional para la } \\
\text { Recolección Silvestre Sostenible de }\end{array}$ \\
\hline GBO & Perspectiva Mundial sobre Diversidad & & Plantas Medicinales y Aromáticas \\
\hline GDM & Mecanismo de desarrollo verde & ISSG & $\begin{array}{l}\text { Grupo especialista de la CSE/UICN } \\
\text { en especies invasoras }\end{array}$ \\
\hline GFP & Alianzas Growing Forests & IUFRO & $\begin{array}{l}\text { Unión Internacional de Organizaciones } \\
\text { de Investigación Forestal }\end{array}$ \\
\hline GHG & Gas de efecto invernadero & IUU & Ilegal, no comunicado y no regulado \\
\hline GISP & $\begin{array}{l}\text { Programa mundial sobre especies } \\
\text { invasoras }\end{array}$ & IWRM & $\begin{array}{l}\text { Manejo Integrado de los Recursos } \\
\text { Hídricos }\end{array}$ \\
\hline GSTC & $\begin{array}{l}\text { Alianza para los Criterios Mundiales de } \\
\text { Turismo Sostenible }\end{array}$ & MDL & Mecanismo para un desarrollo limpio \\
\hline ICCAT & Asociación Mundial para el Agua & NEPAD & $\begin{array}{l}\text { Nueva Alianza para el Desarrollo de } \\
\text { África }\end{array}$ \\
\hline ICMM & Conservación del Atún Atlántico & OCDE & $\begin{array}{l}\text { Organización para la Cooperación y el } \\
\text { Desarrollo Económicos }\end{array}$ \\
\hline & Metales & ODA & Asistencia Oficial para el Desarrollo \\
\hline ICRAF & Centro Mundial de Agroforestería & ODM & Objetivo(s) Idem de Desarrollo del Milenio \\
\hline IDH & $\begin{array}{l}\text { Índice de Desarrollo Humano } \\
\text { Agencia Internacional de la Energía }\end{array}$ & OGM & $\begin{array}{l}\text { Organismo(s) genéticamente } \\
\text { modificado(s) }\end{array}$ \\
\hline IED & Inversiones extranjeras directas & OIMT & $\begin{array}{l}\text { Organización Internacional de las } \\
\text { Maderas Tropicales }\end{array}$ \\
\hline IIDs & $\begin{array}{l}\text { Instituto Internacional para el } \\
\text { Desarrollo Sostenible }\end{array}$ & OMC & Organización Mundial de Comercio \\
\hline IIED & $\begin{array}{l}\text { Instituto Internacional para el Medio } \\
\text { Ambiente y Desarrollo }\end{array}$ & OMM & Organización Meteorológica Mundial \\
\hline IOSEA & $\begin{array}{l}\text { Memorando de Entendimiento sobre } \\
\text { la Conservación y Ordenación de las } \\
\text { Tortugas Marinas y sus Hábitats en el } \\
\text { Océano Índico y Asia Sur Oriental }\end{array}$ & PALNet & $\begin{array}{l}\text { Red de Aprendizaje sobre Áreas } \\
\text { Protegidas } \\
\text { Reacción en cadena de la polimerasa }\end{array}$ \\
\hline IPCC & $\begin{array}{l}\text { Grupo Intergubernamental de Expertos } \\
\text { sobre el Cambio Climático }\end{array}$ & $\begin{array}{l}\text { PIB } \\
\text { Pymes }\end{array}$ & Pequeñas y medianas empresas \\
\hline
\end{tabular}


PNUD Programa de las Naciones Unidas para el Desarrollo

PNUMA Programa de las Naciones Unidas para el Medio Ambiente

PSE Pagos por servicios de los ecosistemas

REDD Reducción de las Emisiones derivadas de la Deforestación y la Degradación de los bosques

RFP Solicitud de propuestas

RSB Mesa Redonda sobre Biocombustibles Sostenibles

RSE Responsabilidad Social Empresarial

SE Servicios de los ecosistemas

SEI Instituto Ambiental de Estocolmo

TEEB La Economía de los Ecosistemas y la Biodiversidad

TI Tecnología de la Información

TIC Tecnología de Información y Comunicación

UICN Unión Internacional para la Conservación de la Naturaleza

UNCCD Convención de las Naciones Unidas de Lucha contra la Desertificación (CNULD)

UNCLOS Convención de las Naciones Unidas sobre el Derecho del Mar (CNUDM)

UNCTAD Conferencia de las Naciones Unidas sobre Comercio y Desarrollo

UNECE Comisión Económica de las Naciones Unidas para Europa

UNESCO Organización de las Naciones Unidas para la Educación, la Ciencia y la Cultura

UNFCCC Convención Marco de las Naciones Unidas sobre el Cambio Climático (CMNUCC)
UNFF Foro de las Naciones Unidas sobre Bosques

UNWTO Organización Mundial del Turismo de las Naciones Unidas (OMT)

VPA Acuerdo de cooperación voluntaria

WBCSD Consejo Empresarial Mundial para el Desarrollo Sostenible

WCED Comisión Mundial sobre Medio Ambiente y Desarrollo

WDPA Base de Datos Mundial sobre Áreas Protegidas

WGWAP Grupo consultivo occidental de la ballena gris

WRI Instituto de Recursos Mundiales

WSSD Cumbre Mundial sobre el Desarrollo Sostenible

WWF Fondo Mundial para la Naturaleza 


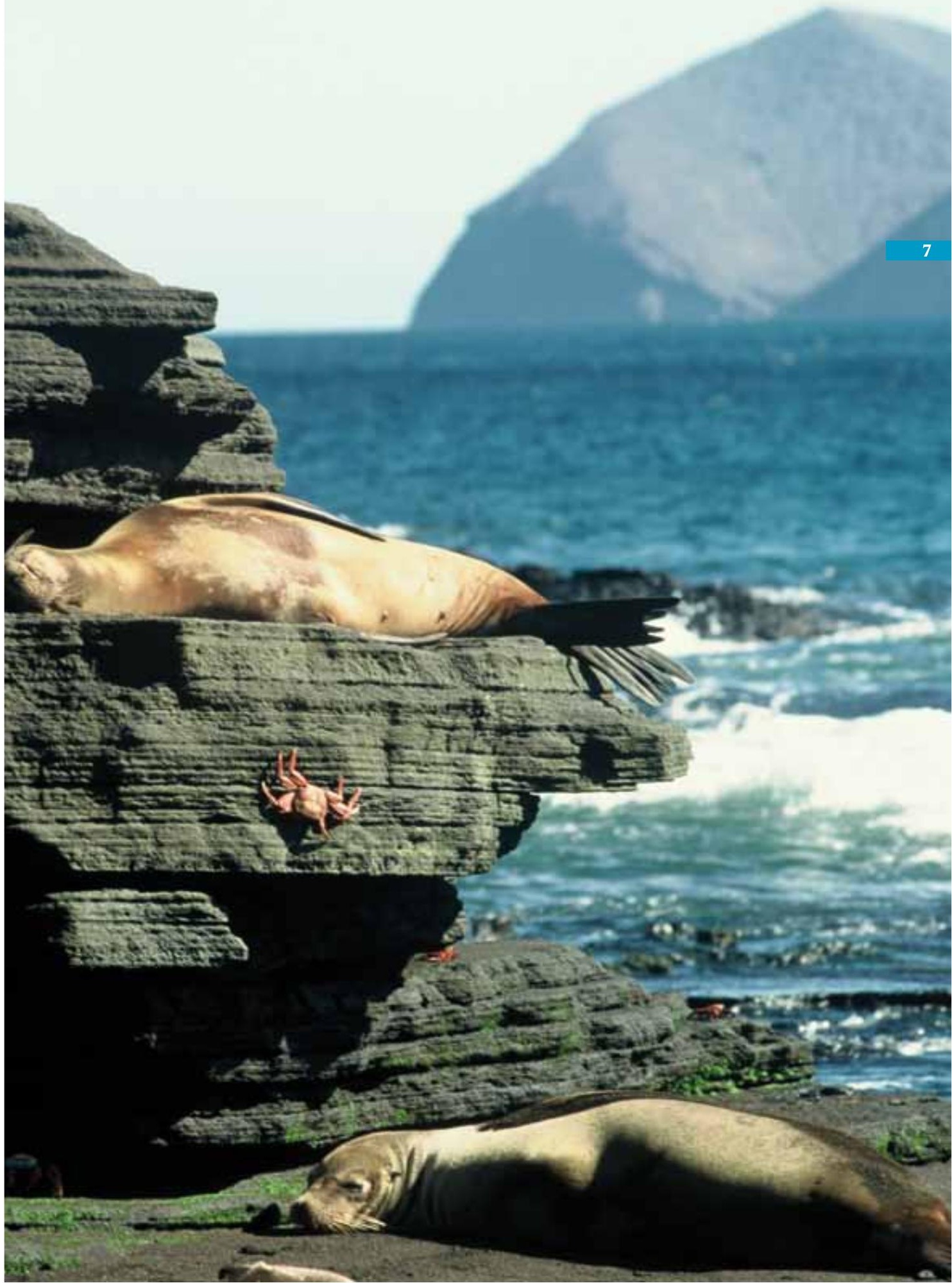




\section{Prólogo}

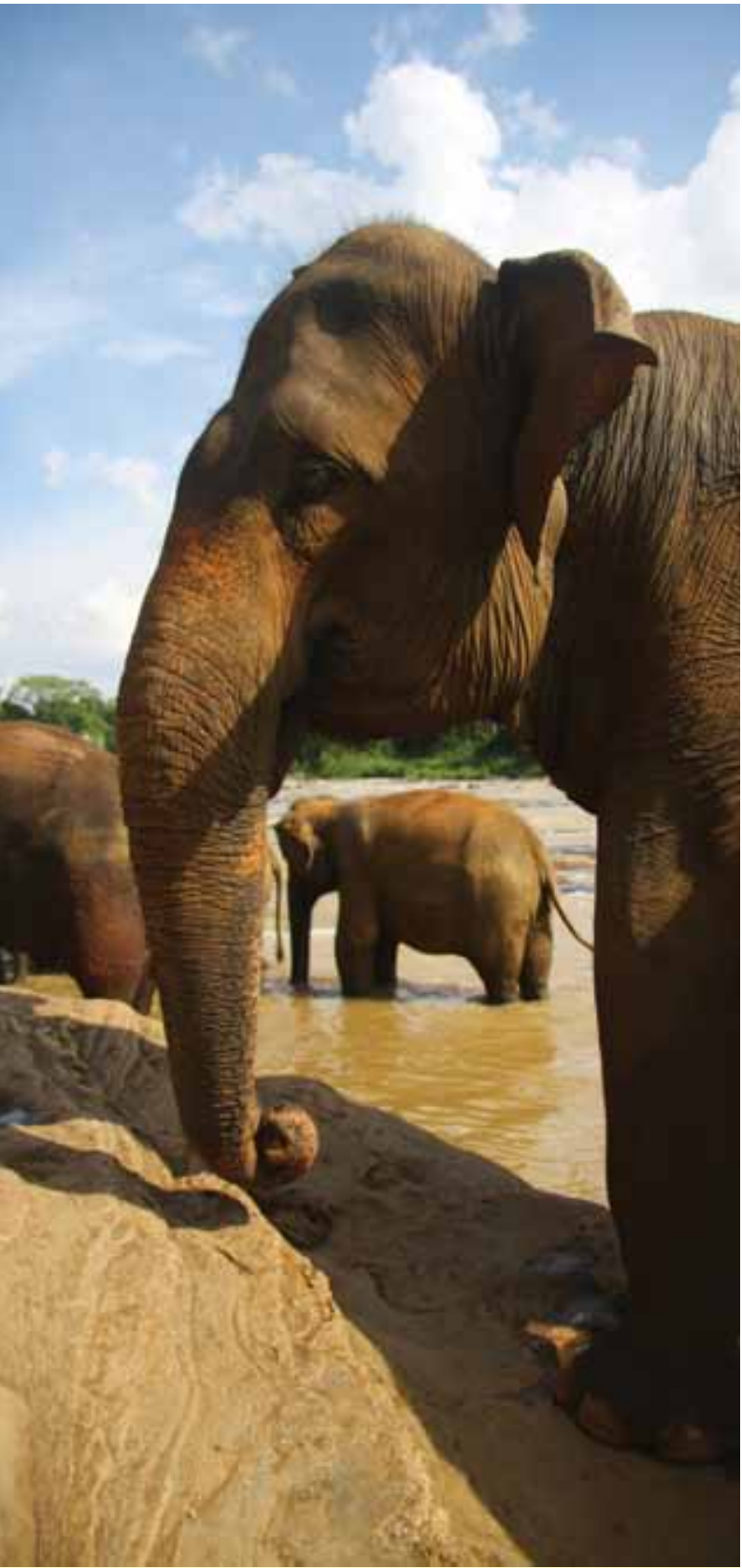

La conversación por sí sola no puede hacer de la conservación una realidad. Ni siquiera una buena conversación.

Para lograr buenos resultados de conservación es preciso mucho trabajo, principalmente a nivel de campo. La vida de un conservacionista conlleva muchas horas viajando de aquí para allá, largas horas de observación, extensos períodos de análisis, pensamiento profundo y síntesis -y aún más horas en el laboratorio y la biblioteca para efectos de documentación y comunicación. Esto no quiere decir que una vida dedicada a la conservación sea tediosa; todo lo contrario, su propia naturaleza es divertida pero su principal diversión está en la naturaleza.

Sin embargo, al igual que en todas las profesiones, el avance del conocimiento en el campo de la conservación depende de compartir, criticar, cuestionar, afinar y perfeccionar ideas de la investigación para la acción mediante la interacción con colegas y pares de otras disciplinas. Si bien las comunicaciones modernas han revolucionado las posibilidades de tal interacción, no hay sustituto igual para los encuentros en los 
que los investigadores y los profesionales tienen la oportunidad de reunirse para intercambiar información sobre lo que están haciendo.

El encuentro supremo es, por supuesto, el congreso mundial periódico que congrega profesionales en cantidades suficientemente numerosas como para demarcar las fronteras del conocimiento actual, crear puntos de referencia colectivos y establecer conexiones y redes para el trabajo futuro. Y nada como un congreso de ese tipo para centrar la mente de un profesional para presentar ante un público interesado los últimos avances e identificar oportunidades para los siguientes saltos cuánticos necesarios en nuestro conocimiento y comprensión.

En otras palabras, aunque la conversación por sí sola no es suficiente, la buena conservación requiere de vez en cuando de una buena conversación.

Es por ello que en 1996 la UICN decidió ampliar la Asamblea de los Miembros que se celebra cada cuatro años en el Congreso Mundial de la Naturaleza $(\mathrm{CMN})$, para reunir a los principales conservacionistas de todas las regiones y naciones para discutir y compartir sus trabajos y conclusiones. El CMN de 2008, celebrado en Barcelona en octubre, y al que asistieron más de 7000 participantes, fue la mayor conferencia de la sociedad civil celebrada en el ámbito del medio ambiente. Representó una valiosa oportunidad para los Miembros, Comisiones y asociados de la UICN, y para ONG, gobiernos y empresas para debatir sobre las numerosas cuestiones que hoy día preocupan a la comunidad de la conservación.
Este libro, La Conservación en una Nueva Era, presenta una síntesis de las diversas discusiones.

Examina el estado actual de nuestros recursos naturales, la fase en la que se encuentra la conservación, y las tendencias actuales. Pone de relieve el claro consenso que surgió del Congreso: el trabajo central de la UICN sobre especies, áreas protegidas y ecosistemas será un elemento cada vez más crítico para cualquier estrategia que pueda conducir a un futuro sostenible. Y describe cómo la comunidad conservacionista está respondiendo a este desafío -y oportunidad.

La riqueza del contenido de este libro y la accesibilidad de su lenguaje, estructura y presentación, servirán de muchas maneras para muchas personas: como libro de referencia para estudiantes escolares; como texto complementario para universitarios; como compendio de recursos para profesionales y organizaciones de la sociedad civil; y como documento de referencia para los responsables de la toma de decisiones a nivel gubernamental, de las empresas y de los profesionales del diseño. Y quizás hasta de material de lectura a la hora de acostarse para los amantes de la naturaleza. En pocas palabras, un magnífico registro de lo que evidentemente fue una conversación muy animada. Que es lo que sin duda merece la conservación.

Ashok Khosla Presidente de la UICN 


\section{Introducción}

Este libro fue inspirado por el Foro Mundial de la Naturaleza, celebrado en octubre de 2008 en Barcelona, España, como parte del cuarto Congreso Mundial de la Naturaleza $(\mathrm{CMN})^{1}$. El Foro congregó a más de 7000 conservacionistas comprometidos que examinaron y debatieron las cuestiones urgentes a las que actualmente se enfrenta la biodiversidad y las que se prevén en el futuro. Durante los cuatro días del Foro tuvieron lugar más de 900 eventos y este libro intenta captar la esencia de esos debates, aunque ciertamente no el detalle. Hemos incorporado libremente muchos ejemplos que se presentaron durante los diversos eventos del CMN, sin pretender especificar qué salió de cuál evento. Los capítulos son más bien eclécticos en su enfoque del tema, reflejando el contenido de los diversos eventos e incorporando partes de la literatura actual sobre el tema. El Centro de Recursos del Foro (http://www.iucn.org/ congress_08) facilita acceso a toda la información que ha sido puesta a disposición del público por los organizadores de eventos y oradores, incluyendo presentaciones en PowerPoint, informes de talleres, documentos preparatorios e informes sumarios.

Este volumen trata de enmarcar el Foro en un contexto más amplio de las preocupaciones mundiales sobre la conservación. Aunque tratamos de captar los mensajes clave del CMN en Barcelona, como editores y compiladores hemos tratado de recoger las distintas perspectivas en una síntesis coherente que también se basa en literatura reciente sobre la conservación. Empezamos haciendo una revisión de las cuestiones clave para luego abordarlas desde la perspectiva de la biodiversidad.

\section{La Conservación en una Nueva Era se presenta} como un acontecimiento histórico que establece el pensamiento actual para los científicos, administradores y políticos -todos ellos se enfrentan a desafíos relacionados con la biodiversidad. Ninguno de estos capítulos pretende ser la última palabra sobre el tema. Por el contrario, están diseñados para ayudar a generar o mantener el debate y profundizar en las investigaciones sobre los diversos temas que se plantean. Esperamos que también motive a todos a actuar con urgencia para abordar los problemas de la conservación. La amplitud de temas aquí tratados también demuestra que la conservación del siglo XXI impregna muchas partes de la sociedad.

Ahora tenemos más pruebas que nunca de que la naturaleza se enfrenta a amenazas sin precedentes, que estas amenazas son provocadas por los seres humanos, y que las soluciones están en nuestras manos. El panorama presentado aquí apunta hacia algunas nuevas orientaciones para la conservación, que esperamos motivarán a una base más amplia de constituyentes a comprometerse con los desafíos y a promover acciones tendientes a lograr una sociedad más sostenible. A la larga las acciones basadas en la colaboración y la innovación serán nuestra mejor esperanza para propiciar cursos de acción productivos.

Jeffery A. McNeely y Susan A. Mainka

1. Históricamente, la UICN separaba sus Asambleas Generales, que se centraban en las exigencias estatutarias de una reunión de los Miembros y Conferencias Técnicas centradas en los problemas de conservación del momento. Antes de la reunión de Montreal en 1996, el Consejo de la UICN decidió que sería más conveniente combinar ambos en un solo evento, llamado el Congreso Mundial de la Naturaleza (CMN). La reunión de Barcelona fue la cuarta bajo esta nueva modalidad. Los tres congresos anteriores se celebraron en Montreal, Canadá, en 1996, Ammán, Jordania, en 2000, y en Bangkok, Tailandia, en 2004. 


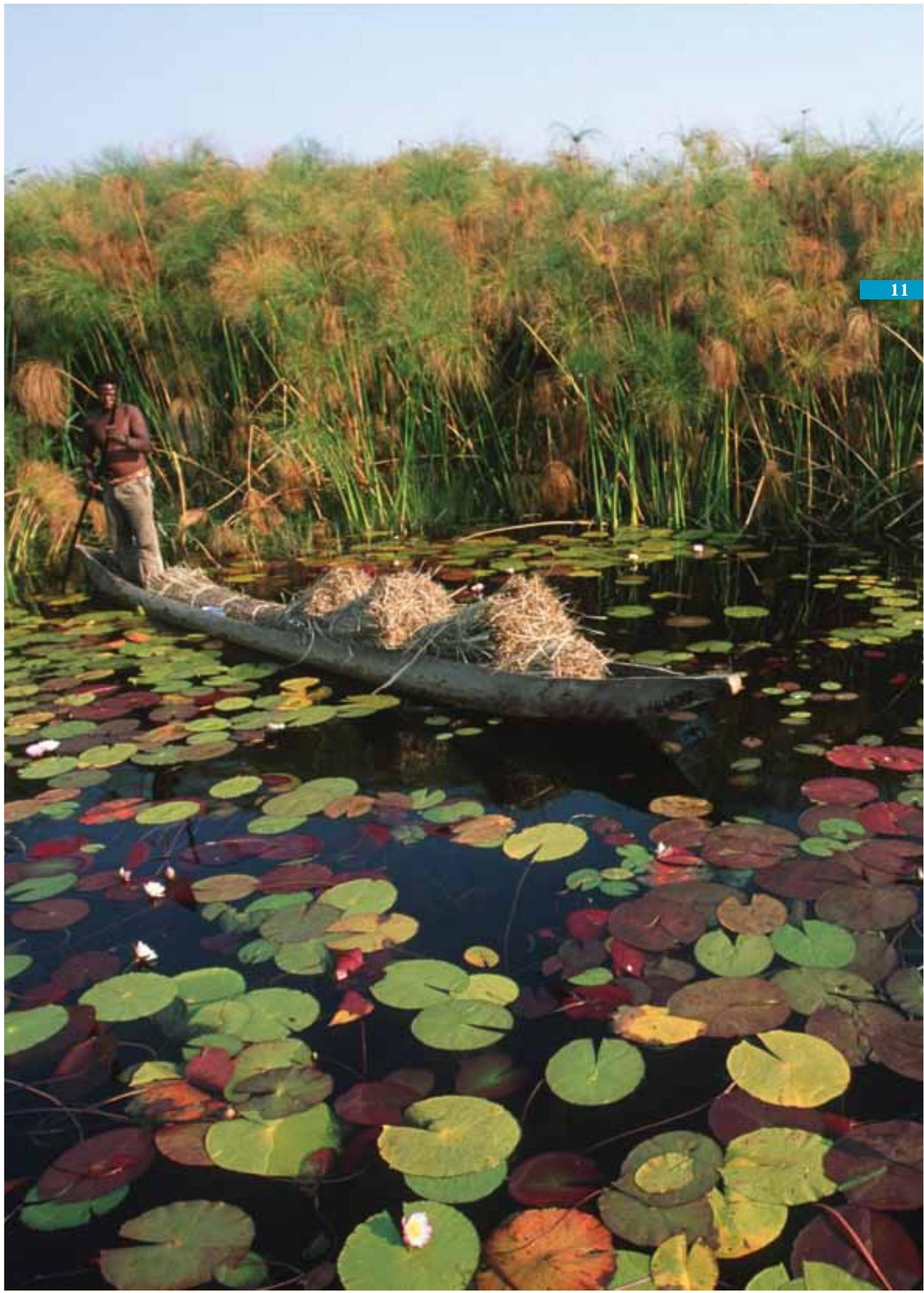




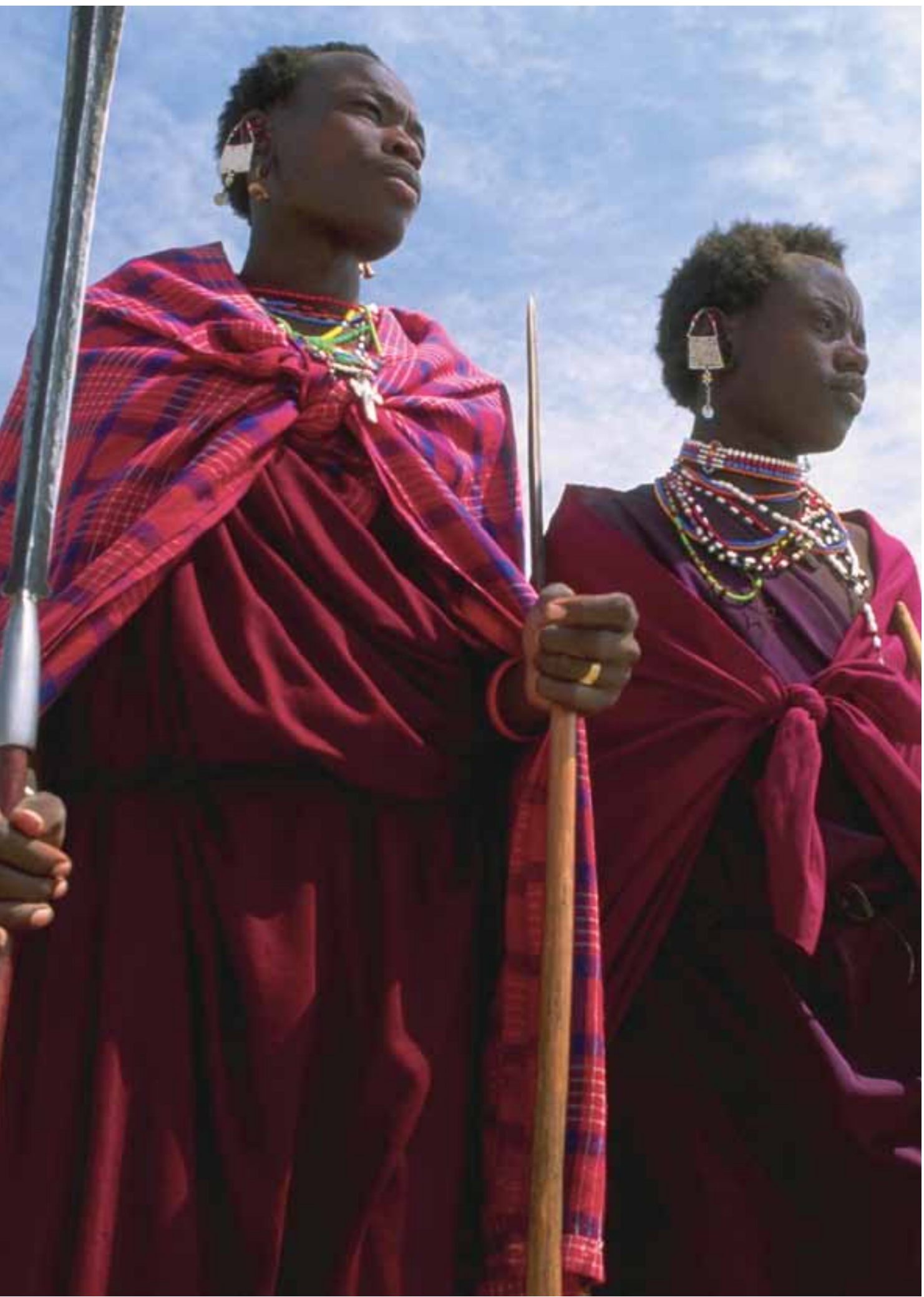




\section{Agradecimientos}

Este trabajo también se ha beneficiado de los comentarios y las

contribuciones sustantivas de las personas que se enumeran a continuación.

Christina Sander realizó una labor encomiable reuniendo los distintos

informes del Foro del CMN y ayudó a compilar algunas de las publicaciones pertinentes. La colaboración de Deborah Murith, Stephanie Achard y Cindy Craker fue decisiva en la producción de esta publicación.

\begin{tabular}{|c|c|c|}
\hline Lorena Aguilar & Annelie Fincke & Steve Osofsky \\
\hline David Allen & Kristina Gjerde & Gonzalo Oviedo \\
\hline Neville Ash & James Gordon & Georgina Peard \\
\hline Andrea Athanas & Sarah Gotheil & Sonia Pena Moreno \\
\hline Tim Badman & Marc Hockings & Jean-Yves Pirot \\
\hline Patrick Blandin & Geoffrey Howard & George Rabb \\
\hline Josh Bishop & David Huberman & Pedro Rosabal \\
\hline Intu Boedhihartono & Ninni Ikkala & Gonzales \\
\hline Maria Ana Borges & Grupo especialista de la & Christina Sander \\
\hline Guido Broekhoven & CDA/UICN sobre ética & Adel Sasvari \\
\hline Tom Brooks & Alejandro Iza & Jeffrey Sayer \\
\hline Ximena Buitron & $\begin{array}{l}\text { Bill Jackson } \\
\text { Sally Jeanrenaud }\end{array}$ & Sara Scherr \\
\hline Giulia Carbone & Nik Lopoukhine & David Sheppard \\
\hline Eric Chivian & Nadine McCormick & Kevin Smith \\
\hline Katherine Cross & Patti Moore & Mark Smith \\
\hline Will Darwall & Roland Melisch & Jerker Tamerlander \\
\hline Jonathan Davies & Russ Mittermeier & Claire Warmenbol \\
\hline Saskia de Koning & Teresa Mulliken & Elizabeth Willetts \\
\hline Joao de Queiroz & James Oliver & Jean-Christophe Vié \\
\hline Nigel Dudley & Samira Omar & Xie Yan \\
\hline
\end{tabular}


1. El Foro de Barcelona:
- Un Mundo Diverso y Sostenible

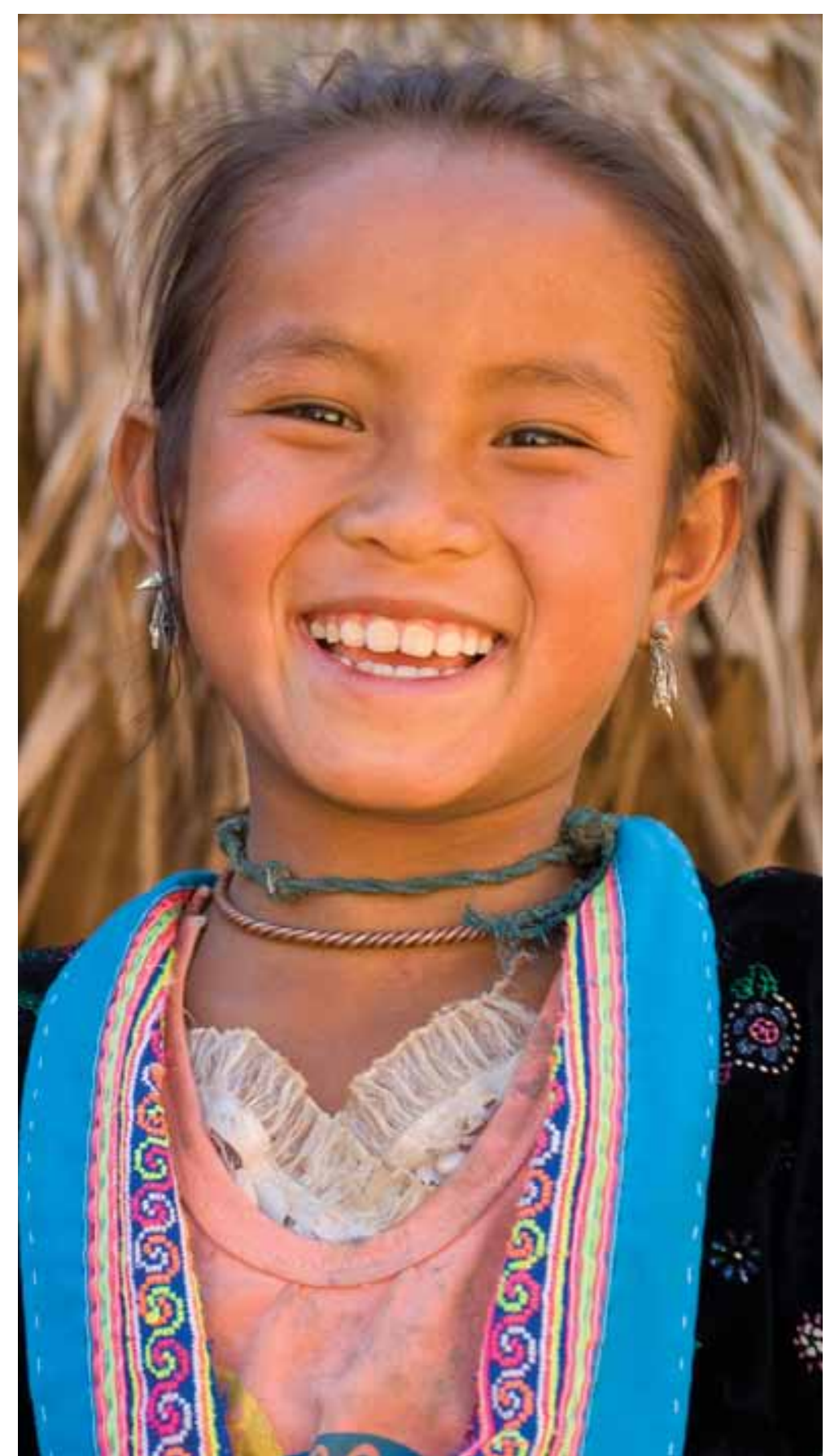


La vida es resiliente. Ha persistido durante más de dos mil millones de años, a través de cinco o más crisis de extinción en masa, la última de las cuales exterminó a los grandes dinosaurios y dejó a las aves como su única descendencia. La naturaleza probablemente sobrevivirá, de alguna manera, a las imprudentes acciones de las sociedades humanas de hoy día que se basan en un consumo cada vez mayor de recursos. Mas si ese modelo permitirá a las sociedades modernas continuar en su forma actual es algo que no es del todo seguro, incluso muy poco probable.

Este libro es una colección de desafios y estrategias discutidas en el Congreso Mundial de la Naturaleza (CMN) en Barcelona, España, en octubre de 2008. El tema del Congreso fue Un mundo diverso y sostenible y los debates en el seno del Foro se centraron en torno a tres grandes temas (recuadro 1.1). El libro no pretende ser exhaustivo, lo cual habría requerido que los grupos de trabajo dedicaran muchos meses de trabajo a cada capítulo. Más bien, hemos tratado de captar la esencia de los temas, de reflejar las opiniones de nuestra membresía, y de aportar otras perspectivas de la labor más reciente en este campo, con miras a catalizar los esfuerzos de conservación para la próxima década.

El Foro Mundial de la Naturaleza se benefició de la presencia activa de participantes procedentes de todo un amplio espectro de la sociedad, incluyendo organizaciones de conservación, comunidades indígenas y locales, gobiernos (locales y nacionales) y empresas. En consonancia con tan amplios intereses en la conservación, incluimos acciones que esta amplia comunidad conservacionista podría contemplar emprender en el futuro.
Si bien los capítulos del libro reflejan la diversidad de temas tratados, es importante destacar algunas cuestiones generales desde el comienzo, incluyendo la meta de Biodiversidad 2010, el vínculo entre la biodiversidad y el desarrollo sostenible, y el logro de los Objetivos de Desarrollo del Milenio (ODM), y la imperativa necesidad de abordar el rápido cambio demográfico. 
Recuadro 1.1 Ejes temáticos del Foro Mundial de la Naturaleza

\section{Salvaguardar la diversidad de la vida}

La rica variedad de genes, especies y ecosistemas de nuestro planeta es la base que sustenta la diversidad cultural, social y económica. Durante 60 años, la UICN ha sido la fuerza unificadora para la conservación de la biodiversidad y los Miembros de la UICN continúan apoyando con firmeza y convicción la importancia de la naturaleza, tanto por su propio bien como por el de la humanidad. Pero a pesar de esta larga historia, muchas cuestiones siguen sin resolverse, desde la ética (¿cómo decidir si las personas o la naturaleza tienen precedencia cuando se requieren soluciones basadas en concesiones?) hasta lo práctico (¿podemos alimentar a 9 mil millones de personas y también detener la pérdida de biodiversidad?). Si bien se reconoce la importancia fundamental de la biodiversidad para el futuro de la humanidad, aún no asignamos los recursos necesarios para conservarla eficazmente, de modo que, ¿a quién recurrimos para llegar a hacer una diferencia?

\section{Un nuevo clima para el cambio}

Las pruebas indican que el mundo está cambiando más rápidamente que en cualquier otro momento en la historia de la humanidad. Durante los próximos 40-50 años, la población mundial probablemente llegará a 9 mil millones, un aumento considerable en comparación a los actuales 6800 millones. Al mismo tiempo, los cambios en el sistema climático mundial se están acelerando y ahora nos enfrentamos al doble desafío de reducir en forma significativa y urgente las emisiones para evitar el peligroso cambio climático y adaptarnos a los impactos del cambio climático ya en marcha. En este mundo cambiante, las personas están cada vez más conectadas -a través de las comunicaciones, el transporte y el comercio, además de la cultura, la política y el medio ambiente. Esta "globalización" trae enormes oportunidades aunque también conlleva riesgos. Por último, el impulso para seguir aumentando el crecimiento económico está disparando la demanda de energía, que requiere que nos alejemos de una economía dependiente de los combustibles fósiles hacia mezclas energéticas más sostenibles.

\section{Ecosistemas sanos - gente sana}

El uso sostenible y la conservación de la biodiversidad contribuyen significativamente a la reducción de la pobreza y a la salud y bienestar de los pueblos; y a la inversa, un mejor bienestar del ser humano es una condición fundamental para el logro de la conservación sostenible. Un importante desafío consiste en encontrar la manera de conciliar el desarrollo rural, la reducción de la pobreza y la conservación de la biodiversidad. La gestión sostenible de los recursos naturales tales como la pesca, los suelos de cultivo y la madera, representa otro desafío. Entre las medidas prometedoras emprendidas debe destacarse mejoras en la legislación y reglamentos, planificación participativa a largo plazo, y nuevas herramientas tales como las áreas marinas protegidas. Una importante pregunta para el futuro es “¿Qué potencial pueden tener las áreas protegidas -establecidas con la finalidad principal de lograr objetivos de conservación- para mejorar el bienestar humano y reducir la pobreza?” 
AVANCE HACIA LA META DE BIODIVERSIDAD 2010 Y MÁS ALLÁ

Muchos acuerdos y convenios ambientales mundiales han integrado las metas en sus estrategias y planificación. Entre estas, la más importante desde la perspectiva de la biodiversidad es la meta de Biodiversidad 2010. El objetivo general de reducir la pérdida de biodiversidad para el año 2010 ha sido adoptado en foros internacionales desde el Convenio sobre la Diversidad Biológica (CDB) hasta la Cumbre Mundial sobre el Desarrollo Sostenible (WSSD), si bien en formas un tanto diferentes (recuadro 1.2).

La necesidad de medir el avance hacia esta meta y más allá ha estimulado el desarrollo de un marco de 17 "indicadores" que se mencionaron por primera vez en la Perspectiva Mundial sobre Diversidad Biológica 2 (GBO2) (CDB, 2006) (cuadro 1.1). La GBO2 resumió la situación señalando que:
- La deforestación, debido principalmente a la conversión de bosques nativos en plantaciones o tierras agrícolas, continúa a un ritmo alarmante.

- Las tendencias de alrededor de 3000 poblaciones de especies silvestres muestran un descenso constante en el promedio de abundancia de especies de alrededor del 40\% entre 1970 y 2000.

- Más especies están siendo expuestas a la extinción, incluyendo $12 \%$ de aves, $21 \%$ de mamíferos y 31\% de anfibios, según la Lista Roja de Especies Amenazadas 2008 de la UICN.

En 2006, reconociendo que la ciencia para sustentar muchos de estos indicadores aún requería una gran atención, 24 organizaciones que trabajan con indicadores (incluida la UICN), establecieron la Alianza 2010 sobre Indicadores de Biodiversidad (BIP), como una iniciativa mundial para promover y desarrollar aún más los indicadores a efectos de asegurar coherencia en el monitoreo y la

\section{Recuadro 1.2 La meta de Biodiversidad 2010}

La meta de Biodiversidad 2010 ha sido adoptada en varias formas como parte de muchos instrumentos de política internacional:

- Junio 2001 - La Cumbre de la UE en Gotemburgo en la que los Jefes de Estado de la UE adoptaron la meta de "el declive de la biodiversidad debe detenerse [en la UE] con el fin de alcanzar este objetivo para el año 2010”.

- Mayo 2002 - La sexta Conferencia de las Partes (COP) del Convenio sobre la Diversidad Biológica (CDB), incluyó una meta para 2010 (esta vez "para lograr para el 2010 una reducción significativa del ritmo actual de pérdida de biodiversidad a nivel mundial, regional y nacional como contribución a la mitigación de la pobreza y en beneficio de toda la vida en la tierra") en el Plan Estratégico que aprobó.
- Setiembre 2002 - La Cumbre Mundial sobre el Desarrollo Sostenible (WSSD) celebrada en Johannesburgo confirmó la meta de Biodiversidad 2010 y exhortó a "lograr para el 2010 una reducción significativa en la tasa actual de pérdida de biodiversidad".

- Mayo 2003 - Los Ministros de Medio Ambiente y los Jefes de delegación de 51 países aprobaron la Resolución de Kiev sobre la Biodiversidad en la quinta Conferencia Ministerial "Medio Ambiente para Europa" y decidieron "reforzar nuestro objetivo de detener la pérdida de biodiversidad en todos los niveles para el año 2010".

- Setiembre 2007 - La ONU decidió adoptar la meta de 2010 (en términos de tasa de pérdida) como un subobjetivo del Objetivo de Desarrollo del Milenio (ODM) 7 Sostenibilidad Ambiental. 
Cuadro 1.1 Situación y tendencias de los parámetros relacionados con la biodiversidad según los indicadores de 2010

Basado en la evaluación en el capítulo 2 de la Perspectiva Mundial sobre la Diversidad Biológica. Las flechas indican la dirección de las tendencias (las flechas anchas indican un alto nivel de confianza en la tendencia; las flechas angostas indican poca confianza; las flechas negras indican una tendencia negativa para la biodiversidad; las flechas blancas indican una tendencia positiva para la biodiversidad). La calidad de los datos y los indicadores se muestra con las estrellas que aparecen a la derecha.

$\star \star \star$ metodología con buenos indicadores con datos coherentes en el transcurso de tiempo;

$\star \star$ buen indicador, pero sin datos en el transcurso de tiempo;

$\star$ el indicador requiere un mayor desarrollo o datos limitados.

ÁREA FOCAL: Situación y tendencias de los componentes de la diversidad biológica

\begin{tabular}{|c|c|c|}
\hline $\mathbf{y}$ & Tendencias con relación a biomas, ecosistemas y hábitats seleccionados & $\star \star \star^{1}$ \\
\hline $\mathbf{4}$ & Tendencias en cuanto a abundancia y distribución de especies seleccionadas & $\star \star \star \star$ \\
\hline $\mathbf{y}$ & Cambios en la situación de especies amenazadas & $\star \star \star$ \\
\hline ע & $\begin{array}{l}\text { Tendencias en la diversidad genética de animales domesticados, plantas cultivadas y } \\
\text { especies de peces de gran importancia socioeconómica }\end{array}$ & $\star$ \\
\hline 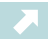 & Cobertura de áreas protegidas & $\star \star \star$ \\
\hline
\end{tabular}

ÁREA FOCAL: Integridad de los ecosistemas y bienes y servicios de los ecosistemas

$\begin{array}{ll}\text { ע Índice Trófico Marino } & \star \star \star \\ \text { \} \text { Conectividad - fragmentación de los ecosistemas } } &{\star \star} \\{\text { ^ Calidad del agua de los ecosistemas acuáticos }} &{\star \star \star}\end{array}$

ÁREA FOCAL: Amenazas a la biodiversidad

入 Depositación de nitrógeno

Tendencias con respecto a las especies exóticas invasoras

ÁREA FOCAL: Uso sostenible

$\begin{array}{llr}\searrow \text { Zonas de ecosistemas boscosos, agrícolas y de acuicultura bajo gestión sostenible } & \star \\ \searrow \text { Huella ambiental y conceptos asociados } & \star \star \star\end{array}$

ÁREA FOCAL: Situación del conocimiento tradicional, la innovación y las prácticas

\Situación y tendencias de la diversidad lingüística y cantidad de hablantes de dialectos indígenas

ÁREA FOCAL: Situación del acceso y la participación en los beneficios

? Indicador de acceso y participación en los beneficios a ser desarrollado

ÁREA FOCAL: Situación de la transferencia de recursos

\. Asistencia oficial para el desarrollo (ODA) provista en apoyo del Convenio

${ }^{1}$ para los bosques: no hay datos a nivel mundial para todos los biomas, ecosistemas y hábitats

evaluación de la biodiversidad (http://www. twentyten.net/Home/tabid/38/Default.aspx).

Partiendo de la información contenida en el informe más los datos de la Evaluación de los Ecosistemas del Milenio (EM) (2005d), la GBO2 llega a la conclusión de que la pérdida de biodiversidad "es probable que continúe en el futuro previsible y, sin duda, más allá de 2010”. No obstante, reconoce posibles éxitos en términos de la conservación de la biodiversidad, incluyendo:

1) con respuestas adecuadas a nivel nacional, regional y mundial, es posible alcanzar, para 2010, una reducción en la tasa de pérdida de biodiversidad para algunos componentes de la 


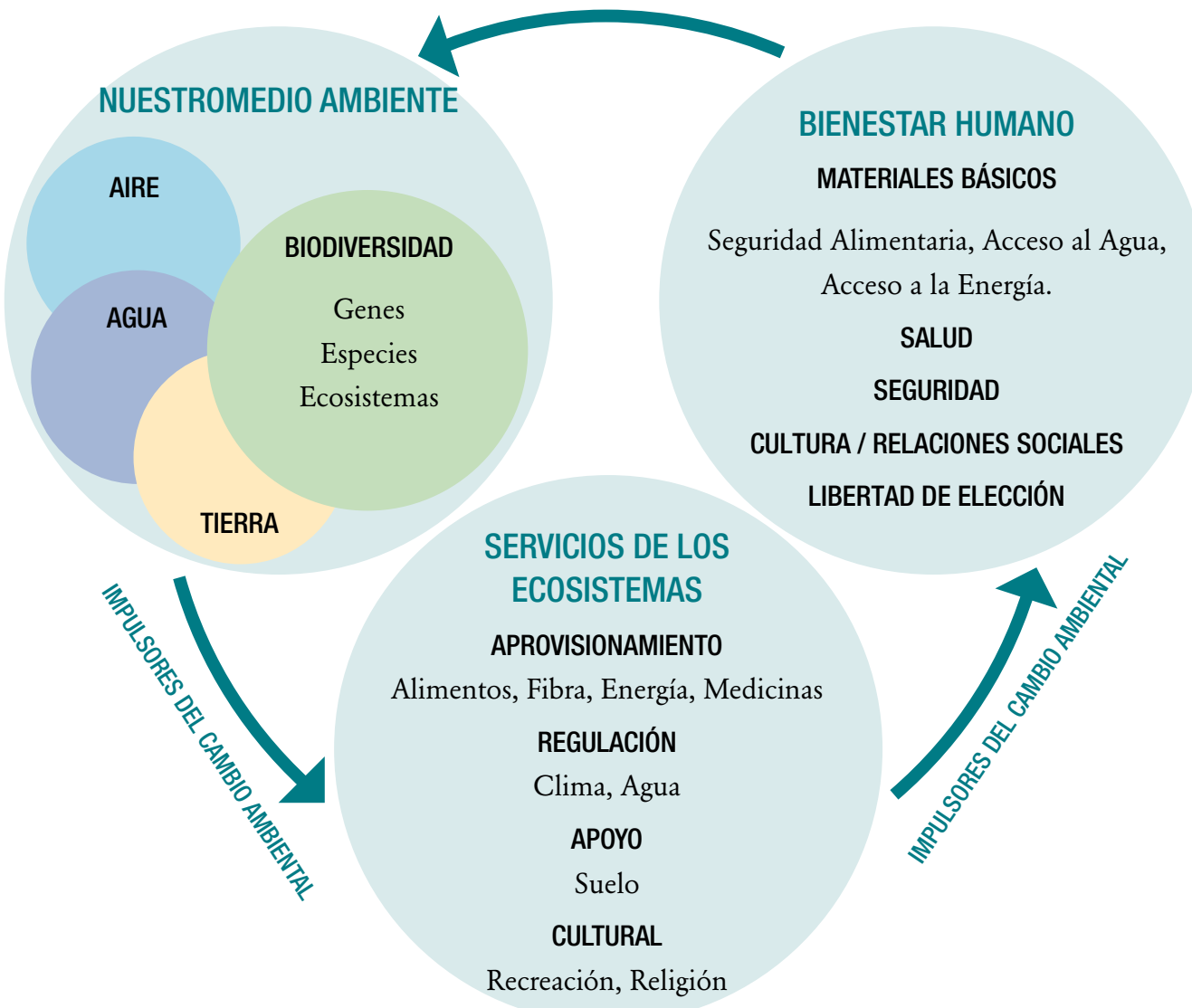

\section{AGENTES DE CAMBIO}

$\begin{array}{llll}\text { Demografia } & \text { Política/Instituciones } & \text { Economía } & \text { Sociocultural } \\ \text { Urbanización } & \text { Seguridad y conflictos } & \text { Mercados y finanzas } & \text { Nuevos paradigmas } \\ \begin{array}{l}\text { Envejecimiento de } \\ \text { las poblaciones }\end{array} & \begin{array}{l}\text { Gobernanza ambiental } \\ \text { Papel del género }\end{array} & \begin{array}{l}\text { Economías } \\ \text { emergentes }\end{array} & \text { Ética } \\ \text { Valoración de la } & \text { Espiritualidad } \\ \text { biodiversidad }\end{array}$

biodiversidad o para determinados indicadores, y en ciertas regiones;

2) la mayoría de las metas que el Convenio ha establecido como parte de su marco para evaluar el progreso hacia la meta 2010 son alcanzables, siempre que se tomen las medidas necesarias; $y$

3) las herramientas necesarias para lograr la meta de 2010, incluidos los programas de trabajo, principios y directrices, ya han sido desarrolladas en su mayor parte.

Los esfuerzos para alcanzar la meta de 2010 han sido medios importantes para prestar atención y enfocar la capacidad y voluntad política hacia la conservación de la biodiversidad. La comunidad 
mundial debe basarse en este avance mediante la adopción de un marco post 2010 que sea visionario, alcanzable y medible.

\section{RELACIÓN ENTRE LA BIODIVERSIDAD, LOS SERVICIOS DE LOS ECOSISTEMAS, LA REDUCCIÓN DE LA POBREZA Y EL DESARROLLO SOSTENIBLE}

Nuestro medio ambiente, los servicios prestados por los ecosistemas y el bienestar humano son el resultado de una compleja red de interacciones y respuestas. Desde una perspectiva pragmática, independientemente del punto de entrada al sistema, ya sea la conservación de las especies o la gestión de los ecosistemas o el apoyo a la prestación de los servicios de los ecosistemas, en última instancia, estamos hablando del mismo imperativo: el apoyo al sistema en el que vivimos (figura 1.1).

En 2008, el Banco Mundial estimó en 1400 millones el número de personas que viven en la extrema pobreza, con la mayoría en el África subsahariana y Asia Meridional. Si bien el porcentaje de quienes viven en la pobreza ha disminuido en los últimos años en la mayor parte del mundo, se ha mantenido estable en el África subsahariana. El Informe sobre el Desarrollo Mundial 2008 señala que las soluciones para reducir la pobreza varían de región a región (Banco Mundial, 2008). Para el África subsahariana, el aumento de la productividad agrícola es la clave del crecimiento, mientras que en Asia la reducción de la creciente brecha entre el bienestar urbano y el rural será la clave del éxito.

Los conservacionistas entienden la importancia de la naturaleza por la naturaleza misma. Pero también reconocen que la biodiversidad puede desempeñar un papel esencial en el apoyo y mejoramiento de los medios de subsistencia de las personas. La conservación puede contribuir a la reducción de la pobreza, en particular mediante la restauración de los ecosistemas y mejorando el acceso de los pobres a los servicios de los ecosistemas, contribuyendo así a garantizar medios de subsistencia seguros para las personas que dependen de ellos (Fisher et al., 2005). Pero la articulación de la relación entre la conservación de la biodiversidad y el desarrollo/reducción de la pobreza sigue siendo un desafío.

La popularización de la idea de los servicios de los ecosistemas (capítulo 4) por Gretchen Daly (1997) y la posterior divulgación de la Evaluación de los Ecosistemas del Milenio poco menos de una década más tarde, en 2005, han ayudado a inspirar una forma de pensamiento que promueve la colaboración y la cooperación entre los profesionales de la conservación y del desarrollo. El concepto de los servicios de los ecosistemas destaca el importante papel de la conservación de las especies y la gestión de los ecosistemas en nuestra vida cotidiana. Al hablar de los servicios de los ecosistemas se habla también de los genes, las especies y los ecosistemas que los sustentan y prestan estos servicios.

\section{EL VÍNCULO ENTRE LA REDUCCIÓN DE LA POBREZA Y LOS SERVICIOS DE LOS ECOSISTEMAS}

Los vínculos más claros entre la reducción de la pobreza y los servicios de los ecosistemas yacen en la provisión de servicios que apoyan el suministro de alimentos (capítulo 20), medicamentos (capítulo 10), productos forestales (capítulo 16), y, en última instancia, ingresos (capítulo 12).

En 2008, la Organización para la Agricultura y la Alimentación (FAO) (FAO, 2008c, d) informó de que el hambre en el mundo es cada vez mayor y que la distribución de las personas que padecen hambre se centra en gran medida en el África subsahariana. El número de personas hambrientas se estimó en 950 millones en 2008, un aumento de más de 80 millones desde el período base de 1990-1992. Las estimaciones de largo plazo 


\section{Objetivos de Desarrollo Ejemplos de vínculos con el medio ambiente del Milenio}

\author{
Objetivo 1 \\ Erradicar la pobreza \\ extrema y el hambre
}

- Las estrategias de medios de subsistencia y la seguridad alimentaria de los pobres a menudo dependen directamente de la funcionalidad de los ecosistemas y la diversidad de los servicios que prestan.

- La inseguridad en términos de los derechos de los pobres a los recursos ambientales, así como el acceso inadecuado a información ambiental, mercados y toma de decisiones, limita su capacidad para proteger el medio ambiente y mejorar sus medios de subsistencia y bienestar.

\section{Objetivo 2}

Lograr la enseñanza primaria universal
- El tiempo que los niños, especialmente las niñas, dedican a recolectar agua y leña puede reducir el tiempo disponible para el estudio.

- Se dispone de ingresos adicionales generados por la gestión sostenible de los recursos naturales para invertirse en educación.

\section{Objetivo 3}

Promover la igualdad entre los géneros y la autonomía de la mujer
- El tiempo que las mujeres dedican a recolectar agua y leña reduce su oportunidad para actividades generadoras de ingresos.

- Las mujeres pobres de las zonas rurales dependen en gran medida de los recursos naturales, pero la inequidad y la falta de derechos limitan su acceso a la toma de decisiones y a los recursos.
Objetivo 4

Reducir la mortalidad infantil

Objetivo 5

Mejorar la salud materna
- Una mejor gestión de las cuencas hidrográficas locales puede reducir la mortalidad infantil relacionada con enfermedades transmitidas por el agua.

- La contaminación del aire y el transporte de cargas pesadas durante las etapas finales del embarazo ponen la salud de la mujer en situación de riesgo antes del parto.

\section{Objetivo 6}

Combatir el VIH/SIDA, el paludismo y otras enfermedades
- Los factores de riesgo ambiental representan hasta una quinta parte de la carga total de morbilidad en los países en desarrollo.

- Las medidas preventivas de salud ambiental son tan importantes, y a veces más rentables, que el tratamiento de la salud.

- Todos los demás objetivos están ligados a la sostenibilidad ambiental, a menudo en forma muy directa (como se describe en otras partes de este libro).

\section{Objetivo 7}

Garantizar la sostenibilidad del medio ambiente

\section{- La compleja interacción entre el bienestar humano, los servicios de} los ecosistemas y la biodiversidad requiere un enfoque integrado, incluyendo asociaciones entre la sociedad civil, el sector privado y el gobierno. 
(disponibles hasta 2003-2005), muestran que algunos países iban por buen camino hacia el logro del ODM 1 de reducir a la mitad el hambre para 2015 (cuadro 1.2). Pero el actual período de altos precios de los alimentos está causando contratiempos, golpeando con más fuerza a los pobres, a los desposeídos de tierra y a los hogares encabezados por mujeres.

Detrás de esta inseguridad alimentaria, especialmente en África, están las tendencias cambiantes en la precipitación que reducen la productividad de los pequeños agricultores que dependen de la agricultura de secano. Esto exige nuevos enfoques para la agricultura. La ecoagricultura es un ejemplo de un enfoque basado en el uso de la tierra que incorpora tres objetivos principales -conservación de la biodiversidad, aumento de la productividad agrícola y medios de subsistencia rurales sostenibles (McNeely y Scherr, 2003). La inversión en un desarrollo agrícola basado en los ecosistemas y en enfoques basados en la ecoagricultura y la adaptación a los impactos del cambio climático, será vital para resolver el problema del hambre en el África rural (Ecoagriculture Partners, 2009). Enfoques similares serán necesarios en otros sectores; tanto los ecosistemas como la tecnología y la práctica ya están disponibles para ejecutar la conservación forestal, hídrica, costera y de tierras secas a nivel del paisaje (para mayor información, véase los capítulos pertinentes).

La provisión fiable de recursos naturales es una fuente de empleo (e ingresos) para millones de personas en todo el mundo. Por ejemplo, a nivel mundial más de 1300 millones de personas trabajaban en la agricultura en 2002 y 34,5 millones estaban empleadas en la pesca y la acuicultura en 2000 (www.earthtrends.org).

A escala micro, los recursos naturales locales representan una importante porción de los
Recuadro 1.3 Cinco razones para incluir la conservación ambiental en las actividades de desarrollo y reducción de la pobreza

1. Los países pobres dependen de recursos ambientales frágiles. Estos recursos, de propiedad privada o en forma de patrimonio común, constituyen la principal fuente de ingresos y supervivencia de los pobres.

2. Si bien la mayoría de los activos artificiales se deprecian con el tiempo, algunos con bastante rapidez, la mayoría de los recursos naturales puede sostenerse e incluso mejorarse con esfuerzos modestos si se gestionan adecuadamente.

3. El 17\% de todos los años de vida perdidos por incapacidad (DALY) en los países en desarrollo se debe a un mal estado del medio ambiente frente a solo el $4 \%$ en los países de la OCDE. La falta de agua potable y saneamiento adecuado constituyen la principal causa, representando el 40\% de la pérdida ambiental inducida de DALY en los países en desarrollo; la segunda peor causa es la mala calidad del aire en interiores.

4. En la actualidad hay una severa subinversión en agricultura, lo que resulta en la pérdida de valiosos recursos de generación de ingresos basados en la naturaleza (e.g. biodiversidad, suelos fértiles debido al anegamiento y salinización del agua, arrecifes y costas) de particular importancia para reducir la pobreza y mejorar el crecimiento del ingreso económico.

5. La gestión racional del medio ambiente reducirá la vulnerabilidad a los eventos naturales extremos y a los impactos del cambio. 
ingresos de los hogares más allá de las necesidades de subsistencia. A nivel nacional, los recursos naturales también tienen un papel importante; en Tanzania, la utilización de los recursos ambientales y naturales representa el 66\% del producto interno bruto (PNUMA, 2008a).

La importancia de los recursos naturales en las economías nacionales, especialmente en el mundo en desarrollo, es razón suficiente para velar por que las estrategias nacionales de desarrollo y crecimiento integren la gestión racional del medio ambiente. Los gobiernos de los países en desarrollo y los organismos de asistencia para el desarrollo ya están reconociendo el papel crucial que la gestión racional del medio ambiente desempeñará en la reducción de la pobreza (Hansen, 2007) (recuadro 1.3).

El reto actual para el apoyo al desarrollo consiste en determinar cuál es la mejor manera de incorporar el medio ambiente en el proceso de mejoramiento del bienestar humano. La integración del medio ambiente debe ocurrir tanto en la etapa de planificación como de implementación de las actividades. Bojo et al. (2004) informaron de que el grado de integración del medio ambiente en 53 estrategias de reducción de la pobreza examinadas era muy variable, pero que el nivel general estaba mejorando en comparación con exámenes anteriores. $\mathrm{Al}$ igual que con cualquier programa de gestión ambiental, los esfuerzos de reducción de la pobreza deben incluir un enfoque de gestión adaptable para garantizar la respuesta oportuna a los cambios ambientales y sociales.

\section{EL DEBATE ENTRE LA CONSERVACIÓN Y LA REDUCCIÓN DE LA POBREZA}

La propia comunidad conservacionista ha debatido activamente si los conservacionistas pueden contribuir y cuánto pueden realmente contribuir al desarrollo global y a los esfuerzos de reducción de la pobreza. La integración de las necesidades de la creciente cantidad de comunidades locales en los proyectos de conservación es un reto adicional para los profesionales del ramo. Roe (2008) ha resumido la evolución del debate sobre la conservación y la reducción de la pobreza, señalando que a lo largo de los años las comunidades conservacionistas y de reducción de la pobreza han convergido y divergido. Determinó que, si bien en algunas de las zonas más necesitadas de conservación son pocas las personas que en realidad viven en ellas, estas personas son a menudo muy pobres y se ven muy afectadas si se les niega el acceso a los recursos. Además, han vivido en la zona por muchas generaciones, y el hecho de que la zona es valiosa para la conservación indica que sus actividades no se contraponen a ella. Por otro lado, las presiones del desarrollo moderno pueden superar las formas tradicionales de conservación y prácticas de gestión de los recursos, dando lugar a la pérdida de biodiversidad y de servicios de los ecosistemas. La relación entre la conservación y el desarrollo en zonas con una biodiversidad de extraordinario valor nacional o global es muy compleja, requiriendo siempre soluciones específicas para el sitio.

\section{LOS OBJETIVOS DE DESARROLLO DEL MILENIO Y EL MEDIO AMBIENTE}

En 2000, la Declaración del Milenio registró el compromiso de los miembros de las Naciones Unidas para erradicar la pobreza extrema y el hambre y construir un mundo seguro y pacífico conducente al desarrollo humano. Se fijaron objetivos generales en el marco de los Objetivos de Desarrollo del Milenio (ODM) y se elaboraron indicadores para evaluar el progreso. El detalle de los ODM y las metas puede dar la impresión de que estos son una especie de lista de control de puntos que pueden lograrse de uno en uno. Sin embargo, es mucho mejor considerarlos como 
un grupo integrado, de suerte que el avance en el logro de cada objetivo o meta dependa también de la consecución de los otros. Aunque el ODM 7 es el único objetivo explícitamente dirigido al medio ambiente, el logro de cada uno de los otros objetivos requerirá el apoyo de un ecosistema estable. A su vez, el logro de los otros ODM apoyará la consecución del ODM 7 (cuadro 1.2). Como los vínculos entre el medio ambiente y el bienestar humano son cada vez más evidentes, también lo son las amenazas para ambos. En particular, el cambio climático, las especies exóticas invasoras y el uso insostenible de los recursos están emergiendo como cuestiones clave que deben abordarse tanto en la planificación de la conservación como en la reducción de la pobreza.
Un examen del avance hacia el logro de los ODM, fundamentalmente en el punto medio entre el año en que se establecieron los objetivos y el plazo para la consecución de los propios objetivos, destacó que, si bien se han logrado algunos éxitos, aún queda mucho por hacer (ONU, 2008). El informe identifica muchos problemas para los que se requiere un "esfuerzo redoblado", a saber:

- La proporción de personas en el África subsahariana que viven con menos de US\$1 por día es improbable que se reduzca a la mitad;

- Alrededor de una cuarta parte de todos los niños en los países en desarrollo se consideran con un peso inferior al normal y corren el

\section{FIGURA 1.2 TENDENCIAS DE LA POBLACIÓN HUMANA}

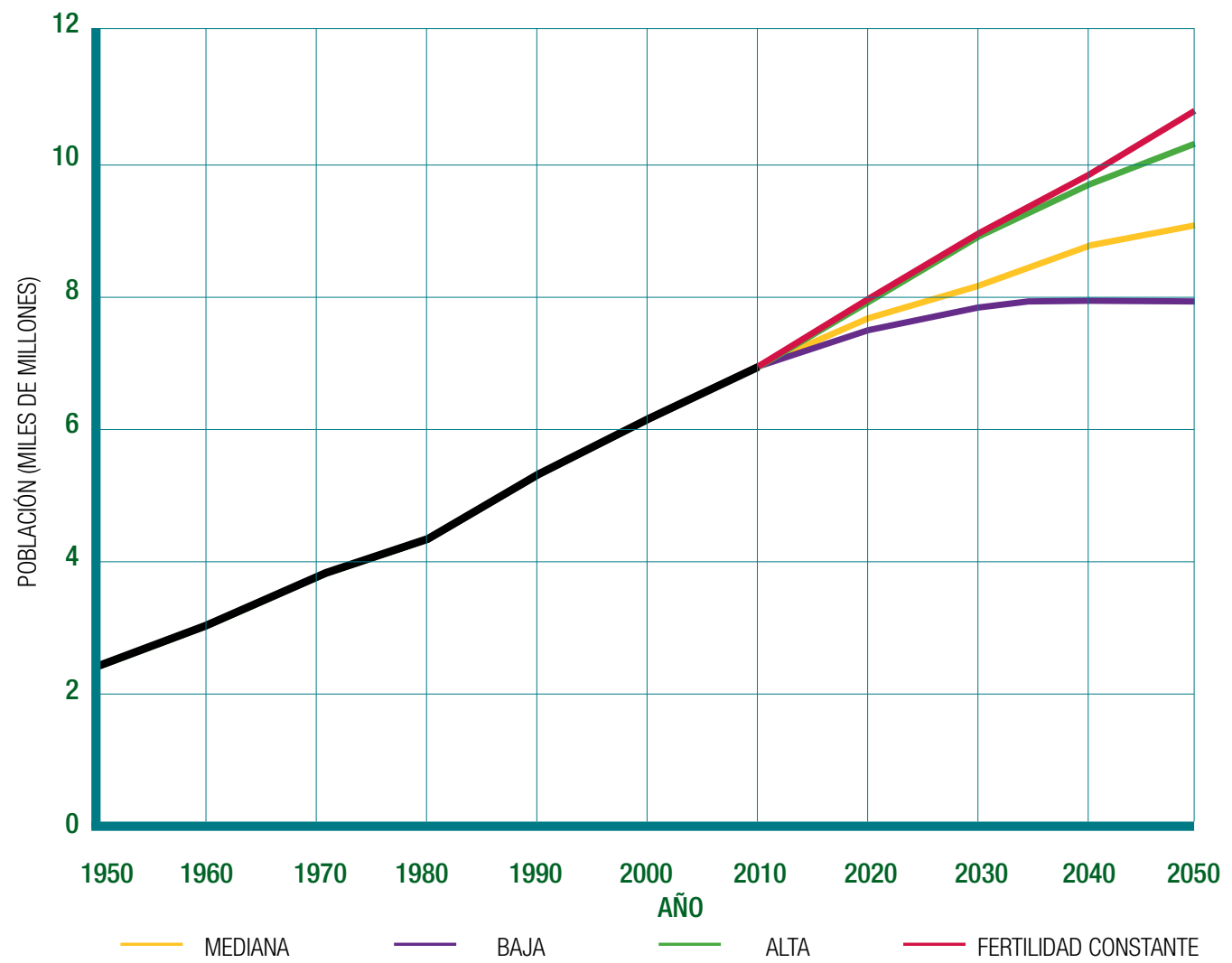


riesgo de tener un futuro asolado por los efectos a largo plazo de la desnutrición;

- De los 113 países que no han alcanzado la paridad de género en la matrícula escolar para enseñanza primaria y secundaria en el año 2005, solo 18 son susceptibles de alcanzar el objetivo para el año 2015;

- Casi dos tercios de las mujeres empleadas en el mundo en desarrollo desempeñan puestos de trabajo vulnerables, ya sea trabajando por cuenta propia o como trabajadoras familiares no remuneradas;

- En un tercio de los países en desarrollo, las mujeres representan menos del 10\% de los representantes parlamentarios;

- Más de 500.000 madres potenciales en los países en desarrollo mueren cada año en el parto o de complicaciones del embarazo;

- Unos 2500 millones de personas, casi la mitad de la población del mundo en desarrollo, viven sin un saneamiento mejorado;

- Más de un tercio de la creciente población urbana en los países en desarrollo vive en barriadas pobres;

- Las emisiones de dióxido de carbono han seguido aumentando a pesar del calendario internacional para resolver el problema;

- La asistencia extranjera de los países desarrollados disminuyó por segundo año consecutivo en 2007 y corre el riesgo de no cumplir con los compromisos adquiridos en 2005; y

- Las negociaciones comerciales internacionales tienen años de retraso y todo parece indicar que los resultados estarán muy lejos de las esperanzas iniciales cifradas en torno a un resultado orientado al desarrollo.

Dado el importante papel del medio ambiente para la consecución de todos los ODM es evidente que, para alcanzar los ODM, es preciso prestar más atención al medio ambiente.

\section{LIDIANDO CON EL CAMBIO: DEMOGRAFÍA Y} CONSERVACIÓN

Además de la meta 2010 y los debates sobre el vínculo con el desarrollo sostenible, el cambio era un factor común en muchos de los debates de Barcelona. Los cambios en el clima, la tecnología y la demografía humana afectan todo lo que hacemos con relación a la conservación de la biodiversidad. Si bien el clima (capítulo 5) y la tecnología (capítulo 13) son temas de capítulos específicos, vale la pena explorar la cuestión de la demografía humana desde el inicio por cuanto influye en tantas otras cuestiones.

La población humana se cuadruplicó durante el siglo XX, pasando de alrededor de 1500 millones en 1900 a cerca de 6800 millones en 2009 (DAES, 2009 - figura 1.2). Este explosivo crecimiento poblacional alcanzó un máximo de $2,1 \%$ en la tasa de crecimiento a fines del decenio de 1960, el proceso demográfico más importante desde el comienzo de la revolución industrial. Desde entonces, la tasa de crecimiento demográfico se ha reducido drásticamente $\mathrm{y}$, en contraste con siglos anteriores en los que las poblaciones se vieron afectadas por graves conflictos y enfermedades epidémicas, en el mundo de hoy la caída está relacionada con las opciones voluntarias para limitar el número de nacimientos (Cohen, 2005).

Pero el crecimiento de la población por sí solo no cuenta toda la historia. Como muestran las conclusiones de la ONU (DAES) (recuadro 1.4), la proporción de personas mayores está aumentando en algunos países y a partir de 2005 habrá un mayor número de personas de 60 años o más que niños de 4 años o menos. Ese cambio será más evidente en el mundo desarrollado, donde se prevé que en 2050 un tercio de la población tendrá más de 60 años en comparación con solo el $20 \%$ en el mundo en desarrollo (Cohen, 2005); sin embargo, en razón de que el mundo en desarrollo alberga mucha más gente, 


\section{Cifras totales}

- Suponiendo que los niveles de fertilidad continúan declinando, se prevé que la población mundial alcanzará 9100 millones en 2050 y que crecerá al ritmo de unos 33 millones de personas anualmente.

- El crecimiento futuro de la población dependerá en gran medida del camino que tome la fertilidad, pero el crecimiento de la población hasta 2050 es inevitable incluso acelerándose la disminución en la fertilidad.

- El crecimiento poblacional de los 49 países menos desarrollados continúa siendo el de más rápido crecimiento en el mundo, 2,3\% por año.

- Se prevé que en nueve países se concentrará la mitad del aumento de la población mundial proyectada para 2010-2050: India, Pakistán, Nigeria, Etiopía, los Estados Unidos, la República Democrática del Congo, la República Unida de Tanzania, China y Bangladesh, en orden de su contribución al crecimiento poblacional mundial.

\section{Demografia}

- A nivel mundial, se prevé que el número de personas de 60 años o más se triplicará, aumentando de 739 millones en 2009 a 2000 millones en 2050.

- A nivel mundial, la esperanza de vida al momento de nacer se prevé que se elevará de 68 años en 2005-2010 a 76 años en 2045-2050.

- En términos de promedios anuales, los principales receptores de migrantes internacionales durante 2010-2050 se prevé que serán los Estados Unidos, Canadá, el Reino Unido, España, Italia, Alemania, Australia y Francia. Los principales países de emigración se prevé que serán México, China, India, Filipinas, Pakistán, Indonesia y Bangladesh.

Fuente: DAES, 2009

"construir el equivalente a una ciudad de un millón de personas cada semana durante los próximos 45 años” (Cohen, 2005).

Un nuevo reto demográfico es la aparición de "migrantes ambientales", especialmente en respuesta al cambio climático. Las poblaciones que viven en naciones insulares de baja altitud, como Tuvalu o las Maldivas, o en zonas costeras vulnerables como partes de Bangladesh y Florida, se verán expuestas a problemas ambientales además de sociales, económicos y de seguridad.

Otra perspectiva de la población se relaciona con el número de hogares, frente al número de personas. Liu et al. (2003) informaron de que aun cuando las cifras de población se mantienen estables o disminuyen, si el número de hogares 
aumenta, las demandas sobre los recursos

naturales también aumentarán. Ellos informan

de que el crecimiento de la población entre 1985

y 2000 en los países con lugares de situación

crítica de la biodiversidad fue superado por el

crecimiento en el número de hogares porque se

redujo el tamaño medio del hogar (y disminuyó

más rápidamente que en los países que carecían

de ellos), planteando graves desafíos a la gestión de los recursos naturales y la conservación de la biodiversidad.

Satisfacer las necesidades de estas cambiantes poblaciones, de un número cada vez mayor de personas de edad avanzada y de concentraciones extremas en las zonas urbanas, tendrá inevitablemente repercusiones sobre el medio ambiente. Las zonas urbanas cada vez más apretujadas tendrán que expandirse, a menudo hacia importantes tierras de cultivo cercanas, limitando -por consiguiente- la productividad de esas tierras. Los cambios demográficos también implicarán un aumento del gasto del sector público en asistencia sanitaria y apoyo a la familia con una posible reducción en inversiones en otros bienes públicos, incluida la gestión ambiental.

Por cuanto en este libro se explora los muchos desafíos a los que hoy día se enfrenta la conservación, es útil tener en cuenta las cuestiones subyacentes examinadas anteriormente y el efecto que tendrán sobre las opciones y acciones en los próximos decenios.

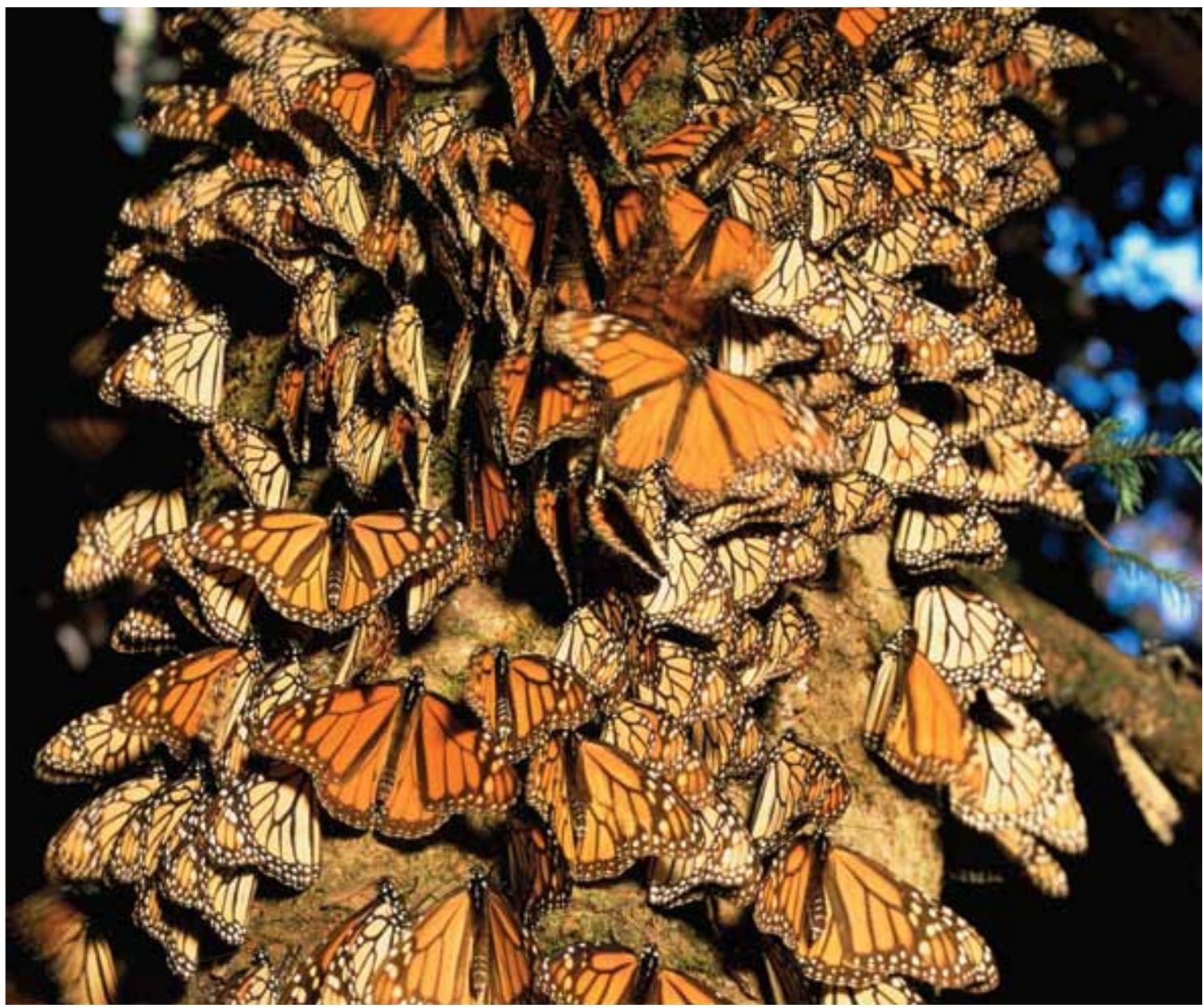




\section{La Ética de la \\ 2. Conservación del Siglo XXI}

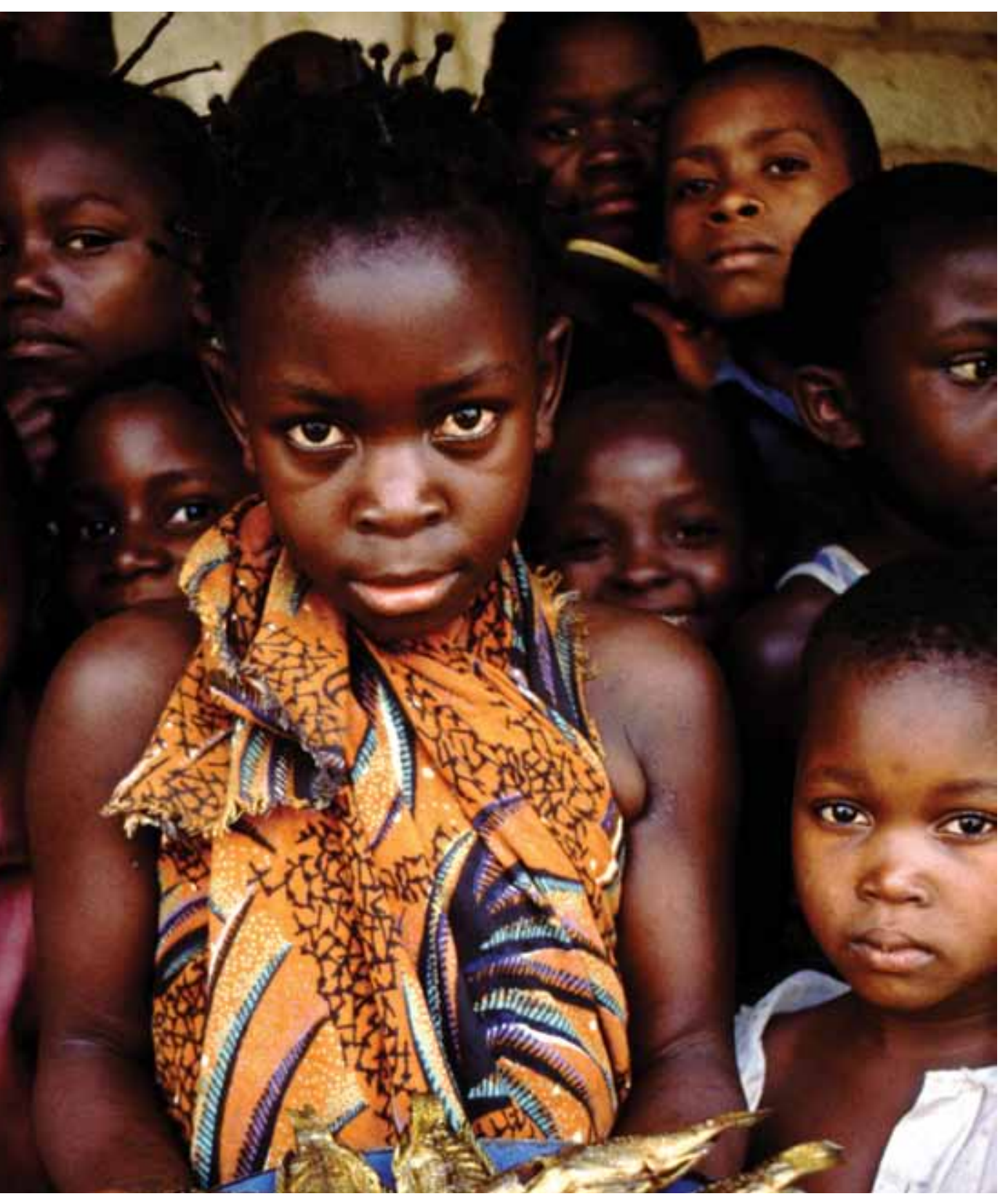




\section{La ética son los principios}

generales que guían la toma de decisiones de los seres humanos, influenciados por factores culturales, religiosos, económicos, del conocimiento y de la ciencia. La ética son valores colectivos formados por las respuestas individuales y personales que también orientan las decisiones acerca de lo que pensamos que debemos hacer y cómo creemos que debemos actuar. La ética puede ser tan diversa como la naturaleza. Basándose en la labor del Grupo de trabajo sobre la ética de la conservación, la UICN busca ofrecer algunos principios generales que pueden adaptarse a una amplia gama de aplicaciones específicas en la conservación.

La conservación, en su esencia, refleja los valores que los individuos y las sociedades tienen con respecto a la naturaleza y las relaciones hombrenaturaleza. La condición humana se define por las necesidades y respuestas individuales y colectivas, físicas, biológicas, intelectuales y espirituales.

Los marcos éticos alternativos pueden aclarar los sistemas de valores que apoyan las decisiones tomadas acerca de la gestión de los recursos.
La ética de la conservación ha sido consagrada en las religiones durante siglos y el vínculo entre la naturaleza y la espiritualidad es de sobra reconocido. Los promotores de la conservación también han debatido los vínculos entre la religión y la conservación, especialmente en una serie de artículos en Conservation Biology en 2005 (Orr, 2005; Stuart et al., 2005).

La ética es necesaria para inspirar cambios e informar la legislación, las políticas y la investigación. La UICN ha hecho contribuciones fundamentales para enriquecer la comprensión de los valores y principios fundacionales de la conservación de la naturaleza, incluso a través de la Estrategia Mundial para la Conservación (1980), la Carta Mundial de la Naturaleza (1982), Cuidar la Tierra (1991) y la Carta de la Tierra (1994).

En 1972, la Declaración de Estocolmo proclamó que "Se había llegado a un punto en la historia en el que debemos configurar nuestras acciones en todo el mundo, con una atención más prudente respecto de sus consecuencias ambientales. A través de la ignorancia o la indiferencia podemos hacer un daño masivo e irreversible al medio ambiente terrestre del que dependen nuestra vida y bienestar. Por el contrario, a través de un mayor conocimiento y acciones más prudentes, podemos conseguir una vida mejor para nosotros y para nuestra posteridad en un entorno más acorde con las necesidades y esperanzas humanas".

Posteriormente, la Carta Mundial de la Naturaleza de 1982 afirmó que toda forma de vida es única y merecedora de respeto independientemente de 

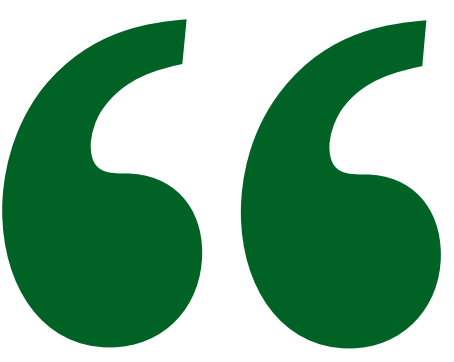

Todas las

especies y sistemas

de la naturaleza

merecen respeto

independientemente

de su utilidad para la

humanidad.
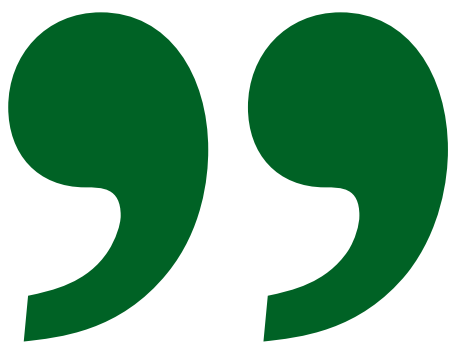
su valor para las personas, y que al conceder tal reconocimiento a otros organismos, las personas deben regirse por un código de acción moral. Las personas pueden modificar la naturaleza y agotar los recursos naturales por sus acciones o sus consecuencias y, por tanto, deben reconocer plenamente la urgencia de mantener la estabilidad y la calidad de la naturaleza y de conservar los recursos naturales.

Cuidar la Tierra definió la posición ética de la UICN como "el respeto y el cuidado de la comunidad de la vida”. Desde entonces, el mundo se ha enfrentado a desafíos cada vez más importantes de acciones colectivas de proporciones mundiales, abordando problemas ambientales que solo pueden resolverse mediante la cooperación internacional. La responsabilidad del hombre por la continuidad de la vida es mayor que nunca.

Cómo utilizar el conocimiento, y cómo cambiar el comportamiento como resultado de ese conocimiento, sigue siendo un reto para los conservacionistas. Los ecosistemas y las sociedades han cambiado profundamente en los últimos años. Frente a los desafíos globales como el cambio climático, las especies invasoras, la pérdida de biodiversidad, la gobernanza en alta mar, y otros, la ética está llamada a motivar los cambios necesarios para resolver estas cuestiones, haciendo frente a menudo a fuertes presiones para acelerar el consumo. Cuidar la Tierra hizo hincapié en argumentos éticos, junto con razonamientos económicos o sociales para promover prácticas de conservación. Se consideró que la ética proporcionaba una base para movilizar tanto la acción colectiva como la responsabilidad individual.

\section{ACCIÓN COLECTIVA}

La ética aplicada a la conservación ha evolucionado rápidamente desde la Declaración de Estocolmo de 1972. Sin embargo, sigue siendo mucho más eficaz argumentar un caso social o económico de los valores de la naturaleza que uno ético. Los conservacionistas han tenido dificultades para convencer al público en general a adoptar una "ética de conservación" o "bioética" como una razón para cambiar significativamente su comportamiento. Parte de esta dificultad ha radicado en la definición de la naturaleza específica de esa ética y, especialmente, cómo valorar el medio ambiente.

Muchos conservacionistas aceptaron la valoración de las acciones de conservación en aras de la postura ética de la naturaleza por la naturaleza misma. Otros utilizaron argumentos éticos para abogar por un enfoque más pragmático, centrándose en los beneficios de la conservación para las personas, a través de los servicios de los ecosistemas, reconociendo que los pobres son a menudo las primeras víctimas de la pérdida de biodiversidad. Como Meffe (2005) señala, "la conservación biológica implica conocimiento ecológico y decisiones de valor”.

El principio enunciado en Cuidar la Tierra de que “Todas las especies y sistemas de la naturaleza merecen respeto independientemente de su utilidad para la humanidad" ha sido aceptado por los gobiernos en el Convenio sobre la Diversidad Biológica (CDB), que reconoce en su preámbulo "el valor intrínseco de la diversidad biológica y de los valores ecológicos, genéticos, sociales, económicos, científicos, educativos culturales, recreativos y estéticos de la diversidad biológica y sus componentes".

En una era de servicios de los ecosistemas y mercados para dichos servicios, el marco de referencia para la ética ha crecido a una escala mundial. Cuidar la Tierra exhorta a "códigos de conducta que implementen la ética mundial en el contexto cultural de cada sociedad". Al examinar esta evolución, se destaca el Protocolo de Montreal de 1987 sobre el ozono como uno de los primeros tratados internacionales vinculantes para el medio ambiente mundial, aunque de gran interés humano. El problema del agotamiento 
del ozono era de índole colectiva y se resolvió mediante un acuerdo multilateral. El Protocolo puso de manifiesto que un movimiento ambiental mundial podría resolver un problema colectivo. En Montreal, las naciones acordaron cuidar la tierra salvando la capa de ozono, y de hecho su piel, de los rayos UV-B.

Cuatro años después de Montreal, Cuidar la Tierra hizo un llamado para que la conservación diera un salto, afirmando que la naturaleza "debe ser cuidada por derecho propio". La idea era radical, ya que pasó de la visión antropocéntrica de los seres humanos en el centro a una perspectiva más holística sobre el medio ambiente, situando a los seres humanos dentro de ella. El Protocolo de Montreal mostró que se puede tomar medidas para conservar la atmósfera para la salud del planeta. Cuidar la Tierra exhortó a las personas a ampliar la motivación para la adopción de medidas para la conservación más amplia de la naturaleza.

Un año más tarde, el Convenio sobre la Diversidad Biológica fue aprobado en la Cumbre de la Tierra en Río de Janeiro y entró en vigencia en 1993. Sus objetivos toman posiciones éticas en el llamamiento para "la conservación de la biodiversidad, la utilización sostenible de sus componentes y la distribución justa y equitativa de los beneficios derivados de la utilización de los recursos genéticos”.

Desde la divulgación de Cuidar la Tierra, ha crecido el movimiento hacia un pacto mundial entre las personas y la naturaleza. La idea de una Carta de la Tierra se lanzó en 1992 en la Cumbre de la Tierra. En 1995, la iniciativa de la Carta de la Tierra había desarrollado el principio de que la ética es esencial para una "sociedad mundial justa, sostenible y pacífica en el siglo XXI”, basada en "valores compartidos a nivel mundial". La Carta de la Tierra expone los problemas mundiales que enlazan a toda la humanidad y a esta con el medio ambiente. Sus temas incluyen ética global y desarrollo, democracia, ecología y religión, cambio climático, biotecnología, salud pública, integridad ecológica, derechos humanos ambientales, animales y ética, y educación.

Para hacer frente a cuestiones tales como la biodiversidad, el desarrollo sostenible y el cambio climático, la ética de la conservación se ha hecho esencial para la movilización de las personas. En los últimos decenios, la vida sostenible se ha convertido en un imperativo ético y esencial para la gestión de la interdependencia mundial. Esta idea de la responsabilidad personal, sentida a nivel mundial, es revolucionaria, pero esencial, si ha de superarse los desafíos ambientales a nivel mundial.

\section{EL PAPEL DE LAS PERSONAS}

La ética personal y el medio ambiente abarcan ahora a toda la sociedad. La ética consiste en ayudar a definir un nuevo pacto social entre los seres humanos y el medio ambiente. Las preguntas que se plantea la ética ambiental son: ¿Cómo queremos vivir en esta tierra? ¿Qué clase de mundo queremos? El futuro y el alcance del cambio dependerán de las respuestas a estas preguntas, y cómo las traducimos en acciones.

No es tarea fácil plasmar las respuestas a estas preguntas en acciones coherentes y productivas. Como apuntan Meadows et al. (1972), "no es posible evaluar el futuro a largo plazo de 
cualquiera de estos niveles [de población, capital, alimentos, recursos no renovables, y contaminación], sin tomar todos los demás en cuenta. Sin embargo, incluso este sistema relativamente simple tiene una estructura tan complicada que impide comprender intuitivamente cómo se comportará en el futuro”. Meadows sugiere considerar ciclos de retroalimentación positivos, tales como el crecimiento industrial y poblacional, y ciclos de retroalimentación negativos, como la contaminación, que se vuelven más fuertes a medida que el crecimiento se aproxima a la capacidad de carga del entorno del sistema. Si bien es imposible predecir lo que sucederá al aproximarse a la capacidad de carga de nuestro planeta, las señales indican que estamos llegando a estos límites, al menos para las personas que viven bajo un moderno estilo de vida de alto consumo (Wackernagel et al., 2002). De hecho, algunos indicadores, como el Índice del Planeta Viviente de WWF, dan cuenta de que ya se ha superado la capacidad de carga a largo plazo del planeta (WWF, 2008).

Aunado a la ciencia y los conocimientos tradicionales, la gente necesita herramientas de evaluación subjetivas, basadas en la ética, tales como el marco de la Carta de la Tierra, para ayudar a aplicar los principios éticos a los actuales desafíos ambientales. De esta manera, la ética de la conservación de la biodiversidad puede incorporarse a las políticas y la ética puede ser más explícita en los esfuerzos de conservación de la biodiversidad del plano global al local.

Una de esas herramientas es el Principio de precaución, que fue elaborado en la Cumbre de la Tierra de Río de 1992. Como Principio 15 de la Declaración de Río, estipuló que "Cuando haya peligro de daño grave o irreversible, no deberá utilizarse la falta de certeza científica absoluta como razón para postergar medidas eficaces en función de los costos para evitar la degradación ambiental”. De amplia aceptación en la actualidad, el Principio de precaución toma en cuenta aspectos éticos en las decisiones que puedan afectar el medio ambiente.

Mediante la incorporación de principios éticos en los procesos de cambio y toma de decisiones, las personas pueden ayudar a romper los ciclos de retroalimentación que están impulsando el sistema ambiental mundial al colapso. La ética debe convertirse en una herramienta eficaz tanto para la acción colectiva como para la acción individual y, ciertamente, el "reverdecimiento" de muchas empresas indica ciertos progresos en esta dirección (capítulo 15).

Al mismo tiempo, los diferentes marcos éticos pueden dar lugar a malentendidos y conflictos. Por ejemplo, las cuestiones relativas a la caza, el sacrificio de las poblaciones silvestres, el uso de organismos genéticamente modificados (OGM) y el uso de animales para la investigación médica, han sido objeto de controversia y atención de los medios. A medida que las dimensiones éticas de la conservación aumentan en los próximos años, la comunidad conservacionista tendrá que resolver este debate entre los valores intrínsecos de las especies y los ecosistemas y su valor instrumental para las personas. Esto puede ser apoyado por investigaciones actualmente en curso sobre la valoración de los servicios de los ecosistemas (capítulo 4), pero los esfuerzos para garantizar la incorporación de todos los valores serán de vital importancia

El desarrollo de una ética de la conservación más sólida es un medio fundamental para apoyar la conservación de la biodiversidad en el largo plazo. Tendremos que forjar alianzas con los líderes religiosos que cada vez hacen más hincapié en la ética ambiental que es inherente a todas las religiones. Como el futuro pertenece a los jóvenes, debemos centrarnos en los jóvenes de hoy, pero incluyendo cuestiones de relevancia para todas las personas. 
3. El Papel Central de las Personas

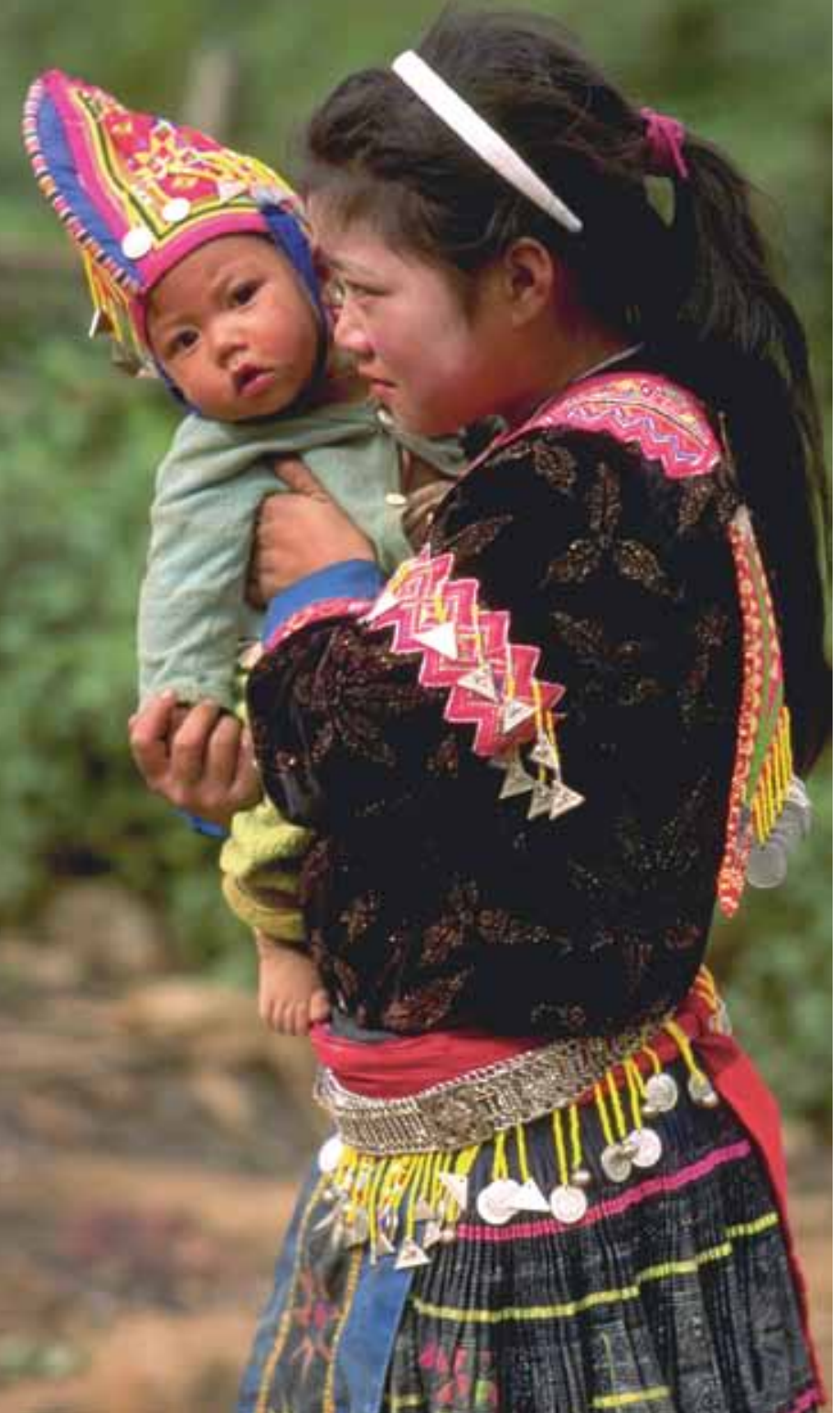


Las personas pueden ser

consumidoras, constructoras,

destructoras y muchas otras

cosas más. Más de tres cuartas

partes de la superficie terrestre

libre de hielo de la Tierra dan

muestras de alteración debido a

la residencia humana y al uso de

la tierra. Desde los primeros años

del movimiento conservacionista

mundial, la conversión del hábitat

fue considerada como la principal

amenaza a la conservación de la

naturaleza (y, en cierta medida,

sigue siéndolo). Las personas fueron

excluidas de las áreas protegidas

(AP) emulando el "modelo de

Yellowstone”, que desplazó a los

nativos americanos de sus tierras

históricas en el nombre de los

intereses nacionales de conservación

(aplicado en los primeros años por

los militares).

El desarrollo humano ha llegado a tal punto que el uso de la tierra se comprime entre las áreas protegidas, las tierras agrícolas, los bosques y la extensión del urbanismo. Las personas que dependen de los ecosistemas para sus medios de subsistencia están demostrando que las tierras naturales pueden incluir a las personas y que, efectivamente, durante mucho tiempo la gente ha sido parte de la naturaleza. Muchos sostienen que la población local tiene derechos tradicionales sobre estos recursos. La mayoría de las organizaciones de conservación ahora reconocen la importancia de incorporar a las personas en los esfuerzos de conservación, aunque algunos sostienen que las zonas selváticas, donde la huella humana es efímera, son esenciales para la conservación de por lo menos algunas especies (por ejemplo, los grandes depredadores) y se requiere la conservación de hábitats "intactos" para efectos de comparación con los modificados por la humanidad moderna.

En los últimos decenios muchas organizaciones de conservación, incluida la UICN, han emprendido iniciativas para encauzar y orientar la capacidad institucional de las comunidades locales en la conservación moderna de la biodiversidad. Estas iniciativas han sido motivadas por el principio de que los ecosistemas sanos prestan servicios esenciales a todas las personas. Pese a estos esfuerzos, el aumento de la desertificación, la pérdida de la fertilidad del suelo y la contaminación del agua han seguido reduciendo la capacidad de los ecosistemas para satisfacer las necesidades humanas (Evaluación de los Ecosistemas del Milenio, 2005). El informe de 2005 de la Evaluación de los Ecosistemas del Milenio (EM) determinó que el 60\% de todos los servicios de los ecosistemas está degradado. Las personas son cada vez menos capaces 
de depender de los ecosistemas y cada vez dependen menos de las fuentes de alimentos. Solo cuatro especies - trigo, maíz, arroz y patatasproporcionan más de la mitad de las calorías vegetales en la dieta humana (Pirages y De Geest, 2003). Quizás inadvertidamente, los seres humanos están incrementando su exposición a los riesgos de los cambios de los ecosistemas y la forma en que gestionemos esos riesgos tendrá un profundo impacto en los resultados.

La comunidad conservacionista en general ha aceptado la premisa de que la pobreza está correlacionada con la reducción de los recursos biológicos y los servicios de los ecosistemas, y las cuestiones de conservación y reducción de la pobreza se analizan con más detalle en otros capítulos.

Los conservacionistas también están reconociendo que el impacto de la riqueza en esos recursos y servicios también es evidente. Los patrones de consumo, las opciones de desarrollo, la distribución de la riqueza, las políticas gubernamentales y la tecnología pueden mitigar o exacerbar los efectos ambientales del cambio demográfico. Las economías industriales de hoy día consumen cantidades insostenibles de energía y materias primas y producen grandes volúmenes de desechos y emisiones contaminantes. Como lo señala el Programa de las Naciones Unidas para el Medio Ambiente (PNUMA) (2003), la consiguiente contaminación y perturbación de los ecosistemas a menudo se produce en países muy alejados del lugar de consumo. Las actitudes y preferencias de los consumidores tienen un profundo efecto sobre el medio ambiente debido a las diferencias en los impactos ambientales de la producción, utilización y eliminación de determinados bienes y servicios. Por otro lado, las preferencias de los consumidores no son estáticas. Los patrones de consumo están arraigados en y contribuyen a la evolución de los sistemas de valores. Culturas que antes eran diferentes y estaban relativamente aisladas se están interconectando cada vez más a través de las relaciones de mercado, fomentando una nueva cultura homogeneizada basada en el consumo y la posesión de bienes materiales. Las culturas tradicionales que alguna vez practicaban el uso de los recursos de baja intensidad están siendo desplazadas rápidamente, o se están transformando radicalmente para adquirir las ventajas comparativas percibidas requeridas para sobrevivir en un mundo impulsado por la competencia económica. La globalización ha ampliado el alcance de los medios de comunicación y la industria de la publicidad, reforzando sistemas de valores basados en ideales del consumo como sinónimo de felicidad y bienestar humano. Tales sistemas de valores son de dudosa sostenibilidad y pueden incluso contribuir a disturbios civiles.

La creciente integración de los mercados internacionales -comúnmente llamada globalización- ha permitido y estimulado la expansión de los modernos patrones de consumo de los países “desarrollados”, con repercusiones de gran alcance para el medio ambiente y la sociedad. El potencial de esos mismos mercados para contribuir a la conservación se aborda en el capítulo 12.

Si bien las personas y sus necesidades y deseos pueden ser la razón por la que nos enfrentamos a los retos apremiantes que tenemos ante nosotros, también son el único medio por el cual podemos resolver los problemas. El desarrollo y la adopción del Enfoque por ecosistemas del Convenio sobre la Diversidad Biológica (CDB) fue una confirmación explícita de la comunidad conservacionista en el sentido de que la consideración a las personas y sus necesidades es fundamental para el éxito (http://www.cbd. int/ecosystem/principles. shtml). La UICN ha acogido estos 12 principios, pero reconoce que muchos otros enfoques por ecosistemas pueden 
ser compatibles con ellos, como por ejemplo, la restauración del paisaje forestal, la gestión integrada de los recursos hídricos y la gestión integrada de las zonas costeras.

Otras cuestiones que deben ser incorporadas incluyen la conservación de las culturas y los conocimientos tradicionales, la promoción de enfoques de la conservación basados en los derechos, y la participación de las comunidades locales y los pueblos indígenas.

\section{VINCULANDO LA DIVERSIDAD CULTURAL Y BIOLÓGICA}

Una importante coincidencia entre la biodiversidad y la diversidad cultural es lo que algunos llaman "biodiversidad cultural" (Posey, 1999; Jianchu, 2000). Esta coincidencia es evidente en los mapas donde los lugares de situación crítica de la diversidad cultural, zonas de gran diversidad cultural, se superponen con zonas ricas en biodiversidad (Maffi, 2005). Esta coincidencia pone de manifiesto que el concepto de la naturaleza no es independiente de las personas o la cultura, sino que se integra con ellas.

Las personas siempre han dependido de las estructuras y normas sociales, un reflejo de cultura, para protegerse contra los riesgos de los cambios ambientales. Estos medios sociales de adaptación pueden tomar la forma de distribución de los recursos locales, dependencia de familias o linajes, adopción de nuevas tecnologías, migración, o cambios de comportamiento. Mediante la incorporación de las invenciones y las prácticas de muchas culturas, la gente está mejor preparada para adaptarse al cambio. Si estos recursos culturales se debilitan, así disminuirá la capacidad de los seres humanos para adaptarse a condiciones cambiantes.

La importancia de los conocimientos ambientales tradicionales y el papel de los pueblos indígenas y las comunidades locales en los esfuerzos de conservación están reconocidos en el Convenio sobre la Diversidad Biológica que exhorta a las Partes a

respetar, preservar y mantener los conocimientos, innovaciones y prácticas de las comunidades indígenas y las comunidades locales que encarnan estilos de vida tradicionales pertinentes para la conservación y la utilización sostenible de la diversidad biológica y promover su aplicación más amplia con la aprobación y participación de los titulares de esos conocimientos, innovaciones y prácticas, y fomentar la distribución equitativa de los beneficios derivados de la utilización de esos conocimientos, innovaciones y prácticas.

El CDB reconoce los conocimientos tradicionales como parte de un marco jurídico mundial. Mediante la creación de un enfoque sistemático para la relación entre las personas y la protección ambiental muestra que las personas, la biodiversidad y los paisajes forman una compleja unidad integrada. Este enfoque permite estrategias de conservación innovadoras tales como explorar la relación entre las mujeres indígenas, la gestión de los recursos y la biodiversidad.

La capacidad humana para cambiar su comportamiento permite a las personas desarrollar resiliencia a los cambios ambientales, reducir su impacto sobre los sistemas naturales y promover la conservación, si así lo decidieran. La UICN está integrando activamente la cultura y los medios de subsistencia en su programa de trabajo. En este sentido cabe mencionar el Programa de Restauración del Paisaje Forestal y la Comisión Mundial de Áreas Protegidas (CMAP), a través de sus grupos de trabajo sobre los paisajes protegidos y los valores culturales y espirituales de las áreas protegidas. Esta perspectiva integrada forma parte cada vez más de casi todos los programas de conservación. 
Uno de los desafíos de este cambio en la política $\mathrm{y}$ en el pensamiento general de la conservación es que ahora se espera que muchas comunidades locales gestionen proyectos de conservación, a menudo sin la amplia gama de habilidades y capacidades necesarias para cumplir con éxito lo que puede ser un enfoque desconocido para la gestión de los recursos. Una solución sería utilizar las técnicas convencionales para apoyar y fortalecer las capacidades locales, las tecnologías y los conocimientos tradicionales que ya están en práctica en las comunidades locales e indígenas. Muchas de las culturas locales ya gestionan en forma adecuada sus tierras y recursos pero necesitan ayuda para adaptarse a las nuevas presiones de una sociedad moderna globalizada. El reto será encontrar las vías más apropiadas para incorporar tanto los procesos locales y las prácticas convencionales de conservación en las nuevas estructuras nacionales y globales de gobernanza de los recursos.

\section{ENFOQUES DE LA CONSERVACIÓN BASADOS EN LOS DERECHOS}

Muchos de los grandes proyectos de desarrollo como la construcción de represas, la urbanización, carreteras, concesiones madereras, y nuevos enfoques a la agricultura, han prestado poca atención a los derechos de las poblaciones locales afectadas. Del mismo modo, la comunidad conservacionista está reconociendo que "las prácticas de conservación pueden afectar el bienestar humano y, en ocasiones, han menoscabado los derechos humanos, incluidos los medios de subsistencia locales, a causa de violaciones a los derechos humanos, reasentamientos forzosos e impactos sobre los medios de subsistencia locales, especialmente en lo referente a los pueblos indígenas y las comunidades locales” (UICN, 2008e). Con esto en mente, la visión de la UICN de "Un mundo justo que valora y conserva la naturaleza” requerirá la aplicación de enfoques basados en los derechos al trabajo de la Unión. Así se garantizará la plena consideración de los derechos humanos, los derechos de tenencia y de acceso a los recursos, y los derechos consuetudinarios de los pueblos indígenas y las comunidades locales.

Los enfoques de la conservación basados en los derechos son especialmente importantes para los pueblos indígenas minoritarios que, hace apenas 30 años, tenían pocos derechos en la mayoría de los países. Esto influenció el pensamiento respecto de la conservación antes de ese momento, con rescoldos en algunas de las prácticas actuales de conservación. Hasta hace relativamente poco, los grupos indígenas solían carecer de capacidad jurídica o derechos formales sobre la tierra, lo que hacía difícil para las organizaciones de conservación trabajar directamente con ellos. Con la promoción de los derechos humanos y el mayor uso de enfoques para el desarrollo basados en los derechos humanos, los derechos de los pueblos indígenas están siendo reconocidos y promovidos a través de la mención explícita de los valores de los conocimientos tradicionales y las comunidades indígenas. En 2003, la adopción del Acuerdo de Durban por el V Congreso Mundial de Parques y la Declaración de las Naciones Unidas de los Derechos de los Pueblos Indígenas de 2007, hacen impensable que la UICN lleve a cabo actividades que afectan a la población local sin el consentimiento libre, previo e informado de las personas directamente implicadas.

Este enfoque en los derechos y la condición jurídica está relacionado con el proceso global de democratización. Con énfasis en la transparencia y la participación ciudadana, la gestión de los recursos se basa más en la comunidad, hecho que para la UICN supone tanto desafíos como oportunidades. 
LAS PERSONAS $Y$ LOS ECOSISTEMAS, 0 LAS PERSONAS ENLOS ECOSISTEMAS

Las comunidades locales, y especialmente los pueblos indígenas, suelen ser los más marginados política y económicamente. Al mismo tiempo, suelen ser los guardianes de las zonas con mayor riqueza biológica. Según Sobrevila (2008), los territorios indígenas tradicionales cubren hasta el $22 \%$ de la superficie terrestre del mundo y apoyan el $80 \%$ de la diversidad de especies terrestres del planeta.

Las modernas prácticas conservacionistas convencionales son a menudo rechazadas por las comunidades locales, especialmente cuando no participan plenamente en la toma de decisiones. Uno de los resultados es la degradación del hábitat y la pérdida de biodiversidad. El modelo Yellowstone de parques nacionales, por ejemplo, ha sido fuertemente resistido en Asia Occidental, el Norte de África y otros lugares. Esto no quiere decir que esas regiones carecen de áreas protegidas, sino más bien que las comunidades locales han encontrado sus propios medios de protección de los recursos fuera de los marcos jurídicos; algunos de estos acuerdos están siendo socavados porque no son reconocidos por la legislación internacional y nacional. Sin embargo, los enfoques tradicionales a la conservación, como el hema en las tierras de pastoreo en Asia Occidental, pueden adaptarse para proporcionar opciones viables para la conservación bajo condiciones modernas.

La mayoría de los programas de conservación requiere mantenimiento y gestión a largo plazo, que también puede beneficiarse del trabajo con las comunidades locales. La conservación se puede considerar como un bien público, razón por la cual posiblemente debería recibir financiación pública, pero esta rara vez es suficiente (en especial en los países en desarrollo sometidos a las restricciones de gasto del FMI). Las fundaciones, los organismos de desarrollo, las organizaciones no gubernamentales (ONG) y filantrópicas han sido extremadamente útiles, pero la conservación requiere apoyo a perpetuidad, que es mucho más de lo que la mayoría de los donantes está dispuesta a financiar. Como resultado de ello, los proyectos de conservación han sufrido un debilitamiento sistémico conforme la financiación se desvanece. Para superar esta dificultad, los conservacionistas están forjando vínculos con las estructuras sociales locales y recurriendo al apoyo de las comunidades locales. Para muchos proyectos, el control local del mantenimiento y la supervivencia del proyecto es más rentable y ha producido resultados más exitosos, como es el caso de los programas de áreas protegidas descentralizados y apoyados localmente.

Un aspecto prometedor que ha reconocido la importancia de las comunidades locales en la gestión de áreas protegidas es el nuevo enfoque de la Comisión Mundial de Áreas Protegidas de la UICN hacia la autogobernanza y gestión por las comunidades indígenas. El 86\% de las zonas clasificadas como parques nacionales en América Latina es hogar permanente o temporal de comunidades indígenas o locales (Amend y Amend, 1995), por lo que este enfoque saca provecho de la ya fuerte presencia de las comunidades indígenas dentro y alrededor de las áreas protegidas. La autogobernanza de los recursos locales también puede ayudar a reducir la pobreza en las comunidades locales, incluso a través de oportunidades tales como la integración de la conservación y el turismo.

El trabajo con las comunidades locales debe incluir apoyo para el abordaje de problemas relacionados con el medio ambiente como el cambio climático, las especies invasoras, los medios de subsistencia sostenibles y la salud. Cada uno de ellos se examina en más detalle en otros capítulos. Los conocimientos tradicionales son una base importante para la adaptación al cambio climático y la disminución de la vulnerabilidad a los 


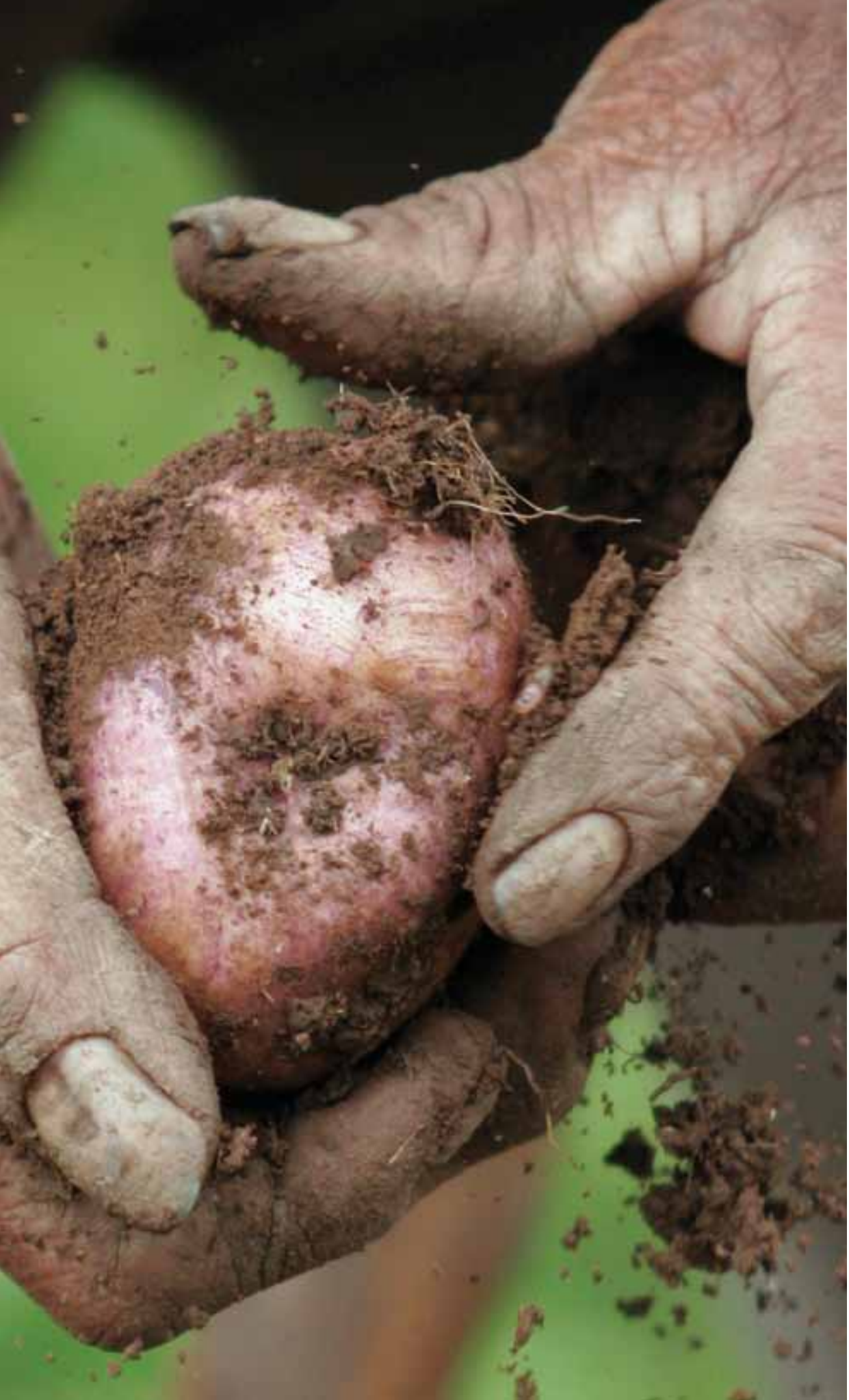


fenómenos extremos, y su pérdida puede acentuar

la vulnerabilidad de la población local a los cambios

(Ford, 2006).

La participación de todos los interesados directos

en la conservación requiere el desarrollo de

herramientas y capacidades, incluyendo el

suministro de recursos para los administradores,

tales como manuales, asistencia técnica y otras guías

prácticas de fácil acceso sobre cómo equilibrar el

manejo de los recursos naturales con las necesidades

de desarrollo económico. Debe facilitarse acceso

a los conocimientos complementarios necesarios

para lograr la reducción sostenida de la pobreza y

el desarrollo sostenible. Debe empoderarse a las

comunidades locales para conservar y gestionar los

recursos naturales de los que dependen y mejorar la cooperación con instituciones vecinas en la gestión

de recursos diversos.

Por otra parte, debe alentarse a los gobiernos a

mejorar la tenencia de la tierra, otorgar titularidad

jurídica colectiva a los pueblos indígenas y

empoderar a la sociedad civil para la gestión de los

recursos naturales renovables para su utilización

sostenible, a través de derechos de acceso basados

en la equidad social y de género. Los donantes y

los gobiernos deben formular y aplicar políticas

que incorporen la conservación ambiental y la

biodiversidad en las actividades de reducción

de la pobreza que financian. Por último, una

política sobre conservación y derechos humanos,

incluyendo enfoques de la conservación basados

en los derechos, medios de aplicación, formas

de promover el intercambio de experiencias, $y$

responsabilidades de gobiernos, comunidades,

sector privado y organizaciones de conservación es

una necesidad apremiante. 


\section{Servicios de los Ecosistemas: Los Beneficios que la Naturaleza Ofrece a las Personas}

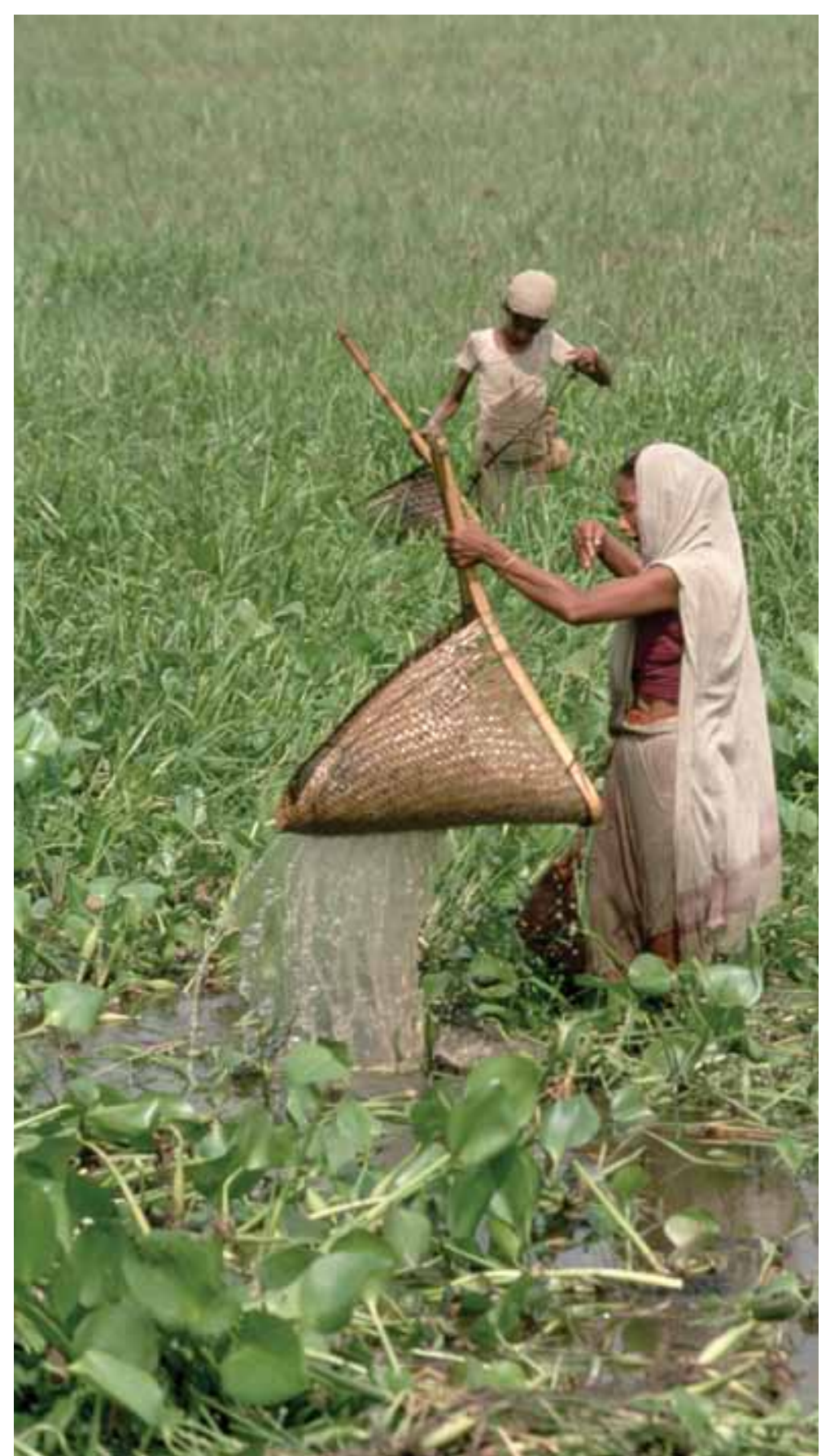


Los ecosistemas apoyan los procesos de limpieza del aire y del agua, la polinización de cultivos, la descomposición de los residuos, el control de plagas y enfermedades nocivas y la regulación de los fenómenos naturales extremos. Tanto el agua como los alimentos, fibras, combustibles y medicamentos son producidos por la intrincada red de la vida. La inspiración para las artes, las culturas y las religiones ha provenido de la naturaleza, que también ofrece recreación y enriquecimiento espiritual.

La vida en la Tierra ha persistido durante más de dos mil millones de años, formando ecosistemas que han proporcionado las funciones para el flujo de nutrientes, las interacciones depredador-presa que ayudaron a impulsar la evolución e, incluso, la atmósfera actual que apoya la vida en la Tierra. A medida que los seres humanos evolucionaron, nuestros antepasados se beneficiaron de muchas de estas funciones básicas que permitieron a nuestra especie llegar a sus niveles actuales de diversidad cultural. Con el surgimiento de la civilización mediante el establecimiento de la agricultura de regadío, la humanidad comenzó a darse cuenta de los beneficios de un espectro mucho más amplio de los servicios de los ecosistemas y los riesgos que conlleva su debilitamiento. Por ejemplo, Platón en 400 a. C. reconoció que la deforestación ocasionaba la erosión y el secado de manantiales (Goldin, 1997). Los tratados médicos árabes del siglo IX registran un pensamiento sofisticado en relación con las técnicas agrícolas incluyendo el riego y la rotación de cultivos, además del control de la contaminación (Watson, 1983). Las civilizaciones de la India, China y el sudeste asiático movilizaron algas acuáticas y fijadoras de nitrógeno para crear ecosistemas de cultivo de arroz de regadío que produjeron las culturas más ricas del mundo de esos tiempos antiguos (McNeely y Wachtel, 1988).

Más recientemente, el matrimonio entre la ciencia y la tecnología movilizó la energía de los combustibles fósiles y la aplicó a la agricultura y la manufactura, produciendo suficientes alimentos y otros productos para apoyar la cuadruplicación de la población humana del mundo durante el siglo XX. A medida que se aceleró el crecimiento demográfico, sin embargo, los posibles límites al aumento han adquirido creciente relevancia progresivo (Malthus, 1798; Meadows et al., 1972). Más recientemente, la Evaluación de los Ecosistemas del Milenio (EM) reunió a más de 1300 científicos para informar sobre la situación de una amplia gama de los servicios de los ecosistemas del mundo y las consecuencias para las personas ahora y en el futuro de los cambios en los ecosistemas (EM, 2005b). Su conclusión de que el $60 \%$ de los servicios de los ecosistemas que fueron evaluados 
se estaban degradando o usando de manera no sostenible a escala mundial, proporcionó una base científica sólida para reafirmar la urgencia de conservar la biodiversidad y los ecosistemas.

\section{CLASIFICACIÓN DE LOS SERVICIOS DE}

\section{LOS ECOSISTEMAS}

Así pues, ¿qué, exactamente, son los servicios de los ecosistemas? En términos simples, son los beneficios que los ecosistemas proporcionan a las personas. El concepto de "ecosistema" destaca las interacciones entre los componentes de la biodiversidad en una gama de escalas y las interacciones entre las especies vivas y el entorno abiótico. De hecho, esas interacciones apoyan, regulan y proporcionan los beneficios que las personas derivan de la biodiversidad. Las personas no obtienen los servicios de una gama de escalas de la biodiversidad que actúan de manera independiente, sino que son producto de la interacción de los ecosistemas y sus componentes como una unidad funcional. Cuando el sistema se degrada, menos servicios se prestan. Esto constituye una potente justificación para el enfoque de la UICN en la conservación

\section{FIGURA 4.1 MARCO PARA LA CLASIFICACIÓN DE LOS SERVICIOS DE LOS ECOSISTEMAS $(E M, 2003)$}

APROVISIONAMIENTO
Bienes producidos o
suministrados por los
ecosistemas
• alimentos
- agua dulce
• combustibles
• fibras
• bioquímicos
recursos genéticos
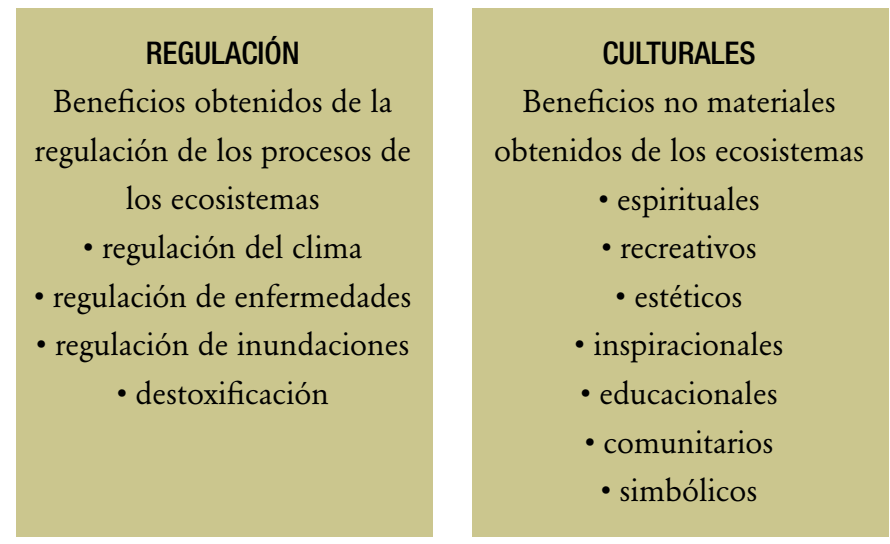

\section{APOYO}

Servicios necesarios para la producción de otros servicios de los ecosistemas

- formación de suelos

- ciclaje de nutrientes

- producción primaria

de los ecosistemas, los servicios que prestan, y la biodiversidad que los sostiene.

La gente a menudo degrada los ecosistemas pero los podemos restaurar y podemos intervenir de manera significativa en su gestión para cambiar el equilibrio y suministrar la multiplicidad de servicios. Ya sea que se trate de administradores de bosques, administradores de humedales, administradores de granjas, o jardineros de traspatio, todos son conscientes de que están gestionando un ecosistema. Incluso aquellos que se centran en la conservación de las especies en la naturaleza reconocen que ninguna especie es una isla, autosuficiente en sí misma, sino que su 
supervivencia depende de sus relaciones con los otros componentes del ecosistema del que forma parte.

La Evaluación de los Ecosistemas del Milenio (EM, 2003) clasificó los servicios de los ecosistemas en cuatro grupos: servicios de apoyo; servicios de regulación; servicios de aprovisionamiento; y servicios culturales (figura 4.1).

\section{SERVICIOS DE APOYO}

Los servicios de apoyo incluyen la producción primaria, el ciclaje de nutrientes, el ciclo del agua, la polinización y la provisión de hábitats. Sus beneficios para las personas son indirectos, y permiten a los ecosistemas proporcionar servicios culturales, de regulación y de aprovisionamiento. Por ejemplo, la provisión del servicio de producción de alimentos depende de los servicios de apoyo del ciclaje de nutrientes, la formación de suelos, el ciclo del agua, y la polinización. Desde una perspectiva económica, no tiene sentido valorar los servicios de apoyo directamente, dado que el valor de estos servicios debe ser capturado (pero a menudo no lo es) por el valor de los beneficios directos que obtenemos de los ecosistemas (por ejemplo, alimentos o agua).

\section{SERVICIOS DE APROVISIONAMIENTO}

Los servicios de aprovisionamiento son los bienes producidos por los ecosistemas. Para la mayoría de las personas, son los servicios de los ecosistemas más inmediatamente reconocibles y constituyen la mayoría de los beneficios tangibles derivados de los ecosistemas (pese a que, como se mencionó anteriormente, son totalmente dependientes de los servicios de apoyo). Desde los recursos genéticos de especies silvestres hasta las plantas y animales domesticados de los que dependemos para la mayoría de nuestros alimentos, los servicios de aprovisionamiento también ofrecen un medio de subsistencia más allá de sus beneficios directos de consumo porque son fácilmente valorados e intercambiados en los mercados. Aunque el proceso rara vez es reconocido como tal, las personas participan en sistemas de pagos por los servicios de los ecosistemas cada vez que compran alimentos, leña o medicinas naturales. Los servicios de aprovisionamiento satisfacen las necesidades de alimentos, fibras naturales, medicamentos y recursos genéticos de la población mundial, y satisfacen las necesidades de combustible para un tercio de la población del mundo que no tiene acceso a combustibles fósiles.

\section{SERVICIOS DE REGULACIÓN}

Los servicios de regulación son los beneficios que se derivan de las formas en que los ecosistemas influyen en el entorno en que vivimos. Estos incluyen la regulación de la calidad del aire y el clima, la calidad y cantidad del agua, las plagas y enfermedades, y las tormentas y otros desastres naturales. Los servicios de regulación funcionan en una amplia gama de escalas; por ejemplo, la regulación del sistema climático opera a escalas mundiales, la regulación del caudal hídrico a escala de cuenca fluvial, y la regulación de los vientos y las mareas de tempestad a escalas muy locales. Los servicios de regulación son difíciles de valorar en términos económicos y rara vez se reconocen en los sistemas de contabilidad nacional. Algunos servicios de regulación también pueden ser considerados como servicios de apoyo, dependiendo de cómo afectan a las personas los cambios en el servicio. Por ejemplo, mientras que la formación y retención de suelos regulan directamente la calidad del agua, las personas también se benefician indirectamente de la formación de suelos, como por ejemplo, a través del servicio de aprovisionamiento de producción de alimentos. Los economistas están ahora trabajando en enfoques que permitan valorar estos servicios, dando lugar a nuevas formas de pago por los servicios de los ecosistemas (PSE). 


\section{SERVICIOS CULTURALES}

Los servicios culturales son los beneficios no materiales y, en ocasiones, intangibles, que las personas derivan de los ecosistemas. Estos incluyen beneficios que las personas derivan de la estética y la inspiración, de los aspectos espirituales y religiosos de los ecosistemas, de la educación y la ciencia, y de la afinidad cultural y los valores del patrimonio que muchas personas asocian con los paisajes y las especies, especialmente en las zonas en las que residen. Los servicios culturales están estrechamente vinculados a los valores y comportamientos humanos y pueden variar considerablemente entre perspectivas sociales, económicas y políticas. Aunque los valores culturales y otros beneficios intangibles de los ecosistemas suelen ser difíciles de valorar, estos, sin embargo, proporcionan beneficios fundamentales a los individuos y a las sociedades de todo el mundo. Sea cual fuere el valor que se asigne a la existencia de especies individuales, como los pandas y las ballenas, el conocimiento científico que se deriva de la observación de la naturaleza o las afinidades culturales y espirituales que muchas personas tienen con arboledas sagradas o especies icónicas, los servicios culturales de los ecosistemas benefician nuestros cuerpos, mentes y almas. Los beneficios recreativos y de turismo derivados de la naturaleza y la biodiversidad, en contraste con muchos de los otros servicios culturales, son fácilmente medibles y cuantificables en términos económicos. Se han convertido en una importante fuente de ingresos a nivel local, regional y nacional, y han contribuido significativamente a mejorar la calidad de vida de las comunidades locales, aunque ello implica algunas concesiones.

\section{LAS POLÍTICAS Y LA PLANIFICACIÓN DE LOS SERVICIOS DE LOS ECOSISTEMAS}

La creciente comprensión acerca de la importancia y el valor de los servicios de los ecosistemas en los últimos 20 años ha impulsado una serie de eventos clave y, a partir de ellos, importantes iniciativas sobre políticas. La más notable de ellas fue la Conferencia de las Naciones Unidas sobre el Medio Ambiente y el Desarrollo, conocida como la Cumbre de la Tierra, celebrada en Río de Janeiro, Brasil, en junio de 1992. Uno de los principales resultados de la Cumbre de la Tierra fue el Convenio sobre la Diversidad

Biológica (CDB), que ahora cuenta con 191 Estados Partes. El concepto de los servicios de los ecosistemas está profundamente arraigado en el CDB a través de los conceptos de "uso sostenible" y "beneficios" que se especifican en sus objetivos.

Los servicios de los ecosistemas fueron también reconocidos cuando la Asamblea General de las Naciones Unidas adoptó los ocho Objetivos de Desarrollo del Milenio (ODM) en 2000. El sétimo de ellos, "Garantizar la sostenibilidad del medio ambiente", se refiere explícitamente al mantenimiento de los servicios de los ecosistemas y la conservación de la biodiversidad (Melnick et al., 2005). Dos años más tarde, la Cumbre Mundial sobre el Desarrollo Sostenible (WSSD), celebrada en Johannesburgo, Sudáfrica, hizo suyos los Objetivos de Desarrollo del Milenio, consolidando el tema del avance hacia estos como un componente central de la política intergubernamental. 
A nivel nacional, también se han adoptado políticas para mantener el suministro de servicios de los ecosistemas. Una búsqueda en la base de datos de ECOLEX (un esfuerzo conjunto de UICN, FAO y PNUMA), arroja no menos de 602 menciones de "servicios de los ecosistemas" en la legislación nacional. Los servicios de aprovisionamiento son el enfoque más común, quizá porque son los más evidentes, más fáciles de medir, y producen la mayoría de los ingresos fiscales.

La otra gran respuesta en términos de políticas para el reconocimiento de los valores de los servicios de los ecosistemas ha sido el desarrollo de mercados para dichos servicios. Costa Rica es un buen ejemplo de un país que ha dado los primeros pasos para desarrollar mercados para los servicios de los ecosistemas (Rojas y Aylward, 2003). El país ha sido durante mucho tiempo líder mundial en la industria del ecoturismo -vendiendo, en efecto, servicios recreativos de los ecosistemas. Durante el decenio de 1990, fue pionero en sistemas mediante los cuales las comunidades y empresas aguas abajo pagaban a los habitantes de las tierras altas para el mantenimiento y restauración de los bosques para la provisión de agua. Más recientemente, Costa Rica ha participado activamente, junto con otros países tropicales, en el desarrollo de incentivos y financiación para la Reducción de Emisiones por Deforestación y Degradación (REDD), como un enfoque para captar los beneficios económicos de la secuestración de carbono y el almacenamiento de biomasa, para la regulación del clima.

Dada la creciente importancia de los servicios de los ecosistemas en las políticas y en los mercados, los Estados, gobiernos locales, y organizaciones no gubernamentales (ONG) están buscando mejores métodos para la prestación de los servicios de los ecosistemas. La clave para una planificación eficaz es una declaración clara de objetivos. Por ejemplo, el objetivo de un determinado organismo podría ser reducir a la mitad la proporción de personas sin acceso a agua limpia (parte del Objetivo de Desarrollo del Milenio 7). Con base en ello se recogen datos y se construyen modelos para informar las opciones que podrían ayudar a alcanzar este objetivo, como la instalación de infraestructura (para la purificación o desalinización), mejoras en el saneamiento, y mantenimiento de hábitats forestales en las cuencas hidrográficas. Las diferentes combinaciones y configuraciones espaciales de estas opciones tendrán diferentes costos y beneficios. Los costos incluirán no solo la construcción y el mantenimiento, monitoreo y evaluación, sino también los costos de oportunidad (por ejemplo, el mantenimiento de los hábitats de los bosques puede implicar la renuncia a la explotación de algunas maderas). Los beneficios serán directos, contribuyendo al logro del objetivo, e indirectos, cuando los servicios de los ecosistemas pueden ser “agrupados" o "desagrupados" para atraer a otros a invertir en el plan (por ejemplo, manteniendo los hábitats de los bosques también se contribuye a REDD). Con estos datos disponibles, pueden utilizarse sistemas como el análisis espacial costobeneficio o el de subasta inversa para obtener un plan que llevará a la consecución de un objetivo a un costo mínimo (o lo más cerca posible del objetivo para un determinado presupuesto).

\section{MÁS ALLÁ DE LA VALORACIÓN}

El concepto de los servicios de los ecosistemas tiene por objeto poner de relieve los desequilibrios existentes en las fuerzas del mercado, que confieren mayor peso a los bienes y servicios pero tienden a descuidar los ecosistemas y otros beneficios ajenos al mercado. Al promover el conocimiento acerca del valor total de los servicios de los ecosistemas, los conservacionistas tienen la esperanza de que los formuladores de políticas tomen cartas en el asunto y promuevan la reforma de los mercados a efectos de que reflejen de mejor manera la verdadera relación entre el bienestar humano y la salud 
de los ecosistemas y, en consecuencia, apoyen la conservación de la naturaleza. Esto a menudo implica la estimación del valor monetario de servicios de los ecosistemas bien definidos, para reforzar el aspecto económico del cambio, seguido de la introducción de mecanismos tales como los pagos por los servicios de los ecosistemas, que pueden transformar el valor potencial en beneficios económicos y cambios en el comportamiento.

El primer paso consiste en valorar los servicios de los ecosistemas. Eso es precisamente lo que hace el estudio La Economía de los Ecosistemas y la Biodiversidad (TEEB). Un informe provisional del estudio (CE y BMU, 2008) afirma que el bienestar humano depende totalmente de "los servicios de los ecosistemas". Sin embargo, dado que estos servicios son principalmente bienes públicos, sin claros derechos de propiedad, mercados o precios, no están reconocidos ni integrados adecuadamente en nuestras políticas y decisiones económicas. Como resultado, la falta de reconocimiento respecto de la totalidad de los costos y beneficios de la conservación lleva a la continuación de la pérdida de biodiversidad. TEEB, a través de la elaboración y difusión de instrumentos económicos de apoyo a la valoración de los servicios de los ecosistemas, confía en poner remedio a esta situación.

Al mismo tiempo, muchas personas rechazan una visión puramente utilitaria de la naturaleza, haciendo hincapié en los valores morales o intrínsecos de la biodiversidad. Si bien estos valores son extremadamente difíciles de cuantificar, hay enfoques claramente definidos para reflejarlos en las políticas (por ejemplo, a través de legislación relativa a la protección de especies en peligro de extinción). El valor intrínseco de la naturaleza puede ser considerado de la misma manera que otros valores culturales o morales -como las grandes obras de arte, quizá, o los derechos humanos.

Las raíces del reconocimiento del valor intrínseco de la biodiversidad están profundamente arraigadas en muchas culturas y religiones del mundo. Todas las religiones han aceptado los conceptos de vigilancia o cuido del mundo natural (Gardner, 2002), al igual que lo hacen importantes filósofos políticos, si bien esos valores no están distribuidos equitativamente entre los componentes del mundo natural (por ejemplo, en la mayoría de las culturas se confiere mucho más valor intrínseco a las especies de animales carismáticos que a las plantas o microorganismos). Entre los pensadores contemporáneos, E. O. Wilson (1984) es quien ha comunicado más poderosamente el valor intrínseco, incluyendo la exploración detallada de su base evolutiva.

El lugar para el valor intrínseco de la naturaleza en el mundo del desarrollo económico y la valoración de los servicios de los ecosistemas puede ser identificado a través de la claridad de objetivos. El objetivo del desarrollo es mejorar el bienestar humano. El objetivo de la conservación de la biodiversidad consiste en mantener y restaurar la biodiversidad y los ecosistemas, sobre todo garantizando que las tasas de extinción irreversible de las especies no excedan los niveles naturales. La valoración de los servicios de los ecosistemas puede ayudar a la consecución del bienestar humano y la conservación de la biodiversidad, un medio para dos fines, pero no un fin en sí mismo.

El concepto de los servicios de los ecosistemas ha provocado algunas críticas (McCauley, 2006), pero todas ellas pueden ser tratadas (McNeely et al., 2009):

- Existen casos en los que son pocos los servicios de los ecosistemas que la naturaleza puede ofrecer más allá de beneficios culturales, por lo que la estrategia puede ofrecer poco apoyo a la conservación de, por ejemplo, las 2000 plantas endémicas de la región de Succulent Karoo de Sudáfrica. Sin embargo, esta región puede ser especialmente importante por sus valores de opción; y sus valores culturales para los sudafricanos son sustanciales. Los argumentos 
basados en los servicios de los ecosistemas no se sustentan únicamente en términos financieros.

- Los mercados fluctúan ampliamente (como quedó demostrado en 2008 en todo el mundo), por lo que ¿deberíamos liquidar nuestros activos naturales si un mercado voluble les atribuye un valor más bajo mañana del que tienen hoy? Ciertamente no, porque los servicios de los ecosistemas no son todos susceptibles de evaluación en términos de valores económicos, y el concepto alienta la consideración de todos los valores intrínsecos, culturales y económicos en la toma de decisiones. La combinación de los valores intrínsecos y económicos es más potente que cualquiera de los dos por sí solo.

- La dependencia en los servicios de los ecosistemas como base para la conservación puede conducir al argumento de que podríamos prescindir de los ecosistemas si se dispusiera de métodos más baratos para prestar los mismos servicios. Esto puede ser menos preocupante cuando reconocemos que los ecosistemas ofrecen múltiples servicios, todos los cuales deben ser considerados en la toma de decisiones.

- Sin duda alguna habrá situaciones en las que se derivará más beneficios económicos a nivel local con la destrucción de la naturaleza que el beneficio económico mundial derivado de su conservación (por ejemplo, la introducción de la perca del Nilo en el Lago Victoria impulsó las economías locales pero devastó las especies endémicas de peces del lago). Tales concesiones son comunes en la gestión de recursos, pero teniendo en cuenta el conjunto completo de servicios de los ecosistemas se obtiene una decisión más informada y acertada sobre las concesiones que podría ser necesario incluir. La experiencia de Costa Rica demuestra que el concepto de los servicios de los ecosistemas puede generar resultados positivos.
Oates (1998) añade una quinta preocupación fundamental: la influencia "corruptora" de la economía en el ámbito de la conservación misma. Pero el concepto de los servicios de los ecosistemas es útil para muchas cuestiones relativas a la gestión de los recursos. Reid et al. (2006) señalan que "nuestro planeta es un mosaico de sistemas que proporcionan a las personas diferentes paquetes de servicios de los ecosistemas y perjuicios. No podemos gestionar estos sistemas de manera eficaz si no nos ocupamos activamente de determinar los flujos de estos servicios, quién se beneficia de ellos, y considerar una serie de políticas, incentivos, normas y tecnologías que pudieran fomentar una mejor gestión y participación en los beneficios”.

Cualquier herramienta puede ser utilizada en forma indebida, pero análisis recientes indican que el uso adecuado de la valoración y los pagos por los servicios de los ecosistemas puede ser de gran beneficio para la conservación. En particular, las nuevas evidencias sugieren una correspondencia espacial elevada (Turner et al., 2007; Polasky et al., 2008) o, al menos, mixta (Chan et al., 2006; Naidoo et al., 2008) entre las prioridades de conservación de la biodiversidad y el valor de los servicios de los ecosistemas. Ello indica que la inversión en la conservación de regiones de alta prioridad para la biodiversidad con frecuencia puede derivar también en, cuando menos, algunos valores significativos de los servicios de los ecosistemas. Dada la concentración de áreas prioritarias para la conservación de la biodiversidad y la necesidad de mitigación de la pobreza en los trópicos, la conservación basada en el concepto de los servicios de los ecosistemas ofrece una perspectiva productiva para la UICN y otras organizaciones de conservación con miras a un futuro sostenible. 


\section{Cambio Climático y Biodiversidad}

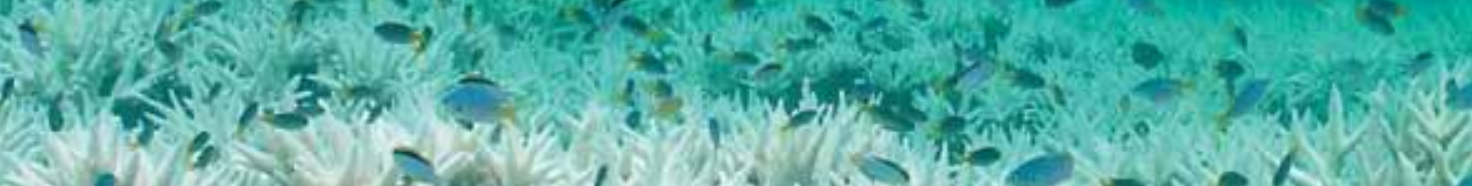

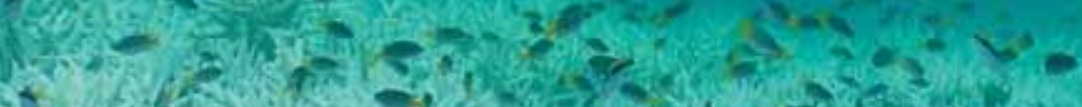

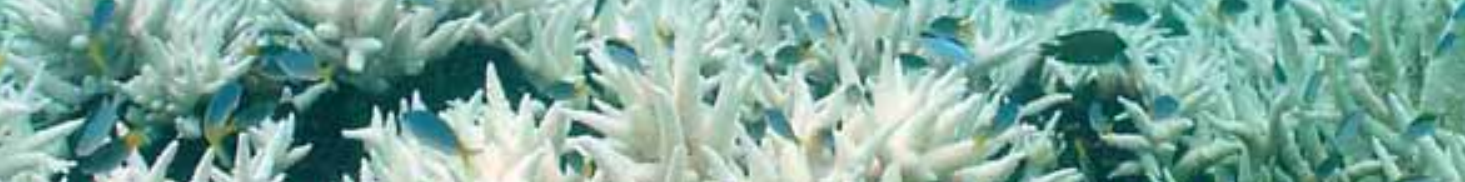
H.

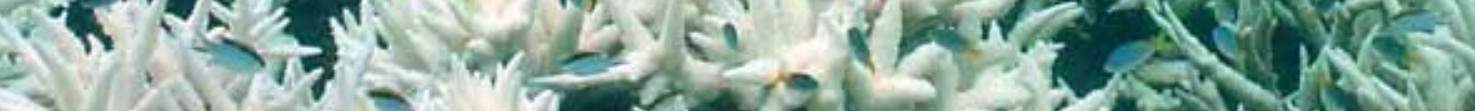

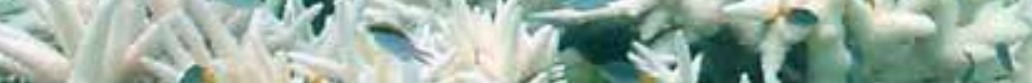

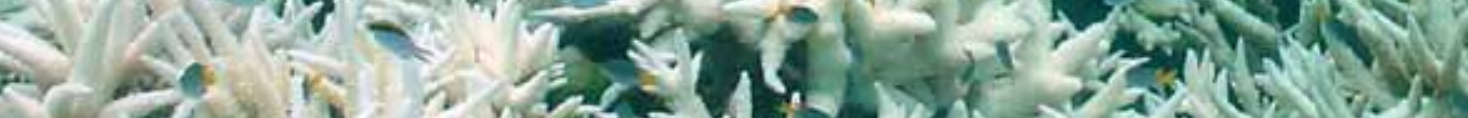
ATU , ST-1,

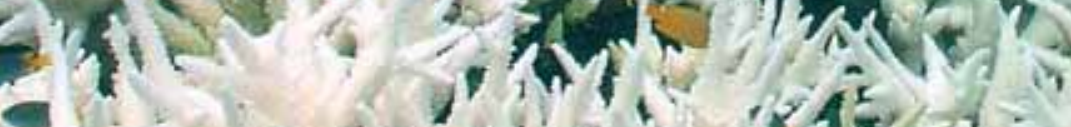

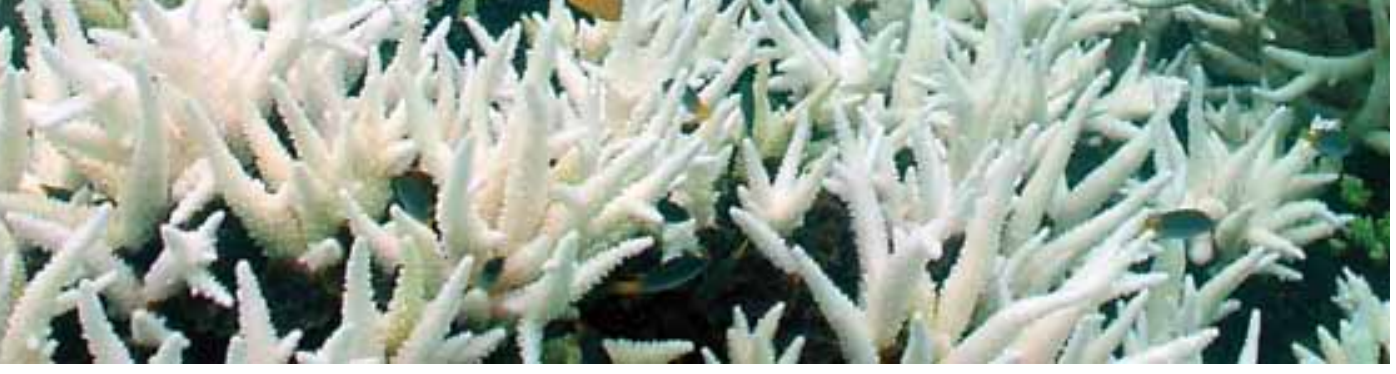




\section{El Grupo Intergubernamental de Expertos sobre el Cambio Climático}

(IPCC) publicó su $4^{\circ}$ Informe de Evaluación en 2007, reforzando las conclusiones de que las recientes emisiones de gases de efecto invernadero (GHG) han superado por mucho los valores pre-industriales, pero añadiendo que las emisiones han aumentado más rápidamente en la década de 1995 a 2005 que nunca antes (IPCC, 2007a). Las isotermas (líneas que conectan los lugares con la misma temperatura) están cambiando a una velocidad de 40 kilómetros por década en el hemisferio norte y a ese ritmo, junto con factores como la pérdida de hábitats y la contaminación, algunas especies tendrán dificultades para sobrevivir (Hansen et al., 2006).

\section{Recuadro 5.1 ¿Qué está cambiando en el cambio climático?}

Mayores niveles de gases de efecto invernadero<smiles>C[13CH]</smiles>

Conducentes a

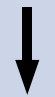

Mayores temperaturas

Elevación en los niveles oceánicos

Cambios en las corrientes oceánicas

Cambios en la composición química del aire y los océanos

Entre las conclusiones más importantes del informe desde la perspectiva de la biodiversidad debe destacarse:

- El calentamiento del sistema climático es inequívoco, como resulta ahora evidente de las observaciones de los aumentos en las temperaturas medias globales del aire y los océanos, el derretimiento generalizado de los casquetes de nieve y los glaciares y el aumento del promedio mundial del nivel oceánico.

- La evidencia recogida de todos los continentes y la mayoría de los océanos muestra que muchos sistemas naturales están siendo afectados por cambios climáticos regionales, particularmente los aumentos de temperatura.

- Es muy probable que la mayor parte del aumento observado en las temperaturas medias mundiales desde mediados del siglo XX se deba al aumento observado en las concentraciones antropogénicas de gases de efecto invernadero.

Pruebas más recientes presentadas por los científicos del IPCC (marzo de 2009) informan 
de que incluso la terrible evidencia presentada en el $4^{\circ}$ Informe de Evaluación era demasiado optimista. El calentamiento entre 2000 y 2007 fue sin precedentes, debido principalmente al rápido crecimiento económico de China y la India, alimentado en gran parte por carbón.

Solomon et al. (2009) informaron de que la gravedad de los impactos resultantes del cambio climático estaba relacionada no solo con la magnitud del cambio sino también con la posibilidad de irreversibilidad. Llegaron a la conclusión de que el cambio climático inducido por las emisiones de dióxido de carbono será en gran parte irreversible hasta por 1000 años después de detener las emisiones en razón del tiempo necesario para disminuir las temperaturas en respuesta a la disminución de las emisiones.

Al reunirse los delegados en abril de 2009 en Bonn, Alemania, para una reunión preparatoria de la Convención Marco de las Naciones Unidas sobre el Cambio Climático (UNFCCC) COP 15 en Copenhague, en diciembre de 2009, la noticia del colapso de la plataforma de hielo Wilkins, una placa de hielo antártico del tamaño de Manhattan, estaba en la mente de todos como un dramático indicador de la aceleración del cambio climático, dando un carácter de mayor urgencia a las negociaciones que tenían lugar.

Los impactos previstos del aumento de las temperaturas se presentan gráficamente en la figura 5.1.

Los impactos del cambio climático por sí solos suponen cambios significativos en nuestro medio ambiente. Sin embargo, el cambio climático es también una amenaza de efecto multiplicador y acelerador -que amplifica los efectos de otras amenazas a la biodiversidad que ya están afectando la naturaleza, incluyendo degradación de hábitats, contaminación, especies invasoras, enfermedades infecciosas emergentes y sobreexplotación. En última instancia, se verá afectada la provisión de prácticamente todos los servicios de los ecosistemas, algunos más que otros. La respuesta humana a estos cambios será una de las principales preocupaciones en las próximas décadas.

Con el sentido de urgencia generado a través de los medios de comunicación y los informes científicos, ya está ampliamente aceptado que el clima es un problema que incumbe a todos -empresas, conservacionistas, comunidades locales, gobiernos municipales, propietarios particulares de tierras, administradores de áreas protegidas y muchos otros. Las asociaciones entre estos diversos sectores de la sociedad, generadas por la acción climática, podrían beneficiar también a la biodiversidad. Es preciso actuar ahora, tanto para gestionar los impactos evitables a través de la mitigación como para hacer frente a los impactos inevitables a través de la adaptación.

\section{CAMBIO CLIMÁTICO Y BIODIVERSIDAD}

Para la biodiversidad, el impacto del cambio climático ya es evidente. Un examen de 1700 especies mostró que la naturaleza está siguiendo las tendencias climáticas, con un cambio promedio en las áreas de distribución de 6,1 kilómetros por década hacia los polos, y los eventos de primavera adelantándose en 2,3 días por década. Esto da fuertes indicios de que el clima ya está cambiando el mundo natural (Parmesan et al., 2003).

El recién publicado Atlas Climático de las Aves Reproductoras de Europa informa de que las zonas de reproducción de la mayoría de las aves reproductoras de Europa se desplazará varios cientos de kilómetros al norte (Huntley et al., 2007). Se prevé que muchas especies de sangre fría como los reptiles se verán afectadas en un mundo más caliente (Kearney et al., 2009). También se ha vinculado las extirpaciones y extinciones de especies anfibias con el cambio climático (Ron $e t$ al., 2003; Burrowes et al. 2004; Pounds et al., 2006). 
Cambio de la temperatura media anual mundial relativa a 1980-1999 $\left({ }^{\circ} \mathrm{C}\right)$

1

2

3
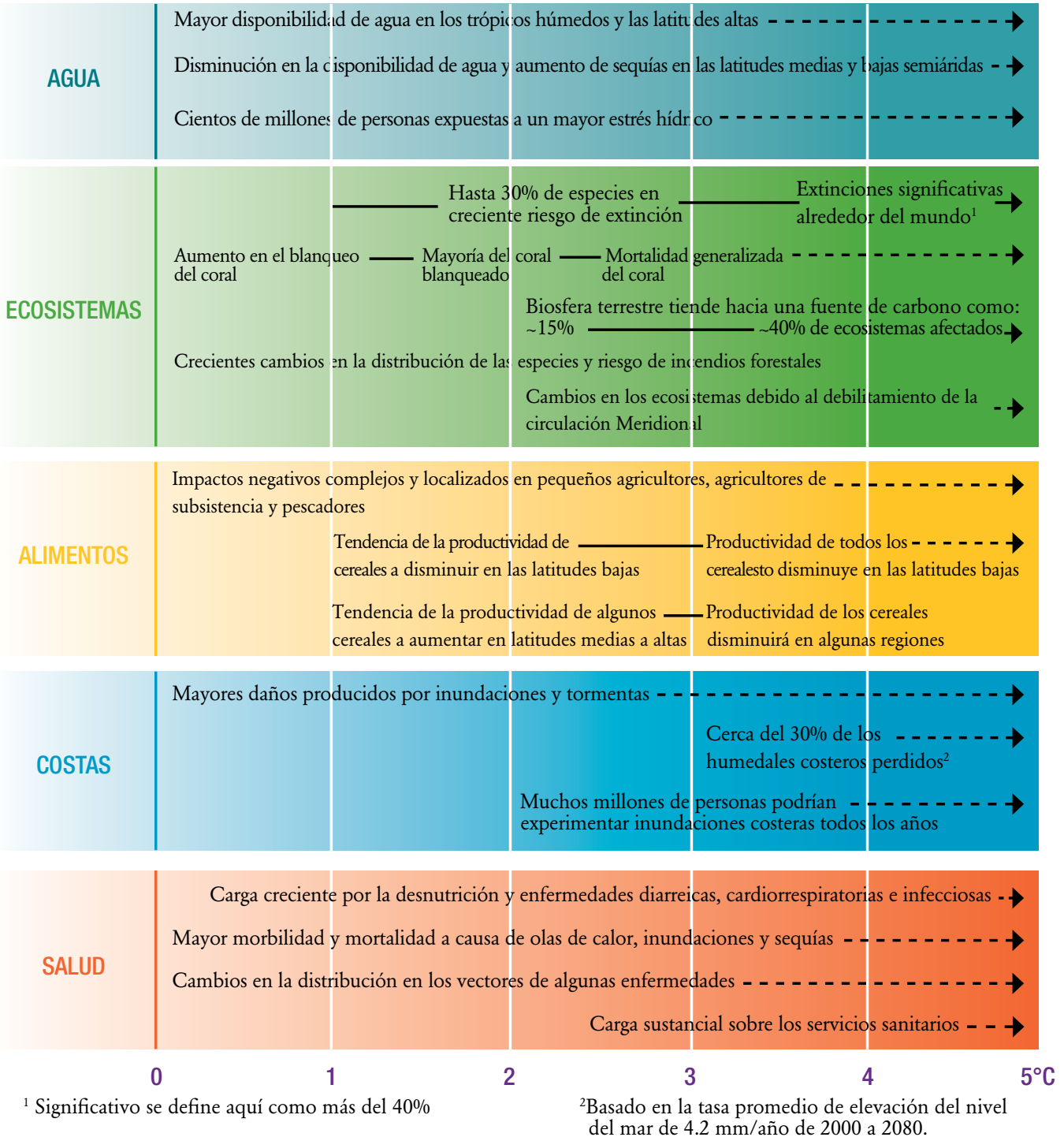

Figura 5.1 Impactos del aumento de las temperaturas (IPCC, 2007a)

Se prevé que los peces marinos se verán afectados por el aumento de la temperatura del agua que cambiará los niveles de oxígeno en los océanos del mundo (Poertner y Knust, 2007), y el aumento de dióxido de carbono está aumentando la acidez de los océanos, con graves repercusiones en algunas comunidades marinas (como los arrecifes de coral). El cambio climático afectará la distribución, la demografía y las historias de vida de las especies, con repercusiones para los medios de subsistencia de los seres humanos, incluyendo cambios en los patrones de distribución de las enfermedades humanas (recuadro 5.2).

Los impactos del cambio climático sobre las especies no se distribuyen equitativamente en todo el espectro de la vida, ya sea geográfica o taxonómicamente. Los grupos de especies que son más vulnerables incluyen las que ya son pocas o 
están amenazadas; especies migratorias; especies con zonas de distribución restringidas (endémicas de área restringida); comunidades polares; poblaciones periféricas; especies genéticamente empobrecidas; y especies especializadas incluidas las especies alpinas e insulares. Aquellas con la más alta especialización en términos de ubicación o estilo de vida suelen estar en mayor riesgo. Con base en tales características, la Comisión de Supervivencia de Especies (CSE) ha llevado a cabo una evaluación de las especies vulnerables al cambio climático y, por consiguiente, con mayor riesgo de extinción (Vié et al., 2009). Se informó de que:

- El 35\% de las aves, el 52\% de los anfibios y el 71\% de los corales poseen características que los hacen especialmente susceptibles a los impactos del cambio climático, y

- El 70-80\% de las aves, anfibios y corales que ya están amenazados son también "susceptibles al cambio climático".

Si bien el cambio climático está teniendo un impacto negativo sobre algunas especies, está creando condiciones más favorables para otras. Las características que hacen invasoras a las especies - la capacidad de sobrevivir en condiciones adversas, rápidas tasas de crecimiento, y amplia dispersión - a menudo las ayudarán a adaptarse con éxito al cambio climático. Actuando juntos, el cambio climático y las especies invasoras pueden poner a muchas especies nativas en situaciones que superan su capacidad de adaptación. Por ejemplo, Mytilus galloprovincialis, una especie invasora de mejillón azul, tiene una mayor tolerancia a las temperaturas cálidas del agua y a un mayor nivel de salinidad que el mejillón azul nativo, Mytilus trossulus, en California. De ahí que M. galloprovincialis ha sustituido al mejillón nativo a lo largo de gran parte de la zona costera meridional y central de California (Braby y Somero, 2006).

El cambio climático también está teniendo repercusiones a nivel de los ecosistemas y se prevé
Recuadro 5.2 Algunos ejemplos de los efectos del cambio climático en las especies

\section{Cambios en la distribución de las especies}

- Peces marinos (Perry et al., 2005)

- Plantas de montaña del sur de California (Kelly y Golden, 2008)

- Mariposas (Warren et al., 2001)

- Anfibios y aves tropicales (Pounds et al., 1999)

- Aves británicas (Thomas y Lennon, 1999)

- Osos polares (Derocher et al., 2004)

- Distribuciones de árboles en Columbia Británica (Hamann y Wang, 2006)

\section{Cambios en la demografia poblacional}

- Cambios potenciales en especies cuya determinación sexual depende de la temperatura (Schwanz y Janzen, 2008)

\section{Cambios en el comportamiento de las especies}

- Tiempos de vuelo prematuros en insectos (Ellis et al., 1997; Woiwod, 1997)

- Anidación prematura en aves, procreación prematura en anfibios, y floración prematura de los árboles (Walther, 2002)

- Salto de temporadas de desove del arenque (Engelhard y Heino, 2006)

- Capacidad de algunos crustáceos para fijar el calcio (Gazeau et al., 2007)

que los ecosistemas polares y los ecosistemas de tipo mediterráneo de la cuenca mediterránea, California, Chile, Sudáfrica y Australia Occidental, se verán fuertemente afectados por el cambio climático (Lavorel, 1998; Sala et al., 2000). La actualización de 2008 sobre la situación de los arrecifes de coral del mundo (Status of Coral Reefs of the World) incluyó tanto buenas como malas noticias. Dio cuenta de que los arrecifes del Pacífico Occidental y el Océano Índico, que ya habían sufrido un severo blanqueo como consecuencia 
del aumento de las temperaturas de los océanos, se estaban recuperando, pero los impactos del cambio climático y de la actividad humana seguían siendo una amenaza para la supervivencia a largo plazo de los arrecifes de todo el mundo (Wilkinson, 2008). Los ecosistemas de gran altura y los bosques nubosos también están en riesgo. Se prevé la sustitución de los bosques tropicales por sabanas en la región oriental de la Amazonia, junto con cambios de vegetación en el noreste de Brasil como consecuencia de los efectos sinérgicos de la utilización de la tierra y el cambio climático (Magrin et al., 2007).

Ciertamente el cambio climático alterará la manera en que se gestiona y conserva la biodiversidad.

Burns et al. (2003) examinaron los efectos del cambio climático en la diversidad de mamíferos en los parques nacionales de EE. UU. e informaron de que, debido a las pérdidas de especies de hasta un 20\% y la rápida afluencia de nuevas especies, las áreas protegidas puede que no sean capaces de cumplir con sus mandatos originales en términos de conservación. Los organismos de gestión tendrán que determinar cuál sería en la actualidad la mejor manera de diseñar y gestionar las áreas protegidas al efecto de permitirles adaptarse a los posibles futuros cambios climáticos y ayudarles a mitigar las causas del cambio climático (por ejemplo, mediante el almacenamiento de carbono en la vegetación, en los suelos y en las aguas). El Comité del Patrimonio Mundial de la UNESCO ha reconocido que el cambio climático ya está afectando las áreas protegidas del mundo y es probable que afecte a muchas más en los próximos años. En respuesta, han adoptado una estrategia para ayudar a los países a lidiar con esta amenaza (UNESCO, 2006).

Con impactos cuantificables ya evidentes tanto a nivel de las especies como de los ecosistemas, la prestación de los servicios de los ecosistemas se verá inevitablemente afectada. Por ejemplo, los científicos proyectan cambios en las precipitaciones para el sur de África a consecuencia de los cambios de temperatura en el Océano Índico, con la consiguiente disminución en la producción agrícola y el aumento de la inseguridad alimentaria en la región (Funk et al., 2008). Por otra parte, los ecosistemas pueden intervenir en la mitigación de los impactos. Sheil y Murdiyarso (2009) dan cuenta del posible papel que desempeñan los bosques en los ciclos hidrológicos y en el mantenimiento de la lluvia. Estos y otros hallazgos dan pie para apoyar enfoques basados en el paisaje para la adaptación y mitigación del cambio climático.

\section{LA SITUACIÓN ESPECIALMENTE DIFÍCIL DE LAS ISLAS}

Los pequeños estados insulares son especialmente vulnerables a la mayoría de los impactos del cambio climático. Su superficie se reduce conforme se eleva el nivel del mar, sus arrecifes protectores disminuyen a medida que los océanos se acidifican, y su cubierta vegetal tiene dificultades para adaptarse a los nuevos climas debido a sus bajos niveles de diversidad. Muchas islas ya están sufriendo los impactos de la destrucción ambiental como resultado de la contaminación, la destrucción de hábitats, las especies exóticas invasoras, y la sobreexplotación. Con la adición de los efectos del cambio climático, solo las especies más resilientes podrán sobrevivir (suelen ser las especies invasoras).

Se necesita un enfoque basado en el paisaje para ayudar a las islas en sus esfuerzos para adaptarse a los impactos del cambio climático. En los casos en que los bosques y los humedales del interior están ligados a ecosistemas costeros, deben gestionarse como una sola entidad. Las diferentes categorías de áreas protegidas pueden servir como parte importante del mosaico de paisajes que pueden ayudar a los ecosistemas a adaptarse a los impactos del cambio climático.

Las islas también ofrecen excelentes laboratorios para el estudio de los impactos del cambio climático y las respuestas a las medidas de mitigación y adaptación. La UICN, a través de la iniciativa Manglares para el futuro, está trabajando con 
otras organizaciones en la gestión sostenible de los ecosistemas costeros a fin de aumentar su capacidad de adaptación y mejorar la resiliencia de las comunidades que dependen de ellos.

\section{MITIGACIÓN, ADAPTACIÓN Y BIODIVERSIDAD}

La mitigación del cambio climático tiene por objeto evitar lo inmanejable; la adaptación al cambio climático busca manejar lo inevitable. Las respuestas, en términos de mitigación y adaptación, deben desarrollarse sobre la base de una mejor comprensión del contexto y la cascada de impactos en todas las amenazas y los impactos potenciales en todos los interesados directos. A finales de 2006, el Gobierno del Reino Unido publicó un informe detallado sobre la economía del cambio climático (recuadro 5.3) que llegó a la conclusión de que las medidas para frenar el cambio climático tienen un buen sentido económico. El informe destacó específicamente la conservación de los bosques como una forma rentable para frenar el cambio climático, reafirmando, así, la necesidad de evitar la deforestación en aras del clima y la conservación (Stern, 2006).

Los Miembros de la UICN, a través de la Resolución 4.075 del CMN y otras, han afirmado los fuertes vínculos entre las acciones relacionadas con la conservación, la biodiversidad y el clima. Estas acciones reconocen el papel de los ecosistemas, incluyendo bosques, turberas, pastizales, humedales y ecosistemas costeros en el apoyo a la mitigación y adaptación al cambio climático.

En particular, en términos de la política internacional sobre el cambio climático en el marco de la UNFCCC, la UICN se ha centrado en dos oportunidades clave para la biodiversidad -Reducción de Emisiones por Deforestación y Degradación de los bosques en los países en desarrollo (REDD) y la adaptación basada en el ecosistema (EbA).

\section{REDD}

En términos de la mitigación, REDD ofrece oportunidades reales para mitigar los impactos climáticos y al mismo tiempo conservar los recursos forestales mundiales y los respectivos servicios de los ecosistemas y los medios de subsistencia dependientes de ellos. La deforestación y la degradación de los ecosistemas forestales son importantes causas del calentamiento global registrado en el siglo pasado, representando el 17\% de las emisiones globales de GHG, más que todo el sector del transporte combinado. La Revisión Eliasch (2008) del Gobierno del Reino Unido sostiene que "sin hacer frente a la pérdida de bosques, es muy poco probable que podamos lograr la estabilización de las concentraciones de gases de efecto invernadero en la atmósfera a un nivel que evite los peores efectos del cambio climático".

Otro recurso que el mundo podría contemplar es el de las reservas permanentes de carbono (bosques) en las áreas protegidas del mundo

Recuadro 5.3 Mensajes clave del Informe Stern sobre el Cambio Climático

Si se permitiera al cambio climático proceder "igual que siempre" supondría costos de entre el 5\% y el 20\% del PIB mundial, mientras que el cambio hacia una economía con bajas emisiones de carbono que estabilice el clima, costaría alrededor del 1\% del PIB mundial. En resumen, el informe considera que los beneficios de la estabilización del clima son muy superiores a los costos.

Los impactos del cambio climático variarán considerablemente entre naciones $\mathrm{y}$, al igual que en análisis anteriores, pareciera que los países en desarrollo serán los más afectados. Fuente: Stern, 2006 
-que se calculan en $312 \mathrm{Gt}$ de carbono

o aproximadamente el 15\% del carbono secuestrado a nivel mundial (CDB, 2008).

Sin embargo, cualquier mecanismo de REDD en el marco de la UNFCCC que no incorpore las consideraciones de las personas más directamente afectadas, inevitablemente fracasará. El éxito de un mecanismo de REDD exige prestar atención a las cuestiones de gobernanza si no ha de privar o enajenar a las comunidades locales que dependen de los bosques, exacerbando los conflictos y socavando así la posibilidad de obtener reducciones adicionales y permanentes en las emisiones. Los países pueden recurrir a un sinnúmero de acuerdos internacionales y mejores prácticas para prestar el apoyo necesario para mecanismos de REDD a nivel nacional. Estos incluyen el Instrumento jurídicamente no vinculante de las Naciones Unidas sobre todos los tipos de bosques; el programa de trabajo ampliado sobre diversidad biológica forestal del Convenio sobre la Diversidad Biológica; y la Declaración de las Naciones Unidas sobre los Derechos de los Pueblos Indígenas, entre otros.

\section{ADAPTACIÓN BASADA EN EL ECOSISTEMA (EbA)}

Los servicios de los ecosistemas (capítulo 4) sustentan el bienestar humano y algunos son críticos para la regulación de nuestro clima y la gestión de los impactos del cambio climático. Por otro lado, los cambios en los patrones climáticos que son inevitables socavarán algunos de los servicios que prestan los ecosistemas, con el consiguiente peligro para la vida humana. Los aumentos en el nivel del mar, las tormentas violentas, el deshielo de los glaciares y las sequías e inundaciones influenciadas por el calentamiento global se traducirán en millones de personas que pierden sus hogares y sus medios de subsistencia, y a veces incluso sus vidas.
La evidencia sugiere que un sistema diverso será más resistente frente a los cambios ambientales y, por tanto, mostrará una mayor adaptabilidad de los ecosistemas. En esencia, una mayor diversidad de especies y poblaciones que ejerzan funciones similares dentro de un ecosistema seguramente resultará en una mayor probabilidad de que los procesos de los ecosistemas se mantengan ante los cambios ambientales (McCann, 2000). EbA identifica e implementa una serie de estrategias para la gestión, conservación y restauración de los ecosistemas para garantizar que continúen prestando los servicios que permitan a las personas adaptarse a los impactos del cambio climático². EbA es una solución de adaptación rentable, inmediata y accesible. Ejemplos de EbA incluyen la gestión de los ecosistemas costeros para reducir las inundaciones durante las marejadas ciclónicas. Los manglares, marismas y otros tipos de vegetación costera proporcionan la infraestructura natural que reduce los impactos tierra adentro de la fuerza del oleaje, actúan como una barrera para los desechos, y reducen la erosión costera. Otro ejemplo incluye el mantenimiento y el aumento de la resiliencia de los ecosistemas a escala del paisaje, a través de sistemas eficaces de gestión de áreas protegidas y mejoras en la gestión de las tierras y los mares circundantes.

Los impactos del cambio climático sobre las personas serán distribuidos de manera diferente entre las diferentes regiones, generaciones, grupos etarios, grupos económicos, ocupaciones, y género. Las comunidades rurales que suelen ser las que más directamente dependen de los recursos naturales locales, serán las más afectadas, especialmente aquellas en los ecosistemas más vulnerables. Los pobres particularmente -aunque no exclusivamente- en los países en desarrollo se verán afectados de manera desproporcionada debido a su limitada capacidad para adaptarse al cambio y su dependencia de los recursos como el agua y los alimentos que se verán afectados por el cambio climático (IPCC, 2007b). Por otra parte, estos

${ }^{2}$ Esta definición es consistente con el informe preliminar del Grupo de expertos del Convenio sobre la Diversidad Biológica (AHTEG) sobre cambio climático y biodiversidad. 
grupos también pueden ser poderosos agentes de cambio y jugar un papel clave en la reducción de los desastres, la deforestación y los usos de la energía.

$\mathrm{EbA}$ también es una forma de adaptación que suele ser más accesible a la población rural pobre que las soluciones tecnológicas o de infraestructura. EbA puede ser un medio para apoyar a los pueblos indígenas mediante el aprovechamiento de los conocimientos tradicionales para adaptarse a la evolución de las condiciones climáticas, que también incorporan necesidades específicas de género en relación a los recursos naturales.

Los impactos del cambio climático podrían poner en riesgo las estrategias de reducción de la pobreza y menoscabar los esfuerzos realizados para lograr todos los Objetivos de Desarrollo del Milenio (ODM). Por lo tanto, las estrategias de reducción de la pobreza y la planificación del desarrollo deben incorporar EbA como un elemento integral de los programas generales para abordar tanto la reducción de la pobreza como la adaptación al cambio climático. Muchas herramientas están disponibles para ayudar a las comunidades locales en la identificación de su vulnerabilidad a los impactos del cambio climático y también sus opciones de adaptación para el futuro. Entre ellos, Cristal (www. cristaltool.org), una herramienta de detección del riesgo climático elaborada por el Instituto Internacional para el Desarrollo Sostenible (IIDS), la UICN, Intercooperation y el Instituto Ambiental de Estocolmo (SEI), ayudan a los planificadores del desarrollo y la conservación a trabajar con las comunidades locales para integrar las necesidades de adaptación al cambio climático.

\section{OTRAS CONSIDERACIONES}

En la gestión de los impactos del cambio climático no podemos ignorar el impacto de las opciones energéticas, tanto en la planificación como en la implementación de la mitigación y la adaptación. Esto se examinará con más detalle en el capítulo 7. Además, las cuestiones del cambio climático deben incluir aspectos de enfoques basados en los derechos, sinergias entre los instrumentos internacionales relacionados con el cambio climático, y la inclusión de la reducción del riesgo de desastres como un enfoque complementario (capítulo 10).

La Declaración de Estocolmo (1972) afirmó que las personas tienen "el derecho fundamental a la libertad, la igualdad y condiciones de vida adecuadas, en un ambiente de una calidad que permita una vida de dignidad y bienestar". Los impactos del cambio climático pondrán en peligro muchos de los elementos básicos que apoyan las "condiciones de vida adecuadas" y, por tanto, puede considerarse que afectan los derechos humanos. Por lo tanto, cualquier acción tomada en términos de adaptación debe incluir la consideración de los derechos humanos como un elemento esencial. En abril de 2009, la Oficina del Alto Comisionado de Naciones Unidas para los Derechos Humanos, a solicitud del Consejo de Derechos Humanos de las Naciones Unidas, dio a conocer un informe sobre la relación entre el cambio climático y los derechos humanos (ONU, 2009).

La gobernanza de lo relativo al cambio climático no es de la exclusiva competencia de la UNFCCC y de los Estados Partes. Los vínculos entre el cambio climático y la biodiversidad requieren la adopción de medidas en muchos otros acuerdos internacionales pertinentes (McNeely, 2008). El Convenio sobre la Diversidad Biológica, por ejemplo, discute el papel de la biodiversidad en la secuestración de carbono y en la adaptación al cambio climático, mientras que las convenciones sobre los humedales (Ramsar) y la desertificación (UNCCD) se refieren a los hábitats cuya gestión eficaz contribuirá a la adaptación al cambio climático en las próximas décadas. La Convención de las Naciones Unidas sobre el Derecho del Mar (UNCLOS) se ocupa específicamente de los ecosistemas marinos, y las investigaciones recientes dan cuenta de cuán importantes son los entornos marinos en el tratamiento de cuestiones relacionadas con el cambio climático. La Convención sobre las Especies 
Migratorias (CMS) se ocupa de la amplia gama de especies que son susceptibles de ser influidas por el cambio climático y, por tanto, podría apoyar el proceso de adaptación. Dada la limitación de recursos y tiempo, una cuestión fundamental será la de centrarse en una coordinación más eficaz de la acción a través de estos instrumentos además del cumplimiento de estrictas medidas de implementación.

La adaptación al cambio climático y la reducción del riesgo de desastres son enfoques complementarios. A través del Marco de Acción de Hyogo 2005-2015, los países se han comprometido a integrar la adaptación al cambio climático y la reducción del riesgo de desastres a través de la identificación de riesgos de desastres relacionados con el clima, el desarrollo de medidas específicas de reducción de riesgos, y el mejoramiento y uso sistemático de información sobre los riesgos climáticos por parte de planificadores, ingenieros y otros responsables de la toma de decisiones.

El cambio climático es el principal impulsor del cambio en el mundo actual y una creciente amenaza para la biodiversidad y los servicios de los ecosistemas que ella proporciona. Conforme el mundo se reúne en Copenhague para debatir y acordar un marco sobre el cambio climático post 2012, es vital que los Estados Partes de la UNFCCC negocien:

- La incorporación de la biodiversidad en todos los esfuerzos para mitigar el cambio climático y adaptarse a los cambios inevitables, como por ejemplo, a través de la Reducción de Emisiones por Deforestación y Degradación de los bosques en los países en desarrollo (REDD) y la adaptación basada en los ecosistemas;

- Enfoques basados en la transversalización del género y en los derechos; $\mathrm{y}$

- Considerar la labor llevada a cabo en el Marco de Acción de Hyogo al diseñar e implementar planes y estrategias de adaptación.

Pero el trabajo no es solo de los gobiernos. A raíz de la crisis financiera, las iniciativas para renovar la economía mundial también deben aprovechar la oportunidad de descarbonizar esa economía, incluyendo el desarrollo de incentivos innovadores como los mercados de carbono, que ofrecen modelos de pagos más amplios para los servicios de los ecosistemas. Los precios pagados por bienes y servicios deben incluir el "costo social del carbono" para reflejar los impactos sobre el cambio climático de todo el proceso de suministro, producción, distribución y consumo de materias primas. Esto debe aplicarse a todos los países, incluso para los productos exportados. Algunos han sugerido que los países deberían aplicar un "arancel de carbono" sobre las importaciones, para reflejar cualquier emisión de GHG asociada a su producción. Los impuestos sobre el carbono de las importaciones pueden ser desagradables para algunos, pero se puede argumentar con la misma convicción que son esenciales para la supervivencia del planeta.

Las áreas protegidas ya han demostrado su valor para la conservación de la biodiversidad que, de otro modo, podría perderse. Cuando están debidamente diseñadas y administradas, las áreas protegidas también pueden proporcionar la capacidad para mitigar y adaptarse al cambio climático. La conservación de la cubierta forestal en las áreas protegidas podría ser una útil contribución a REDD, siempre que se pueda superar el desafio de demostrar la "adicionalidad", en tanto que la gestión de los ecosistemas a escala del paisaje que incluyen las áreas protegidas será un aspecto importante de la planificación para la adaptación climática.

Por último, pero ciertamente no menos importante, los esfuerzos para mitigar el cambio climático deben garantizar que las estrategias energéticas alternativas, incluido el uso de biocombustibles, tomen plenamente en cuenta y eviten cualquier impacto negativo asociado con el clima, la biodiversidad y los medios de subsistencia. 


\section{En 2003, la comunidad conservacionista se congregó en Durban para el V Congreso Mundial de Parques de la UICN y aprobó el Acuerdo de Durban como un nuevo paradigma para el futuro (UICN, 2003). El Acuerdo reconoce el papel fundamental de las áreas protegidas (AP), tanto en el apoyo a la conservación de la biodiversidad, como en los esfuerzos para reducir la pobreza, apoyar el desarrollo económico y promover la paz. Reconoció la triplicación del número de áreas protegidas en los últimos 20 años.}

Empero, el Acuerdo también planteaba preocupaciones. Si bien el 11,5\% de la Tierra se encontraba bajo algún tipo de conservación, la red existente no era representativa de todo el ámbito de la biodiversidad -especialmente para el reino marino. Los costos y beneficios de las áreas protegidas no eran asignados equitativamente y las finanzas para estas valiosas zonas eran deplorablemente inadecuadas. Como resultado, la gestión de muchos sitios estaba comprometida hasta el punto de que "existen muchos más parques en el papel que en la práctica”. El papel histórico de las comunidades locales y de los pueblos indígenas y trashumantes en la conservación de la biodiversidad y el valor de las áreas protegidas para estos grupos rara vez eran reconocidos o incluidos en la planificación e implementación. El cambio, especialmente el cambio climático, estaba acrecentando los desafíos existentes para las áreas protegidas del mundo.

Los éxitos y preocupaciones planteadas en el Acuerdo de Durban mantienen vigencia. Por ejemplo, 13 de los 199 sitios naturales del
Patrimonio Mundial están clasificados “en peligro”, incluyendo sitios importantes de biodiversidad como las Galápagos, el Parque Nacional de Manas en la India y cinco parques nacionales en la República Democrática del Congo. Causas incluyen conflictos civiles e impactos del turismo y de las especies invasoras (UNESCO, 2009, cifras al mes de mayo de 2009). El número de sitios del Patrimonio Mundial que están críticamente amenazados tampoco está plenamente representado en la lista de sitios en peligro de la UNESCO (Badman et al., 2009).

Los debates en Barcelona examinaron los avances en torno a muchas de estas cuestiones y están incluidos en varios capítulos a lo largo de este volumen. El papel de la población local y de las zonas protegidas se aborda en el capítulo 3, el cambio climático y las áreas protegidas en el capítulo 5, las áreas protegidas, parques de paz y conflictos en el capítulo 9, y las áreas marinas protegidas en el capítulo 17. Aquí se exploran más a fondo los retos de la representatividad, la eficacia de la gestión y las finanzas para las áreas protegidas. 


\section{UNA RED REPRESENTATIVA DE ÁREAS PROTEGIDAS}

Incluso con el 11,5\% de las tierras designadas como áreas protegidas, aún persisten brechas importantes. Rodrigues et al. (2004) señalaron los retos de la utilización de los objetivos globales como medio para establecer redes representativas de áreas protegidas y señalaron varias deficiencias en la red actual. Dieron cuenta de que de las especies consideradas, al menos el 12\% no están representadas en ninguna área protegida, y que otros taxones con altos niveles de endemismo, como plantas e insectos, están aún menos representados, dada la tendencia en los grupos de especies con rangos de distribución más pequeños a tener mayores proporciones de “especies ausentes”.

Se necesitan herramientas para ayudar a identificar las carencias en más detalle y aumentar la conciencia al respecto. Un importante esfuerzo en ese sentido fue el lanzamiento de la Base de Datos Mundial sobre Áreas Protegidas de 2008 (la actualización de 2009 ya está disponible - www. wdpa.org), una renovada herramienta en línea que permite a los usuarios acercarse, sobrevolar y explorar más de 100.000 parques nacionales.

Otro paso en esa dirección ha sido el lanzamiento de Google Ocean, un esfuerzo conjunto de la UICN, Google y otros asociados que se centra en la actual red de áreas marinas protegidas (http://earth.google.com/ocean/). Otras herramientas disponibles incluyen la elaboración de directrices para la identificación, priorización y análisis de áreas clave de la biodiversidad (KBA), sitios de importancia mundial para la conservación de la biodiversidad, identificados mediante la aplicación de criterios y umbrales uniformes a nivel mundial (Eken $e t$ al., 2004). Armados con el conocimiento de las KBA, los administradores de áreas protegidas pueden realizar análisis de brechas y consolidar redes más completas de áreas protegidas para conservar la biodiversidad (Langhammer et al., 2007).
Cada país debe hacer su propio examen de su sistema de áreas protegidas, para garantizar que todos los hábitats y características naturales más importantes estén protegidos bajo la adecuada categoría de gestión. Especial atención merecen las áreas marinas protegidas (AMP) (capítulo 17). Las 5000 AMP existentes cubren más de 2,35 millones de kilómetros cuadrados, pero esto es solo el 1,6\% del total de áreas marinas dentro de las zonas económicas exclusivas. La Comisión Mundial de Áreas Protegidas (CMAP) y el Programa Marino de la UICN están trabajando con muchos otros asociados para proteger el 10-30\% de los hábitats marinos para el año 2012 (Laffoley, 2008).

\section{GESTIÓN EFICAZ DE LAS ÁREAS PROTEGIDAS}

Entre los asuntos debatidos en Barcelona en torno a la eficacia de la gestión se incluyeron herramientas y directrices, la participación de las comunidades locales, las especies invasoras, y la necesidad de un enfoque basado en el paisaje para la gestión de áreas protegidas.

Desde Durban, la CMAP ha dedicado esfuerzos considerables al desarrollo de herramientas y directrices para mejorar la eficacia de la gestión de la red de áreas protegidas. Hockings et al. (2006) elaboraron un marco para evaluar la eficacia. En Barcelona se divulgaron las Directrices para la aplicación de las categorías de gestión de áreas protegidas de la UICN (Dudley, 2008), haciendo hincapié en que, si bien el objetivo prioritario de todas las áreas protegidas es la protección de la naturaleza, también tienen otros objetivos importantes destinados a mejorar los medios de subsistencia de las personas.

Debe prestarse más atención a las necesidades de las personas que viven en y alrededor de las áreas protegidas. Fearn y Redford (2007) examinan las concesiones, los conflictos, los flujos de beneficios y costos, los asuntos 
legales, y otra serie de aspectos que deben ser abordados a medida que se democratiza la gestión de áreas protegidas. Coad et al. (2008), que también examinaron los costos y beneficios de las áreas protegidas para las comunidades locales, informaron de que los impactos sobre los medios de subsistencia de las áreas protegidas varían según la condición del área protegida, las estrategias de gestión, y la participación de la comunidad en la gobernanza. Los principales costos respecto de los medios de subsistencia estaban asociados con las áreas protegidas con estructuras de gestión de arriba hacia abajo (generalmente asociadas con las Categorías de gestión I-II de la UICN) o en áreas protegidas en las que se carecía de capacidad institucional y de gestión y no se resolvían las cuestiones de gobernanza y tenencia de la tierra. Por otra parte, los esquemas de gestión comunitaria y la gestión de áreas protegidas que permitía la utilización sostenible de los recursos (más a menudo asociados con las Categorías de gestión V-VI de la UICN) pueden proporcionar beneficios tangibles. BorriniFeyerabend et al. (2004) discuten mecanismos para mejorar la conservación y la equidad de las comunidades locales e indígenas en las áreas protegidas.

Tanto el Convenio sobre la Diversidad Biológica (CDB), como muchos gobiernos y organizaciones de conservación, están reconociendo los derechos, habilidades y conocimientos de los pueblos locales e indígenas y prestando especial atención y respeto a los sitios naturales sagrados. Esas dimensiones culturales de las áreas protegidas merecen mayor atención en los próximos años y su inclusión en consideraciones sobre la representatividad de dichas áreas protegidas. La UICN y la UNESCO han desarrollado Directrices sobre sitios naturales sagrados para los administradores de áreas protegidas, que reconocen la importancia de los valores culturales y espirituales en la conservación de la naturaleza y ofrecen orientación práctica sobre la gestión de estos valores en las áreas protegidas (Wild y McLeod, 2008). Los Miembros de la UICN reforzaron en la Resolución 4.038 del CMN la importancia de los sitios sagrados en las áreas protegidas.

En casi todas partes del mundo, una de las grandes amenazas biológicas para las áreas protegidas es la invasión de especies no nativas, que van desde las cabras en Galápagos hasta el jacinto de agua en los Grandes Lagos de África. Algunos administradores de áreas protegidas han introducido intencionalmente las especies exóticas invasoras en sus parques, como la trucha en algunas de las áreas protegidas de montaña en los Estados Unidos, en la creencia de que eso haría los ríos más atractivos para los visitantes incluso si algunas especies nativas estaban amenazadas. Es necesario centrarse mucho más en impedir la invasión de especies no nativas en áreas protegidas, erradicándolas tan pronto invaden y minimizando sus impactos en caso de establecerse (McNeely et al., 2001). Además, las estrategias para erradicar las especies invasoras en las áreas protegidas deben, en la medida de lo posible, incluir la gestión del riesgo para los efectos secundarios indirectos (Bergstrom et al., 2009).

En cualquier escenario realista del futuro, las áreas protegidas por sí solas serán insuficientes para la conservación de la biodiversidad del planeta a menos que la tierra y las aguas fuera del sistema 
de áreas protegidas sean gestionadas de manera coherente con los objetivos de conservación de áreas protegidas. Las áreas protegidas no pueden continuar siendo islas de hábitats naturales en un mar de usos incompatibles de la tierra, mucho menos fortalezas contra los intereses humanos locales. Por el contrario, las áreas protegidas deben considerarse como parte de los paisajes regionales, conectadas por corredores de hábitats que amplían el territorio efectivo de especies de amplio rango de distribución y aportan servicios de los ecosistemas para la población local y apoyan la adaptación a condiciones cambiantes. Para lograr este objetivo, la conservación requiere un trabajo a mayor escala, incluso a nivel del paisaje terrestre y marino, ya que los desafíos que enfrentan las áreas protegidas son demasiado complejos e involucran a muchos grupos de interés como para resolverse a nivel individual.

Los Miembros de la UICN han reconocido la necesidad de la conectividad en la Resolución 4.062 , en la que se pide una mayor atención a la conectividad en iniciativas de conservación en gran escala, incluyendo la vinculación de las áreas protegidas al paisaje más amplio. Ejemplos de este enfoque basado en el paisaje son el Corredor de Yellowstone al Yukón, el Corredor Biológico Mesoamericano, el Cinturón Verde de Europa, y el Arco de Terai en la India y Nepal. El abordaje de esas cuestiones será más fácil si la opinión pública apoya las áreas protegidas, y por cuanto más personas vivirán en las ciudades, ello requerirá formas innovadoras de concientizar a la población urbana.

En apoyo de una gestión eficaz, la CMAP ha producido alrededor de 16 directrices de mejores prácticas, incluyendo (además de las ya mencionadas), temas tales como las directrices para la planificación de la gestión (Thomas y Middleton, 2003) y las áreas protegidas transfronterizas (Sandwith et al., 2001). La lista completa está disponible en http://www.iucn.org/ about/union/commissions/wcpa/wcpa_puball/ wcpa_bpg/. La capacitación se está haciendo accesible a través de herramientas de internet tales como la Red de Aprendizaje sobre Áreas Protegidas (PALNet) y las actividades apoyadas por Miembros de la UICN y sus asociados.

\section{FINANCIACIÓN Y CAPACIDAD ADECUADAS PARA LAS ÁREAS PROTEGIDAS}

Aunque se dispone de fondos considerables para las áreas protegidas, estos no han sido suficientes para acoplarse a su ritmo de expansión en los últimos años (Emerton et al., 2006). Gran parte de la financiación para áreas protegidas ha sido de corto plazo y centrada en la inversión de capital, con muy poco apoyo para el sostenimiento de las estructuras e instituciones relacionadas con las áreas protegidas a través del tiempo. Esto ha dejado a muchas áreas desprotegidas en términos financieros y probablemente ello seguirá así en las condiciones actuales. Bruner et al. (2004) estimaron que el déficit en la financiación de la gestión de las áreas protegidas en los países en desarrollo era de aproximadamente US\$1300 millones, señalando que irónicamente esta cantidad representa el 2\% de lo que los estadounidenses gastan cada año en refrescos (Jacobsen, 2004). Otras estimaciones sobre el déficit de financiación de las áreas protegidas son mucho más elevadas (por ejemplo, Balmford et al. (2002) estiman que se requerirán US\$45 mil millones por año durante 30 años para garantizar y ampliar áreas protegidas terrestres y marinas).

Sea cual fuere la cifra, es evidente que para lograr la financiación sostenible se requerirá la creación de capacidades dentro de las comunidades de áreas protegidas para la planificación financiera y empresarial, así como políticas de apoyo y condiciones de mercado.

Como ya se ha destacado en el Acuerdo de Durban, si las áreas protegidas han de sobrevivir ante la creciente demanda, será necesario contar con un importante apoyo financiero. Esto no debería ser 
siempre difícil considerando los beneficios que generan las áreas protegidas. Por ejemplo, en 2003, unos 266 millones de personas visitaron los parques nacionales de los EE. UU. y se estima que gastaron cerca de US\$10 mil millones durante sus visitas. El turismo alrededor de los parques nacionales generó US $\$ 4500$ millones en sueldos, salarios y beneficios, y apoyó 267.000 puestos de trabajo. La garantía de que las áreas protegidas reciban una parte justa de los beneficios que generan es un tema que merece un pensamiento creativo, pero es probable que tenga más éxito basándose cada vez más en el principio de que el usuario paga, incluyendo el aumento de las tarifas de admisión a los parques o tasas de concesión más elevadas para los operadores turísticos. Además, los gobiernos pueden verse precisados a acoger con más entusiasmo el concepto de que el usuario paga, permitiéndole a las áreas protegidas conservar una mayor proporción de los ingresos que generan. Por ejemplo, el Parque Nacional Serengeti en Tanzania genera ingresos por concepto de admisión de alrededor de US\$6 millones al año, monto suficiente para apoyar un nivel adecuado de gestión.

Sin embargo, probablemente habrá algunas áreas protegidas que no sean capaces de generar ingresos suficientes por sí solas en razón de su limitada atracción. Por lo tanto, continuarán dependiendo de la financiación pública u otras formas innovadoras de compensación por los servicios de los ecosistemas que prestan a la sociedad en general. Las áreas protegidas deben verse a sí mismas como proveedoras de servicios para la sociedad, proporcionando tanto servicios generadores de ingresos (recreación, turismo, funciones de los ecosistemas) como servicios que no lo son (conservación de la biodiversidad, educación, valores culturales). Con respecto a los servicios culturales, los gobiernos deben considerar las inversiones en las áreas protegidas igual que la inversión en la educación y las artes -un medio importante para apoyar a la sociedad y la creatividad y los valores que la sustentan.

\section{MÁS ALLÁ DE BARCELONA}

Los próximos años ofrecerán importantes oportunidades para las áreas protegidas en términos de gobernanza y participación de los jóvenes en los esfuerzos asociados a las áreas protegidas.

En términos de gobernanza ambiental a nivel internacional, la estructura de los convenios internacionales -incluyendo el CDB, la Convención del Patrimonio Mundial, la Convención sobre los Humedales de Importancia Internacional (Ramsar), la Convención Marco de las Naciones Unidas sobre el Cambio Climático (UNFCCC), la Convención de las Naciones Unidas sobre el Derecho del Mar (UNCLOS)- en el apoyo a la conservación a través de las áreas protegidas ya está demostrando su valor, pero claro está que es mucho lo que todavía se puede hacer, incluyendo el apoyo a la gobernanza de las áreas protegidas en mar abierto y transfronterizas, y mejorando la cooperación para el intercambio de información y la creación de capacidades (UICN, 2001). Si bien la Convención del Patrimonio Mundial es un mecanismo de conservación sumamente exitoso que cubre un $8 \%$ de sitios naturales del patrimonio mundial de áreas protegidas, se podría mejorar su función aumentando el reconocimiento y apoyo para su aplicación, especialmente en términos de una mayor acción para hacer frente a los desafíos de conservación que enfrentan los sitios incluidos en la lista de la UNESCO (UICN, 2009b).

\section{En 2010, las Partes en el CDB examinarán el} programa de trabajo para las áreas protegidas acordado en 2004 (CBD, 2004b), debiendo garantizar una mayor sinergia a través de los numerosos instrumentos relacionados con las áreas protegidas. Las Partes en el CDB aprobarán también un nuevo plan estratégico y, potencialmente, un marco post 2010 para la conservación de la biodiversidad, en el que debe integrarse el papel fundamental de las áreas protegidas. 
Tal como se señala en un comentario muy

directo del representante de la juventud en el V Congreso Mundial de Parques, el futuro de las áreas protegidas está en manos de los jóvenes de hoy. La CMAP está trabajando activamente para lograr la participación de personas jóvenes en los esfuerzos relacionados con las áreas protegidas, entre los que cabe mencionar el establecimiento, conjuntamente con la Federación Internacional de Guardaparques, del premio Young

Conservation Award, otorgado anualmente a una persona joven por su extraordinario trabajo en áreas protegidas o en actividades de conservación y por los esfuerzos para promover la participación de los jóvenes en la Comisión con base en una meta del 30\% para los menores de 35 años para el año 2012.

En conclusión, la conservación de la biodiversidad a través de las áreas protegidas puede ser una importante contribución para forjar una relación justa, equitativa y sostenible entre las personas y el resto de la naturaleza. Empero, este objetivo se enfrenta a varios retos. Para continuar con la fuerte tradición de la contribución de las áreas protegidas a la conservación, la UICN debe continuar apoyando los esfuerzos para garantizar la implementación de un sistema plenamente representativo de las áreas protegidas, la gestión eficaz de dichas áreas y la financiación adecuada para la implementación de dicha gestión. Deben, además, promoverse e implementarse las oportunidades que ofrecen las áreas protegidas como mecanismos de apoyo a la reducción de la pobreza (Scherl et al., 2004) y de mitigación y adaptación al cambio climático. 


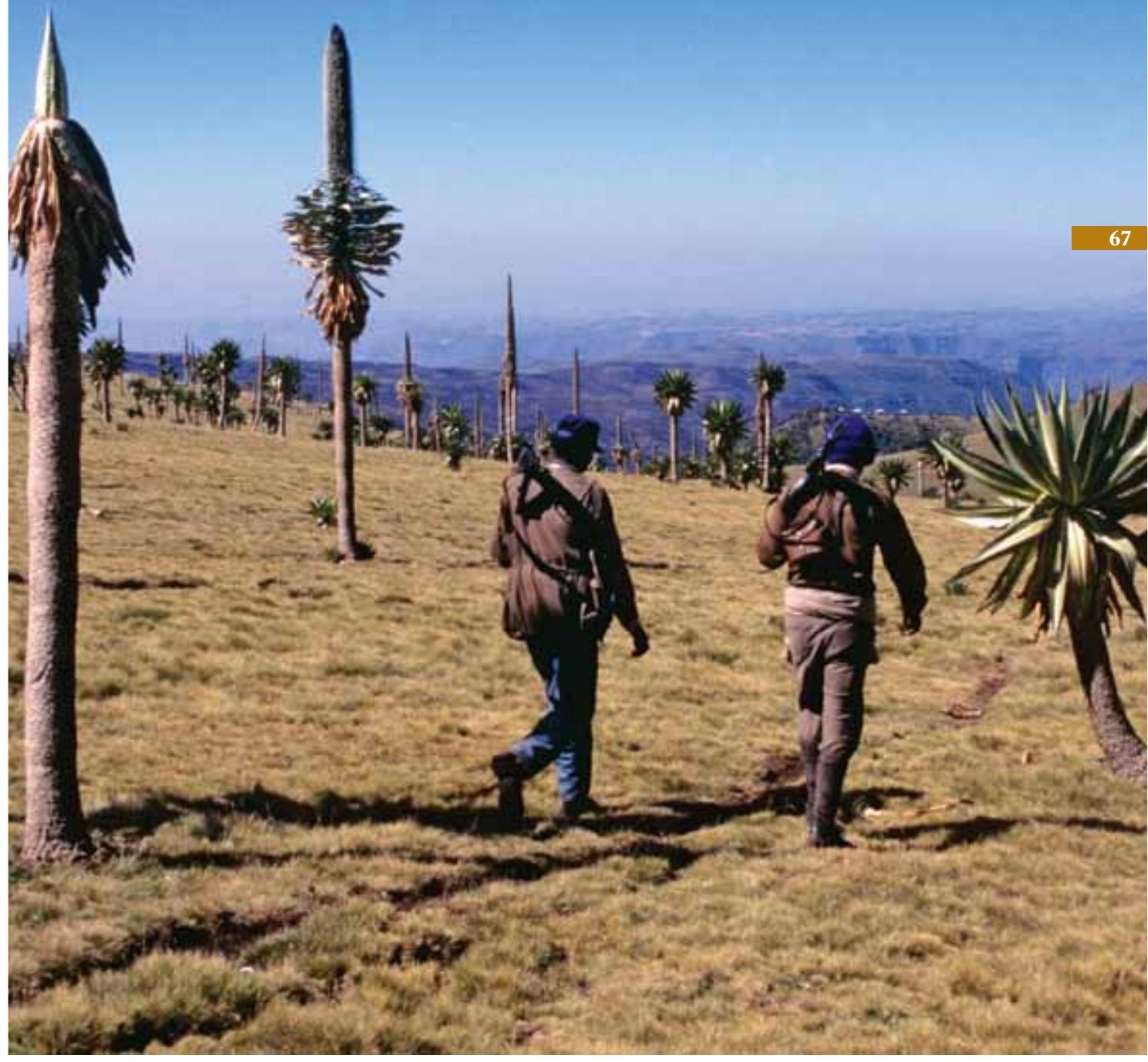


7. Lonservación de las Especies:

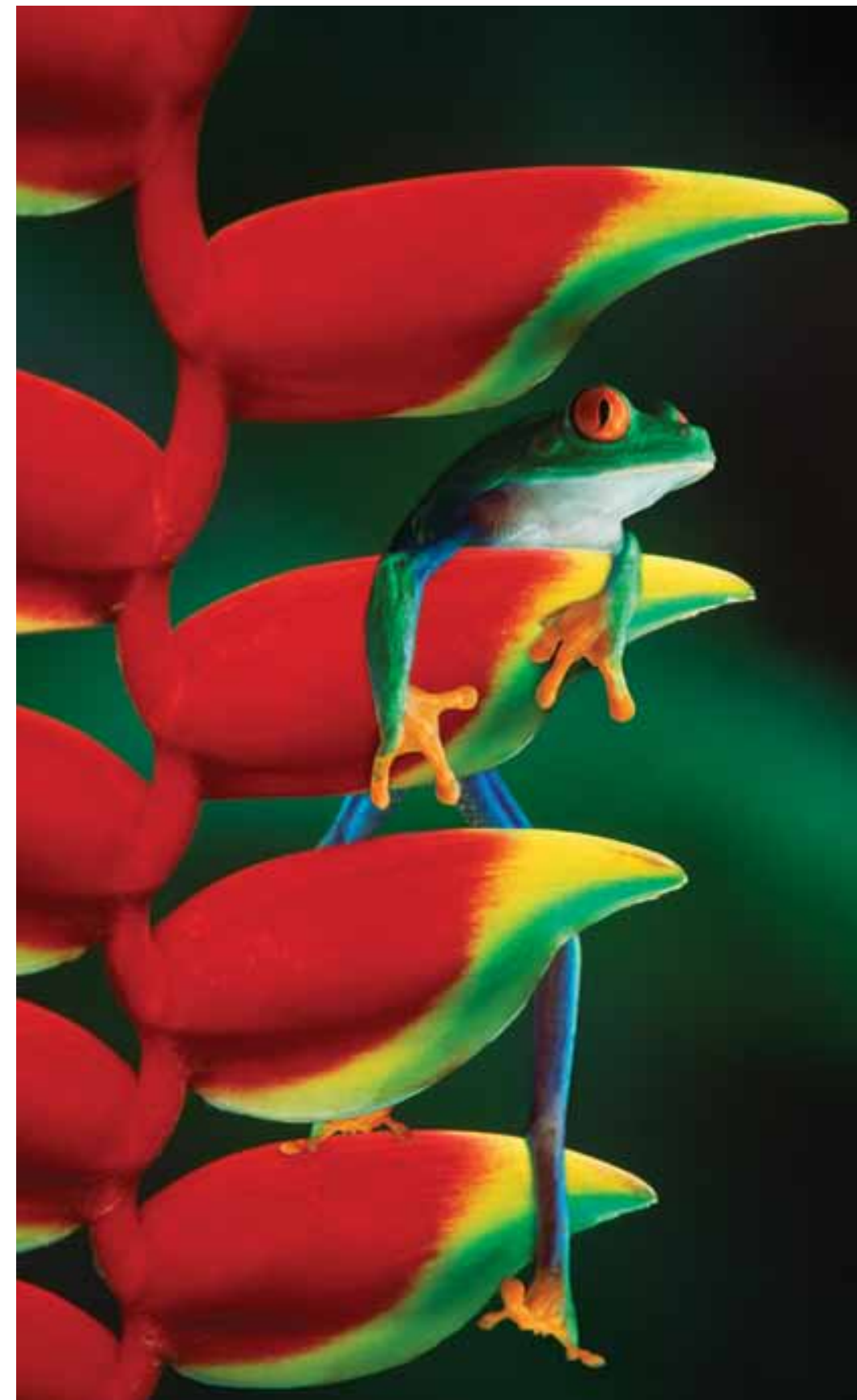


Los primeros intentos para catalogar la vida en la Tierra fueron realizados por Linnaeus y sus contemporáneos a mediados del siglo XVIII a nivel de las especies. Desde entonces, al menos 1,7 millones de especies han sido descritas formalmente y las estimaciones de especies desconocidas en la Tierra oscilan entre 10 y 100 millones. Como los mejor entendidos y más ampliamente descritos componentes básicos de la naturaleza, las especies son un foco natural para las actividades de conservación. La primera Comisión de la UICN estaba centrada en las especies, a saber, el Servicio de Supervivencia de Especies, que se estableció en 1949, a un año solamente de haberse fundado la UICN. Algunos de los programas de conservación más conocidos han sido los programas basados en especies, tales como el "Proyecto Tigre", lanzado en 1973, en la India, como resultado de un censo de tigres que daba cuenta de la caída en las poblaciones de estos felinos.

Desde aquellos primeros días de la conservación, los planteamientos para la conservación de la naturaleza se han ampliado a efectos de incluir enfoques basados en el paisaje y en los servicios de los ecosistemas. Pero la conservación de las especies sigue siendo una piedra angular de la conservación actual, ofreciendo una base cuantificable que puede ser fácilmente presentada y comprendida por muchos públicos. Gran parte de la teoría actual de la conservación se basa en las especies; tanto las especies clave como las especies emblemáticas, los lugares de situación crítica de la conservación y la mayoría de los indicadores de biodiversidad, se basan en la cuantificación de las especies. En el Foro Mundial de la Naturaleza, las especies fueron un popular tema para las presentaciones de los talleres y las cuestiones relativas a las especies abarcan el mayor número de Resoluciones y Recomendaciones del Congreso Mundial de la Naturaleza (CMN).
Sin embargo, aún quedan muchos retos para la conservación basada en las especies, incluyendo una comprensión todavía rudimentaria de la diversidad y situación de las especies en muchos taxones, sobre todo invertebrados y especies marinas; un debate permanente en torno a la utilización sostenible de las especies; conflictos entre las personas y la vida silvestre; e, irónicamente, la necesidad de controlar algunas especies (las invasoras) para que otras especies puedan sobrevivir.

\section{SUBSANANDO LA FALTA DE CONOCIMIENTO SOBRE LAS ESPECIES}

Los científicos pueden haber identificado solo alrededor del 10\% de las especies existentes. Llenar la brecha entre lo que sabemos y lo que no sabemos sobre la biodiversidad es una enorme tarea que se ve complicada por muchos factores. Las nuevas 
tecnologías en genómica están haciendo "más fácil” la identificación de las especies a través de técnicas avanzadas, como las reacciones en cadena de la polimerasa, mientras que los avances exponenciales en la gestión de la información permiten un acceso más rápido a fuentes de referencia (McNeely, 2002).

No obstante, persisten importantes dificultades tales como llegar a un acuerdo sobre las definiciones de las especies, la creación de capacidades en taxonomía y el apoyo al libre acceso a todo el conocimiento relacionado con las especies.

Muchas iniciativas basadas en información sobre las especies se están desarrollando e implementando a diferentes niveles, desde la Infraestructura Mundial de Información en Biodiversidad (GBIF - una iniciativa intergubernamental - http://www.gbif. org/) hasta el Inventario de todos los taxones existentes (una organización sin fines de lucro - http://www.dlia.org/atbi). La mayoría de estas iniciativas se concentra en la catalogación de las colecciones existentes en museos, herbarios y en el mundo académico. Algunos, como el Servicio de Información sobre Especies de la UICN, también están tratando de identificar y evaluar poblaciones actuales in situ. Sin embargo, la magnitud de la tarea es enorme y exigirá un esfuerzo global coordinado para desarrollar un conocimiento detallado acerca de la situación y tendencias de una gama representativa de biodiversidad biológica a nivel de las especies.

La taxonomía, el medio mediante el cual los científicos catalogan las especies, se enfrenta a muchos obstáculos que desafian nuestra capacidad de gestión del conocimiento sobre las especies. Dentro de las especies descritas, una proporción significativa ha sido formalmente descrita más de una vez, dando lugar a complicados problemas de sinonimia taxonómica. Por ejemplo, una estimación indica que aproximadamente 13.000 nuevas especies se nombran cada año, pero la tasa actual de resolución de sinonimias reduce este número a alrededor de 10.000 especies distintas para una tasa de sinonimia del 20\% en especies nombradas (mayo de 1999). La controversia acerca de la situación de las tortugas de agua dulce de China como verdaderas especies o híbridos es un ejemplo de ello (Dalton, 2003). Las especies nombradas no están disponibles en una sola obra de referencia o índice, planteando un problema para quienes buscan una visión de conjunto. Por último, los mismos taxónomos se están convirtiendo en una especie en peligro. Hay una desesperada necesidad de alentar a los estudiantes de biología a centrarse en la taxonomía como una carrera,

Anfibios

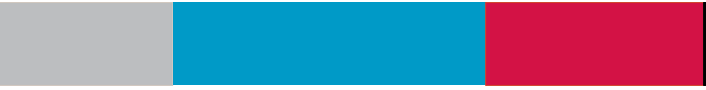

Aves

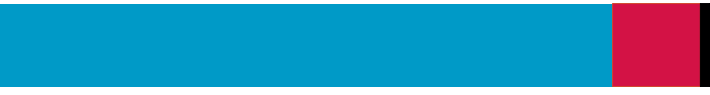

Mamíferos

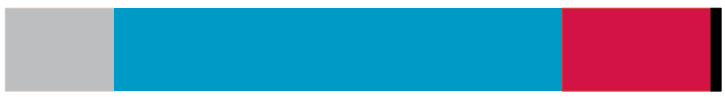
Vulnerable/En Peligro/En Peligro Crítico Preocupacion Menor/Casi Amenazado Datos Insuficientes

Gimnospermas

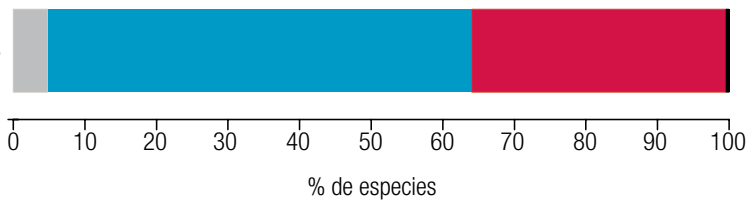




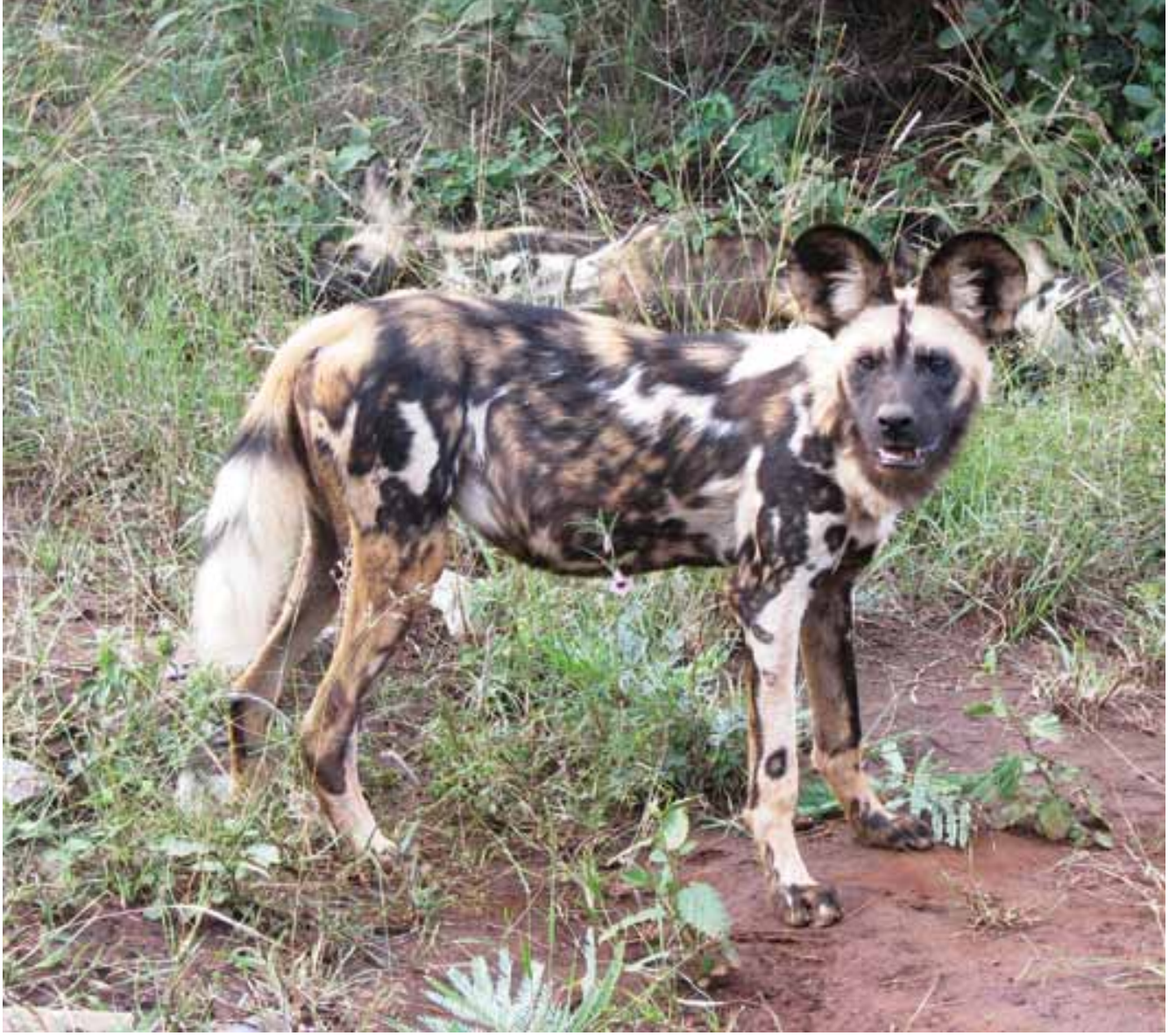

comenzando por hacer de la disciplina un campo más desafiante y gratificante a nivel intelectual.

Varias iniciativas mundiales se están llevando a cabo en apoyo de la taxonomía. La Iniciativa Mundial sobre Taxonomía (http://www.cbd.int/ gti/) está funcionando en virtud de un mandato del Convenio sobre la Diversidad Biológica (CDB), en tanto que Species 2000, es el trabajo de una "federación" de organizaciones de base de datos que trabajan en estrecha colaboración con usuarios, taxónomos y organismos patrocinadores (http://www.species2000.org/). La nueva tecnología también está ayudando a la taxonomía y la biología de campo en un sentido más amplio. Las evaluaciones de ADN han duplicado el número de grandes divisiones conocidas dentro de las arqueas y bacterias (Boucher y Doolittle, 2002). El conocimiento sobre la situación de las especies está consagrado en la Lista Roja de Especies
Amenazadas de la UICN. La actualización de 2008 de la Lista Roja incluye 44.838 especies, de las cuales $16.928(38 \%)$ están amenazadas por la extinción (figura 7.1). De las 223 especies que experimentaron un verdadero cambio en su situación en la Lista Roja entre 2007 y 2008, 183 (82\%) están más amenazadas y 40 (18\%) están menos amenazadas (UICN, 2008d).

Usando datos históricos de las compilaciones de la Lista Roja, la UICN y sus asociados han desarrollado el Índice de la Lista Roja que, para las aves, muestra un deterioro constante en lo que a la situación de amenaza se refiere entre 1988 y 2004. Este deterioro se observa en todos los biomas (figura 7.2).

\section{USAR 0 NO USAR LAS ESPECIES}

En su forma más simple, el concepto de "uso sostenible" supone que, con la correspondiente moderación y eficiencia de recolección, las especies silvestres pueden ser utilizadas sin 
llegar a agotarse (Mace y Hudson, 1999). Sin embargo, el término "uso sostenible" se utiliza también para describir el criterio de promover activamente su uso como una estrategia de conservación. El argumento es que promoviendo el uso, o permitiendo que este continúe, animará a las personas a valorar los recursos silvestres. Y cuando las especies silvestres y sus hábitats tienen valor, esto favorece su conservación y desalienta la conversión del hábitat natural a otros usos competitivos de la tierra. La gestión de los animales de caza como los ciervos y patos en América del Norte suele citarse en apoyo de los argumentos a favor de un uso consuntivo como táctica de conservación.

El valor del comercio internacional de vida silvestre, una forma económicamente mensurable de uso, ha ido en aumento, pasando de valores de importación declarados de US\$158.900 millones en el decenio de 1990 a más de US\$330 mil millones en 2005 (Engler, 2008). La gran mayoría $(82 \%)$ de este valor corresponde a madera y pesca, pero el comercio también es significativo en productos forestales no madereros (US $\$ 27.700$ millones), plantas ornamentales (US $\$ 13.400$ millones), plantas medicinales (US\$13.000 millones), y pieles y productos de peletería (US\$4900 millones).

En una revisión de las opiniones de los expertos sobre los impulsores sociales y económicos del comercio de especies silvestres en cuatro países del sudeste asiático, el ingreso de los consumidores, el estado de las leyes y reglamentos, la disponibilidad y abundancia de la especie en cuestión y el precio, fueron identificados como impulsores de cambio en los niveles de comercio de fauna silvestre (TRAFFIC,
2008). Otros factores asociados con el comercio de vida silvestre incluyen el aumento de la comunicación y conectividad a los mercados, mejores carreteras e infraestructura y la tala ilegal en el sitio. La gestión en torno al comercio de especies silvestres tendrá que formular estrategias para contrarrestar estos problemas si ha de contenerse el incremento del comercio ilegal o insostenible de los recursos silvestres.

El Grupo especialista de la CSE/UICN sobre uso sostenible ha identificado un conjunto de consideraciones necesarias para lograr el uso sostenible con base en la experiencia colectiva mundial. Para aumentar la probabilidad de que cualquier uso de un recurso silvestre vivo sea sostenible se requiere la consideración de los siguientes principios (UICN, 2000b):

- La oferta de productos biológicos y servicios ecológicos disponibles para su uso está limitada por las características biológicas intrínsecas tanto de las especies como de los ecosistemas, incluyendo productividad, resiliencia y estabilidad, que sí están sujetas a cambios ambientales extrínsecos.

- Las estructuras institucionales de gestión y control requieren incentivos positivos y sanciones negativas, buena gobernanza e implementación a una escala adecuada. Estas estructuras deben incluir la participación de los interesados directos pertinentes y prestar la debida atención a la tenencia de la tierra, los derechos de acceso, sistemas normativos, conocimientos tradicionales y el derecho consuetudinario.

- Las especies silvestres vivas tienen muchos valores culturales, éticos, ecológicos y económicos, que pueden proporcionar incentivos para la conservación. Cuando se puede asignar un valor económico a una de las especies silvestres vivas, 
eliminar incentivos perversos, e interiorizar costos y beneficios, se pueden crear las condiciones favorables para la inversión en la conservación y utilización sostenible de los recursos.

- Los niveles y fluctuaciones de la demanda de los recursos silvestres vivos se ven afectados por una compleja gama de factores sociales, demográficos, y económicos que, además, es probable que aumenten en los próximos años. Por lo tanto, es necesario prestar atención a la demanda y la oferta para fomentar la utilización sostenible.

Si bien el concepto y los principios subyacentes a la utilización sostenible están disponibles, la realidad es que muchas especies se están usando de manera no sostenible y con impunidad. Por ejemplo, los informes de la Organización para la Agricultura y la Alimentación (FAO) sobre el estado de las pesquerías del mundo cuentan la eterna historia de sobreexplotación en tanto que las discusiones de la UE en torno a una política pesquera común se ven obstaculizadas por intereses contrarios que están resultando en "niveles desconocidos de captura" (The Economist, 2009). Brashares et al. (2004) también han informado de que, en el África Occidental, la disminución de las capturas debido a la sobreexplotación pesquera está dando lugar a un aumento de la presión sobre otros recursos naturales, especialmente la carne de animales silvestres.

El uso insostenible está ocurriendo en otros sectores además de la pesca. El uso de la carne de animales silvestres está provocando extinciones locales (Milner-Gulland et al., 2003) y es motivo de creciente preocupación, especialmente a medida que la seguridad alimentaria es objeto de atención por parte de los responsables de las decisiones. Además de los impactos directos sobre las especies cuya carne se está utilizando, los científicos informan de cambios más amplios a los ecosistemas como consecuencia de la eliminación de dichas especies, incluyendo cambios en la diversidad de plantas (Núñez-Iturri y Howe, 2007).

Se requiere una efectiva gobernanza y orientación para apoyar el uso sostenible de los recursos. Por ejemplo, la conservación de los bosques tropicales de producción es el objetivo de las Directrices para la conservación de la biodiversidad en los bosques tropicales de producción, de reciente aprobación, que debe ser el marco para el uso sostenible de productos forestales (madera y productos forestales no madereros, incluida la carne de animales silvestres) fuera de las áreas protegidas (OIMT, Decisión 6 (XLIV) - www.itto. int/en/decisions).

No obstante, algunos mecanismos instituidos para gestionar la utilización de los recursos tienen limitaciones, incluyendo la no menos importante presión política para fijar cuotas insosteniblemente altas, cual es el caso de la política pesquera de la UE anteriormente señalado. Otro ejemplo en el caso de la Convención sobre el comercio internacional de especies amenazadas de fauna y flora silvestres (CITES) es el peligro de que durante la transición de un tipo de regulación del comercio a otro, puede ocurrir un marcado aumento en la explotación (Rivalan et al., 2007).

Están evolucionando nuevas tecnologías como la identificación de cuernos de rinoceronte, o el uso de técnicas moleculares para la identificación de productos de aves, peces y ballenas en los mercados (Palsbøll et al., 2006; Baker et al., 2007) aunque Rubinoff (2006) advierte que los códigos de barras del ADN proporcionan solo algunos de los datos necesarios para la identificación y, sobre todo con especies menos conocidas, esto debería tenerse en cuenta en las decisiones sobre su uso. El análisis de isótopos de agua (Bowen et al., 2005) es también un medio para gestionar el comercio de partes de la vida silvestre. Los 
isótopos estables de agua y nieve precipitada varían amplia y sistemáticamente en una base geográfica y su presencia en el tejido animal como resultado de la ingestión alimentaria significa que son marcadores potenciales del origen geográfico. Sin embargo, se requiere la calibración contra muestras de origen conocido.

Si bien la utilización sostenible de al menos algunos de los recursos naturales es parte integral de cualquier programa de desarrollo sostenible, continúa siendo un tema muy controvertido en la comunidad conservacionista (Hutton y Leader-Williams, 2003). La atención a todos los factores, más allá de las características biológicas y ecológicas de los recursos involucrados, es la clave del éxito, al igual que una mayor colaboración en la identificación de los enfoques con más probabilidades de tener éxito en la reducción del uso ilegal o insostenible (TRAFFIC, 2008). De gran importancia es el establecimiento de incentivos positivos para la conservación y el uso sostenible. La plena resolución de las controversias en torno a la utilización de una determinada especie seguirá siendo un reto dado que algunos grupos pueden no aceptar jamás el uso de dicha especie.

\section{EL ETERNO CONFLICTO ENTRE LOS SERES HUMANOS Y LA VIDA SILVESTRE}

Grandes depredadores, como los grandes felinos, osos, cocodrilos y lobos, junto con otras especies como los elefantes, constituyen una amenaza real para la vida humana y los medios de subsistencia en razón de la destrucción de bienes tales como cultivos y ganado. Por ejemplo, una revisión de las pérdidas de ganado sufridas por los agricultores que residen en el Parque Nacional Jigme Singye Wangchuk de Bután informó de pérdidas por hogar de hasta dos tercios de los ingresos anuales (Wang y McDonald, 2006). Entre los factores que influyen en las tasas de depredación cabe mencionar el pastoreo permisivo, prácticas inadecuadas de vigilancia, pastoreo excesivo, falta de establos adecuados para encorralar al ganado por la noche y la distancia entre el hogar y los pastizales.

Estos conflictos no son nuevos; sus registros históricos que datan de 1700, documentan lobos que se alimentan de humanos en Europa y tigres que también se alimentan de humanos en Asia. Pero a medida que se retraen los espacios verdaderamente silvestres y tienden a expandirse las poblaciones humanas, aumenta la probabilidad de enfrentamientos y conflictos. Además de las causas directas de los conflictos, los impactos indirectos incluyen la pérdida de ingresos debido al tiempo empleado para lidiar con estos problemas relacionados con las especies.

Las respuestas pueden dividirse en protección, mitigación (sistemas de compensación e incentivos) y prevención (a través de cambios en las prácticas de gestión o reubicación), y enfoques exitosos que combinan enfoques biológicos a corto plazo con enfoques sociales a largo plazo (Distefano, 2005; Thouless, 2008). En primer lugar, es necesario reducir los conflictos, luego aumentar la tolerancia y, por último, implementar la distribución de beneficios y la planificación del uso del suelo para evitar que se produzcan conflictos en el futuro. Las medidas clave incluyen:

- Atención a la planificación del uso del suelo. La fragmentación del hábitat y los conflictos suelen estar directamente relacionados. En algunos casos, las zonas de amortiguamiento pueden ser eficaces, pudiéndose crear mediante canjes de tierra.

- Empoderamiento comunitario. Un sentido de propiedad sobre la fauna silvestre a menudo lleva a la gestión de la vida silvestre por parte de la población local.

- La creación de incentivos económicos para incrementar la tolerancia. 
Cuando los conflictos se producen en paisajes enteros es difícil resolver los problemas en forma individual, razón por la cual es importante desarrollar un marco de respuesta que implique la colaboración de todos los interesados directos. Aunque se han desarrollado métodos estandarizados para medir los conflictos con los elefantes, es imperativo hacer lo mismo para otras especies, a fin de proporcionar medios fiables para comparar la intensidad de los conflictos entre los sitios a efectos de establecer las prioridades de respuesta.

\section{ESPECIES INVASORAS}

Las especies exóticas invasoras suponen una importante amenaza para la biodiversidad y los servicios de los ecosistemas; están consideradas como una de las cinco principales amenazas a la integridad de los ecosistemas por la Evaluación de los Ecosistemas del Milenio (EM) (2005). Las especies invasoras pueden causar pérdida de biodiversidad, cambios en la química del agua, alteración de los procesos biogeoquímicos, modificaciones hidrológicas, y alteraciones a las redes alimentarias (Dukes y Mooney, 2004; Ehrenfeld, 2003), así como cambios en la disponibilidad de luz, aire, alimentos, refugio y sitios de reproducción. Para las aves, Butchart et al. (2008), señalan que las especies invasoras amenazan a las aves de varias maneras, incluyendo la depredación sobre los adultos, estrés reproductivo a través de la depredación de huevos o polluelos, y la degradación del hábitat (en particular por los herbívoros o plantas invasoras). Un tercio de las especies de aves amenazadas se encuentran amenazadas por las especies invasoras, en gran parte a causa de la depredación de carnívoros y roedores.

Baillie et al. (2004) informaron de que los invasores son una gran amenaza para el 11\% de las especies amenazadas de anfibios y el 8\% de los mamíferos amenazados de los que se dispone de datos. También informaron de que las especies insulares son especialmente sensibles, señalando que el 67\% de las aves amenazadas de las islas oceánicas están afectadas por especies invasoras, en comparación con el $8 \%$ de las aves continentales. Darwall et al. (2008) señalan que el 85\% de peces amenazados en el África Meridional, el 55\% de las especies amenazadas de peces de agua dulce en Europa y algo menos del 45\% de los peces de agua dulce en peligro en Madagascar, se ven afectados por las especies invasoras; estos últimos en gran medida como resultado de la implementación de un plan de restablecimiento de la pesca local mediante la introducción de 24 especies de peces no nativos (Benstead et al., 2003).

Las características que definen a las especies potencialmente invasoras incluyen tanto factores intrínsecos a la especie invasora como al hábitat a ser invadido. Howard y Ziller (2008) señalan factores tales como:

- tasa de crecimiento rápido;

- capacidad para crecer adecuadamente en condiciones secas o adversas (amplia tolerancia ambiental);

- producción de muchos frutos y semillas adecuadamente protegidos (especies de alto rendimiento);

- producción de frutos y semillas (u otros propágulos) en etapas tempranas de crecimiento y desarrollo;

- capacidad de dispersión a través del viento o el agua o por medio de los animales que se alimentan de ellas o llevan sus propágulos; y

- competencia efectiva con otras plantas.

El Grupo especialista de la CSE en especies invasoras (ISSG) dispone de una red de expertos en especies invasoras y una base de datos sobre muchas de las especies más invasoras (www. issg.org). El Programa mundial sobre especies invasoras (GISP - www.gisp.org) es una asociación 
internacional (que incluye a la UICN) abocada a hacer frente a la amenaza de las especies invasoras aumentando el conocimiento y la conciencia en torno a este tema y desarrollando herramientas y métodos necesarios para prevenir y controlar las invasiones.

La predicción del potencial de invasión de cualquier especie puede ser un proceso difícil debido a que las invasiones, como los empresarios humanos, pueden confundirse por cuestiones de época y cambio (Baskin, 2002). A pesar de que las invasiones biológicas son complejos problemas ecológicos, evolutivos y socioeconómicos, se está logrando una mejor comprensión, sobre todo en la ecología de la invasividad y la vulnerabilidad a la invasión. Este conocimiento es esencial para determinar cuánto esfuerzo debe dedicarse al control de una especie invasora que ya se ha establecido o para aclarar las concesiones que los administradores y planificadores de la tierra tendrán que considerar.

La erradicación y el control de especies invasoras han utilizado diferentes estrategias y tácticas (Wittenburg y Cock, 2001; Veitch y Clout, 2002). El control químico de las especies vegetales invasoras, combinado a veces con la eliminación mecánica como la poda o el corte, ha sido útil para el control de al menos algunas plantas invasoras, pero no ha resultado ser particularmente exitoso en términos de la erradicación. También se ha intentado el control biológico de las especies invasoras. El fundamento de este enfoque es aprovechar las relaciones ecológicas como la competencia, la depredación, el parasitismo y la herbivoría, entre un invasor y otro organismo no nativo introducido como un agente de control (el agente de control es a menudo del mismo hábitat natural original de la especie invasora). Los resultados son mixtos. Por ejemplo, la polilla del nopal (Cactoblastis cactorum), que se utiliza para combatir la invasión de la especie Opuntia en Australia, invadió recientemente los Estados Unidos suponiendo una grave amenaza para las especies nativas de Opuntia (Stiling, 2002).

Los casos exitosos de erradicación tienen tres factores clave en común: características biológicas particulares de la especie (por ejemplo, capacidad de dispersión deficiente); suficientes recursos económicos dedicados durante mucho tiempo; y amplio apoyo de los organismos pertinentes y del público (Mack et al. 2000). Cuando la erradicación total no es posible, o no se desea, como en el caso de las especies nativas que invaden a través de la expansión, se puede intentar algunas medidas de "control de mantenimiento" destinadas a mantener las poblaciones de las especies invasoras a bajos niveles aceptables. Sin embargo, los controles químicos y mecánicos utilizados plantean muchos problemas, incluyendo el alto costo y la limitada aceptación pública de algunas prácticas (Mack et al., 2000).

\section{EL FUTURO DE LA CONSERVACIÓN DE LAS ESPECIES}

Tanto los paradigmas de los servicios de los ecosistemas como la conservación a favor de los pobres y los enfoques de la conservación basados en los derechos están tomando auge, pero todos ellos exigen atención continua a la función fundamental que desempeñan las especies para sustentar esos paradigmas. En el nuevo mundo de la conservación, los enfoques basados en las especies siguen siendo la principal razón de ser. Debemos continuar aplicando las herramientas disponibles en la caja de herramientas de la conservación de las especies, desde el desarrollo e implementación de planes de acción para especies hasta la reintroducción, la gestión ex situ, etc.

En la próxima década, no debe permitirse la extinción de especie alguna. La comunidad conservacionista debe seguir contribuyendo al monitoreo y evaluación de la situación y de 
las tendencias de las amenazas de las especies, incluido el apoyo para el desarrollo de indicadores y presentación de informes. De fundamental importancia será trabajar en aras de una mejor comprensión de los parámetros de la definición de "uso sostenible" de las especies y alentar a los administradores de esas especies a hacer uso de dicho conocimiento. Del mismo modo, el mundo de la conservación debe promover todos los esfuerzos posibles en torno a la gestión y control de las especies invasoras.

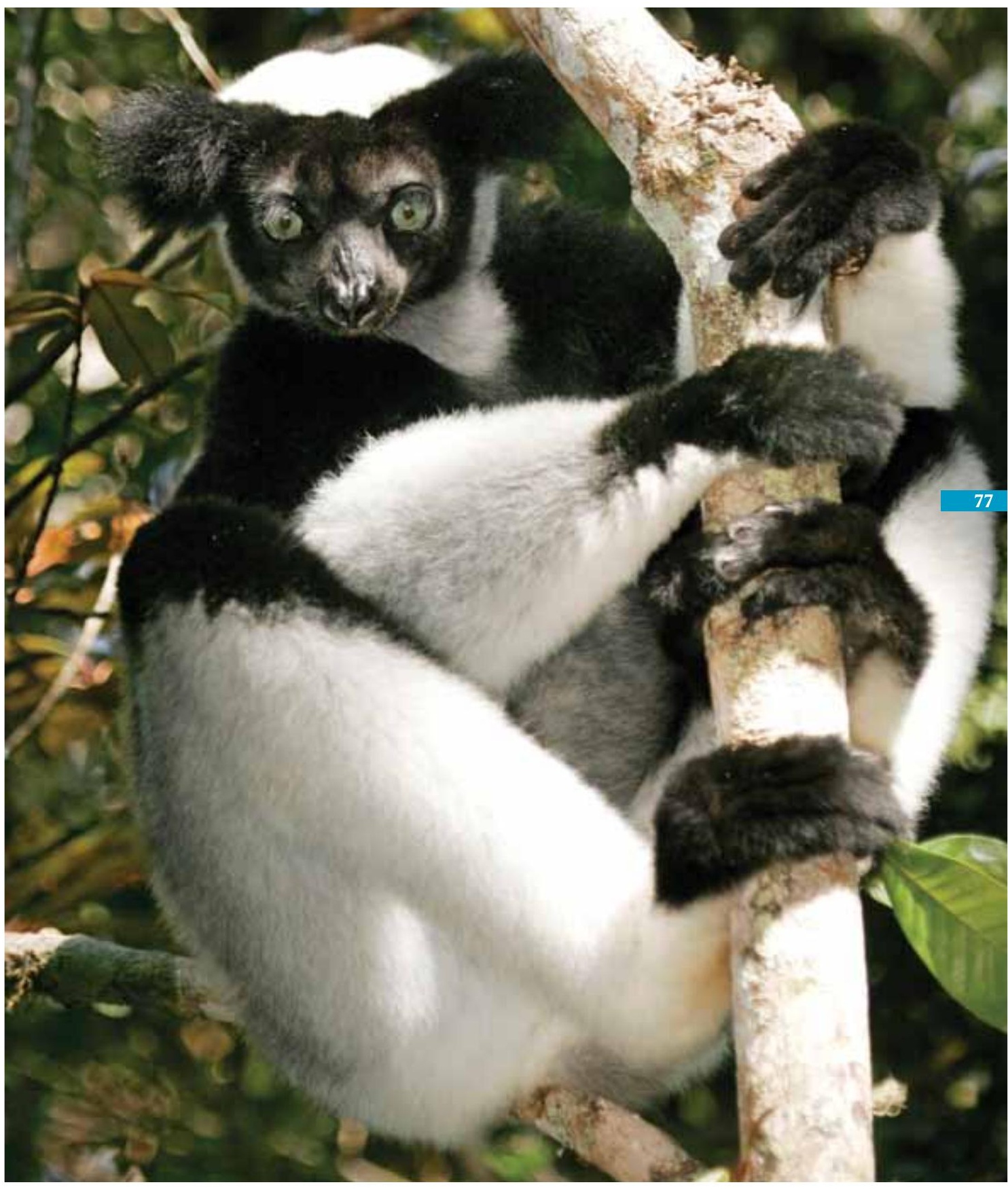




\section{Un Futuro Post Petróleo: 8. ¿Qué Significa para la Conservación?}

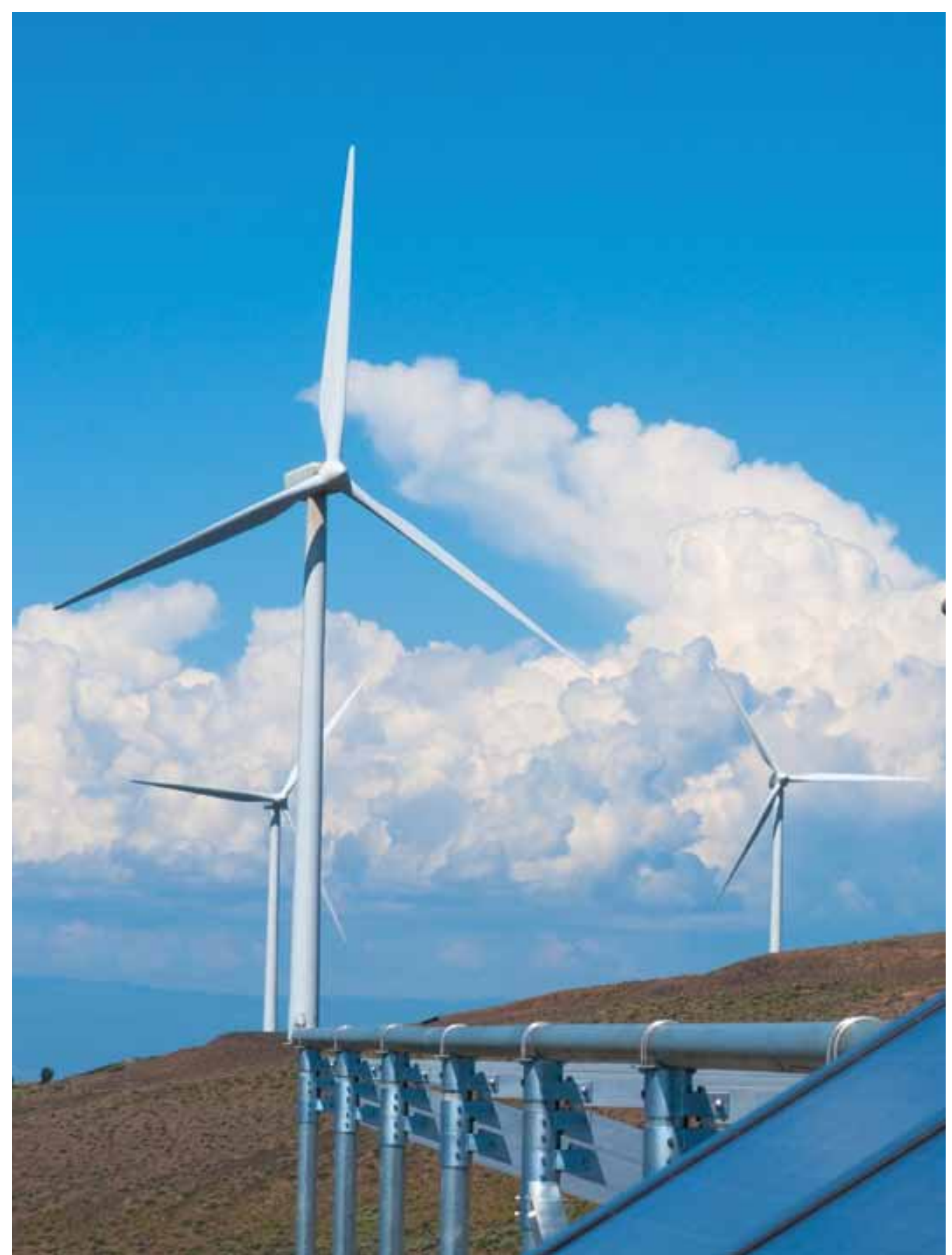


uso de energía coloca a los seres humanos en una ventajosa posición con respecto a todas las demás especies. Desde el momento en que nuestros antepasados fueron capaces de convertir el carbono en energía a través del uso del fuego, el uso de la energía ha sido una parte sumamente importante de nuestras relaciones con el resto del medio ambiente. El fuego nos mantuvo cálidos en invierno, nos permitió cocer los alimentos, nos ayudó a despejar la maleza para facilitar la caza, y nos permitió ser más activos por la noche. El posterior aprovechamiento del agua para operar molinos, el viento para propulsar botes de vela, y los molinos de viento para bombear agua y moler granos, etc., ayudó a convertir otras formas de energía que nos permiten ampliar nuestro nicho ecológico y nuestra población. El carbón alimentó la revolución industrial, y sigue siendo la principal fuente de energía en muchos países (Estados Unidos, China e India, para mencionar unos pocos). El uso generalizado de petróleo en el siglo XX dio lugar a numerosas aplicaciones de la energía, incluyendo una gran movilidad por medio de los automóviles y los aviones.

Cuando el precio del petróleo llegó a US\$147 por barril en el verano de 2008, para muchos conservacionistas fue motivo de júbilo y desesperanza. Desde la óptica del júbilo, este aumento del precio del petróleo indicaba claramente cuán dependientes del petróleo se habían hecho nuestras sociedades modernas e hicieron hincapié en la necesidad de empezar a pensar seriamente en una alternativa energética para el futuro. Muchos pensaron que este aumento era un síntoma del "pico del petróleo", el punto en que se había producido la mitad del petróleo disponible, es decir, que el suministro de petróleo empezaría a disminuir a partir de ese momento (Deffeyes, 2005). Si la demanda de petróleo se mantiene elevada, los precios continuarán siendo altos, con la esperanza de que se empiece a dirigir la inversión hacia fuentes alternativas de energía que son mucho menos perjudiciales para el clima. Si bien la demanda de petróleo se redujo, el alza de precios es una clara advertencia de que se debe buscar alternativas.

La preocupación por los precios del petróleo debe considerarse en el contexto de las proyecciones de la demanda energética. Las Perspectivas de la energía en el mundo - 2008 predice 
un crecimiento del 50\% de la demanda energética en 2030, con el 70\% de aumento de la demanda proveniente de los países en desarrollo, 30\% solo de China (OCDE/EIA, 2008). Si bien se prevé que los combustibles fósiles formarán la mayoría de la combinación energética para las próximas décadas, ahora que el petróleo está mostrando signos de agotamiento es el momento para considerar otras opciones energéticas.

Estas consideraciones están impulsadas por preocupaciones sobre el cambio climático, la seguridad energética y la distribución equitativa de los beneficios derivados de la energía.

Todas las opciones energéticas disponibles tienen el potencial de provocar impactos sobre la biodiversidad. Por ejemplo, los combustibles fósiles están mayormente asociados al cambio climático y la contaminación del aire, con los consiguientes impactos en la naturaleza. Sin embargo, también debemos considerar el impacto directo de los derrames de petróleo sobre los ecosistemas marinos y acuáticos y los efectos indirectos a través del desarrollo de los yacimientos de petróleo y sus infraestructuras y las actividades humanas en zonas remotas (como el Refugio de Vida Silvestre del Ártico, en Alaska), que son valiosos para la conservación de la biodiversidad.

\section{OPCIONES PARA UN FUTURO POST PETRÓLEO}

\section{Eficiencia energética}

La única opción más rápida y barata que no tiene efectos negativos sobre el medio ambiente es la conservación de la energía -utilizando menos energía, tanto mediante una simple reducción del consumo como haciendo que los procesos de producción sean más eficientes. Japón, por ejemplo, solo utiliza aproximadamente un $10 \%$ más de energía por unidad de producción económica que China. Los altos precios del petróleo demostraron claramente que la conservación es muy factible, abarcando todo, desde el uso del transporte público hasta el uso de aparatos con un mayor rendimiento energético para mejorar el aislamiento de los edificios. Las personas también pueden realizar importantes ahorros de energía. La eficiencia energética y la conservación deben seguir siendo la primera respuesta para hacer frente a un futuro post petróleo, con múltiples beneficios para todo, desde las emisiones de carbono hasta la seguridad energética y la biodiversidad.

\section{Fuentes energéticas alternativas}

\section{Nuclear}

Aunque la energía nuclear perdió adeptos durante la segunda parte del siglo pasado, ahora está de nuevo en la palestra en razón de los elevados precios del petróleo y el cambio climático. Los defensores sostienen que la energía nuclear es muy limpia en términos de su impacto sobre el clima, que ha demostrado su eficacia en los países que utilizan cantidades sustanciales de energía nuclear (tales como Francia y Suiza), y que podría ser mejorada aprovechando las nuevas tecnologías. Empero, "limpio” no significa necesariamente "verde". Sus detractores plantean el eterno asunto de la eliminación de residuos y el riesgo de proliferación y las consecuencias para la seguridad mundial, los altos costos de capital, los peligros inherentes de un derretimiento, los altos requerimientos de agua para refrigeración, y la ineludible realidad de que la principal materia prima, el uranio, es un recurso no renovable (con impactos asociados a la minería) y es escaso. Los nuevos tipos de reactores avanzados, tales como los reactores reproductores y el reactor nuclear con lecho de bolas, podrían ser una respuesta parcial a esta última preocupación, pero aún no han demostrado su viabilidad técnica y cualquier uso comercial está muy lejos de concretarse. Además, el costo real de la energía nuclear es muy difícil de determinar porque los 
costos de desarrollo rara vez son considerados, al igual que los costos de desmantelamiento de reactores y la eliminación de los residuos nucleares. Por otro lado, la energía nuclear parece requerir altos niveles de apoyo gubernamental. Por ejemplo, la energía nuclear en los Estados Unidos es elegible para recibir hasta 32 tipos diferentes de subvenciones y es una de las formas más ineficientes de reducir los gases de efecto invernadero (GHG) (Earthtrack, 2008).

\section{Biomasa}

La biomasa es una antigua forma de energía. Actualmente, más de 2500 millones de personas en todo el mundo dependen de las formas tradicionales de biomasa como madera, carbón vegetal y estiércol animal para la iluminación, la calefacción y la cocina (OCDE/EIA 2008), que puede representar más del 90\% de la demanda de energía primaria de los hogares en muchos países en desarrollo. El uso tradicional de biomasa para producir energía en sí no es necesariamente insostenible; pero la proporción y el método de uso pueden causar problemas ambientales y de salud. La euforia inicial por la producción de biocarburantes a escala industrial se está moderando por la comprensión de que la tierra utilizada para la producción de biocarburantes puede ser desviada de otros usos importantes, incluida la producción de alimentos. Los cultivos de biocombustible suelen basarse en el monocultivo, una estrategia que es intrínsecamente arriesgada, por cuanto las plagas y enfermedades tienen más probabilidad de extenderse rápidamente en monocultivos que en policultivos. La UICN y el Programa mundial sobre especies invasoras han advertido sobre los riesgos de las especies invasoras en las plantaciones de biocombustibles. Además, la percepción de los beneficios climáticos de los biocombustibles está demostrando ser efímera y muchos pueden hacer más daño que beneficio, dependiendo de cómo y dónde se cultiva la materia prima (Howarth y Bringenzu, 2009).

Los impactos de los biocarburantes en la biodiversidad pueden ser significativos. Curiosamente, muchas de las características de los cultivos para biocombustibles son compartidas por las especies invasoras, como el rápido crecimiento, alta productividad, adaptabilidad a una variedad de suelos y condiciones climáticas y resistencia a plagas y enfermedades. La palma de Nipa, por ejemplo, ha invadido y colonizado más de 200 kilómetros cuadrados de la costa atlántica de Nigeria y, según algunos expertos, puede producir mucho más biocombustible por hectárea que la caña de azúcar. Por tanto, todos los cultivos introducidos para la producción de biocombustible deben ser tratados como especies potencialmente invasoras hasta que se demuestre lo contrario. Si bien el cultivo de especies invasoras existentes como el jacinto de agua, Lantana camara y la palma de Nipa pueden presentar una opción interesante para proporcionar materia prima para biocarburantes, no lo controlarán y pueden suponer un riesgo perverso en el sentido de crear mercados para tales especies invasoras, fomentando su propagación y mayores daños a la biodiversidad.

En la Resolución 4.082, la UICN exhortó a los gobiernos a optar por desarrollar bioenergía a gran escala o a escala industrial para implementar y aplicar criterios para la producción y uso 
ecológicamente sostenible, socialmente adecuado y económicamente viable de la biomasa, que:

a. No cause pérdidas globales a la biodiversidad;

b. No cause emisiones de la deforestación y degradación de los bosques y degradación de otros ecosistemas naturales;

c. No tenga efectos adversos en la seguridad alimentaria;

d. Garantice que la energía de la biomasa reduzca las emisiones de los gases de efecto invernadero en comparación con otras alternativas;

e. Proporcione beneficios a los productores de materias primas, especialmente los grupos vulnerables como los pobres de las zonas rurales, las mujeres y los pueblos indígenas;

f. Requiera métodos de producción que utilizan el agua de manera eficiente y sostenible, que favorecen la siembra de especies nativas y evitan la siembra de especies potencialmente invasoras; $y$

g. Desaliente el comercio de bioenergía producida en forma no sostenible, usando medidas proteccionistas.

La Mesa Redonda sobre Biocombustibles Sostenibles ha enunciado 12 principios que enmarcan la orientación para un desarrollo más sostenible de los biocarburantes en el futuro (RSB, 2008), y el Consejo Internacional de Gobernabilidad del Riesgo (IRGC) ha emitido directrices sobre la forma de gobernar los riesgos que plantean los biocombustibles (IRGC, 2008a).

\section{Hidroenergía}

La energía hidroeléctrica proporciona el 2\% de la demanda energética primaria de todo el mundo y es la principal fuente de electricidad renovable producida (Perspectivas de la energía en el mundo-2008). La mayor parte del potencial hidroeléctrico ha sido explotado por completo en los países desarrollados, en tanto que el resto de los sistemas hídricos suele mantenerse protegido. Sin embargo, se espera un gran crecimiento en los países en desarrollo. Algunos países, como Nepal, la RDP Lao y el Congo, tienen el potencial para ser las "baterías" de sus respectivas regiones debido a las escarpadas montañas y grandes sistemas hídricos. Empero, muchas represas hidroeléctricas son objetadas debido a la restricción de los caudales de agua en las cuencas fluviales y su repercusión en los medios de subsistencia como la pesca, así como el desplazamiento de biodiversidad y comunidades para la creación de embalses.

Para encontrar una manera de equilibrar los riesgos ambientales y sociales con la creación de energía renovable, la UICN participa en el Foro de Evaluación de la Energía Hidroeléctrica, que tiene por objeto establecer una herramienta de evaluación de la sostenibilidad de amplia aceptación para medir y orientar el desempeño en el sector hidroeléctrico, aprovechando las experiencias de la Comisión Mundial de Represas (que la UICN ayudó a establecer). Para la UICN es especialmente importante fomentar en el sector hidroeléctrico la gestión sostenible de las cuencas aguas arriba e implementar caudales ambientales que mantienen los ecosistemas aguas abajo y los servicios que prestan a las personas.

La UICN trabaja en proyectos en todo el mundo que demuestran la importancia de mantener los caudales en todos los sistemas fluviales incluidos los de las represas. Por ejemplo, en la cuenca Huong de Vietnam, una evaluación de caudales puso en evidencia cómo los cambios en el caudal de los ríos afectaron tanto los beneficios económicos como la salud de los ecosistemas. Las autoridades de la cuenca pudieron determinar cuáles opciones generaban objetivos económicos al tiempo que protegían los ecosistemas y sus servicios. La aplicación de los caudales ambientales permite la toma de decisiones integrales sobre el uso del agua dentro de los límites de disponibilidad para atender las prioridades para el crecimiento económico, 
los medios de subsistencia sostenibles y la conservación, aumentando así la sostenibilidad de la infraestructura hídrica incluyendo la energía hidroeléctrica.

\section{Eólica}

Según el Consejo Mundial de Energía Eólica, el total de la capacidad eólica instalada para el año 2009 ascendía a casi 120.798 megavatios (MW) en todo el mundo. La capacidad ha estado creciendo a una tasa del 25\% anual durante los últimos años. Los Estados Unidos recientemente superaron a Alemania con una mayor capacidad instalada total de 25.170 MW, equivalente a una quinta parte de la capacidad mundial.
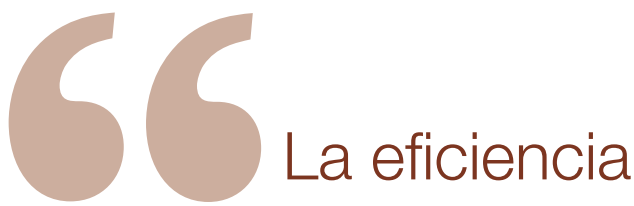

Alemania tiene 23.903 MW, y España tiene $16.754 \mathrm{MW}$.

China también está ampliando rápidamente su capacidad eólica con $12.210 \mathrm{MW}$, superando a la India, con 9.045 MW. Un factor crítico para el éxito del desarrollo de la energía eólica es el adecuado apoyo gubernamental, que a menudo implica energética y la conservación deben seguir siendo la primera respuesta para hacer frente a un futuro post petróleo.

una estructura de incentivos por tarifas, subvenciones o incentivos fiscales para promover formas más limpias de energía.

Tanto las aves como los murciélagos son víctimas de los parques eólicos, normalmente por colisión con las aspas de las turbinas. Entre las aves, se reportó que las paseriformes nocturnas migrantes eran muy sensibles, y entre los murciélagos las especies migrantes que se posan en los árboles fueron más susceptibles (NRC, 2007). Las razones de la elevada mortalidad en los murciélagos se atribuyen a las especies que se posan en los árboles que se sienten atraídas por las altas torres de los parques eólicos, a los posibles aumentos en la disponibilidad de insectos debido a los cambios en el uso del suelo asociados con la construcción de parques eólicos, o a la atracción que ejercen los sonidos creados por las turbinas y al colapso de sus pulmones debido a cambios bruscos en la presión del aire (Kunz et al., 2007b).

Para gestionar los posibles impactos de los parques eólicos sobre las aves nocturnas y los murciélagos, Kunz et al. (2007a) han publicado directrices para orientar la construcción y el funcionamiento de tales sitios.

Viéndole el lado positivo, las tierras asociadas a las áreas de los parques eólicos costa afuera pueden continuar siendo utilizadas para la agricultura o como reservas de biodiversidad, dependiendo de los deseos de las comunidades afectadas. De igual modo, los defensores de la energía eólica costa afuera sugieren que beneficiará la pesca, proporcionando un "área protegida” para la reproducción de los peces. Sin embargo, algunos estudios iniciales han indicado que las vibraciones generadas por las turbinas eólicas pueden alterar a algunas especies de peces 
y mamíferos marinos. Por lo tanto, la hipótesis de que los parques eólicos marinos beneficiarán la pesca queda por demostrarse en la realidad.

\section{Solar}

Aunque actualmente solo corresponde al 0,1\% del consumo de energía en todo el mundo, el potencial de la energía solar fotovoltaica es muy grande, especialmente en los países con abundante sol. El sector de la energía solar es el de más rápido crecimiento para la generación de energía, abarcando desde los nuevos avances incorporados en pequeños fotovoltaicos incorporados en los edificios hasta torres térmicas de concentración de energía solar de gran escala. Si bien el uso de la tierra y el acceso de las comunidades locales a desarrollos de energía solar en gran escala es un motivo de preocupación, el principal obstáculo para una mayor introducción de la energía solar es el elevado costo de la inversión. Además, los materiales semi conductores utilizados para fabricar la nueva generación de células solares requieren materiales minados como el galio e indio; ambos son extremadamente raros, y esto sugiere que para un uso más eficiente la evolución solar debería concentrarse en los países con más abundancia de sol. Las instalaciones solares elevadas podrían nutrir el crecimiento de pasto y hierbas bajo su cobijo, además de la posibilidad de proporcionar hábitat para algunas especies.

\section{Geotérmica}

Si bien Islandia es el líder en energía geotérmica, proporcionando el 26\% del total de la demanda de electricidad, muchos países cuentan con potencial geotérmico. Nueva Zelanda, Indonesia, Japón y Rusia tienen un extraordinario potencial. El Instituto de Tecnología de Massachussets (MIT) (2007) informó de que con una razonable inversión en investigación y desarrollo, la energía geotérmica podría proporcionar a los Estados Unidos 100 gigavatios (GW) de energía en los próximos 50 años. Desde una perspectiva de desarrollo, es interesante notar que el Valle del Rift en África Oriental tiene un potencial de 14.000 MW a través de la energía geotérmica, sin embargo, solo $200 \mathrm{MW}$ son capturados en la actualidad, con Kenia a la cabeza en la región, que actualmente proporciona el 14\% de su electricidad (Economist, 2008). Los impactos ambientales son insignificantes.

\section{Olas y mareas}

El océano tiene enormes cantidades de energía generada por la fuerza de sus olas y mareas. Actualmente se están considerando muchas maneras para capturar esta energía. El Reino Unido es el principal inversor, con una decidida política para fomentar la energía oceánica. Por ejemplo, la barrera de 10 millas de ancho que se propone para el estuario de Severn en el suroeste de Inglaterra podría aprovechar la segunda mayor diferencia de mareas en el mundo para generar el 5\% de las necesidades de electricidad del Reino Unido, equivalente a ocho centrales térmicas de carbón. Pero esto también afectará los humedales y las reservas de aves locales. Este ejemplo demuestra que los ecosistemas costeros ya están sometidos a muchas presiones, a veces conflictivas y, en consecuencia, son algunos de los ecosistemas más degradados.

\section{ENERGÍA Y DESARROLLO SOSTENIBLE}

Las sociedades necesitan de energía para sobrevivir y prosperar. Sin embargo, el acceso asequible a energía sostenible todavía no llega a muchas partes del mundo. Elsayed (2009) informa de que para más de 30 países, la mayoría de los cuales se encuentra en el África subsahariana, menos de la mitad de la población tiene acceso a electricidad (figura 8.1). Un mapa de países que dependen de los combustibles sólidos (combustibles tradicionales como madera, estiércol, residuos agrícolas y 


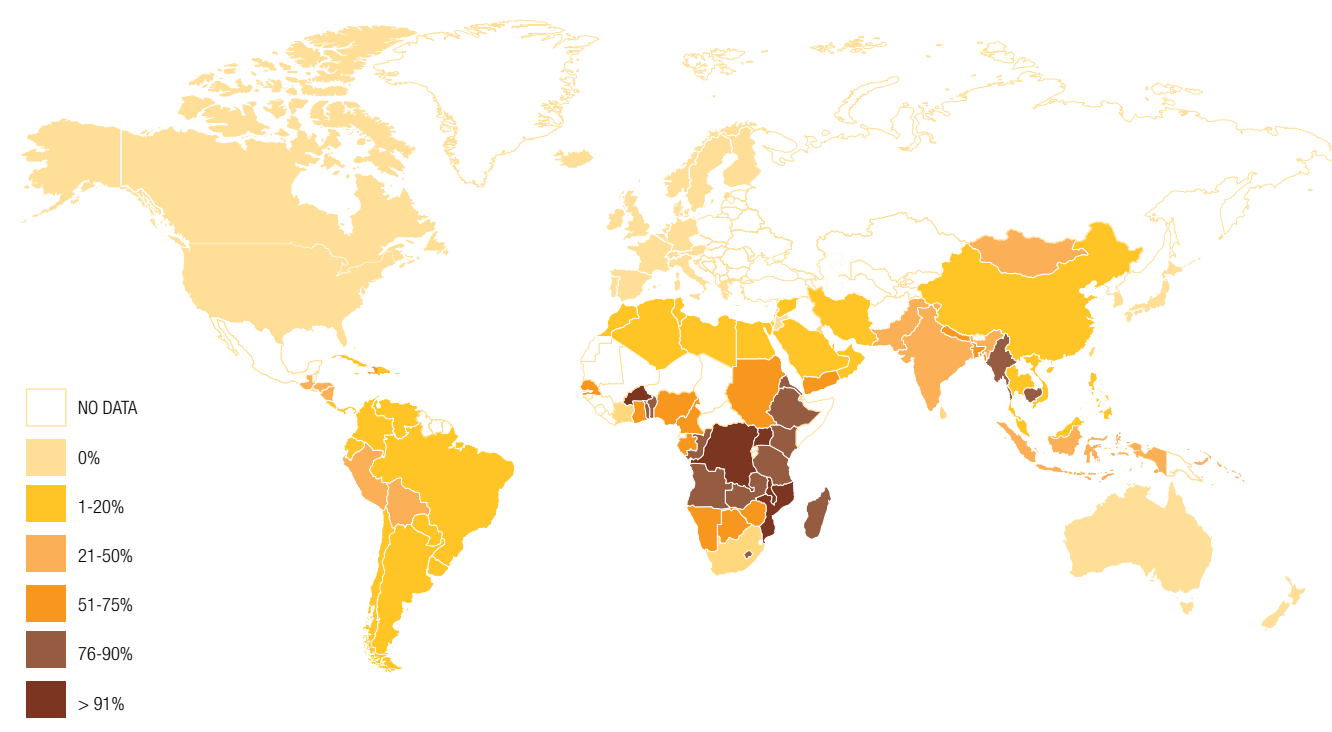

Figura 8.1 Porcentaje de la población sin acceso a electricidad (Earthtrends 2009 (www. earthtrends.org) basado en datos del Informe de Desarrollo Humano 2007/2008)

carbón) es prácticamente la contraimagen de la figura 8.1 con una gran dependencia en el África subsahariana y los países en desarrollo en Asia (Elsayed, 2009).

El uso de las formas tradicionales de energía supone una amenaza especial para las mujeres y los niños. Las responsabilidades tradicionales de recolección de combustible y agua implican tiempo y esfuerzo físico por parte de las mujeres y las niñas para recolectar combustible $y$ transportar agua en lugar de ir a la escuela o generar ingresos. Muchas mujeres y niñas también sufren de problemas de salud relacionados con la recolección y el uso de combustibles de biomasa. Las mujeres están expuestas a una variedad de peligros para la salud por cocinar en interiores mal ventilados, incluyendo infecciones respiratorias, cáncer y enfermedades de los ojos. El humo del fuego en interiores con escasa ventilación, representa casi dos millones de muertes prematuras al año. La sustitución de combustibles de baja calidad como la biomasa tradicional con combustibles más eficientes como el queroseno, el gas natural, la electricidad o los biocarburantes, puede hacer mucho para reducir los efectos del humo en la salud y el ejercicio físico que afectan desproporcionadamente a mujeres y niñas (PNUD, 2004).

$\mathrm{Al}$ establecer los criterios de diseño para las nuevas formas de energía, las opciones energéticas deben, por tanto, considerarse en el contexto del medio ambiente y de los costos y beneficios asociados a los medios de subsistencia. Se están considerando muchas opciones para un futuro post petróleo, algunas más sostenibles que otras. Aunque todas las fuentes de energía tienen impactos sobre el medio ambiente, es importante evaluar la totalidad de los costos y beneficios para promover la más equitativa, eficiente y sostenible de las opciones. Sin embargo, solo las fuentes de energía que dependen del aprovechamiento sostenible de los recursos ambientales tienen el potencial de ser verdaderamente renovables, y los esfuerzos deben centrarse en mejorar el papel que puede desempeñar el medio ambiente, al tiempo que se reconoce los límites.

La UICN ha instado a todos los interesados directos y donantes a prestar el apoyo necesario 
para permitir el desarrollo e implementación de sistemas energéticos ecológicamente sostenibles, socialmente equitativos y económicamente eficientes en apoyo del desarrollo sostenible (Resolución 4.081 del CMN de la UICN).

Habida cuenta de los desafíos enfrentados por el aumento de la demanda energética a la vez que estamos sintiendo cada vez más los efectos del cambio climático, tenemos que trabajar con urgencia hacia una transición en nuestro futuro energético. En primer lugar, deberíamos promover la conservación de la energía como parte de cualquier plan de conservación y cualquier nuevo enfoque basado en la energía. Cada uno de nosotros debe tomar medidas para conservar energía -evitar viajes innecesarios, apagar las luces, el aire acondicionado, las computadoras y otros artículos eléctricos cuando no estén en uso, etc. Pero, además de la eficiencia energética, tendremos que explorar otras opciones. Tendremos que invertir en evaluaciones ambientales y sociales más estratégicas con respecto a las diversas opciones energéticas, incluyendo análisis precisos de costo-beneficio. $\mathrm{Al}$ igual que lo estamos haciendo para los biocarburantes y los parques eólicos, debemos promover el desarrollo e implementación de directrices para todas las opciones energéticas en términos de su impacto medioambiental. El desarrollo sostenible dependerá de ello. 


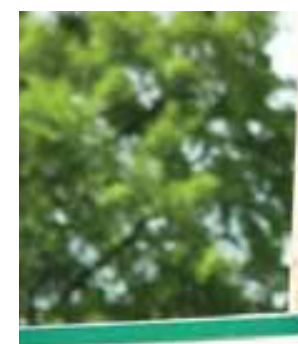

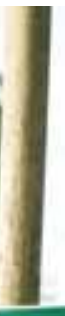
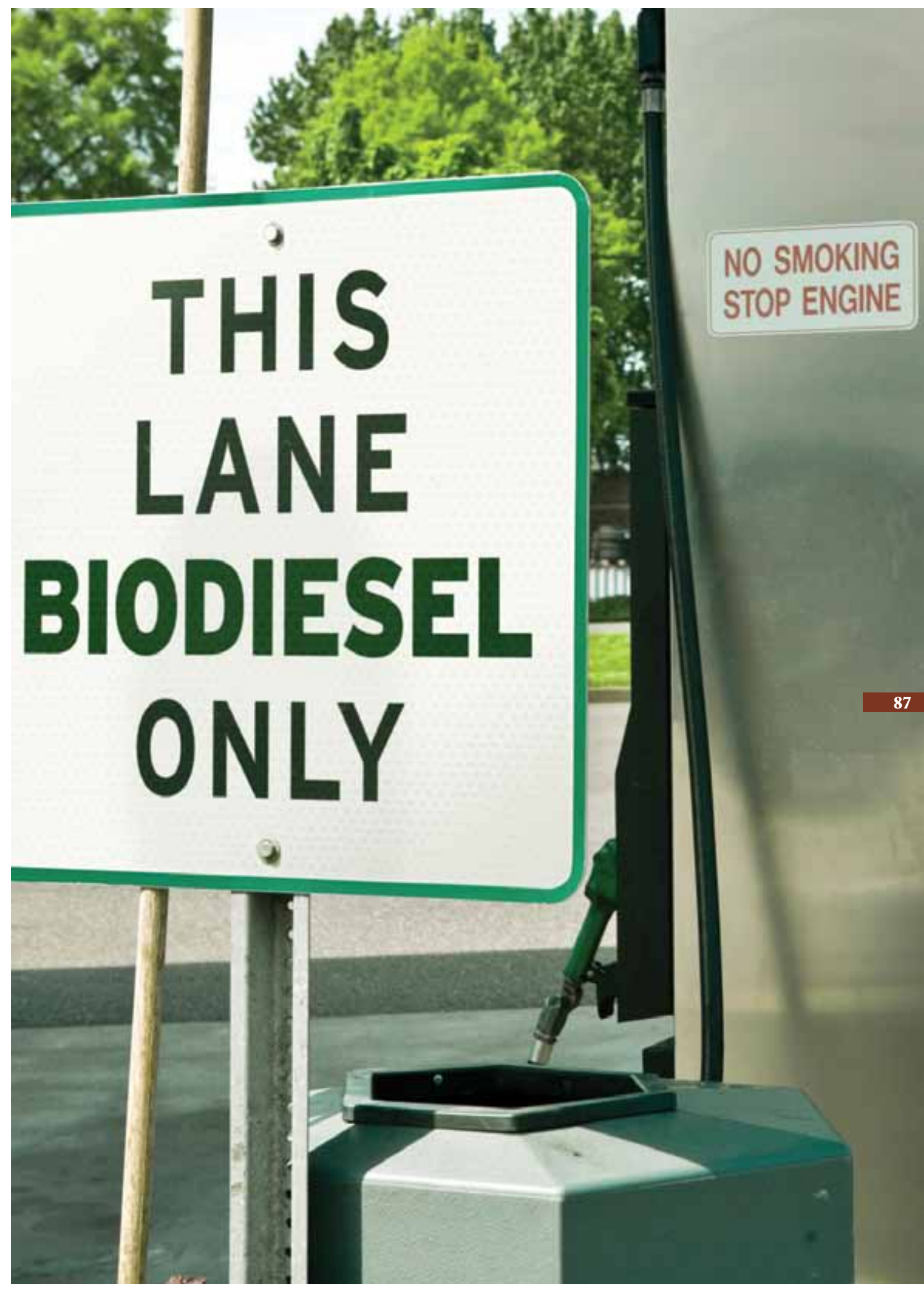


\section{La Conservación y los Conflictos Armados}

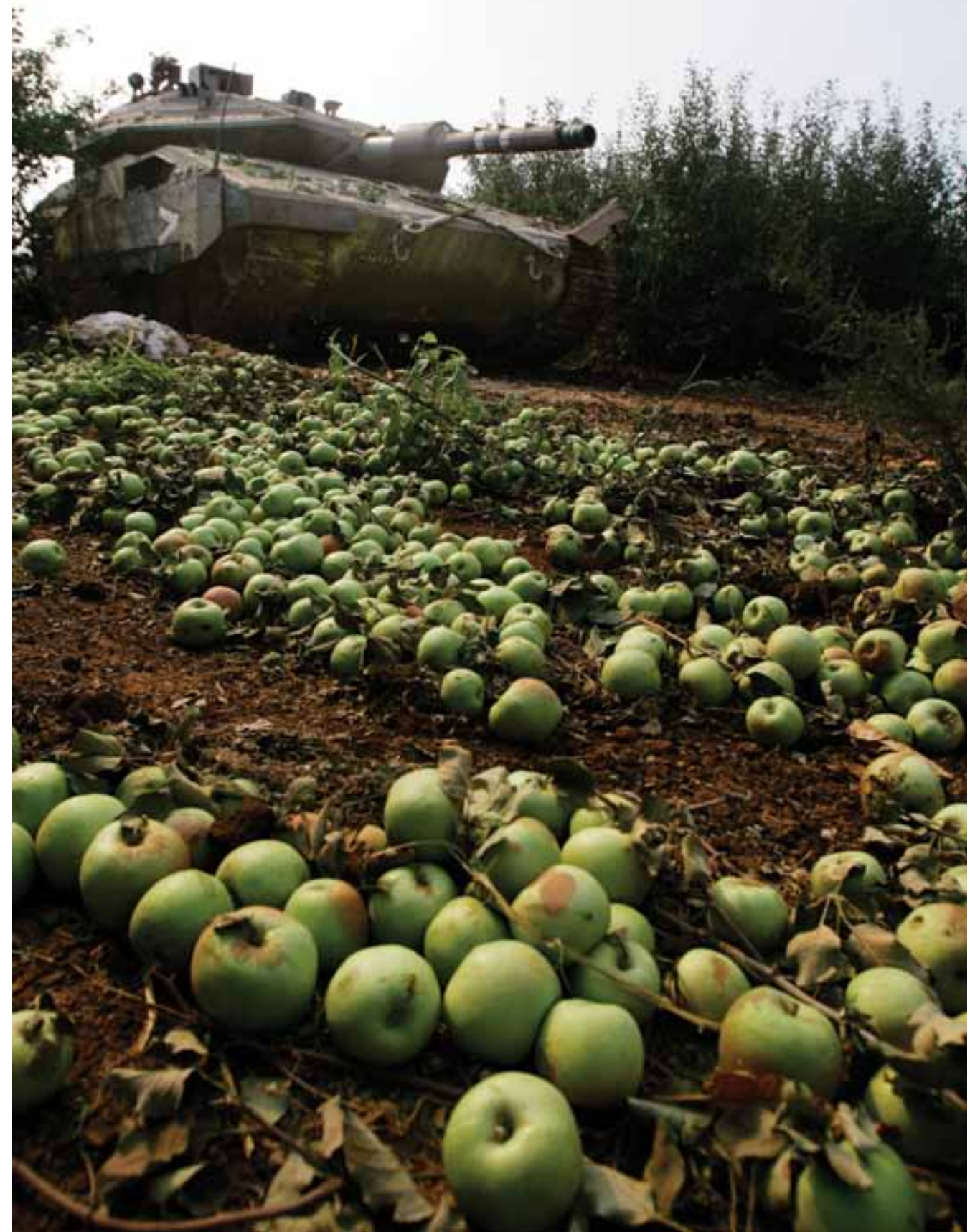


La guerra -conflictos armados entre entidades competidoras- tiene importantes repercusiones tanto en las sociedades humanas afectadas como en la biodiversidad en general. Si bien el sufrimiento humano es el de mayor preocupación, los aspectos ecológicos de la guerra y la reconstrucción al término de los conflictos también son dignos de mayor atención. La UICN trabaja activamente en muchas zonas de conflicto, lo que le ha dado gran experiencia en el tratamiento de problemas de conservación en condiciones difíciles en países como Nepal, Pakistán, Somalia, Sudán, Sri Lanka y la República Democrática del Congo.

En la actualidad, los conflictos armados son particularmente frecuentes en áreas importantes para la biodiversidad. Más del $80 \%$ de los principales conflictos armados en la segunda mitad del siglo XX ocurrieron en lugares de situación crítica de la biodiversidad, zonas que contienen la totalidad de las poblaciones de más de la mitad de todas las especies de plantas y más del $42 \%$ de todos los vertebrados. Dos tercios de los 34 lugares de situación crítica de la biodiversidad del mundo experimentaron guerras durante ese tiempo (Hanson et al., 2009). Estos puntos también se caracterizan por estar expuestos a amenazas particulares porque la pobreza en los países pobres donde se encuentran ejerce gran presión sobre los recursos que se encuentran en el medio ambiente natural. Los focos de guerra en estos lugares hace la conservación aún más difícil por cuanto los refugiados de los combates suelen recurrir a los bosques en busca de alimentos y materiales de construcción, ejerciendo una presión adicional sobre la biodiversidad.
Las guerras en hábitats importantes para la vida silvestre han afectado a numerosos países desde 1990. Una lista parcial incluye a Angola, Bosnia, la República Democrática del Congo, Camboya, República Centroafricana, Colombia, Guatemala, India, Indonesia, Liberia, México, Myanmar, Nepal, Pakistán, Perú, Filipinas, Sierra Leona, Senegal, Sri Lanka, las Islas Salomón, y Sudán -una lista bastante deprimente. Estos conflictos civiles a menudo tienen lugar en las zonas alejadas del control gubernamental donde pocos servicios públicos están a disposición de los cientos de millones de personas que habitan en esas zonas remotas.

\section{CONFLICTOS Y BIODIVERSIDAD}

Los recursos naturales pueden ser un factor importante en los conflictos, especialmente en los conflictos civiles. Un análisis de 47 guerras civiles determinó que el factor que mejor predecía la guerra civil era el nivel de dependencia de la exportación de productos básicos, como madera, 
Recuadro 9.1 Estudios de caso sobre los conflictos civiles y la vida silvestre

\section{Los naxalitas de la India y los tigres}

India se enfrenta a problemas de aumento de la insurgencia, especialmente porque las tribus desafectas se han volcado en contra del gobierno y han estado apoyando a grupos como la guerrilla maoísta, conocidos como naxalitas. Los naxalitas son una amenaza para la recuperación de los tigres en la India, ya que controlan vastas zonas remotas de los bosques en el centro y en el este de la India -las áreas que sirven como principal hábitat del tigre. Si bien pueden no estar dirigiendo intencionalmente sus acciones a los tigres, están evitando las actividades de conservación en las regiones bajo su control, lo que puede ser tanto como el 30\% del área de distribución del tigre de la India. E incluso si el tigre no es un objetivo, la excesiva captura de animales que son presa habitual del tigre, tales como los ciervos y jabalíes, está obligando a los tigres a cazar animales domésticos (o incluso personas), con el consiguiente conflicto con las comunidades rurales.

\section{Los rebeldes de Filipinas promueven la conservación}

En Filipinas, los rebeldes en Mindanao han amenazado con hacer daño a los madereros a menos que el gobierno ponga coto a las actividades de tala que amenazan con despojar la cubierta forestal en la isla. En febrero de 2005, un portavoz del Frente Democrático Nacional afirmó que los rebeldes estaban haciendo su parte en la protección del medio ambiente mediante la reforestación y el lanzamiento de campañas de educación entre la población rural para apoyar el uso sostenible de productos forestales y reducir al mínimo los efectos perjudiciales del cambio de cultivos. Sostienen que estas actividades están ayudando a mantener el hábitat silvestre para las numerosas aves y mamíferos endémicos de Mindanao, y demuestran que la conservación es una cuestión de todos los ciudadanos, no solo responsabilidad del gobierno. minerales o petróleo, lo que podría llamarse recursos “saqueables” (Collier, 2003). Estos pueden generar fondos suficientes para apoyar un movimiento armado que permitirá a los vencedores continuar la recolección de tales recursos. El conflicto a menudo se relaciona también con las facciones políticas y étnicas que pueden estar ya en conflicto con respecto a otros temas, pero la principal motivación, al menos en algunos casos, es el deseo de obtener los beneficios financieros de la explotación de los recursos. A manera de ilustración, la madera vendida de zonas controladas por los rebeldes de Liberia permitió a los insurgentes comprar armas y continuar percibiendo ingresos, quizás incluso disuadiéndoles de buscar la paz en razón de los beneficios obtenidos por la prolongación de los combates.
Los impactos de los conflictos sobre la

biodiversidad incluyen cambios en las áreas de distribución de las personas y las especies silvestres, posibles cambios en los patrones de explotación y exacerbación de otros problemas como la pobreza (recuadro 9.1).

Los patrones de la guerra han influido siempre la distribución de las especies y los ecosistemas, y la biodiversidad en general. Algunos de los grandes mamíferos son especialmente vulnerables en tiempos de conflicto. Por ejemplo, el rinoceronte blanco fue exterminado de Sudán durante su guerra civil (1955-1972), y la guerra de 1978-1980 entre Uganda y Tanzania prácticamente erradicó el rinoceronte negro de esos países. 
La guerra civil que comenzó en la República Democrática del Congo en 1996 es trágica por su costo humano, que incluye más de 3,8 millones de muertes y por haber obligado a los agricultores a abandonar sus tierras para convertirse en cazadores furtivos itinerantes o refugiados, a menudo asentados alrededor o dentro de los parques nacionales. A pesar del Acuerdo de Paz de 2003, el Parque Nacional de Virunga está todavía ocupado por hombres armados que cazan furtivamente para su alimentación y para la venta. En tales condiciones, el comercio de carne de animales silvestres en la República Democrática del Congo está estrechamente ligado a la comunidad informal. Merode y Cowlishaw (2006) recopilaron información sobre la venta de especies protegidas y no protegidas en los mercados urbanos y rurales, y la cadena de suministro de carne de animales silvestres a estos mercados, en condiciones de inestabilidad política y conflictos armados. En tiempos de paz, la carne de las especies protegidas del Parque Nacional de Garamba (mayormente elefantes y búfalos) rara vez aparecía en los mercados rurales, si bien comprendía más de la mitad de todas las ventas de carne de animales silvestres en los mercados urbanos. Este patrón reflejaba diferencias en las cadenas de suministro rurales y urbanas. Se requería armas automáticas para cazar las grandes especies protegidas, las cuales eran facilitadas a los cazadores por los oficiales militares que controlaban el comercio urbano. El uso de esas armas fue desalentado por los jefes tradicionales, que administraban los mercados de las aldeas. En tiempo de guerra, la venta de especies protegidas en los mercados urbanos se quintuplicó porque los oficiales militares huyeron de la escena, dejando atrás un sistema de acceso abierto que llevó a un incremento masivo en la explotación de especies protegidas. En contraste, los mercados rurales se mantuvieron relativamente estables debido a la continuación de la autoridad de los jefes de aldea. Estos hallazgos sugieren que, incluso en tiempos de conflictos violentos, las autoridades tradicionales pueden desempeñar un importante papel en la conservación de la biodiversidad.

La continua serie de guerras en el África Central está teniendo un profundo impacto negativo sobre las personas y las especies silvestres como los hipopótamos. En el lago Edward, en la frontera entre Uganda y la República Democrática del Congo, por ejemplo, la población de hipopótamos ha disminuido de 9600 en el decenio de 1970 a alrededor de 680 en 2005 debido a la caza furtiva de milicianos insurgentes que buscan la carne. El impacto ecológico de este declive es profundo, ya que la población sana de hipopótamos depositaba cerca de 100 millones de kilogramos anuales de nutrientes en el lago a través de sus excrementos, que alimentaban el fitoplancton microscópico, que a su vez alimentaba gusanos y larvas de agua, que luego alimentaban las tilapias del lago, que eran recolectadas por los varios miles de pescadores que habitaban en el interior del Parque Nacional de Virunga. El estrés de la disminución de peces se ve agravada por el aumento de la demanda de tilapia, lo que conduce a que cantidades crecientes de personas utilicen redes de malla más fina. Esto significa la captura de peces cada vez más jóvenes con la consiguiente disminución en la captura, que está forzando a la gente a recurrir a la vida silvestre como fuente de proteína. Si bien esto es 
desastroso para los pescadores y la vida silvestre, puede no ser tan malo para el lago Edward, ya que la tilapia es una especie no nativa y su agotamiento puede permitir la recuperación de las especies nativas endémicas de peces -muchas de las cuales continúan sin documentarse. El problema más grave es el de la vida silvestre del Parque Nacional de Virunga, que limita con el lago Edward y está amenazada por los conflictos activos y los efectos secundarios del asentamiento de los refugiados de los combates.

Una respuesta de la vida silvestre podría consistir en trasladarse a hábitats menos peligrosos. La historia sugiere que en muchas partes del mundo, las zonas de amortiguación entre los grupos étnicos que han estado en conflicto pueden ser particularmente ricas en biodiversidad, al menos en parte, debido a que estas zonas están sujetas a una menor presión de caza por el temor a los conflictos con otros grupos étnicos. Por ejemplo, un estudio en el sur de Sudán llevado a cabo por la Wildlife Conservation Society en 2007, encontró la que posiblemente es la más importante migración de mamíferos en el mundo, con más de 1,3 millones de antílopes de oreja blanca prosperando en la región circundante al Sudd, el mayor humedal de agua dulce en África. El estudio también identificó en esa región un estimado de 8000 elefantes, 13.000 reebok, 8900 búfalos, y cerca de 4000 antílopes del Nilo (una especie que solo se encuentra en esa región). El Sudd ha permanecido subdesarrollado a causa de la guerra civil de Sudán, pero muchos intereses en materia de desarrollo han fijado ojos codiciosos en el área, reconociéndola como un granero en potencia para el Asia Occidental, China y África Occidental.

\section{LA BIODIVERSIDAD POST CONFLICTO}

La paz después de los conflictos puede suponer un mayor problema para la conservación que el conflicto mismo. Cuando los combatientes cesan los combates, las áreas que una vez fueron inaccesibles debido a los conflictos se convierten en sitios importantes para el desarrollo, dando lugar a la deforestación, la caza furtiva de fauna silvestre y otras formas de degradación. Si bien se han establecido algunas áreas protegidas, la biodiversidad bien puede estar sufriendo ahora más que durante la guerra (por ejemplo, en Angola y Mozambique). Además, las armas disponibles durante los conflictos están muy extendidas y, a juzgar por la experiencia histórica, la paz animará a algunos ex combatientes a convertirse en cazadores furtivos que están ansiosos por convertir la fauna silvestre en carne como un medio de supervivencia en tiempos de gran incertidumbre.

Aún más sorprendente es el hecho de que una vez que termina la guerra, los biólogos pueden hacer nuevos descubrimientos. Por ejemplo, cuando los científicos regresaron a los bosques de Vietnam tras el conflicto de Indochina, un sorprendente número de nuevas especies fueron descubiertas por los biólogos de organizaciones miembro de la UICN tales como la Wildlife Conservation Society. Estos descubrimientos incluyeron el ciervo gigante muntjac, el más grande de los ciervos muntjac, el Saola, un antílope de bosque tan distintivo que se le asignó a un nuevo género; un nuevo género y especie de cabra de bosque conocida localmente como Linh duong; evidencia de al menos otras dos nuevas especies de ciervos y un cerdo que había sido visto por última vez 100 años atrás. Las actividades de la UICN en la República Democrática Popular Lao, Vietnam y Camboya están contribuyendo a la conservación post conflicto.

\section{EVITANDO LOS CONFLICTOS Y MITIGANDO SUS IMPACTOS EN LA BIODIVERSIDAD}

La seguridad nacional es algo que no va a desaparecer y las amenazas para los gobiernos son reales, aunque pueden adoptar formas 


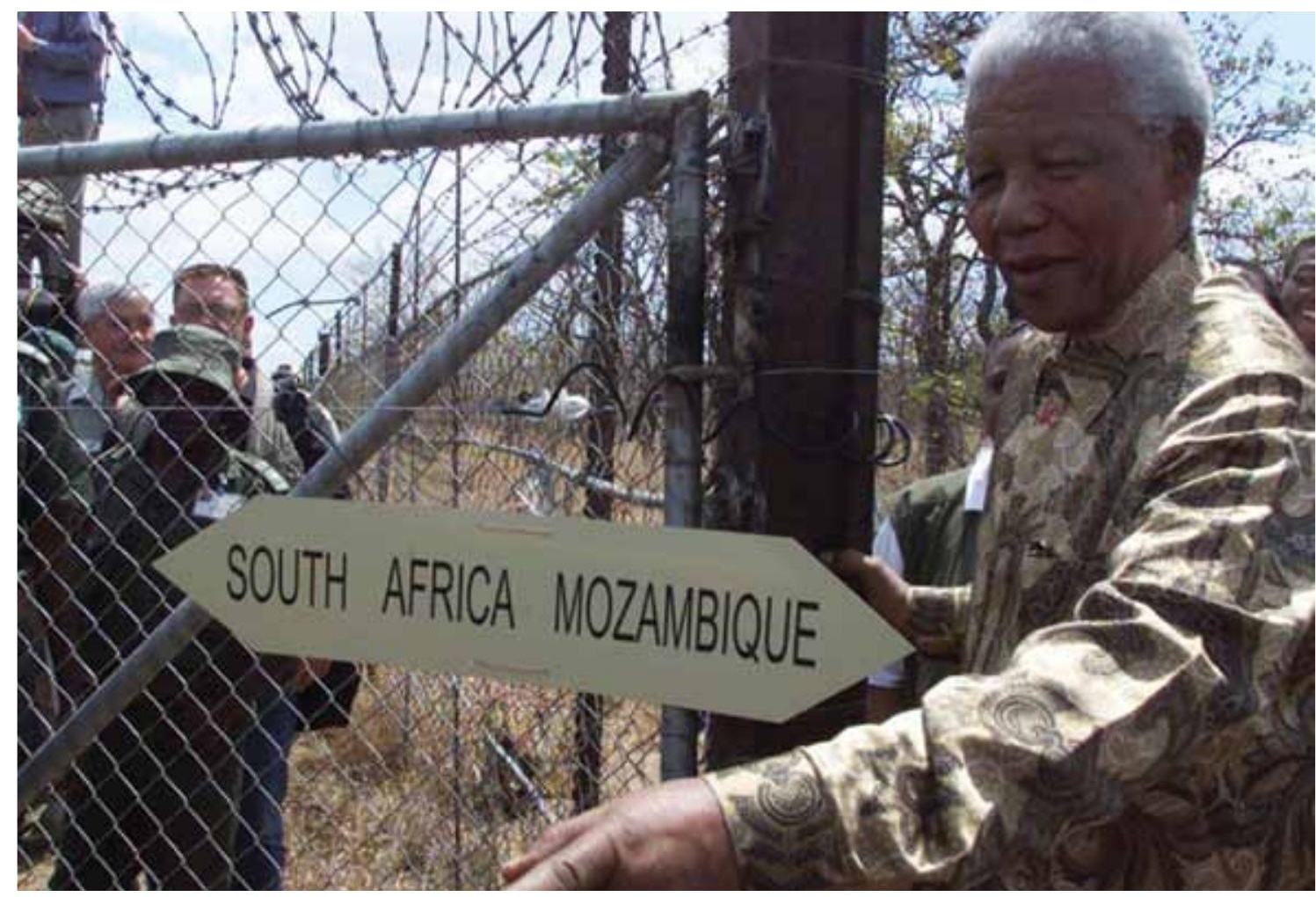

imprevistas. Una respuesta para adelantarse a los conflictos armados es el establecimiento de parques de paz internacionales y áreas protegidas transfronterizas, con la consiguiente necesidad de una mayor cooperación con los países vecinos. Por ejemplo, África Meridional tiene al menos cuatro áreas protegidas transfronterizas: el Kgalagadi entre Botsuana y Sudáfrica; la Maloti-Drakensberg, entre Lesotho y Sudáfrica; el Gran Limpopo, compartido por Mozambique, Sudáfrica y Zimbabue, y el Nyika entre Malaui y Zambia. Estas zonas plantearán nuevos retos y oportunidades.

Una mejor comprensión de las causas y consecuencias de los conflictos y la ecología de la guerra puede propiciar que las organizaciones de conservación sigan funcionando, incluso en tiempos de conflicto armado, como en el reciente conflicto civil en Nepal. Por ejemplo, algunas de las áreas protegidas, tales como la extraordinaria
Área de Conservación Kangchenjunga, fueron entregadas a las comunidades locales para la gestión, y la caza local de animales silvestres para la carne se redujo sustancialmente, al menos en algunas de las áreas protegidas. Muchos proyectos de la UICN en Nepal pudieron continuar durante el conflicto, lo que les permitió florecer una vez que la paz había regresado.

Muchos conflictos tienen lugar a lo largo de las regiones fronterizas que muchas veces están alejadas de la administración central. Estas zonas a menudo son también ricas en vida silvestre. La posibilidad de desarrollar las áreas protegidas transfronterizas como medio de promoción de la paz se ha hecho cada vez más popular. Los parques de paz no son nada nuevo, actúan como una especie de zona de amortiguación entre los gobiernos que están en conflicto. La Red Global de Áreas Protegidas Transfronterizas ha identificado 227 complejos de áreas protegidas transfronterizas, con la participación de cerca 


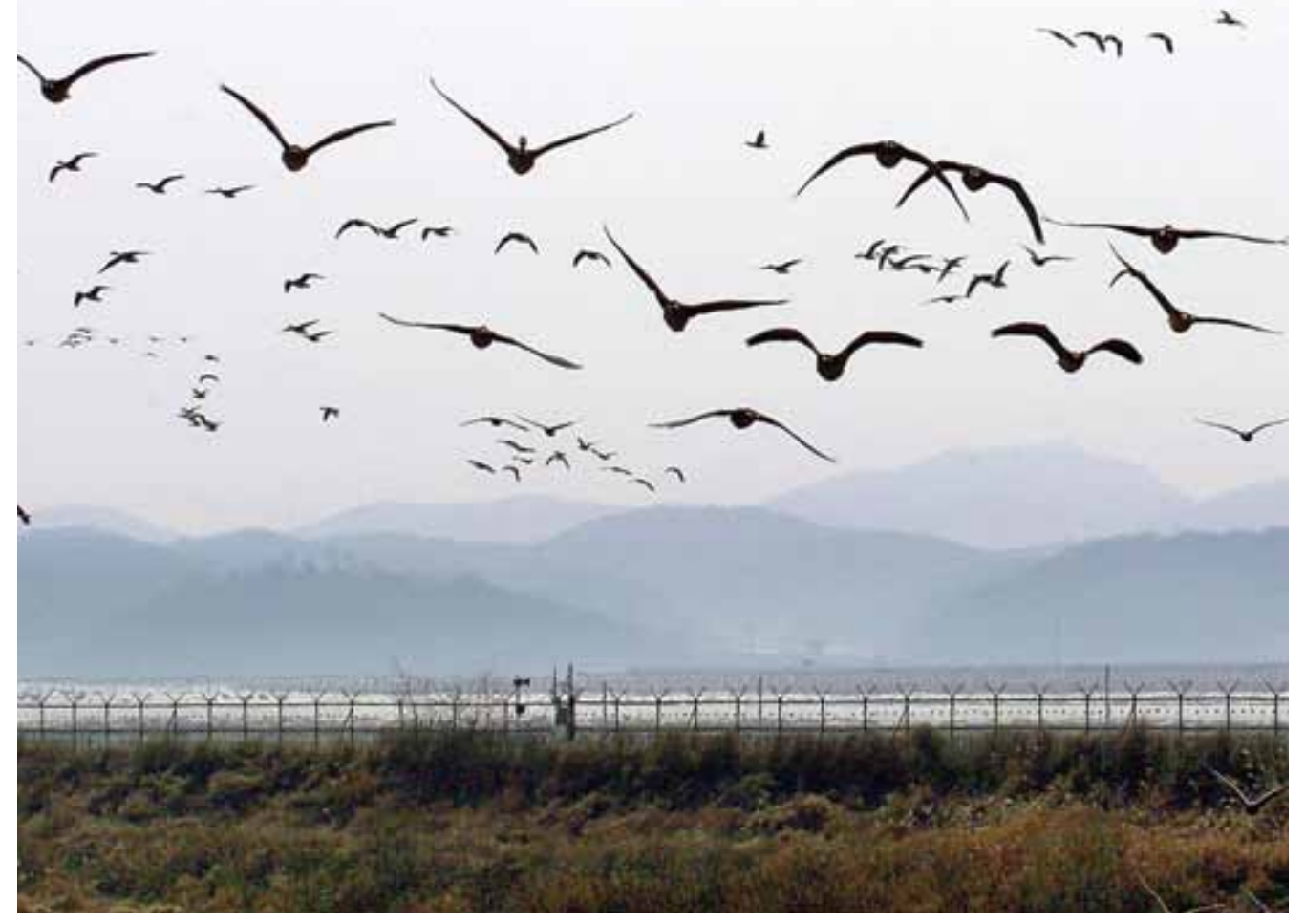

de 3043 áreas protegidas o sitios designados que cubren 4,6 millones de kilómetros cuadrados (GTPAN, 2009). Estos llamados "parques de paz” pueden establecer actividades de cooperación internacional, promover los intereses y las identidades regionales, reducir la probabilidad de conflicto, ampliar el área de los hábitats naturales para la vida silvestre, y promover un sentimiento de esperanza de que la conservación puede ayudar a llevar la paz a las personas y a la naturaleza.

Los ejércitos siguen siendo una fuerza política, social y económica dominante en la mayoría de los países. Los ejércitos modernos reconocen cada vez más que los factores políticos y económicos y la viabilidad ecológica están estrechamente relacionados entre sí, y están contribuyendo a la conservación en muchos países. Controlan grandes extensiones de tierra como zonas de entrenamiento o reservas militares y a menudo patrullan zonas fronterizas remotas que son importantes para la biodiversidad. Se podría incluso argumentar que muchas de las amenazas a la seguridad nacional tienen sus raíces en una gestión inadecuada de los recursos naturales (Klare, 2001), por lo que cabría esperar que los militares apoyen una mejor conservación de los recursos. Varios Miembros de la UICN están trabajando con los militares hacia este fin.

Ciertamente los gobiernos son plenamente conscientes de los peligros que los conflictos suponen para la biodiversidad. El Convenio sobre la Diversidad Biológica (CDB), en su artículo 3, apoya la Carta de las Naciones Unidas en el reconocimiento de la responsabilidad de los Estados "para garantizar que las actividades bajo su jurisdicción o control no causen daños al medio ambiente de otros Estados o de zonas más allá de los límites de la jurisdicción nacional”. Ello establece una clara base jurídica internacional para evitar los daños al medio ambiente en los conflictos violentos entre gobiernos. El Convenio subraya también el valor de la paz para la biodiversidad, concluyendo que, “en última instancia, la conservación y utilización sostenible de la biodiversidad fortalecerán las relaciones de amistad entre los Estados y contribuirán a la paz para la humanidad”. 
Sin embargo, persisten algunas importantes lagunas en el derecho internacional que rige la protección del medio ambiente durante los conflictos armados, tanto normativa como administrativamente (una de las cuales es la cuestión de cómo llevar a la práctica los requisitos normativos), y nuevas medidas son necesarias para hacer frente a estas lagunas. En los sistemas de responsabilidad e indemnización por las transgresiones contra el medio ambiente y los recursos naturales durante los conflictos armados se podría incluir un tribunal internacional especial para investigar las reclamaciones por daños ambientales y estudios de casos sobre el impacto medioambiental de los conflictos armados.

Así pues, ¿cuáles son las implicaciones de todo esto para las organizaciones de conservación, incluidas la UICN y sus Miembros? Si participan en la conservación en una zona de conflicto, los conservacionistas deben hacer todo lo posible para mantener una presencia en estas zonas. Esto puede suponer trabajar a través de las organizaciones no gubernamentales (ONG) y evitar ser vistos como instrumentos del gobierno, y más bien como defensores de los intereses legítimos de las personas que residen en la zona de conflicto. La experiencia de la

UICN en Centroamérica, Nepal, India y partes de África muestra que los grupos insurgentes a menudo permiten a las organizaciones no gubernamentales llevar a cabo actividades de conservación que beneficien a las comunidades rurales. Además, la comunidad conservacionista debe seguir apoyando en la medida de lo posible a los organismos locales de conservación. Ello puede suponer la intensificación de actividades una vez retirado el apoyo del gobierno, y ayudar a los funcionarios locales a mantener buenas relaciones con las comunidades locales, cuya gestión de los recursos es fundamental para la conservación.
Es fundamental buscar la comprensión objetiva de cualquier queja histórica de las comunidades que viven en zonas remotas donde el conflicto es endémico, y utilizar dicha comprensión para diseñar las formas adecuadas de apoyo a los intereses de la conservación.

La experiencia de los últimos 30 años demuestra que una gestión eficaz de los recursos naturales puede apoyar la consolidación de la paz y la recuperación post conflicto; por otra parte, si no se aborda el tema de los recursos naturales o su gestión eficaz, esto podría socavar la paz en las sociedades post conflicto. Así pues, mientras los conflictos y sus consecuencias son un desastre indiscutible para las personas, no necesariamente tienen que serlo para la vida silvestre (McNeely, en proceso de impresión).

Para ayudar a las comunidades en situaciones post conflicto, quienes trabajan en el ámbito del medio ambiente, del conflicto y de la consolidación de la paz, no deben crear expectativas poco realistas para las comunidades locales porque la gestión de los recursos naturales en los procesos de consolidación de la paz es a muy largo plazo, lento, y difícil. Los conservacionistas también deben colaborar con los organismos humanitarios para fomentar el reasentamiento de los refugiados en zonas que no dañarán los valores de la conservación. 


\section{Afrontando el Desastre: \\ 10. Consideraciones sobre los Ecosistemas para la Recuperación Post Desastre}

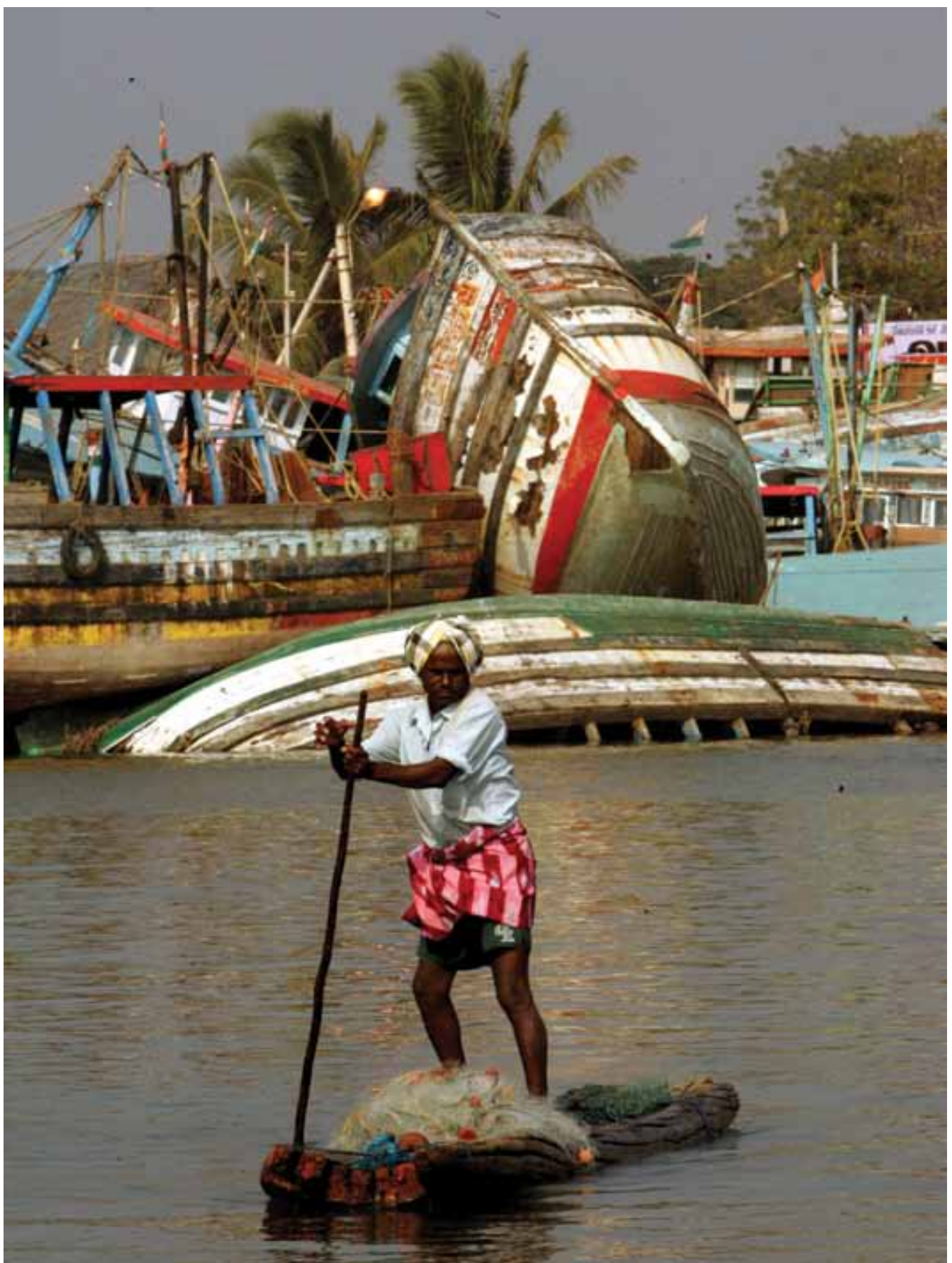


En años recientes, fenómenos naturales extremos - desde terremotos hasta huracanes y maremotos- parecen más comunes, convirtiéndose en desastres cuando se ven afectados los intereses humanos. El creciente impacto de esos desastres puede tener origen en la creciente población humana en las zonas vulnerables. Tan importantes y urgentes como las necesidades humanas después de los desastres, los esfuerzos de recuperación también deben considerar cómo podría contribuir la naturaleza. A la vez que los servicios de los ecosistemas (capítulo 4) se ven afectados por estos fenómenos extremos también pueden ser parte de la respuesta a ellos. Los esfuerzos de reconstrucción después de los desastres suelen presentar oportunidades para lograr cambios de mayor alcance y a más largo plazo que ayudarán a la recuperación de los medios de subsistencia y la seguridad de las personas y los ecosistemas de los que muchos dependen.

La atención a las cuestiones ambientales es una parte integral del éxito de un plan de recuperación y también reducirá la vulnerabilidad de la población local si ocurrieran desastres futuros. La historia demuestra que los terremotos tienden a repetirse en las mismas regiones, mientras que eventos como inundaciones, ciclones y sequías están aumentando en frecuencia e intensidad. Considerando este aviso previo, la planificación debe incluir todas las medidas posibles tendientes a la mitigación y adaptación a este mundo cambiante. Quienes participan en la reconstrucción ahora tienen la oportunidad de cambiar la forma en que responden a las tareas de más largo plazo para la reconstrucción y el establecimiento de medios de subsistencia sostenibles. Pero para aprovechar

al máximo esta oportunidad, deben estar seguros de tomar en cuenta las lecciones aprendidas al enfrentar desastres anteriores y emplear las estrategias adecuadas en el desarrollo de su respuesta.

El medio ambiente debe ser una preocupación central en todas las etapas de una respuesta post desastre. Inicialmente, desde luego, la fase de salvamento debe centrarse en las necesidades inmediatas de las personas afectadas por el evento. Sin embargo, en las fases de rescate y socorro, el impacto potencial de las medidas adoptadas para aliviar el sufrimiento humano puede tener también efectos negativos imprevistos sobre el medio ambiente. Por ejemplo, la provisión de leña como combustible en lugar de queroseno o gas 
natural puede conducir a la deforestación en la región circundante, aumentando la amenaza de posteriores deslizamientos de tierras. Las decisiones adoptadas para medidas a corto plazo tales como el reasentamiento temporal pueden tener consecuencias a largo plazo, por ejemplo, si los refugiados del desastre son alojados en un parque nacional. La recuperación a más largo plazo generalmente requiere acciones concertadas y dirigidas para las personas y su medio ambiente.

\section{PLANIFICACIÓN PARA LA RECUPERACIÓN A CORTO PLAZO Y EL MEDIO AMBIENTE}

Dos actividades clave en la fase de socorro -la gestión de los residuos y el reasentamiento de las personas afectadaspueden tener profundas repercusiones en la función de los ecosistemas.

En términos de las causas directas de la degradación del medio ambiente, ambos pueden resultar en la pérdida o fragmentación de hábitats, contaminación y propagación de especies invasoras. El reasentamiento también puede llevar a la sobreexplotación involuntaria de los recursos naturales por cuanto las personas enfrentadas a nuevas situaciones probablemente tendrán necesidad de rebuscar alimentos, leña para calefacción y cocina, y productos naturales para consumir o vender para generar ingresos.

Ejemplos concretos sobre importantes lecciones para la planificación futura pueden extraerse de experiencias con respuestas anteriores a grandes catástrofes. Por ejemplo, el Banco Asiático de Desarrollo (ADB), en una revisión acerca de la recuperación del maremoto de 2004 en el mar de Andaman en Hambantota, Sri Lanka, señaló que los desechos acumulados en las lagunas y otros ecosistemas costeros, además de la intrusión salina tierra adentro, afectaron negativamente la pesca y la productividad agrícola locales. El informe también determinó que las actividades de limpieza estaban afectando el medio ambiente debido a que los municipios vertían desechos en los humedales con las consiguientes repercusiones en los sistemas de drenaje y retención de áreas de inundación, aumentando el potencial de enfermedades transmitidas por el agua. Algunos de los lugares de reasentamiento propuestos pondrían en peligro zonas de gran biodiversidad, por lo que el informe recomendó que dichos lugares fueran ubicados con una adecuada amortiguación entre ellos y los sitios biológicamente sensibles, asegurando, además, que el número de hogares reubicados se mantuviera dentro de la capacidad de carga de la zona (ADB, 2005).

Las especies invasoras suponen otra importante, pero a menudo ignorada, amenaza. Una evaluación ambiental post maremoto llevada a cabo por el Programa de las Naciones Unidas para el Medio Ambiente (PNUMA), junto con el Ministerio de Medio Ambiente y Recursos Naturales de Sri Lanka encontró, entre otras cosas, que las olas gigantes llevaban más al interior especies exóticas invasoras como la suculenta (Opuntia) y el mesquite (Prosopis) tolerante a la sal, hasta llegar a las áreas protegidas como el Parque Nacional Yala. Estas especies no autóctonas están sustituyendo a las especies nativas que son más apetecibles para el ganado y la fauna silvestre de Sri Lanka (2005). 
Las especies invasoras también fueron motivo de preocupación en los planes de recuperación tras el huracán Katrina que golpeó Nueva Orleans en 2006. La termita subterránea de Formosa, Coptotermes formosanus, es nativa de China, pero fue introducida accidentalmente a los Estados Unidos, y desde entonces ha invadido al menos nueve estados del sur. Antes del huracán Katrina, la termita de Formosa era responsable cada año de unos US\$100 millones en daños a viviendas y negocios en el área de Nueva Orleans (EPA EE. UU., 2005). Tras el huracán Katrina, el Departamento de Agricultura y Silvicultura de Louisiana aprobó la Ley para combatir la termita de Formosa, una iniciativa de cuarentena para los escombros de la catástrofe (Departamento de Agricultura de Louisiana, 2005). La ley señalaba que "El huracán ha dejado millones de toneladas de desechos de madera, incluyendo desechos infestados de termitas de Formosa” y que "es necesaria la imposición de esta cuarentena para evitar la propagación de termitas de Formosa y la infestación de las zonas, los hogares y las estructuras que actualmente no están infestadas o que se van a construir o reconstruir".

Una de las prioridades a corto plazo es la gestión de residuos y escombros. En el caso del terremoto de 2008 en China Central, el tema de los residuos es un desafío. Se ha reportado que el ejército militar de China ha eliminado más de 8 millones de metros cúbicos de residuos del terremoto, suficiente como para llenar 16 veces el espacio interior del estadio olímpico "Nido de Pájaros" de Beijing (WRI, 2008). Además, la dispensación de tratamiento a la gran cantidad de heridos generó cantidades considerables de desechos médicos que exigían una cuidadosa eliminación. Por último, China Central es un importante fabricante de muchos productos químicos para la agricultura y varios informes de evaluación de los daños incluyen la liberación de productos químicos tales como fósforo y amoníaco en el medio ambiente (RSC, 2008).
Los desechos médicos y los escombros, sumados a las posibles filtraciones de las instalaciones de productos químicos, constituyen amenazas potenciales para el medio ambiente del que depende la gente para su alimentación, agua y refugio. La incapacidad de hacer frente a estas amenazas a los servicios de los ecosistemas en el corto plazo, retrasará, a largo plazo, el restablecimiento de los medios de subsistencia de las personas.

\section{PLANIFICACIÓN PARA LA RECUPERACIÓN A MÁS LARGO PLAZO}

La planificación para la recuperación a más largo plazo que se ocupa de las cuestiones ambientales es un enfoque eficaz en función de los costos. A medida que comienza la planificación inicial de la recuperación, las consideraciones ambientales deben basarse en tres elementos clave -el conocimiento, la capacidad y el apoyo de políticas.

\section{Conocimiento}

La comprensión de los impactos sobre el medio ambiente y, posteriormente, sobre los servicios prestados por los ecosistemas, es un paso importante en la planificación y el establecimiento de una línea de base para medir la eficacia de las acciones de recuperación. Los impactos de los eventos se suelen sentir más allá de la zona de impacto inmediata, hecho que debe contemplarse en las evaluaciones de impacto. Por ejemplo, el empleo de las personas puede depender de los recursos dentro de un área afectada aunque vivan a cientos de kilómetros de distancia.

La adopción de medidas eficaces exigirá no solo una sólida base de conocimiento sobre la situación ambiental al inicio de las acciones, sino también el monitoreo a largo plazo de los cambios de los ecosistemas en apoyo de una gestión adaptable. 


\section{Capacidad}

La capacidad para responder a cualquier desastre será un factor importante para el éxito. El gran alcance de la mayoría de los desastres significa que se requerirá la ayuda de todo el recurso humano disponible. La rehabilitación de los ecosistemas requerirá el apoyo de los pobladores de la zona y, con frecuencia, financiación gubernamental para los organismos de asistencia. La capacidad también incluye apoyo y participación pública para todas las acciones emprendidas. También serán necesarias campañas de concientización pública sobre la importancia de la función del medio ambiente en el apoyo a la recuperación.

\section{Políticas de apoyo}

De los desastres anteriores ya se han aprendido varias lecciones acerca de la necesidad de políticas de apoyo para la gestión ambiental a largo plazo. Por ejemplo, podría ser necesario establecer políticas sobre códigos de construcción en términos de tipos de zonificación para los diferentes tipos y materiales de construcción utilizados. Y, por supuesto, la obligatoriedad en cuanto a evaluaciones de impacto ambiental (EIA) para infraestructura de corto y largo plazo, es esencial. Asimismo, debido a que los desastres pueden generar varias zonas de entornos gravemente alterados, la rehabilitación podrá exigir el establecimiento y la ejecución de áreas protegidas como zonas de amortiguamiento.

Para el desarrollo de planes a más largo plazo se debe prestar atención a las siguientes políticas:

- Políticas sobre los ecosistemas que fomenten la heterogeneidad espacial y biológica al elegir los sitios y que también mejoren la resiliencia ecológica reestableciendo procesos ecológicos claves de los que dependen las comunidades agrícolas y naturales (por ejemplo, ciclos hidrológicos, ciclos de nutrientes y caudales); y

- Políticas socioeconómicas que apoyen el desarrollo de infraestructura que minimice el impacto sobre los ecosistemas y creen recursos nuevos y potencialmente sostenibles y contribuyan a la diversidad de los recursos económicos disponibles.

El conocimiento, la capacidad y las políticas pueden complementarse con una acción eficaz. Esa acción debe tomarse con base en un enfoque a escala del paisaje. La gestión a escala del paisaje actúa en una escala lo suficientemente amplia como para reconocer el papel crítico de todos los factores que influyen y los interesados directos que dan forma a las decisiones sobre el uso del suelo (McNeely y Scherr, 2003; Scherr y McNeely, 2007). Una adecuada gestión del paisaje llenará las necesidades de la sociedad con un equilibrio justo entre las necesidades productivas, sociales y ambientales del actual uso de la tierra.

Los enfoques basados en el paisaje deben incluir consideraciones concretas en torno a los caudales ambientales. Un caudal ambiental es el agua provista dentro de un río, humedal o zona costera para mantener los ecosistemas y sus beneficios (Dyson et al., 2003). El desarrollo de recursos hídricos aguas arriba tiene consecuencias para los medios de subsistencia de los usuarios y los ecosistemas aguas abajo. Los caudales ambientales adecuados hacen contribuciones fundamentales para la salud de los ríos, el desarrollo económico y la reducción de la pobreza. Garantizan la continua disponibilidad de los múltiples beneficios que los sistemas saludables de ríos y aguas subterráneas aportan a la sociedad. Esto es fundamental para el cumplimiento del Objetivo de Desarrollo del Milenio (ODM) 7 (sostenibilidad ambiental) y para el apoyo indirecto a la consecución de los ODM relacionados con la salud y la educación.

En la elaboración de planes de recuperación de los ecosistemas deben considerarse varias opciones. Muchos interesados directos están involucrados, desde los pobladores locales hasta los habitantes de la ciudad, dependiendo de los productos procedentes de la región, hasta los turistas internacionales que aportan valiosos 
ingresos. Cada uno puede desear algo diferente y las opciones de desarrollo elegidas deben equilibrar dichas exigencias. Existen herramientas para ayudar con este ejercicio, incluyendo el desarrollo de escenarios, la estimación de caudales, y la realización de evaluaciones estratégicas de impacto ambiental. En última instancia, sin embargo, los planificadores tienen que reconocer que es poco probable un resultado ideal en el que todos ganen, y tendrán que buscar la opción que más convenga a todos.

La experiencia en la recuperación de los ecosistemas de desastres naturales y amenazas provocadas por el hombre ha generado varios principios fundamentales que deben incorporarse en la planificación de la recuperación de un desastre:

- Aprovechar la oportunidad para hacer mejor las cosas

- No limitarse a planear para volver a crear lo que había antes

- Elegir las zonas más viables para trabajar

- No todas las zonas afectadas por el desastre necesitan una rehabilitación activa

- Crear un plan con flexibilidad para adaptarse

- Asumir que el plan cambiará a medida que se implementa

- No asumir una estrategia de "talla única"

- Evitar más daños al medio ambiente a través de las medidas adoptadas.

\section{LA INFLUENCIA DEL CAMBIO CLIMÁTICO EN LA PLANIFICACIÓN DE LA RECUPERACIÓN}

Por último, en la elaboración del plan de respuesta, será fundamental incluir los posibles impactos del futuro cambio climático, tanto en términos de adaptación como de mitigación. Las opciones de restauración deben incluir esfuerzos para mitigar las emisiones de gases de efecto invernadero (GHG), deben evitar medidas que podrían resultar en un aumento de las emisiones e incluir el diseño de medidas que ayuden a las comunidades afectadas a adaptarse a los cambios previstos en el clima.

Teniendo en cuenta estas lecciones aprendidas en la gestión de las respuestas a otros desastres, así como los conocimientos actuales de factores tales como los impactos del cambio climático, todas las medidas adoptadas como parte del plan de recuperación de desastres deben incluir la consideración de los ecosistemas. Esto podría incluir la adaptación al futuro a través de una cuidadosa consideración sobre cuáles especies son utilizadas para la reforestación y el cambio de ubicación de las aldeas a efectos de reducir la vulnerabilidad a futuras amenazas.

La plena recuperación de los desastres conlleva un inmenso esfuerzo coordinado y una inversión considerable de recursos. Pero es también una oportunidad para unir a las personas y crear un futuro mejor, que incluya la gestión sostenible de los servicios de los ecosistemas en apoyo del desarrollo y la oportunidad de tomar medidas para la mitigación y adaptación al cambio climático en el proceso.

La incidencia de los fenómenos extremos y los desastres, especialmente bajo la influencia del cambio climático, es una creciente preocupación para el medio ambiente. En la próxima década, la comunidad conservacionista debe aprender de las experiencias en torno a la adaptación al cambio climático basada en los ecosistemas y aplicarlas para ayudar a reducir la vulnerabilidad de las personas a los fenómenos extremos. Debemos también promover una mejor gestión de los servicios de los ecosistemas que protegerán a las comunidades de los eventos naturales extremos y ofrecer opciones productivas para la reconstrucción y la adaptación. 


\section{Salud Humana y Biodiversidad: \\ 11. Cómo Puede Contribuir la Conservación}

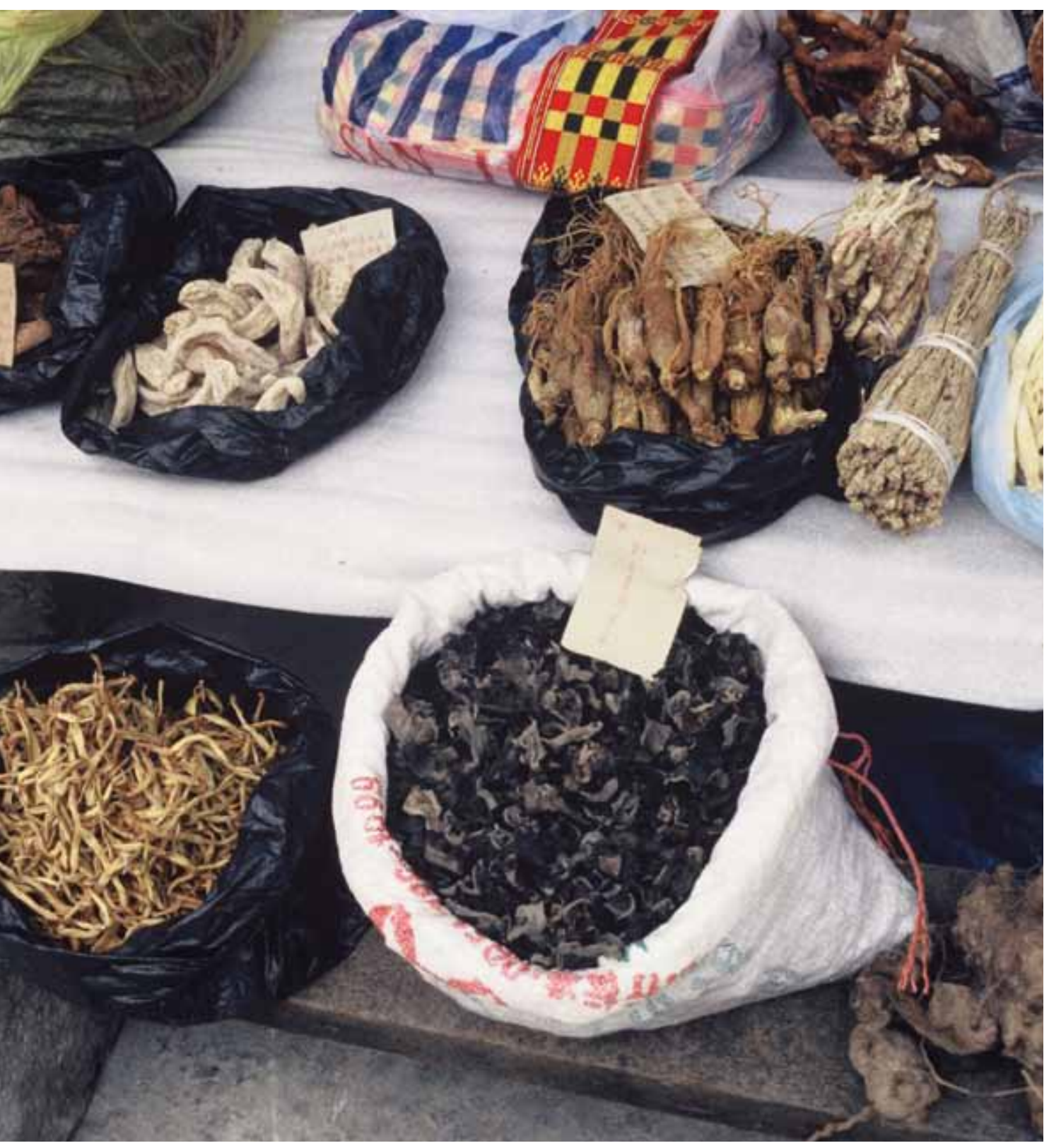


Hubo un momento en el siglo $X X$ en que parecía que las enfermedades transmisibles habían sido derrotadas o, al menos, controladas. Pero hoy día, la pandemia del SIDA continúa, más agentes infecciosos se están haciendo resistentes a los antibióticos, un número cada vez mayor de enfermedades endémicas están surgiendo en lugares en los que antes estaban controladas, los agentes patógenos se están propagando, y nuevas enfermedades están emergiendo con más rapidez de lo que las sociedades pueden responder.

A medida que la situación sanitaria mundial se torna más alarmante, la relación entre la salud y la biodiversidad está siendo objeto de mayor atención (Chivian y Bernstein, 2008). ¿Cuáles son los vínculos entre la salud, el cambio climático y la biodiversidad? ¿Podemos crear respuestas políticas más eficaces mediante la investigación de los vínculos? ¿Pueden las alianzas entre los científicos y los responsables de la formulación de políticas relacionadas con estos sectores encontrar un terreno común que conduzca a una acción más eficaz?
La vida urbana y la tecnología moderna han disminuido la conciencia pública sobre el hecho de que la continuación de la buena salud humana depende de un medio ambiente natural saludable. Por otro lado, la investigación médica moderna ha tendido a centrarse en los comportamientos de riesgo individuales u organismos únicos causantes de enfermedades. Poca atención se está prestando a las influencias sobre la salud que actúan a nivel de la población, como la calidad del agua y del suelo, contaminantes que pueden causar cambios en el sistema inmunológico, productos químicos orgánicos que perturban el sistema endocrino y aumentan el riesgo de ciertos tipos de cáncer, o cambios en el clima que pueden influir en la propagación de los vectores de ciertas enfermedades como los mosquitos que transmiten la fiebre del dengue o el paludismo.

Estos factores también deben ser considerados en los enfoques más amplios para la salud humana.

Pese a ser parte de la economía mundial, muchas personas todavía piensan que la salud es un asunto fundamentalmente personal, con la prevención y la cura centradas en el individuo. Pero la salud es también una característica de las poblaciones, y la consideración del tema desde una perspectiva más amplia y holística de la sociedad, puede llevar en una dirección muy diferente. Por supuesto, es el individuo quien finalmente contrae las enfermedades, pero el riesgo de hacerlo se ve significativamente determinado por el contexto sociológico y ecológico en que vive la población. 
Las enfermedades infecciosas que emergen a raíz de la destrucción y fragmentación de los bosques tropicales y otros ecosistemas (como el virus del ébola), los vínculos entre las enfermedades de la vida silvestre y el hombre (como el virus del Nilo Occidental), los muchos productos farmacéuticos conocidos y aún por descubrir que se encuentran en la naturaleza, la contribución de los ecosistemas para la salud humana, el reconocimiento cada vez mayor de los alteradores endocrinos tanto en la salud humana como en la salud animal, y los efectos del cambio climático sobre los ecosistemas, todo ello confirma la importancia de la biodiversidad en el conjunto de cuestiones relacionadas con la salud.

Los componentes de la biodiversidad pueden ser a la vez aliados y enemigos de nuestra salud. Las bacterias y los virus pueden causar enfermedades; grandes carnívoros, criaturas venenosas y plantas pueden matarnos; conflictos con pequeños herbívoros como las ratas y grandes herbívoros como los elefantes pueden socavar nuestros sistemas de producción de alimentos, minando así nuestra nutrición; y las especies no nativas pueden incluir algunas que pongan en peligro nuestra salud.

Superiores a los impactos negativos de la biodiversidad en la salud humana son sus beneficios, como en el caso de las medicinas provenientes de plantas y animales, y de los servicios de los ecosistemas que proveen agua y aire limpios. Si bien muchos estudios se centran en los beneficios de las especies vegetales y animales para la salud, otros aspectos de la biodiversidad son también importantes para la salud humana. La naturaleza puede ser una fuente de salud mental y física, especialmente para los jóvenes (Louv, 2005). Sin embargo, algunas de nuestras acciones de hoy amenazan nuestra salud de mañana e incluso del futuro. La degradación ambiental por la pérdida de hábitats, la sobreexplotación y el cambio climático pueden tener consecuencias para la salud humana y el bienestar.

\section{BIODIVERSIDAD: CÓMO PUEDEN CONTRIBUIR LAS ESPECIES VEGETALES Y ANIMALES A LA SALUD}

Nuestra comprensión de la biodiversidad medicinal se basa en las especies. El papel de las especies en la salud humana varía desde fuentes directas de medicamentos hasta la provisión de modelos para la investigación. Por otro lado, la forma en que gestionamos la biodiversidad (incluidos nosotros mismos) puede tener consecuencias para la salud humana.

\section{Un aliado de la salud}

Unas 50.000-70.000 especies de plantas se utilizan en medicamentos, de las cuales 15.000 se encuentran amenazadas (Schippman et al., 2006). La fabricación y producción de productos farmacéuticos derivados de plantas medicinales pueden ayudar a la salud humana y a la conservación de la biodiversidad vegetal. Alrededor del $80 \%$ de la población mundial usa remedios y fármacos que contienen agentes vegetales naturales, muchos originarios de sus propios países. El comercio mundial de plantas medicinales se ha incrementado en un $85 \%$ desde 1991, aunque la gran mayoría del comercio supone solo alrededor de una docena de países.

Las especies medicinales forman parte de la farmacopea de la medicina tradicional y la “medicina occidental”. Los tratamientos para los problemas de salud como la obesidad se están tratando a través de plantas medicinales procedentes de África, como Hoodia sp. La conexión con el mundo natural es una parte integral de gran parte del conocimiento indígena tradicional. Se ha constatado que muchas prácticas sanitarias tradicionales tienen beneficios cuantificables y pueden seguir ayudando a conducir a descubrimientos de plantas o animales medicinales. 
El conocimiento tradicional (CT) relacionado con la salud que poseen los hombres y

las mujeres suele ser diferente. Un estudio etnobotánico realizado en el Parque Nacional de Jaú, en Brasil, determinó que las parteras tenían conocimiento sobre ciertas plantas en tanto que los hombres dedicados a la medicina tradicional tenían conocimiento sobre otras. En la comunidad de Los Guatuzos en Nicaragua, cuando se les preguntó sobre el tipo de plantas medicinales que se encontraban en sus parcelas de tierra y en el bosque, los hombres pidieron a sus esposas responder la pregunta (Azofeifa, 2003, citado en Rodríguez, Blanco, y Azofeifa 2004).

Muchos animales también proveen importantes modelos para la investigación en la salud humana, como las consecuencias para la osteoporosis de la hibernación de los osos que no pierden masa ósea (Chivian y Bernstein, 2008). Los animales también poseen fisiologías únicas que están proporcionando información valiosa que podría mejorar la salud humana, tales como las ranas de incubación gástrica, que ayudan a entender las úlceras pépticas (si bien estas ranas pueden ya haberse extinguido). Muchos animales también proporcionan medicamentos derivados de toxinas utilizadas para el ataque (por ejemplo, de serpientes venenosas y caracoles cónicos) o para la defensa (anfibios).

\section{Un reto para la salud}

Nuestra especie alberga más microorganismos en nuestro cuerpo que células humanas. De esta cantidad asombrosa, más de 1400 especies podrían ser patógenas para los seres humanos en al menos algunas condiciones. Incluyen por lo menos 217 virus y priones, 538 bacterias y rickettsias, 307 hongos, 66 protozoos y 287 helmintos (Chivian y Bernstein, 2008). Si bien la mayor parte del tiempo nuestro cuerpo depende de estos microorganismos para un funcionamiento saludable, tal abundancia y diversidad también es campo fértil para la aparición de nuevas enfermedades. Los seres humanos albergamos tal diversidad de organismos porque somos excelentes hospedantes de distribución mundial al viajar mucho más ampliamente y ocupar más tipos de ecosistemas que cualquier otra especie.

A medida que más microorganismos entran en contacto unos con otros, ya sea a través de los viajes o cambios en los ecosistemas, emergen nuevas enfermedades. Por ejemplo, casi 190 nuevas especies de arbovirus y otros virus se identificaron en la Amazonia brasileña entre 1954 y 1998 (Vasconcelos et al., 2001). La Amazonia brasileña es muy rica en arbovirus, lo que refleja la riqueza de su biodiversidad en general. Se sabe muy poco sobre la mayoría de estos virus. Los tipos de cambios ambientales que conducen a la pérdida de la biodiversidad -a saber, la deforestación, la minería, la construcción de represas y carreteras, la colonización y la urbanización- han sido los principales cambios ambientales asociados con la aparición y reemergencia de los arbovirus, incluyendo algunos agentes patógenos conocidos para los seres humanos. Otras enfermedades también pueden ser efecto secundario de la pérdida de biodiversidad.

El cambio de las relaciones ecológicas puede aumentar los riesgos epidemiológicos a través de la introducción de nuevos patógenos a nuevas poblaciones. Por ejemplo, a medida que los seres humanos se extienden a más zonas de anidación de aves silvestres, pueden aumentar las oportunidades para el intercambio genético. Un mecanismo particularmente preocupante es el intercambio genético entre los virus que infectan a las personas y los que infectan a los animales domésticos o silvestres, recogiendo ambos virus genes el uno del otro, lo que a su vez permite al virus producir una nueva capa exterior y así 
evadir el sistema inmunológico humano. Este es el principal mecanismo por el cual surgen las pandemias de gripe, que a menudo son producto de un virus de la gripe que infecta a los seres humanos y otro que es transportado por los patos, incluidos los patos silvestres y otras especies de aves.

Algunos programas de lucha contra enfermedades dirigidos a los microorganismos, incluso si tienen éxito, podrían socavar la salud en general si interrumpen sistemas ecológicos. Un ejemplo de ello es la aplicación de DDT para eliminar a los mosquitos vectores del paludismo. Una consecuencia no deseada fueron las interacciones interrumpidas entre los insectos polinizadores, la reducción en la reproducción de algunas especies de aves y la reducción en la producción de alimentos. Los proyectos de desarrollo agrícola, destinados a mejorar la salud a través de una mejor nutrición, también pueden afectar los ecosistemas alterando los patrones de las enfermedades. Al promover la salud sostenible debe tenerse en cuenta las múltiples escalas y perspectivas y los altos grados de incertidumbre, mediante la adopción de un enfoque por ecosistemas para abordar cuestiones relacionadas con el tema de la salud.

La Organización Mundial de la Salud (OMS) (2002) informó de que los peligros ambientales son responsables de aproximadamente el 25\% de la carga total de morbilidad en todo el mundo y hasta un 35\% en el África subsahariana. La mejora de las condiciones ambientales podría salvar hasta 13 millones de vidas por año. Una mejor gestión ambiental podría prevenir el 40\% de muertes por paludismo, $41 \%$ de muertes por infecciones del aparato respiratorio inferior, y $94 \%$ de las defunciones por enfermedades diarreicas -tres de los principales asesinos de niños en el mundo. Garantizando la salud de los ecosistemas también puede ayudar a disminuir la vulnerabilidad de la población a los impactos de fenómenos naturales extremos.

Los impactos sobre la salud humana relacionados con la biodiversidad pueden verse agravados por otras amenazas. Por ejemplo, la globalización, con un número cada vez mayor de viajeros y mercancías comercializadas a nivel mundial, está ampliando las áreas de distribución de muchos virus que son potencialmente peligrosos para los seres humanos. Y el cambio climático tiene impactos en la biodiversidad -las distribuciones cambiantes y los cambios de los patrones de lluvia tienen efectos secundarios sobre la salud humana, incluyendo los cambios en la distribución de vectores de enfermedades, así como los cambios en el suministro de alimentos y agua. Patz et al. (2004) dan cuenta de los vínculos entre el cambio en el uso del suelo y la aparición de enfermedades infecciosas, haciendo hincapié en la necesidad de una perspectiva más amplia sobre el uso de la tierra en razón de las complejas relaciones entre ecosistemas en un paisaje.

\section{LA BIODIVERSIDAD AL SERVICIO DE LA SALUD HUMANA}

Todos los servicios de los ecosistemas apoyan la salud humana. Esto incluye la provisión de servicios en forma de medicamentos y alimentos, servicios de apoyo en forma de suelos para la alimentación y una mejor nutrición, la regulación de los servicios para una adecuada provisión de agua y aire de calidad, y servicios culturales en apoyo de la salud mental. La investigación ha demostrado que la interacción con la naturaleza tiene un efecto calmante en las personas, y el tiempo en el exterior puede restablecer la salud, aliviar las tensiones y darle equilibrio a la vida. Estos valores derivados del contacto con la naturaleza son universales y no se limitan a los países “desarrollados”. Cuando a las personas se 
les pide que imaginen un lugar tranquilo, la gran mayoría cita un lugar en la naturaleza como la playa, un bosque o un lago.

El reconocimiento acerca de cómo los cambios en el mundo actual pueden afectar la biodiversidad y la salud es crucial para reconocer dónde pueden presentarse amenazas y cómo responder a ellas. Los conservacionistas pueden contribuir a través de la valoración de las plantas medicinales y la promoción de la investigación y el uso sostenible de especies nativas que son relevantes para la industria de la salud, reconociendo el impacto de la naturaleza sobre todos los aspectos de la salud y centrándose en las políticas relacionadas con la biodiversidad.

La protección de las plantas medicinales involucra diversos tipos de interesados directos. Los interesados en la conservación de la naturaleza se centran principalmente en la protección del hábitat, la recolección sostenible de especies silvestres, los controles adecuados sobre el comercio, y así sucesivamente. Aquellos con intereses sociales buscan el reconocimiento de los conocimientos tradicionales e ingresos confiables y suficientes para los agricultores. Para quienes el principal interés es de carácter comercial se ocupan de las normas de calidad, un comercio próspero y una industria de transformación rentable para un comercio lucrativo.

La OMS, junto con la UICN, WWF y TRAFFIC, ha elaborado directrices para la conservación de especies medicinales (1993). Además, el reciente Estándar Internacional para la Recolección Silvestre Sostenible de Plantas Medicinales y Aromáticas (ISSCMAP) (Grupo especialista de la CSE/UICN en plantas medicinales, 2007), creado mediante una asociación de colaboración entre interesados de la industria, la conservación, la comunidad y el gobierno, con base en las directrices de 1993 y en las Directrices de la OMS sobre buenas prácticas agrícolas y de recolección de plantas medicinales (BPAR) (OMS, 2003), es un medio importante para un futuro enfoque de colaboración para el uso y el comercio sostenible de plantas medicinales y aromáticas silvestres.

Los vínculos entre la salud humana y animal también están siendo explorados por los conservacionistas. La iniciativa Salud animal para el ambiente y el desarrollo (AHEAD) fue lanzada por la Wildlife Conservation

Society, la UICN y sus asociados en el Quinto Congreso Mundial de Parques en 2003. Desde entonces, AHEAD ha reunido a diversas partes interesadas en el Sur de África para examinar el nexo a nivel del paisaje representado por el triángulo formado por la salud de la vida silvestre, la salud de los animales domésticos y la salud humana y los medios de subsistencia, apoyado por la responsabilidad ambiental.

Especial atención ha merecido la Gran Área de Conservación Transfronteriza de Limpopo (TFCA), donde AHEAD ha estado apoyando el diálogo y la planificación multidisciplinaria sobre la gestión de las enfermedades de la fauna silvestre y el ganado (incluidas las zoonosis -las enfermedades transmisibles entre los animales y las personas) en el paisaje transfronterizo. Los corredores en las áreas de conservación transfronteriza sirven no solo para conectar los animales y las personas sino también para facilitar un "puente biológico" para los agentes 
patógenos y vectores que transportan. La necesidad de un enfoque holístico para tan gran escala de actividades de uso del suelo y planificación no puede ser más urgente. En las TFCA como la del Gran Limpopo, por primera vez en décadas se están eliminando las cercas para permitir el acceso de la fauna silvestre y el ganado a las zonas y entre sí. Si bien esto supone un hito potencial para la conservación y los ingresos provenientes del turismo ecológico (fotográfico, caza, etc.), también exige un examen más detallado de algunas de las implicaciones. ¿Qué efectos podrían tener estas zonas transfronterizas en la salud y la sostenibilidad de la vida silvestre, los animales domésticos y las comunidades humanas? AHEAD, un mecanismo de convocatoria y facilitación, está trabajando activamente para crear entornos favorables que permitan a los diferentes sectores sentarse literalmente a la misma mesa y buscar vías de colaboración para hacer frente a esos desafíos y no considerar la salud y las enfermedades en forma aislada, sino dentro del contexto socioeconómico y ambiental de la región (Osofsky et al., 2005).

El crecimiento de la población humana, la globalización y el comercio internacional, y el cambio climático están acelerando la pérdida de hábitats, la introducción de nuevas cepas de enfermedades, y cambiando la manera como los sistemas naturales se regulan a sí mismos. Es posible que una mayor diversidad de especies con funciones similares dentro de un ecosistema mejore la probabilidad de que los procesos de los ecosistemas se mantengan frente a los cambios ambientales. Desde una perspectiva de la salud humana, a mayor diversidad en un ecosistema, mayor será la probabilidad de continuación de los servicios de los ecosistemas de los que depende nuestra salud.

Considerando la biodiversidad desde la óptica de la salud humana puede ayudar a proporcionar nuevas perspectivas sobre la política y la práctica de la conservación de la biodiversidad con miras a apoyar la salud humana. Asimismo, la conservación de la biodiversidad para la salud humana puede ayudar a atraer más adeptos a las prácticas de conservación. Al demostrar los vínculos de la biodiversidad para la salud humana se coloca la conservación en el centro de las preocupaciones humanitarias.

Considerando la obvia importancia de todos los componentes de la biodiversidad para la salud humana, en la próxima década la conservación de la biodiversidad que apoya el mantenimiento o la mejora de la salud humana requerirá un mayor intercambio de conocimientos, ampliación de asociaciones de colaboración y la gestión de los recursos de la biodiversidad a escala del paisaje y la implementación de políticas y directrices, como las de ISSC-MAP, dirigidas a la conservación de la biodiversidad medicinal. 
12. Desarrollo de una Economía "Verde"

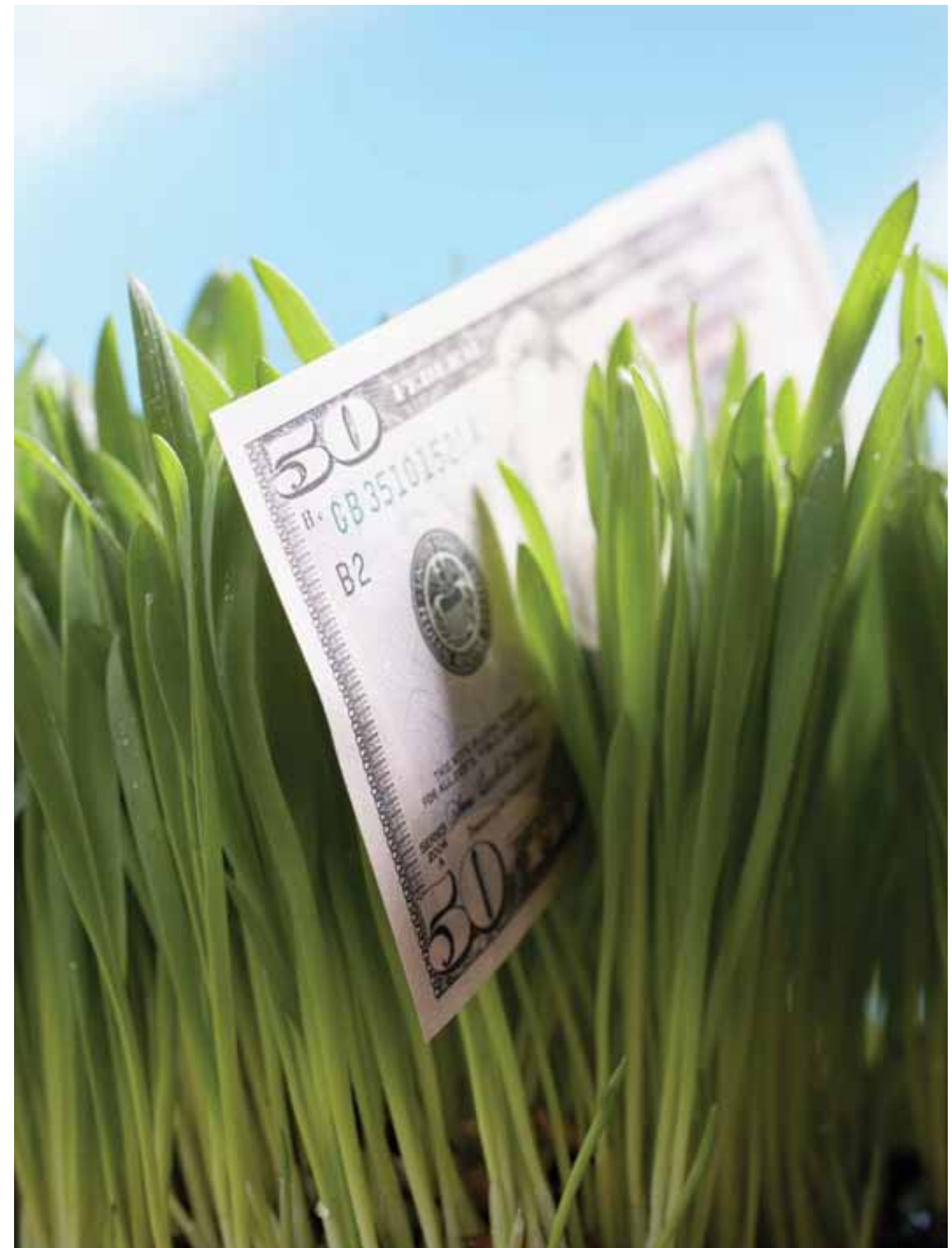


La crisis financiera de 2008 y la posterior respuesta de los rescates financieros y las medidas de austeridad han tenido algunas consecuencias potencialmente alentadoras para los conservacionistas: con un sistema listo para el cambio puede encontrarse más espacio para una economía verde. Pero la preocupación por el colapso del sistema económico está desviando la atención de otro sistema que está al borde del colapso: el ecosistema global.

El cambio climático, la pesca en vías de agotamiento, la disminución del acceso a agua dulce, los ecosistemas degradados más allá de la reparación, y la letanía continúa, como lo recoge la Evaluación de los Ecosistemas del Milenio (EM). El mismo modelo de crecimiento que llevó a la crisis financiera está dando lugar a una crisis ecológica de proporciones devastadoras. Un modelo de crecimiento que desafía los límites y externaliza los costos no es sostenible. La Madre Naturaleza, a diferencia de los gobiernos, no hace "rescates".

El sistema operativo actual para la economía monetaria se basa en la producción no sostenible de energía y bienes materiales y en el consumo de los productos resultantes y los servicios que van con ellos. Las personas han sido felices con el consumo y, de hecho, muchos quieren más de él. Sin embargo, los impactos del consumo insostenible sobre el medio ambiente son cada vez más conocidos y los consumidores están empezando a reaccionar. National Geographic, en colaboración con GlobeScan, ha desarrollado el indicador Greendex para medir las opciones de los consumidores y el medio ambiente. Su informe de 2009 facilitó información sobre 17 países, de los cuales India y Brasil son los consumidores más conscientes del medio ambiente, mientras que los consumidores canadienses y los estadounidenses se encontraban en la parte inferior de la lista (figura 12.1).

¿Cómo puede hacerse el consumo neutral con el medio ambiente a escala mundial y no solo en los países con la calificación más alta en Greendex? Este es el desafío fundamental para una economía verde. A nivel individual, la vida sostenible se basa en la gestión de nuestro consumo personal para no someter a la Tierra a un exceso de estrés. En el otro extremo de la escala, la sostenibilidad para una empresa es una cuestión de devolverle a la Tierra más de lo que se le quita. La economía verde reconoce que el medio ambiente, la economía y la sociedad son parte del mismo equilibrio. La salud de la economía, basada en el consumo y la producción, yace en el equilibrio con la salud del medio ambiente. 
GREENDEX: CLASIFICACIONES GENERALES CONSUMIDORES EN CADA PAÍS, 2008-2009

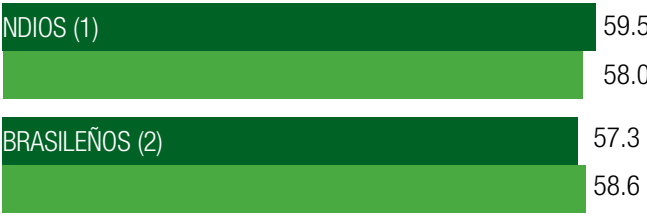

CHINOS (3) 56.7
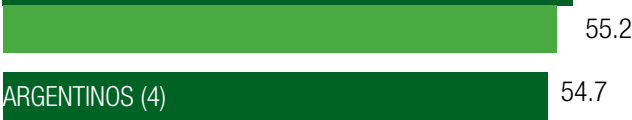

NA
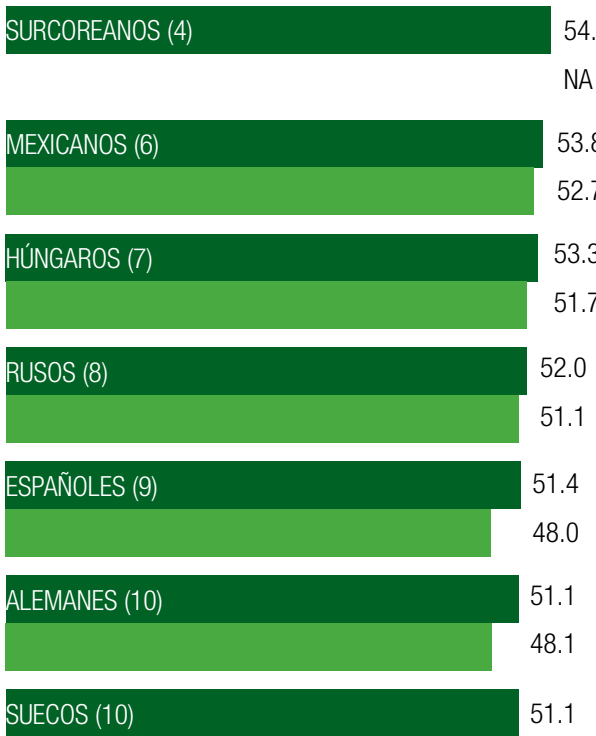

NA
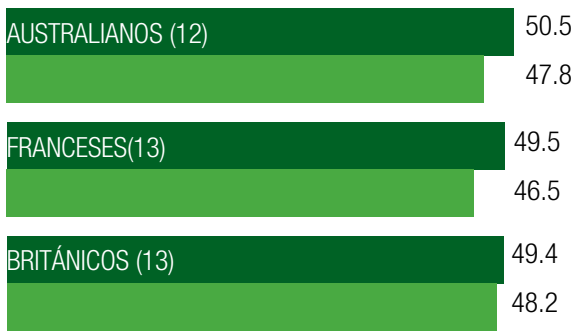

JAPONESES (13)
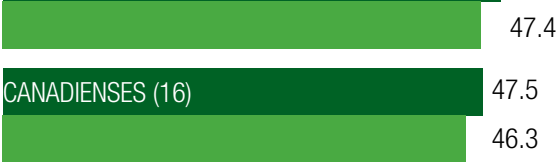

NORTEAMERICANOS (17) 43.7 42.4

\section{MEDICIÓN DE LA SOSTENIBILIDAD}

Un elemento importante para una Tierra más equilibrada y saludable es alejarse de la utilización de los recursos naturales como el motor del crecimiento económico. Al incluir el medio ambiente y los servicios de los ecosistemas en el cálculo de la economía mundial, se pueden usar instrumentos económicos para apoyar el medio ambiente y la protección y conservación de este. Pero la forma en que actualmente medimos el progreso, a través del Producto Interno Bruto (PIB), el Índice de Desarrollo Humano (IDH), y otros indicadores similares, no refleja adecuadamente la contribución del medio ambiente.

El impacto ambiental del exceso de consumo en los países desarrollados es mayor porque los precios de los bienes naturales y servicios no reflejan correctamente la realidad de los costos para los ecosistemas y el medio ambiente en general. Las personas adineradas hacen daño al medio ambiente a través de sus prácticas adquisitivas, impulsando fuerzas de mercado que agotan los recursos naturales tanto a nivel nacional como en el mundo en desarrollo, donde las normas ambientales a menudo están ausentes o se aplican a medias.

\section{HERRAMIENTAS PARA LA TRANSICIÓN A UNA ECONOMÍA VERDE}

\section{Valoración del medio ambiente}

La comprensión del valor del medio ambiente para nuestra economía, así como los costos de la inacción o de no atender su conservación, es objeto creciente de estudio económico. Ten Brink (2008) ha estimado que si no detenemos la

2009 Nota: Las calificaciones de Greendex para 2008 han sido recalibradas de forma que no ha afectado el significado de los resultados generales. 
pérdida de biodiversidad hoy, el costo mundial para el bienestar humano en el 2050, como resultado de la pérdida de bienes y servicios forestales podría ascender a 14 millones de billones de euros (7\% del PIB mundial).

\section{La Economía de los Ecosistemas y la Biodiversidad} (TEEB, capítulo 4) tiene por objeto mejorar la comprensión de los costos reales del consumo, así como los problemas de las externalidades en las modernas cadenas de suministro y sistemas de producción (TEEB, 2008). Las cadenas de suministro son los productores primarios interrelacionados, fabricantes y distribuidores que compran y venden entre sí con el fin de entregar los productos terminados a los consumidores. Los gerentes de las cadenas de suministro que buscan la optimización de costos a veces encuentran ahorros negándose a pagar la totalidad de los costos de la producción sostenible. Los ejemplos incluyen el dinero "ahorrado" al no tratar el agua contaminada, o por no compensar los sumideros de carbono perdidos durante el desbroce de tierras. Estos son costos reales que deben reflejarse en las cadenas de suministro y, en última instancia, trasladarse a los compradores, a efecto de que los consumidores entiendan el valor de los servicios de los ecosistemas que intervinieron en la producción de los productos que adquieren.

\section{INCENTIVOS - BUENOS Y MALOS}

Los mecanismos de mercado utilizados para apoyar la conservación son muy variados y van desde sencillos sistemas de fijación de precios del agua hasta sofisticados fondos de protección del medio ambiente. Idealmente, cualquier mecanismo financiero de este tipo, en lugar de limitarse a proporcionar una financiación única, debe funcionar como un incentivo sostenido para la conservación. Al contabilizar la función a largo plazo de los ecosistemas a través de esos mecanismos, la sostenibilidad se incorpora en las decisiones económicas. Por supuesto, esos sistemas solo funcionan eficazmente si se basan en normas creíbles y en sistemas de verificación e implementación.

\section{Compensaciones}

Una compensación es una medida adoptada para contrarrestar o compensar los efectos de otras acciones. Para el cambio climático, el programa de compensación de carbono más conocido es el Protocolo de Kioto de 1997 (y en particular el Mecanismo para un desarrollo limpio-MDL), que fue concebido para permitir que los países con compromisos de control de emisiones pudieran implementar algunas de sus necesidades de reducción de emisiones en los países en desarrollo. Si bien el MDL está diseñado para ayudar a cumplir los compromisos intergubernamentales, en virtud de un marco jurídico vinculante, también existen los mercados voluntarios de carbono que, en 2008, casi se duplicaron en términos del volumen y valor del carbono comercializado, en comparación con 2007, con un valor total de mercado de US\$705 millones en 2008 (Hamilton et al., 2009).

Las compensaciones también se han aplicado en algunos casos a las especies y hábitats. Estas últimas aplicaciones son relativamente nuevas, pero el Programa de Compensaciones de Negocios y Biodiversidad (BBOP) está tratando de definir principios y metodologías en apoyo de mejores prácticas en la compensación voluntaria de biodiversidad (BBOP, 2009).

\section{Pagos por los servicios de los ecosistemas (PSE)}

Los pagos por los servicios de los ecosistemas (PSE) han sido mencionados con frecuencia en este estudio como un importante medio para reflejar el valor de los beneficios que las personas reciben de la naturaleza (Wunder, 2005). Uno de los sistemas de PSE aplicados en varios países, especialmente en América Latina, es el pago para la protección de cuencas hidrográficas. A medida 
que los consumidores son más conscientes de los muchos servicios prestados por las cuencas hidrográficas (calidad y cantidad del agua para cubrir las necesidades del uso industrial, doméstico y recreativo), crece la motivación de pagar para su conservación (Smith et al., 2006). Estos pagos pueden incluir pagos por parte de los usuarios particulares del agua a los organismos ambientales y ONG de conservación, así como pagos directos por parte del gobierno central a los propietarios particulares. La experiencia indica que los pagos para la protección de las cuencas hidrográficas son más apropiados cuando:

- la compra directa de recursos es muy costosa (e innecesaria);

- los pagos son menos costosos que las soluciones técnicas alternativas (e.g. infraestructura);

- la provisión del servicio deseado es verificable y aplicable;

- los costos de transacción no son prohibitivos; y

- alguien está dispuesto a pagar el precio (Kousky, 2005).

El desarrollo y la aplicación efectiva de los mercados para los servicios de los ecosistemas se ven limitados por varios factores, incluyendo instituciones de mercado débiles, derechos de propiedad especialmente mal definidos, la falta de reconocimiento de responsabilidad por los daños ambientales, ausencia de recompensa por contribuciones positivas para la salud de los ecosistemas, y débil capacidad de regulación (Bishop et al., 2009).

\section{Certificación}

Las normas y los sistemas de certificación relacionados con la biodiversidad son considerados en forma creciente como herramientas importantes para mejorar el desempeño medioambiental de las empresas. Los sistemas de certificación suponen que los consumidores prefieren comprar o incluso pagar más por bienes y servicios certificados. Ya la certificación es una parte importante de varios sectores incluyendo la agricultura, la silvicultura, el turismo y los servicios financieros (Bishop et al., 2009). El valor de los productos certificados es sustancial y va en aumento, incluido el valor del mercado mundial de productos orgánicos de US\$23 mil millones (2002) (Willer y MinouYussefi, 2006). Del mismo modo, el volumen de la producción certificada también es cada vez mayor; por ejemplo, la extensión forestal certificada aumentó de 5,8 millones de hectáreas en 1998 (www.earthtrends.org) a más de 300 millones de hectáreas en todo el mundo a mediados de 2008, con la mayoría en la región de la UNECE, impulsada por sistemas de construcción y políticas de contratación pública ambientalmente responsables (UNECE y FAO, 2008)

\section{Subvenciones e incentivos fiscales}

Los incentivos económicos para la conservación de la biodiversidad se han utilizado durante décadas (McNeely, 1988), pero este uso ha sido relativamente modesto y debe ser significativamente mayor (como se pide en el artículo II del Convenio sobre la Diversidad Biológica (CDB) (CBD, 2004a). En varios países los incentivos para fomentar la conservación de los recursos han incluido subvenciones e incentivos fiscales, por ejemplo, en forma de desgravaciones fiscales sobre donaciones a obras de caridad. Este mecanismo ha servido de motivación para donaciones de tierras en los Estados Unidos y Europa para la protección de millones de hectáreas (The Trust for Public Land, 2009; Bräuer et al., 2006).

Sin embargo, el potencial para impactos negativos derivados de incentivos tales como las subvenciones está tipificado en la situación actual con respecto a la pesca mundial. En 2000, se estima que se pagaron US\$26 mil millones en subsidios en el sector pesquero, 
de los cuales US\$16 mil millones eran para aumentar la capacidad de pesca en un mundo en el que la mayoría de las pesquerías ya están sobreexplotadas (capítulo 17) (Sumaila y Pauly, 2006).

\section{HACIENDO DE LA INVERSIÓN EN LA GESTIÓN DE RECURSOS NATURALES SOSTENIBLES UN FACTOR DETERMINANTE PARA EL CRECIMIENTO}

Los recursos naturales han sido la base para el crecimiento económico. Cuando este crecimiento es mal gestionado o se gestiona sin control alguno, ha provocado pobreza, conflictos y degradación ambiental a largo plazo. Históricamente, gran parte del colonialismo fue impulsado por la búsqueda de recursos naturales, principalmente en beneficio de las potencias coloniales. Ejemplos más recientes incluyen la producción de cobre, cobalto y coltán en la República Democrática del Congo, la extracción de diamantes en Sierra Leona, y la perforación de petróleo en Nigeria.

Gran parte de esta degradación de los recursos naturales obedece a la mala gobernanza. Incluso países con una gobernanza sólida importan recursos para la fabricación y la producción de energía, señal inequívoca de que la producción no es sostenible a nivel local y fuerte justificación para el comercio mundial. La gestión sostenible de los recursos naturales en los planos local y mundial tiene el potencial para el apoyo a largo plazo del crecimiento económico a favor de los pobres y, por consiguiente, del logro de objetivos de desarrollo más amplios.

El uso de los recursos naturales puede contribuir a la reducción de la pobreza y a la salud y el bienestar de las personas. El capital natural es esencial para la preservación del capital humano. La OCDE (2008) llama a esto "capital natural crítico" -el umbral del capital natural necesario para la existencia de otro capital, como el capital humano. Los agricultores de subsistencia que son
Recuadro 12.1 Diamantes para el desarrollo: el caso de Botsuana

Botsuana ha estado usando la riqueza de sus recursos naturales (diamantes) para la reducción de la pobreza, mediante el establecimiento de un Fondo de Estabilización de Ingresos y un Fondo de Servicio de Deuda Pública. Si bien los diamantes no son un recurso renovable, el capital humano sí lo es. Mediante el desarrollo de su industria de transformación de diamantes y el aumento de la diversificación económica, y la canalización de los ingresos fiscales del sector de los minerales a los sectores de educación y salud, Botsuana ha sido capaz de reinvertir los beneficios obtenidos de la industria de los diamantes mejorando el país a través del desarrollo de instituciones comunitarias, empoderamiento local, identidad y cultura local, y reducción de la dependencia del apoyo gubernamental. Todo esto, a su vez, ha reducido la presión sobre el medio ambiente, al no verse las personas impulsadas a explotar los recursos naturales para la subsistencia.

Source: PEP, 2005

expertos en los procesos agrícolas son un ejemplo. Una vez colapsada la fertilidad del suelo, estos agricultores no podrán continuar cultivando, por lo que perderán las destrezas humanas junto con el capital natural en el suelo. Para garantizar que los recursos naturales apoyen el crecimiento y lo sostengan y contribuyan a sacar a la gente de la pobreza, los países en desarrollo están buscando usos eficientes, equitativos y sostenibles de los recursos naturales (recuadro 12.1).

\section{OTRA OPCIÓN: DESARROLLAR UN NUEVO SISTEMA ECONÓMICO}

Los instrumentos económicos arriba mencionados persiguen la incorporación de los costos ambientales en las políticas 
macroeconómicas. Aunque muchos aplauden estos pasos hacia el acercamiento de los sistemas naturales y monetarios, otros se preocupan de que la economía actual se basa en el modelo de crecimiento perpetuo, e independientemente de cuánto modifiquemos el modelo, estamos inevitablemente transitando por un camino insostenible (por ejemplo, Speth, 2008). El actual modelo llegará pronto al punto donde la economía estará superando la capacidad de la Tierra para sostenerlo. Estamos viviendo más allá de nuestra capacidad de carga (recuadro 12.2).

Muchas personas (aunque no necesariamente la mayoría de los economistas) creen que el mundo debe invertir en un nuevo sistema, uno que no implique incentivos perversos para un crecimiento insostenible. El mundo necesita un sistema que cambie los hábitos de consumo de las personas, que invierta en infraestructura verde (es decir, tanto en términos de las inversiones en el medio ambiente como infraestructura fundamental, como en infraestructura física construida en formas ambientalmente responsables) y uno que piense estratégicamente acerca de cómo queremos vivir en este frágil
Recuadro 12.2 Más allá de la capacidad de carga

En noviembre de 2005, la Agencia Europea de Medio Ambiente publicó su "Informe del Medio Ambiente en Europa 2005”. Llegó a la conclusión de que para apoyar a Europa se requiere 2,1 veces su capacidad biológica. Con una población que asciende a 7\% del total mundial, su demanda sobre la capacidad ecológica mundial es de casi el 20\% de la productividad global. Esa capacidad biológica para Europa proviene del resto del mundo. ¿Cuál sería un precio justo por este exceso de demanda y cómo se pagaría?

Fuente: PEP, 2005

planeta. Los sistemas colapsantes del mundo hacen dolorosamente patente que ha llegado el momento de un cambio fundamental. Entre los modelos propuestos se incluye una "economía circular" articulada en China mediante la cual se persigan objetivos económicos y ambientales en tándem y "los residuos de una instalación sean los insumos de otra instalación” (Pinter, 2006). McDonough y

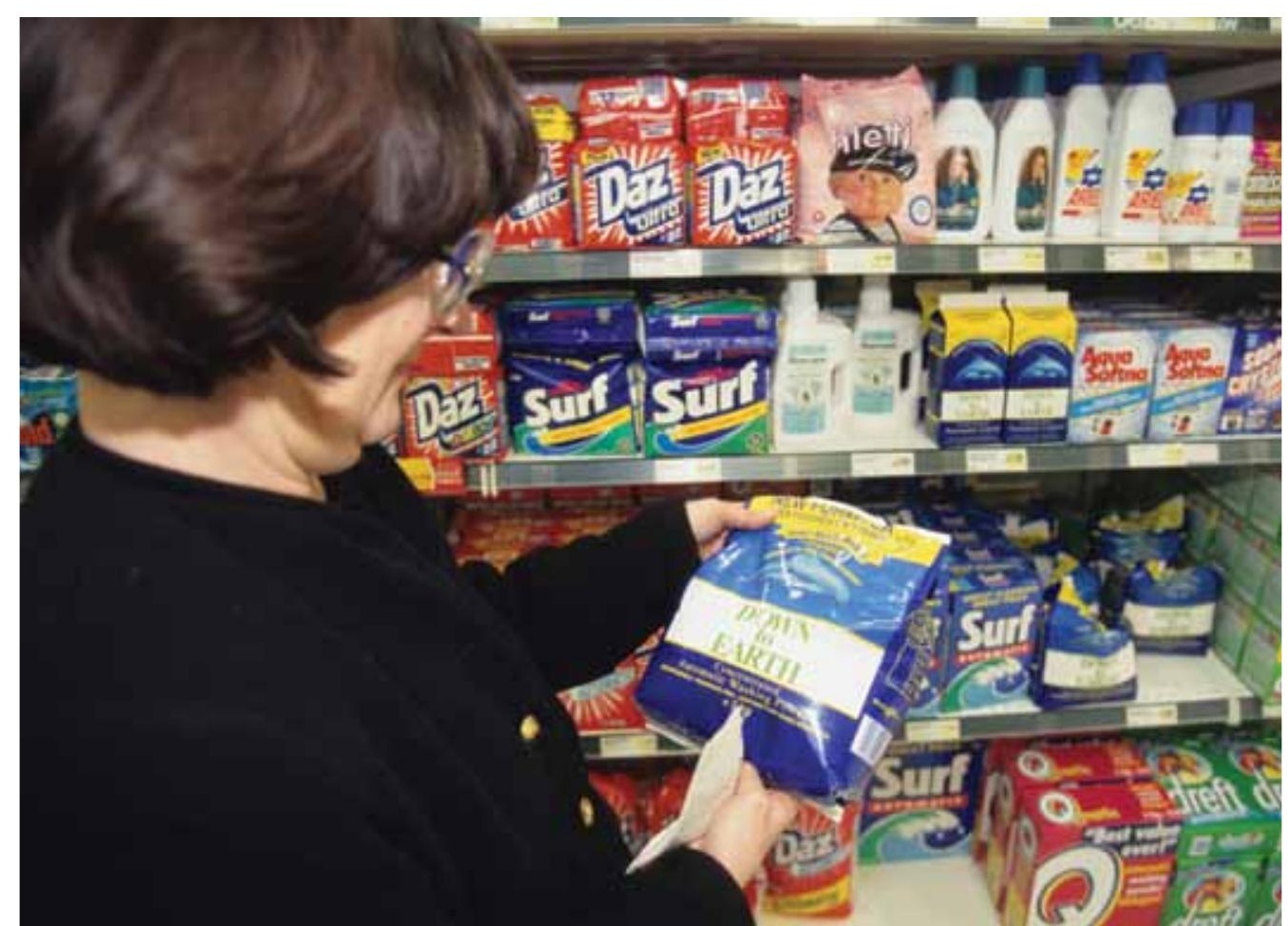


Braungart abrazan una filosofía similar en Cradle to Cradle (2002). Otro enfoque es una reforma conceptual hacia una economía sostenible que promueva el desarrollo en lugar del crecimiento, que integre plenamente los valores de la naturaleza en el sistema y aplique un enfoque de precaución en la política económica pública (Worldwatch Institute, 2008).

Otra opción es una economía verde que regrese más cerca de casa para la mayoría de sus insumos. El movimiento "comprar localmente" es un indicador de ello. Mientras que sus defensores reconocen que el comercio mundial es esencial, rechazan la subordinación total a la economía mundial y, en su lugar, apoyan el desarrollo de una mayor autonomía local para todo, desde comida hasta energía. Esto implicaría una mayor colaboración dentro de las comunidades, que ha sido una antigua adaptación que se ha descuidado en los tiempos modernos (McKibben, 2007).
Independientemente de cuál sea el modelo elegido, las decisiones personales sobre el consumo y los valores de la naturaleza serán importantes impulsores hacia un sistema económico más sostenible. El apoyo a instrumentos económicos tales como las contrapartidas a la fijación de carbono pueden ocurrir a nivel individual cada vez que una persona viaja y la compra de productos certificados como sostenibles es un medio para garantizar que los recursos naturales consumidos se gestionan responsablemente.

Para la UICN, una "economía verde" es condición previa esencial para lograr su misión. Si bien la forma de esta nueva economía está evolucionando rápidamente a través de actividades como TEEB, la iniciativa Economía Verde del Programa de las Naciones Unidas para el Medio Ambiente (PNUMA), los pagos por los servicios de los ecosistemas y diversas iniciativas nacionales, los Miembros de la UICN están trabajando activamente para asegurar la consideración de la biodiversidad y los servicios de los ecosistemas.

\section{$\int$ El uso de los recursos}

\section{naturales puede contribuir a la reducción}

\section{de la pobreza y a la salud y el bienestar}

\section{de las personas.}




\section{Tecnología y Conservación}

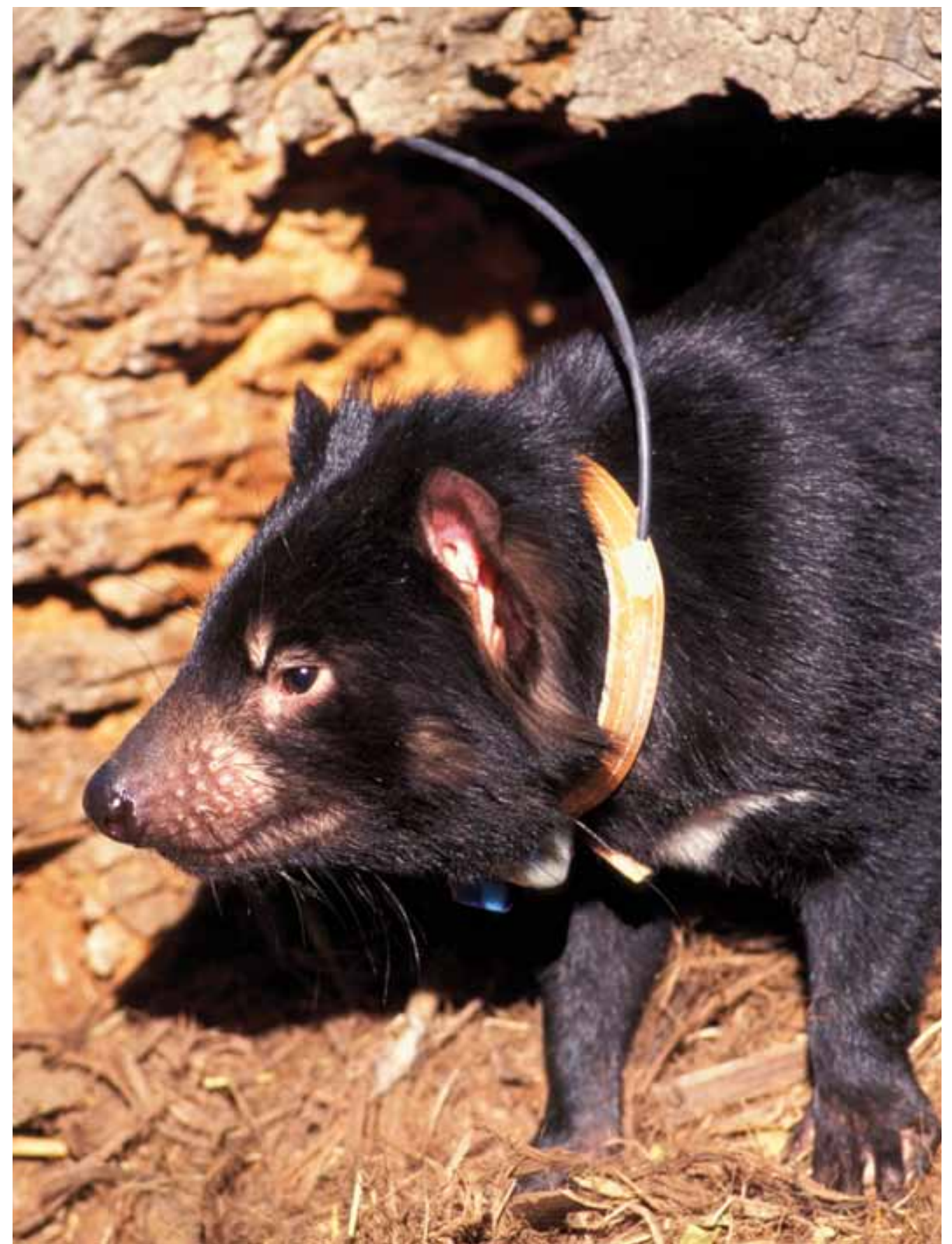


En octubre de 1992, Julian Simon y Norman Myers sostuvieron un debate histórico en la Universidad de Columbia sobre "La escasez o la abundancia" (Myers y Simon, 1994). Si bien Myers, entonces identificado por algunos como un "adivino de la fatalidad", sostuvo que todos los indicadores ambientales avanzaban en la dirección equivocada y que, en última instancia, la gente iba a pagar el precio, Simon aplaudió el crecimiento de las poblaciones humanas y afirmó que un mayor número de personas aportaba más mentes para desarrollar soluciones tecnológicas para hacer frente a los retos futuros. Todavía resuena este argumento del poder de la tecnología para superar los impactos humanos en nuestro mundo (Ehrlich y Ehrlich, 2008), pero se están acumulando pruebas que demuestran que Myers pudo haber tenido razón en 1992. Sin embargo, cabe preguntarse si la tecnología puede ayudarnos a evitar las peores consecuencias del pronóstico maltusiano de que la humanidad sobrepasará la capacidad de carga de la Tierra.

Las comunidades de todo el mundo han desarrollado sus propias tecnologías durante miles de años. Estas tecnologías tradicionales han sido superadas por formas más modernas, pese a tener mucho que ofrecer (Klee, 1980; Gadgil y Berkes, 1991). Muchas de estas tecnologías tradicionales se basan en la biomimética y se pueden mejorar mediante la incorporación de algunos elementos modernos. La Comisión de Política Ambiental, Económica y Social (CPAES) de la UICN ha promovido ampliamente esos enfoques, que en forma creciente están siendo incorporados al pensamiento del desarrollo y encierran un gran potencial como parte de las economías verdes.
Mucha de la tecnología moderna ha contribuido a la más completa explotación de los recursos naturales y a los efectos secundarios no previstos que han sido causa de algunos de los más dificiles problemas medioambientales. Sin embargo, como diría Simon, las nuevas tecnologías también pueden ser la base para algunas de las soluciones a esos problemas.

\section{¿CUÁLES TECNOLOGÍAS Y CUÁL IMPACTO?}

Desde una perspectiva medioambiental, algunas de las principales tecnologías que han beneficiado y obstaculizado la conservación del medio ambiente incluyen la tecnología de gestión de la información (TI), la biotecnología y la geoingeniería, y la tecnología de la energía (capítulo 8). 


\section{Tecnología de la información}

En el momento de la Cumbre de la Tierra en Río de Janeiro, en 1992, nadie tenía teléfonos móviles, Internet todavía no funcionaba, y las computadoras portátiles eran más bien como computadores de escritorio portátiles. En poco más de 15 años, la TI ha realizado notables avances, que han resultado tanto en costos como en beneficios para la biodiversidad.

Los costos de los avances de la TI se pueden calcular tanto en términos de los impactos de un mayor acceso a la información como de los impactos del desarrollo

y la aplicación de tecnología para apoyar dicho acceso. El mayor acceso a la información ha facilitado a quienes tratan de explotar la naturaleza determinar dónde están los recursos valiosos y los mercados potenciales. Las materias primas para fabricar las computadoras y los teléfonos móviles con los que recogemos y compartimos nuestros conocimientos, y cómo disponemos de ellos cuando un nuevo modelo sale al mercado, también pueden tener efectos negativos significativos sobre el medio ambiente. La exploración y extracción de materias primas como el coltán ya han tenido efectos devastadores sobre la biodiversidad en lugares como la República Democrática del Congo. La fabricación y el funcionamiento de las computadoras y los teléfonos móviles es un ejercicio de uso intensivo de energía y agua con el consiguiente impacto sobre el clima.

El uso de productos de TI consume enormes cantidades de energía, incluyendo la electricidad para operar computadoras personales, así como las necesidades de bancos de servidores y otra infraestructura de TI para mantener a Internet funcionando. El consumo anual de energía de las computadoras varía de 52 a $482 \mathrm{kWh}$ y para los monitores oscila entre 22 y 754 kWh (Bray, 2006), con diferencias en función de las especificaciones y la edad de las computadoras y monitores que se están probando. En comparación, la media anual del consumo de energía de las refrigeradoras en los Estados Unidos fue de $1.239 \mathrm{kWh}$ (http:// www.eia.doe.gov/emeu/reps/enduse/er01_ us.html\#Electricity).

Por último, cuando se descartan computadoras obsoletas, el plomo, el mercurio y otras sustancias tóxicas utilizadas en su fabricación pueden causar graves problemas de contaminación. La escala de estos residuos es inmensa. En 2005, el equipo electrónico usado ascendió a cerca de dos millones de toneladas de residuos, la mayoría de los cuales se depositaron en vertederos. Solamente en el Reino Unido, 1700 teléfonos móviles se desechan cada hora, 15 millones cada año. Sus metales pesados y otros contaminantes como el mercurio, el plomo, el cadmio, y los retardantes de llama bromados, se dejan contaminando los suelos. Gran parte del hardware electrónico desechado por los países industrializados se destina a los países pobres de África o de Asia que tienen políticas ambientales deficientes. Por otra parte, el reciclaje de teléfonos móviles reduce las emisiones de gases de efecto invernadero (GHG), conserva el material valioso fuera de los vertederos e incineradores, y conserva los recursos naturales. El reciclaje de apenas un millón de teléfonos móviles reduce las emisiones de GHG equivalentes a sacar de circulación 1368 coches durante un año.

Si bien la tecnología de la información y las comunicaciones (TIC) no es especialmente responsable en términos ambientales, se está 
movilizando cada vez más para mejorar la gestión de los servicios de los ecosistemas y la biodiversidad. Por ejemplo:

- La consolidación de la información, como la Base de Datos Mundial sobre Áreas Protegidas (www. wdpa.org), una fuente de libre acceso y descarga de información sobre las áreas protegidas del mundo, está siendo utilizada para el análisis de brechas ecológicas, evaluaciones de impacto ambiental, toma de decisiones del sector privado, y creación de nuevos productos de datos.

- La síntesis de la información, como en el caso de las guías electrónicas para plantas y animales, permiten a los científicos y a los turistas identificar las especies que encuentran en la naturaleza.

- La teleobservación y rastreo de especies esquivas tales como los tigres y leopardos de nieve permite a los científicos censar e incluso fotografiar especies esquivas recién descubiertas como el saola.

- El rastreo dinámico de los cambios ambientales está prestando asistencia para actuar en respuesta a los incendios forestales o al cambio climático.

- Los dispositivos portátiles, especialmente los teléfonos móviles, permiten a los agricultores mejorar su productividad y rentabilidad a través de un mejor e inmediato acceso a los precios que se están pagando por sus cultivos, a las previsiones meteorológicas, y a mejores regímenes de riego. Al eliminar a los intermediarios, esta TIC puede ayudar a los agricultores a salir de la pobreza.

- El acceso público a la información sobre el medio ambiente, por ejemplo, a través de Google Earth, o a través de los muchos sitios web con transmisiones en vivo sobre la vida silvestre, ha aumentado la conciencia y el aprecio por el mundo natural y los cambios que se producen.

- La TI ha dado lugar a nuevas formas de democracia en la gestión de los recursos, por cuanto la población rural está utilizando esta tecnología para tener mayor control sobre sus recursos naturales.
- La teledetección, a menudo utilizando satélites para ayudar a recoger información espacial y temporal de la Tierra, se ha convertido en una de las principales tecnologías de gestión ambiental que se utilizan en una extensa variedad de contextos.

También se han logrado avances en TI en términos de la reducción del tamaño de los instrumentos. Muchas especies esquivas pueden ahora ser estudiadas a través del rastreo por radio y minúsculos transmisores ya han sido adheridos a las mariposas, clara indicación del grado de miniaturización posible hoy día. Cámaras de vídeo en miniatura se han sujetado al cuervo de Nueva Caledonia, bajo amenaza crítica, lo cual permite a los científicos, por primera vez, comprender plenamente la complicada vida de estas inteligentes aves. En el otro extremo de la escala, los elefantes también han sido equipados con transmisores de radio para su rastreo, tanto para fines científicos como para ayudar a advertir a los agricultores cuando sus campos podrían ser allanados por paquidermos hambrientos en busca de una comida gratis.

Los avances en las tecnologías de la información y la información que ya está disponible como resultado de ello, permiten a los encargados de formular políticas y a los conservacionistas mejorar la gestión de las especies y los ecosistemas amenazados. La TI también está apoyando la toma de decisiones en otros ámbitos, especialmente el cambio climático, ayudando a evaluar sus efectos reales, por ejemplo, comparando el tamaño de los glaciares en zonas remotas, midiendo el cambio en los casquetes polares, y tomando la temperatura de la Tierra a distancias lejanas. También será vital para la comprensión y el monitoreo de la respuesta de los ecosistemas a las medidas adoptadas.

El más sofisticado uso de TI se está dando en el ámbito de la genética. Sin la tecnología moderna, los geneticistas no habrían podido comprender la 
estructura genética de las especies cuyos genomas han sido mapeados. Se han establecido docenas de bases de datos de conocimientos genómicos que abarcan todo, desde el arroz hasta las ratas hasta los peces cebra hasta los seres humanos e incluso el ornitorrinco. Estas bases de datos de organismos modelo están ofreciendo una muy avanzada herramienta de investigación para los científicos, que les permite ir años adelante en la sofisticación del tipo de preguntas de investigación que son capaces de responder.

A pesar de los avances, sin embargo, el mayor desafío radica en garantizar que el conocimiento más amplio de la biodiversidad contribuya a una efectiva política y toma de decisiones. La TI puede y debe ayudar a desempeñar un papel fundamental para hacer frente a este desafío. Todo indica que estos avances tecnológicos seguirán acelerándose, proporcionando un acceso rápido y fácil a una creciente gama de información importante, desde el análisis de $\mathrm{ADN}$ hasta la riqueza de los microorganismos del suelo hasta el cálculo de la huella ecológica de la humanidad. Todo esto ofrece una oportunidad para construir un futuro tecnológico que también ayude a mejorar significativamente la gestión de los recursos biológicos, un matrimonio de la tecnología y la biología que puede conducir a un futuro más sostenible.

Además de los aspectos de hardware de la TI, los medios por los que gestionamos y manipulamos la información también están cambiando. A medida que las computadoras se tornan más poderosas, acorde a las previsiones de la Ley de Moore (la capacidad de almacenamiento de los microchips se duplicará cada 18 meses), nuestra capacidad para explorar áreas que requieren amplios y complejos cálculos también se ha ampliado.

Uno de los factores limitantes en la proyección de los impactos en la naturaleza es la incertidumbre -algo que ha asolado a la comunidad climática durante muchos años. Están surgiendo nuevas metodologías para la integración de la incertidumbre en los cálculos y modelos incluyendo el uso de "números difusos" y redes bayesianas. Todos ellos también están siendo utilizados en la investigación y la gestión ambiental, incluyendo las evaluaciones realizadas como parte de la Lista Roja de Especies Amenazadas de la UICN.

\section{BIOTECNOLOGÍA}

La biotecnología está estrechamente ligada a la gestión de la información emergente. La biotecnología puede definirse como cualquier aplicación de tecnología a los sistemas biológicos. Tiene una larga historia, que se remonta a la utilización de la levadura para hacer pan y la fermentación para hacer bebidas alcohólicas. A estas aplicaciones históricas se han sumado otras más modernas, incluyendo la nanotecnología, la biomimética y la modificación genética. Algunas de estas nuevas aplicaciones de la biotecnología son poderosas y novedosas y exigen la aplicación de un criterio de precaución.

\section{Nanotecnología}

La nanotecnología implica trabajar en la escala atómica, aproximadamente a un tamaño de una mil millonésima de un metro. En esta escala, los materiales se comportan de maneras muy diferentes a cuando se combinan con otros para formar moléculas, compuestos, etc. Las nanopartículas son tan pequeñas que pueden entrar en las células impermeables a partículas más grandes. De ahí que su uso en cosméticos, por ejemplo, podría acarrear consecuencias para la salud. Además, las nanopartículas tienen una gran superficie en relación con su volumen, mejorando sus propiedades químicas y eléctricas y aumentando el riesgo de que pudieran dar lugar a reacciones perjudiciales dentro de una célula invadida.

Si bien las nanopartículas se pueden producir de forma natural, por ejemplo, por los volcanes, el diseño de nanopartículas se está convirtiendo 
en un gran negocio. La inversión mundial en nanotecnología en el año 2005 fue US\$10 mil millones y se prevé que aumente a US\$1 millón de billones para 2011-2015 (Navarro et al., 2008). Se prevé beneficios para las personas en lo referente a medicamentos, electrónica y medio ambiente. Por ejemplo, la capacidad de las nanopartículas para combinarse con productos químicos contaminantes podría reducir la biodisponibilidad de esas sustancias tóxicas. Sin embargo, también se ha reconocido el potencial de las nanopartículas para generar efectos tóxicos, como por ejemplo, irritación pulmonar. También son muchas las incógnitas que rodean el uso de nanopartículas (Navarro et al., 2008).

En la actualidad, el campo de la nanotecnología está prácticamente desregulado, y son pocos, si es que los hay, los estudios que se han realizado sobre los posibles impactos en la biodiversidad. Como cualquier tecnología nueva y potente, la nanotecnología debe ser tratada con cautela, y la aplicación del criterio de precaución parece apropiada. Sutherland et al. (2008) incluyeron la nanotecnología entre las 25 nuevas amenazas que enfrenta la biodiversidad. Recomendaron que "si se hace un uso generalizado o si se incorporan las estructuras a "sistemas casi vivientes", sería necesario considerar nuevos enfoques basados en el riesgo. Por su parte, la Comisión Europea (CE) ha publicado un "código de conducta" para la nanotecnología (CE, 2008). Su sección sobre sostenibilidad dice:

\section{Las actividades de investigación en nanociencias y nanotecnologías deben ser seguras y éticas y contribuir al desarrollo sostenible al servicio de los objetivos de desarrollo sostenible de la Comunidad, así como contribuir a los Objetivos de Desarrollo del Milenio de las Naciones Unidas. No deben dañar o crear una amenaza biológica, física o moral para las personas, animales, plantas o el medio ambiente, en la actualidad o en el futuro.}

El Consejo Internacional de Gobernabilidad del Riesgo (IRGC) también observa que, si bien la nanotecnología presenta grandes beneficios potenciales, también plantea graves riesgos con consecuencias sociales, económicas, políticas y éticas. El IRGC sugiere que, debido a que las cuestiones planteadas por la nanotecnología son más complejas y con mayor alcance que muchas otras innovaciones, los responsables de la toma de decisiones deben ser conscientes de las incertidumbres y los riesgos asociados

(IRGC, 2007).

\section{Biomimética}

"Biomimética" se deriva de las raíces griegas "bios", que significa vida, y "mimesis”, que significa imitación. La palabra se aplica a las aplicaciones de modelos y procesos de la naturaleza a diseños industriales o agrícolas para resolver los problemas humanos. Como lo acuñó Janine Benyus (1997), es un enfoque que aprende de la naturaleza, y no solo sobre la naturaleza.

La biomimética se basa en el principio de que, a través del proceso de evolución, la naturaleza ha aprendido qué funciona, qué es apropiado y qué es sostenible. La naturaleza incluye organismos que vuelan, que ocupan todo el mundo, mantienen condiciones de vida apropiadas, y construyen estructuras complejas asombrosas. La naturaleza ha desarrollado materiales biodegradables como los pegamentos producidos por mejillones que funcionan bajo el agua, las sedas de las telarañas que son más fuertes que los productos más fuertes fabricados por humanos, los montículos de termitas que son capaces de mantener constante la temperatura interna pese a temperaturas externas que van de $40^{\circ} \mathrm{C}$ durante el día a cerca de la congelación en la noche, y las patas de las lagartijas que les permiten aferrarse a un techo liso.

Ya estamos usando aplicaciones de biomimética en nuestra vida diaria. Velcro se inspiró en el 
la seguridad alimentaria y el medio ambiente. La preocupación se refleja en la Resolución 3.007 del CMN de la UICN en la que la Unión exhorta a "una moratoria sobre nuevas liberaciones ambientales de OMG hasta que se pueda demostrar que son seguros para la biodiversidad y para la salud humana y animal, más allá de toda duda razonable”. Los Miembros de la UICN también han reconocido la rapidez de los avances en los campos de la tecnología genética y han solicitado actualizaciones permanentes a este efecto.

Los potenciales impactos negativos de los OGM incluyen una reducción de la biodiversidad, amenazas a la salud humana, consecuencias inesperadas de transferencia de genes entre las plantas, y la creación de plagas o malas hierbas resistentes a los controles. Las Partes en el Convenio sobre la Diversidad Biológica (CDB), han reconocido tanto los beneficios como los costos potenciales de los OGM a través del Protocolo de Cartagena, que promueve el uso informado y prudente de esta tecnología y trabaja en aras de la creación de capacidades en todos los países para apoyar el proceso de toma de decisiones implicadas. Los Miembros de la UICN han exhortado a los gobiernos a ratificar el Protocolo de Cartagena.

\section{Las organizaciones de las Naciones Unidas} responsables de la salud humana y la producción de alimentos no han encontrado hasta la fecha pruebas de los impactos negativos de los OGM sobre la biodiversidad o la salud humana. Una revisión de 2003 en torno a las investigaciones realizadas para evaluar el impacto ambiental de los cultivos transgénicos concluyó que el monitoreo y las pruebas llevadas a cabo son insuficientes para tomar una decisión en ese sentido (Ervin et al., 2003). Aunque los científicos han encontrado pocas pruebas concluyentes de impactos negativos directos de los OGM sobre la biodiversidad o la salud humana, debe considerarse otras cuestiones éticas. Algunas organizaciones intercambian puntos de vista con los de Vía Campesina, un movimiento mundial de campesinos, que creen que la tecnología de los OMG plantea una grave e inmediata amenaza a la seguridad y a los medios de subsistencia de los campesinos (www.viacampesina.org). Por otra parte, algunos agricultores en los países en desarrollo como China, India, Argentina y Brasil, han acogido los cultivos de OGM, especialmente el algodón, la soja y el maíz.

\section{Geoingeniería}

La geoingeniería es la modificación deliberada del medio ambiente para lograr resultados específicos con relación a las necesidades humanas. Con respecto al cambio climático, se consideran dos aspectos de la geoingeniería: la gestión de la radiación solar, por ejemplo, a través de la creación de aerosoles de azufre solar, y la gestión de las emisiones de GHG, por ejemplo, a través de las técnicas de captura y almacenamiento de carbono o empleando biochar como sumidero de carbono (Víctor et al., 2009). Los efectos secundarios de estas tecnologías siguen siendo prácticamente desconocidos. Al menos una tecnología de geoingeniería, la fertilización de los océanos con hierro para promover el crecimiento del fitoplancton para la secuestración de carbono, ha sido probada, dando lugar a un considerable debate en la arena mundial de la política ambiental, y los gobiernos han acordado una moratoria sobre nuevas pruebas de esta tecnología.

Centrándose específicamente en el tema de la gestión de la radiación solar, Mathews y Caldera (2007) informaron de que, si bien la geoingeniería puede proporcionar algunas soluciones de mitigación, estas tecnologías también enmascararon aumentos en las emisiones de GHG. Si fracasaran o se detuvieran abruptamente las soluciones de geoingeniería, el resultado podría ser un cambio climático muy rápido, con un calentamiento de hasta 20 veces superior a las tasas actuales. Llegaron a 
la conclusión de que si se dependiera únicamente de la geoingeniería sin esfuerzos complementarios para reducir las emisiones de carbono, ello supondría un alto riesgo para el sistema climático mundial.

\section{Biología sintética}

Si bien algunos consideran que la biología sintética es simplemente una extensión de la ingeniería genética, en realidad es mucho más compleja; implica la ingeniería de nuevos sistemas, piezas o dispositivos biológicos que no existen en la naturaleza y el rediseño o reingeniería de elementos biológicos existentes con fines útiles (IRGC, 2008b). Mientras que la ingeniería genética implica típicamente solo uno o unos pocos genes a la vez, la biología sintética crea nuevos organismos o unidades metabólicas. Si bien esta tecnología está todavía en pañales, se ha demostrado que es posible crear genomas virales como el virus de la poliomielitis (Cello $e t$ al., 2002) y reconstruir el virus que fue responsable de la pandemia de gripe de 1918 (Tumpey et al., 2005).

Como una nueva rama de la biología, la mayoría de los trabajos en este campo dista mucho de tener aplicaciones comerciales. Sin embargo, sus defensores ven potencial en la biorremediación (por ejemplo, la degradación de los plaguicidas y la eliminación de los contaminantes), el desarrollo de biosensores que pueden detectar productos químicos tóxicos, el desarrollo de bacterias o virus que pueden identificar las células cancerosas y suministrar los agentes terapéuticos donde se requieren, el desarrollo más efectivo de productos farmacéuticos, la ingeniería de microorganismos que pueden producir nuevas fuentes de energía, y otras aplicaciones que escapan a la imaginación.

Por otro lado, la biología sintética podría suponer importantes riesgos, como efectos negativos no deseados sobre el medio ambiente, resultantes de la liberación accidental de organismos sintéticos, como los concebidos originalmente para la biorremediación. El uso de la biología sintética para crear microorganismos podría dar lugar a efectos muy imprevisibles; $y$, en el peor de los casos, los organismos nocivos podrían ser creados deliberadamente (aunque en la actualidad es mucho más fácil obtener agentes patógenos de otras maneras). En un plano filosófico, es factible que la biología sintética pueda conducir a que la mayoría de la evolución tenga lugar en el laboratorio y no en la naturaleza, con el consiguiente posible riesgo para el concepto mismo de la naturaleza y para la biodiversidad.

En 2003, J. Craig Venter y su equipo de investigadores construyeron con éxito un cromosoma sintético en dos semanas. Desde entonces, el Instituto Venter se ha mantenido a la vanguardia de la tecnología genómica sintética para examinar y reproducir la genética de la vida (Smith et al., 2003). En 2008, científicos del Instituto de Investigación J. Craig Venter anunciaron el primer genoma bacteriano completamente sintético (Mycoplasma genitalium), trascendental paso hacia la vida artificial.

Las herramientas para la biología sintética están a disposición en línea en una biblioteca de libre acceso, el Registro de Partes Biológicas Estándar (http:// parts.mit.edu). Los estudiantes universitarios ya están haciendo concursos para el uso de "bioladrillos" para desarrollar sus propios dispositivos biológicos sintéticos, aunque todavía no hay medidas reguladoras para garantizar que esos experimentos no sean una amenaza para el medio ambiente (IRGC, 2008). La biología sintética es un campo que sin duda requiere criterios de precaución y merece más atención por parte de la comunidad conservacionista de la que actualmente recibe.

\section{APROVECHAMIENTO DE LA TECNOLOGÍA ACTUAL} APOYANDO A LA VEZ EL MEDIO AMBIENTE

Para hacer frente a los retos actuales de la conservación, la nueva tecnología será especialmente importante para proporcionar 
los medios para hacer frente a algunas de las principales amenazas a la biodiversidad y los servicios de los ecosistemas, tales como el cambio climático, la contaminación y las especies exóticas invasoras. En todos los casos, el aprovechamiento al máximo de tecnologías que sean compatibles con la conservación del medio ambiente significa que en el próximo decenio tendremos que apoyar el desarrollo de herramientas y tecnologías de la información para propiciar la gestión eficaz de los ecosistemas vulnerables y garantizar medios de subsistencia sostenibles para las personas que habitan en estas áreas. Además, tendremos que aplicar un criterio de precaución para la gestión de las muchas incertidumbres con respecto a los impactos a largo plazo de algunas de estas tecnologías y adoptar algunos cambios fundamentales en el comportamiento para gestionar los efectos del consumo de estas tecnologías, incluyendo prestar atención a las $3 R$ - reducir, reciclar y reutilizar. 


\section{Cooperación Internacional}

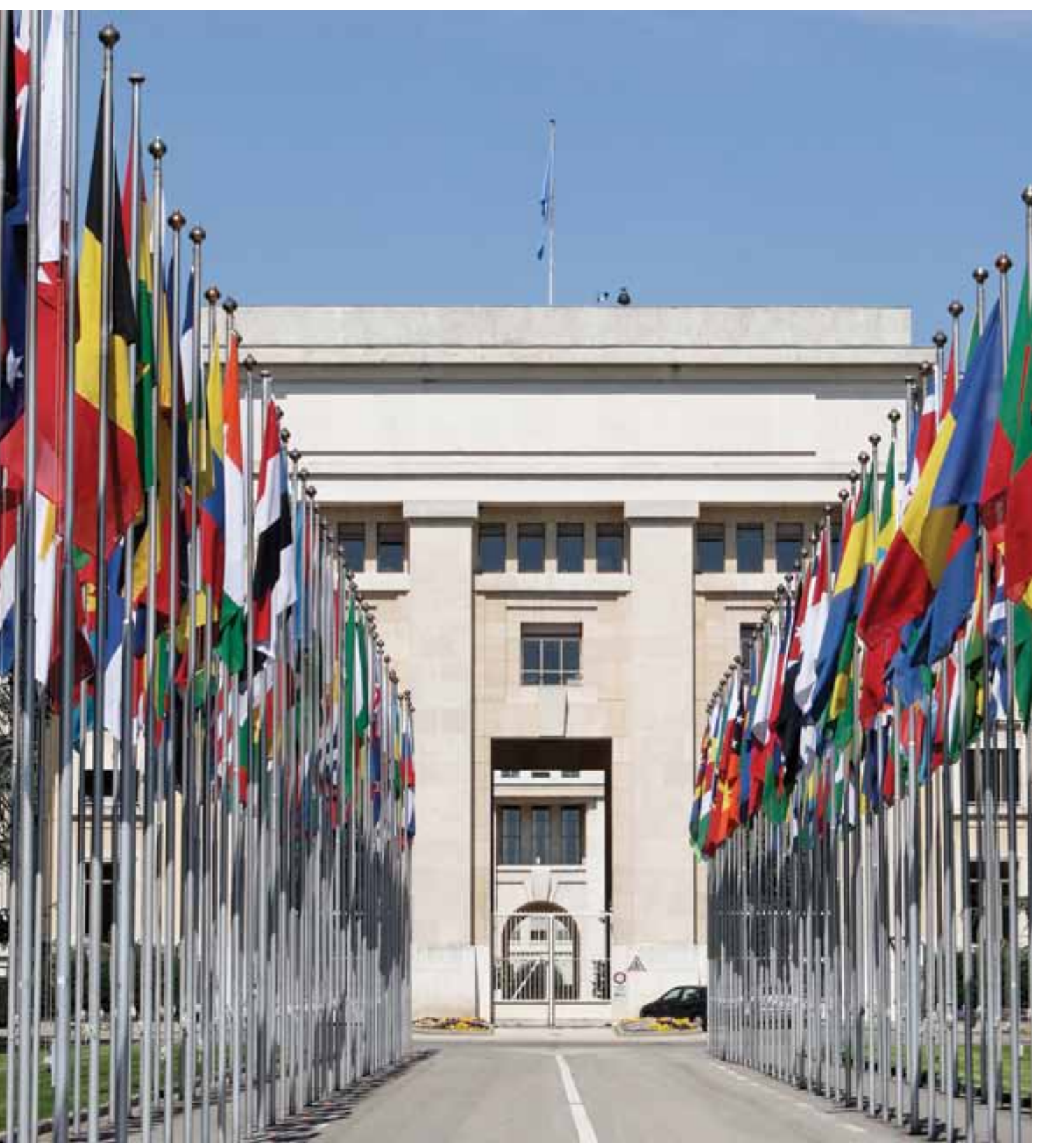




\section{La agenda política internacional está en gran parte centrada en}

cuestiones económicas y de seguridad, incluyendo las amenazas de colapso financiero, terrorismo, proliferación de armas y cambio climático. Las dimensiones ambientales de estos problemas están empezando a ser objeto de atención pero aún está muy rezagada en términos de los impactos directos sobre las personas alrededor del mundo. Sin embargo, la aceptación de la responsabilidad de los impactos sobre los bienes públicos mundiales, incluida la biodiversidad y los servicios prestados por los ecosistemas, recién está comenzando a discutirse en el seno de muchos sectores, desde la pesca hasta el cambio climático.

En términos de la agenda internacional de la biodiversidad, la mayoría de los acuerdos y procesos multilaterales sobre el medio ambiente (AMMA) se centran en la implementación de los compromisos y programas de trabajo. Entre los nuevos desafíos se incluyen los debates sobre la necesidad de una meta y marco de biodiversidad post 2010, la negociación de un régimen internacional sobre el acceso y participación en los beneficios (APB) en el marco del Convenio sobre la Diversidad Biológica (CDB), y medidas para abordar la gobernanza de los mares fuera de la jurisdicción nacional en el contexto de la Asamblea General de las Naciones Unidas. El año 2010 ha sido declarado por este organismo como el Año Internacional de la Biodiversidad, centrando la atención en los debates previos a los hitos de 2010, la Asamblea General de las Naciones Unidas y su período de sesiones de alto nivel sobre la biodiversidad y la $10^{\mathrm{a}}$ Conferencia de las Partes del Convenio sobre la Diversidad Biológica (COP 10 del CDB) que tendrá lugar en
Japón en octubre de 2010. La Comisión sobre el Desarrollo Sostenible (CSD) se centrará también en la biodiversidad en 2010 .

El cambio climático, en particular, está proporcionando un espacio para que las cuestiones ambientales se conviertan en un aspecto importante de estas negociaciones. No obstante, existen muchas limitaciones a la plena integración del medio ambiente en las actuales deliberaciones. Estas incluyen la necesidad de un acuerdo para la armonización a través de los instrumentos y los debates, la integración convincente de la biodiversidad y el cambio climático (capítulo 5), la creación de capacidades (técnicas y financieras) para implementar las decisiones resultantes, y la movilización de la voluntad política para actuar en interés del bien mundial. 
ARMONIZACIÓN Y SINERGIA EN LOS ACUERDOS INTERNACIONALES

Durante la segunda mitad del siglo XX, y en particular a raíz de la Conferencia de Estocolmo sobre el Medio Humano en 1972 y la divulgación del Informe de la Comisión Brundtland en 1987, se redactaron y ratificaron cientos de acuerdos ambientales. Los más notables desde la perspectiva de la biodiversidad incluyen el Convenio sobre la Diversidad Biológica, la Convención sobre las Especies Migratorias (CMS), la Convención sobre el comercio internacional de especies amenazadas de fauna y flora silvestres (CITES), la Convención del Patrimonio Mundial y la Convención sobre los Humedales de Importancia Internacional (Ramsar).

Esta red de instrumentos ha creado, en algunos casos, un marco muy enredado y difícil de aplicar para la conservación. Por ejemplo, para las tortugas carey en la región del Gran Caribe esta especie está sujeta a la jurisdicción de más de 12 instrumentos mundiales (desde CITES hasta Ramsar hasta la Convención de las Naciones Unidas sobre el Derecho del Mar-UNCLOS), más de siete acuerdos regionales, y tres acuerdos del Atlántico (CITES, 2001). Lamentablemente, las obligaciones y requisitos de todos estos instrumentos jurídicos no siempre coinciden, dejando a los países en el Caribe luchando por identificar un plan de gestión adecuado para la tortuga carey.

Del mismo modo, mientras que la Convención Marco de las Naciones Unidas sobre el Cambio Climático (UNFCCC) es el instrumento por excelencia para la cooperación mundial sobre el cambio climático, muchos otros acuerdos mundiales y regionales incluyen también el clima dentro de su trabajo. Desde una perspectiva de la biodiversidad, entre ellos están el CDB, la Convención de las Naciones Unidas de Lucha contra la Desertificación (UNCCD), UNCLOS, CMS, y Ramsar en el plano internacional
Recuadro 14.1 Definición de tierras secas en términos de políticas

Definición de la UNCCD de regiones áridas y semiárida:

Las zonas, a excepción de las regiones polares y subpolares, en las que la relación de la precipitación anual y la posible evapotranspiración oscila entre 0.05 y 0.65 .

Definición del CDB de tierras secas y subhúmedas:

Tierras secas y subhúmedas, incluyendo regiones áridas y semiáridas, pastizales, sabanas y paisajes mediterráneos.

(McNeely, 2008). Pero las agendas y requisitos particulares a través de estos instrumentos también varían, dejando a las Partes con una desequilibrante serie de acciones a implementar. En algunos casos, incluso la definición de la cuestión o ámbito de acción es diferente, como por ejemplo, la definición de tierras secas en la UNCCD y en el CDB (véase el recuadro 14.1).

Más de 700 acuerdos internacionales están relacionados con el medio ambiente y no se ha establecido una arquitectura internacional eficaz para coordinar esta gran cantidad de compromisos oficiales, lo que resulta en la fragmentación y duplicación, así como en graves problemas de capacidad para muchos países -los llamados problemas de "congestión de tratados". A medida que aumenta el número de acuerdos, y junto a ellos el número de decisiones y acciones a implementarse, las Partes piden mayor armonización y sinergia. Los intentos para apoyar la eficiencia, la armonización y la sinergia han incluido Tematea (www.tematea. org), una herramienta en línea que proporciona información rápida sobre las decisiones y resoluciones de una serie de tratados y convenios según el tema, y ECOLEX (www.ecolex.org), una plataforma creada por el Centro de Derecho 


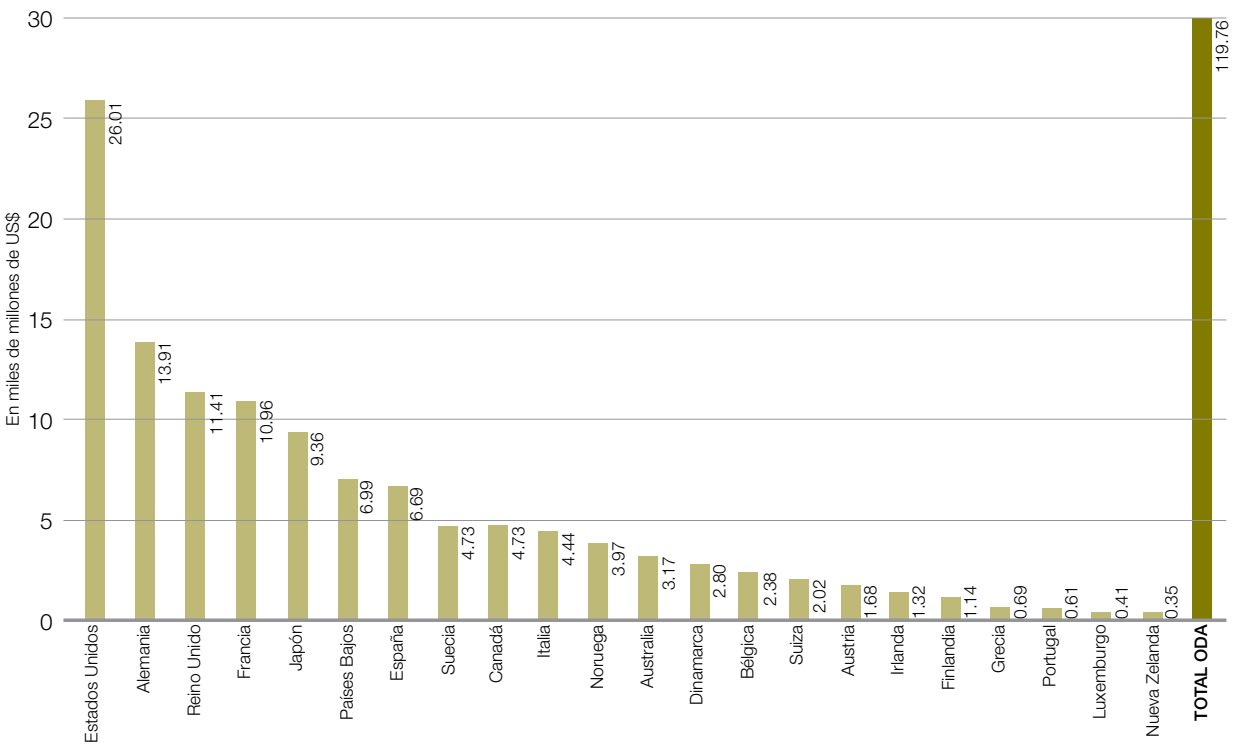

ODA en 2008 - como porcentaje del INB

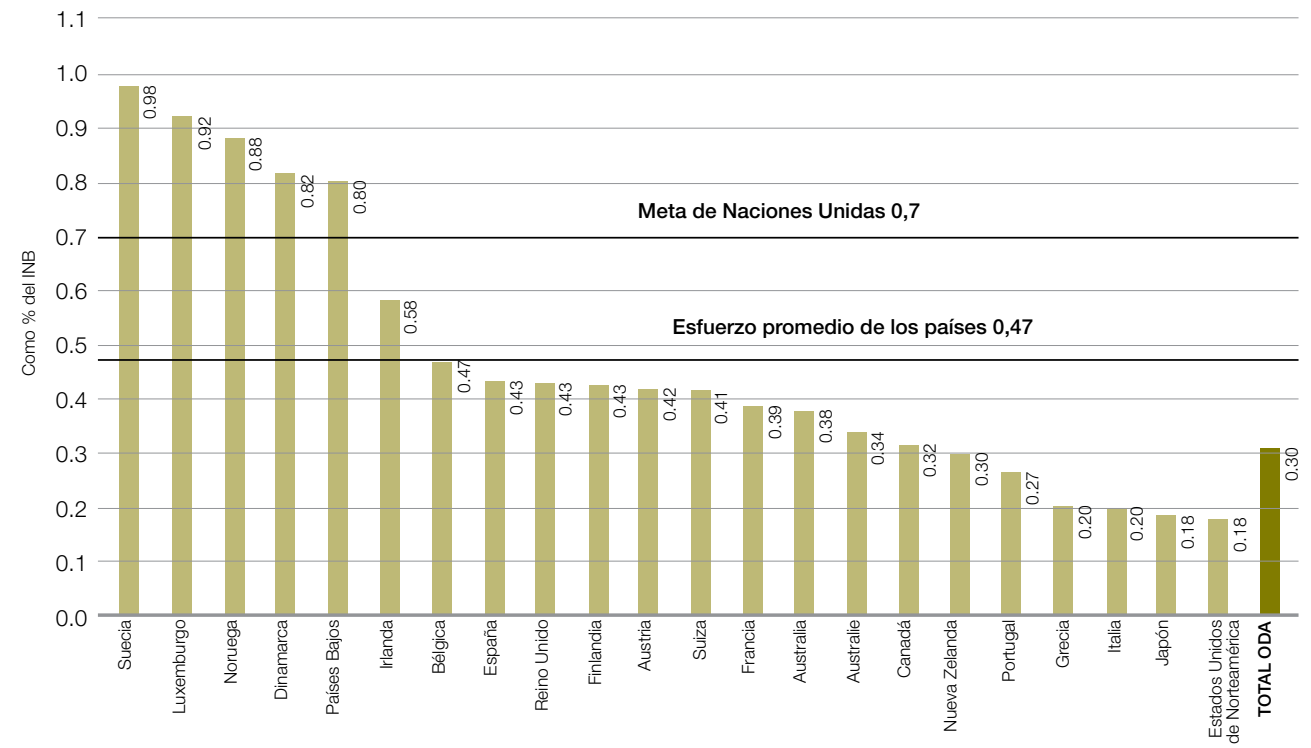

Figura 14.1 Tendencias de ODA (OCDE, 2009)

Ambiental (CDA) de la UICN, en colaboración con el Programa de las Naciones Unidas para el Medio Ambiente (PNUMA) y la Organización para la Agricultura y la Alimentación (FAO), que proporciona acceso a más de 600 tratados multilaterales y 45.000 leyes y reglamentos nacionales, que abarcan tanto la conservación y la utilización de los recursos naturales, como la contaminación ambiental a causa de contaminación y residuos. La posibilidad de caer en un asesoramiento contradictorio, como ya se ha señalado para la tortuga carey, aumenta con cada instrumento adicional redactado y debe prestarse atención a garantizar que armonice con los ya existentes, además de los medios para su aplicación efectiva. 


\section{CAPACIDAD PARA LA IMPLEMENTACIÓN}

Si bien la armonización será, sin duda, parte de la respuesta, otro aspecto de la cooperación internacional que debe abordarse es la capacidad, tanto técnica como financiera, para aplicar los compromisos existentes. Esta es una preocupación particular para los países en desarrollo que se espera que sean socios de pleno derecho en la consecución de un acuerdo durante las discusiones en reuniones intergubernamentales, pero carecen de apoyo y sistemas para participar plenamente en las negociaciones o para aplicar las decisiones resultantes.

El Fondo para el Medio Ambiente Mundial (FMAM) fue creado como el principal mecanismo financiero en apoyo del CDB. Entre 1991 y 2006, el FMAM desembolsó alrededor de US\$2200 millones en donaciones y movilizó unos US\$5170 millones para la cofinanciación de más de 750 proyectos sobre biodiversidad en 155 países. Estas cantidades son insignificantes en términos de las necesidades globales de conservación. Se ha estimado que para una conservación global eficaz se requiere una inversión de US\$20-25 mil millones por año (James et al., 2001) -un objetivo perfectamente posible dentro de los actuales sistemas financieros que están invirtiendo miles de millones en el rescate de los bancos.

En términos de capacidad financiera, dado el papel de la biodiversidad en el apoyo al bienestar humano, otra vía de apoyo debería ser la Asistencia Oficial al Desarrollo (ODA) a los países en desarrollo. En 2008, la ODA fue de US\$119.800 millones, representando solo el 0,3\% de la suma del Ingreso Nacional Bruto (INB) del Comité de Asistencia al Desarrollo de OCDE (ODA OCDE) de los países miembros, muy por debajo del 0,7\% acordado (OCDE, 2009 - figura 14.1). La ODA suele dirigirse a los problemas de desarrollo humano (por ejemplo, educación o salud), no a la conservación, pero a la luz de nuestra creciente conciencia respecto de la dependencia de las poblaciones vulnerables en los servicios de los ecosistemas de su entorno, ODA OCDE ha puesto de relieve el papel de la gestión de los recursos naturales sostenibles en el "crecimiento en beneficio de los pobres" y recomendó "brindar cooperación al desarrollo para mejorar la gestión de los recursos naturales" (OCDE, 2008).

Cinco países superaron el objetivo de las Naciones Unidas del 0,7\% del INB: Dinamarca, Luxemburgo, los Países Bajos, Noruega y Suecia. Los mayores aumentos en volumen provinieron de los Estados Unidos, el Reino Unido, España, Alemania, Japón y Canadá. Sin embargo, dado el repentino cambio en el clima financiero mundial en 2008, este nivel de inversión puede ser difícil de mantener. Por otra parte, a medida que los daños ambientales provocados por los países ricos se hacen más palpables, los países en desarrollo que están sufriendo desproporcionadamente los efectos de estos daños tienen un caso sólido para argumentar a favor de apoyar el mantenimiento (o recuperación) de la salud de los ecosistemas (Srinivasan et al., 2008). El pago a nivel internacional por los servicios de los ecosistemas (PSE) puede ser un medio importante para reverdecer la economía mundial y propiciar colaboración internacional para la conservación.

Pero cualquier enfoque en el apoyo de ODA para los países en desarrollo o el apoyo del FMAM para la conservación de la biodiversidad ignora la realidad de que el más importante apoyo financiero a estos países proviene de fuentes bilaterales de inversión. En 2007, la Conferencia de las Naciones Unidas sobre Comercio y Desarrollo (UNCTAD) dio cuenta de casi US\$2 mil billones de inversión extranjera directa (IED), de los cuales US\$500 mil millones se invirtieron en las economías de los países en desarrollo. La cantidad de fuentes de IED ha superado por 
mucho a la ODA, si bien las cantidades de un año a otro pueden ser muy volátiles y cambiar rápidamente, como ocurrió durante la caída de las economías de los "tigres" asiáticos a finales del decenio de 1990, y es probable que continúe por unos años más, a medida que se comience a sentir el descalabro financiero alrededor del mundo.

Esta inversión extranjera directa refleja también el importante número de acuerdos bilaterales existentes. Crawford y Fiorentino (2005) informan de que los acuerdos comerciales regionales (ACR) son "una importante y, quizás, irreversible característica del actual sistema de comercio multilateral (SCM)”. Sugieren que los escasos progresos en las negociaciones comerciales multilaterales en virtud de la Ronda de Desarrollo de Doha parecen haber acelerado el desarrollo de acuerdos comerciales regionales en todo el mundo y particularmente en el hemisferio occidental y la región Asia-Pacífico (figura 14.2).

\section{VOLUNTAD POLITICA Y OPINIÓN PÚBLICA}

En última instancia, el factor limitante para toda la cooperación internacional es la voluntad política, tanto para llegar a acuerdos sobre las decisiones como para apoyar la plena aplicación de esas decisiones.

Desde 1992, la Fundación Asahi Glass ha realizado estudios sobre los problemas del medio ambiente y la supervivencia de la humanidad. Los resultados del estudio de 2008 (figura 14.3), incluidas las respuestas de 732 personas en 81 países, señalaron que el 70\% de los encuestados citó el calentamiento global como la principal preocupación ambiental seguida por la escasez de agua $(50 \%)$ y la pérdida de biodiversidad (43\%). El estudio incluye una medida de la conciencia en torno a las repercusiones de los problemas ambientales que enfrenta la humanidad con base en un "Reloj del fin del mundo" (que gira en dirección a la medianoche). En 2008, los encuestados en todas las regiones con excepción del Oriente Medio y Asia, al elegir una hora en el "Reloj del fin del mundo" que correspondiera a su nivel de preocupación por el deterioro del medio ambiente, en promedio eligieron las 21:33, un adelanto de 2 minutos hacia la medianoche, el mayor aumento de un año a otro desde el inicio del estudio (Fundación Asahi Glass, 2008).

En la medida en que la voluntad política refleja la opinión pública, este factor limitante implica

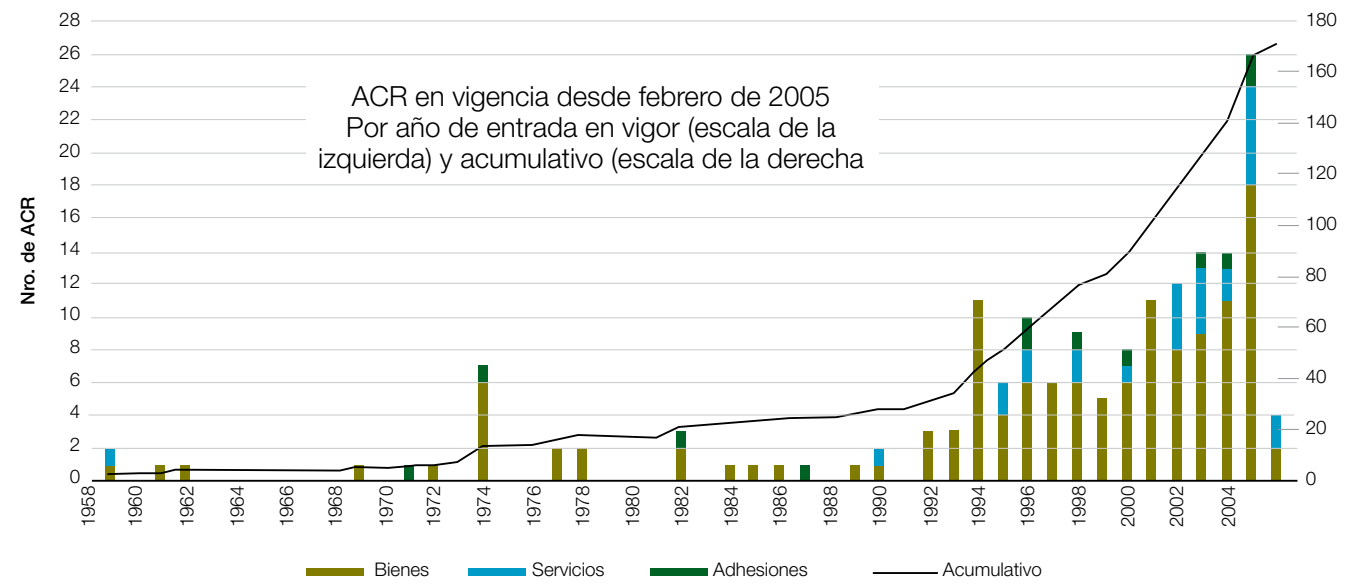


también comunicar de manera efectiva al público las cuestiones ambientales. El tiempo, esfuerzo e inversión necesarios para llevar el clima a la agenda política deben replicarse para la diversidad biológica.

Para la comunidad conservacionista, el reconocimiento del papel de la conservación en el debate no ambientalista es un medio importante para motivar a los responsables de la toma de decisiones y generar esa voluntad política y un fuerte apoyo público. Nuevas formas de pensar respecto del desarrollo y la ayuda al desarrollo exigen que se preste atención a los planes de reducción de la pobreza para asegurar que el medio ambiente sea considerado parte de la corriente principal del desarrollo. Será preciso aclarar las necesidades de gobernanza para el logro de una eficaz y equitativa conservación y gestión de los recursos naturales, especialmente a nivel de la comunidad. El interés de los donantes en estos aspectos de la gobernanza resultó evidente, por ejemplo, en el lanzamiento de la
Comisión de Alto Nivel para el Empoderamiento Jurídico de los Pobres en el marco de la Cumbre Mundial 2005 (PNUD, 2005).

Los compromisos contraídos fuera de los acuerdos ambientales multilaterales relacionados con la biodiversidad, incluido el compromiso de la Cumbre Mundial sobre el Desarrollo Sostenible (WSSD) con la meta de Biodiversidad 2010 y más allá, puede resultar fundamental para lograr la conservación y el desarrollo en el futuro. Sin embargo, el progreso hacia la implementación de la meta de 2010 y de los Objetivos de Desarrollo del Milenio (ODM) en general, ha sido lento (capítulo 1). El logro de estos objetivos requiere el esfuerzo sin precedentes de la comunidad internacional.

En algunos casos, la voluntad política puede ser más fácil de lograr a escala regional o en el ámbito transfronterizo. Ya un número considerable de procesos e instituciones regionales constituyen una parte importante de la agenda ambiental y de desarrollo sostenible.

$\begin{array}{lllllllll}0 & 10 & 20 & 30 & 40 & 50 & 60 & 70 & 80(\%)\end{array}$

Problemas ambientales generales

Calentamiento global

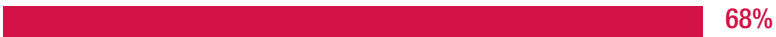

Contaminación del aire, contaminación del agua, contaminación de los ríos/océanos

Escasez de agua, problemas alimentarios

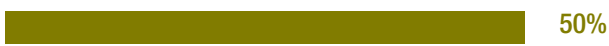

Deforestación, desertificación, pérdida de biodiversidad

Estilos de vida de las personas, problemas relacionados con los residuos

Problemas ambientales y actividades relacionadas con la economía y el comercio

Población, pobreza, condición de las mujeres Otros 
Al respecto cabe citar la Convención de África, el Convenio de Barcelona, la Comisión Centroamericana de Ambiente y Desarrollo (CCAD), la Conférence sur les Ecosystèmes de Forêts Denses et Humides d'Afrique Centrale (CEFDHAC), la Estrategia Paneuropea sobre Diversidad Biológica y Paisajística, la Nueva Alianza para el Desarrollo de África (NEPAD), el Memorando de Entendimiento sobre la Conservación y Manejo de Tortugas Marinas y sus Hábitats del Océano Índico y Asia Sur Oriental (IOSEA), el Programa Ambiental del Caribe, el Tratado de Cooperación Amazónica, y el Área de Libre Comercio de las Américas (ALCA). La importancia de estos procesos ha sido ampliamente reconocida por iniciativas diplomáticas a nivel mundial (por ejemplo, la WSSD, la CSD, y el Foro de las Naciones Unidas sobre los Bosques), si bien los gobiernos todavía están luchando por encontrar modelos eficaces de coordinación y colaboración entre los planos mundial y regional. El público en general es ajeno a estos procesos, lo que sugiere que el apoyo público a menudo se da por sentado en vez de promoverse cuidadosamente.

Los mecanismos para crear voluntad política y pública a niveles más locales incluyen las áreas de conservación transfronteriza como la Gran Área de Conservación Transfronteriza de Limpopo, y la gestión de los ecosistemas a escala del paisaje (por ejemplo, cuencas hidrográficas), que a menudo implica también la cooperación y la colaboración multinacional.

\section{EL FUTURO DE LA COOPERACIÓN INTERNACIONAL}

Los retos actuales para lograr una sinergia a través de los instrumentos jurídicos y la capacidad para su implementación, sugieren que una mayor eficacia en el futuro de la cooperación internacional exige una nueva mirada a los mecanismos actuales y la consideración de nuevos enfoques para lograr las metas acordadas.
Una posible "victoria rápida" sería la de coordinación de los objetivos y resultados de las muchas reuniones importantes en el próximo decenio relacionadas con el medio ambiente y el desarrollo. De 2009 a 2015, se celebrarán numerosos encuentros internacionales de políticos relacionados con el medio ambiente (Conferencias de las Partes de la UNFCCC [COP] 15 y más allá, COP 10, 11 y 12 del CDB, Río +20, ODM 2015), además de las reuniones regulares del G8 y la Organización Mundial del Comercio (OMC) (que también deben abordar las cuestiones ambientales). Si la capacidad invertida en todos estos diferentes acontecimientos se pudiera centrar en objetivos comunes, habría una mayor posibilidad de lograr soluciones integradas para resolver problemas medioambientales, sociales y económicos.

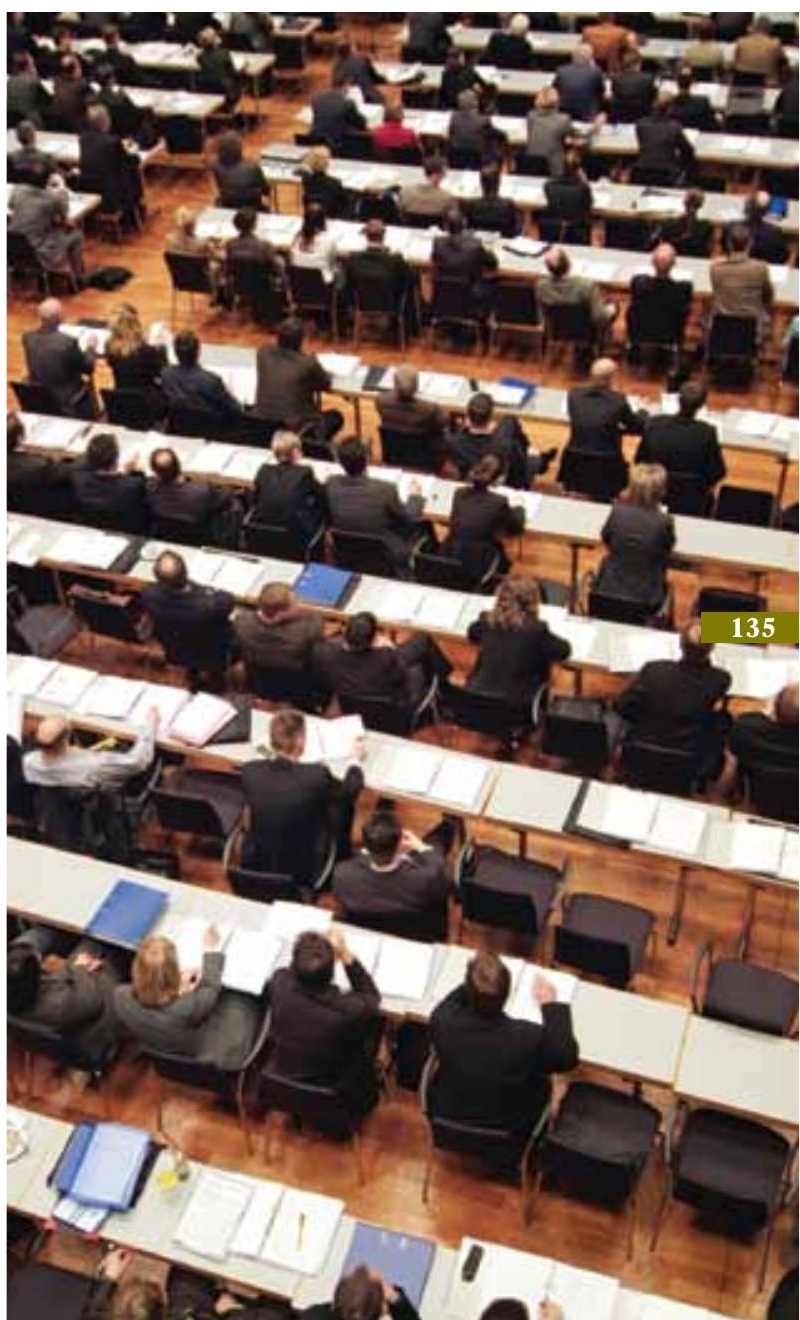


Los desafíos de la implementación y el cumplimiento de la legislación ambiental (y de los compromisos internacionales en general) sugieren reconsiderar la dependencia de medidas legales. No se trata solo de las limitaciones con respecto a la aplicación y el cumplimiento, sino también de las técnicas legislativas que tradicionalmente han sido la fuente de las regulaciones ambientales que podrían tener que cuestionarse. Si bien sigue siendo una herramienta fundamental, la legislación está siendo complementada cada vez más por medidas más blandas, sobre todo instrumentos económicos con incentivos para alcanzar objetivos deseables. Esto incluye conceptos como el pago por los servicios de los ecosistemas (PSE), que permiten concesiones a través de arreglos legales o contractuales entre los compradores y vendedores de los servicios de los ecosistemas (capítulo 4). Esta tendencia también incluye el uso de enfoques basados en los derechos, que se espera ofrezcan una mejor ventaja para la aplicación de enfoques tradicionales basados en la responsabilidad de los Estados para cumplir los compromisos con sus ciudadanos y con la salud de los ecosistemas de los que dependen.

Las nuevas responsabilidades y derechos en la gobernanza ambiental se derivan de un reconocimiento creciente de que los gobiernos no son los principales impulsores del cambio. A nivel mundial, el papel de las empresas (como lo demuestra cada vez más la IED) tiene importantes repercusiones tanto para el medio ambiente como para el bienestar humano. La integración de instrumentos económicos "más blandos" de apoyo a la conservación internacional, tales como los pagos por los servicios de los ecosistemas (capítulo 12), junto con los enfoques basados en los derechos y la responsabilidad social empresarial (RSE) ayudará a llevar el sector privado a la escena de la conservación internacional.
Muchos de los problemas ambientales que enfrenta la humanidad son cuestiones globales que requieren esfuerzos internacionales concertados para lograr soluciones exitosas. En la próxima década, la comunidad conservacionista deberá promover sinergias entre los acuerdos multilaterales y con cualquier nuevo instrumento que se desarrolle. El apoyo a la plena aplicación de los acuerdos existentes mediante la creación de capacidades y la participación de todos los interesados directos, especialmente las empresas, debe ser prioritario en la agenda de todos. Por último, la ampliación de las herramientas disponibles en los acuerdos vinculantes y la legislación restrictiva hacia opciones voluntarias e incentivos positivos debe contribuir a promover la participación activa en la conservación. 


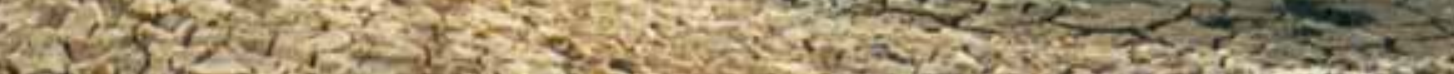

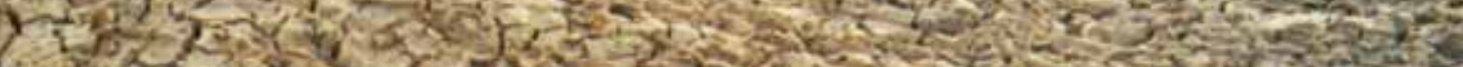
(2)

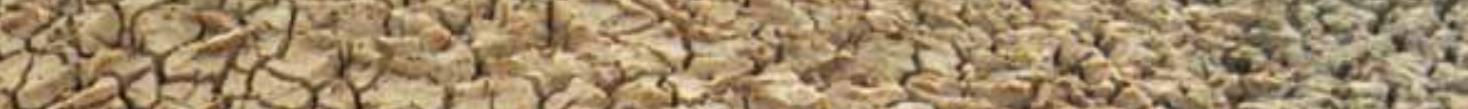

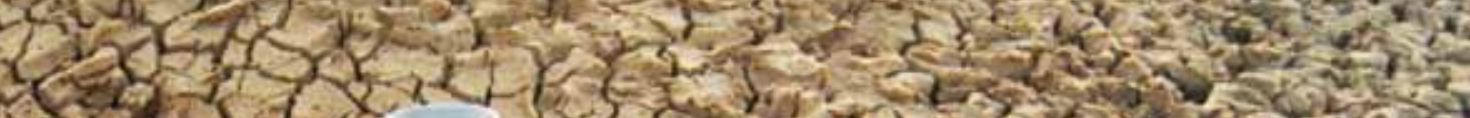

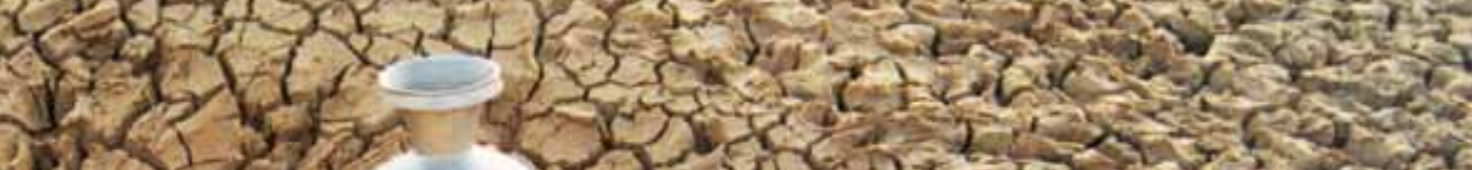
395 (3) ate
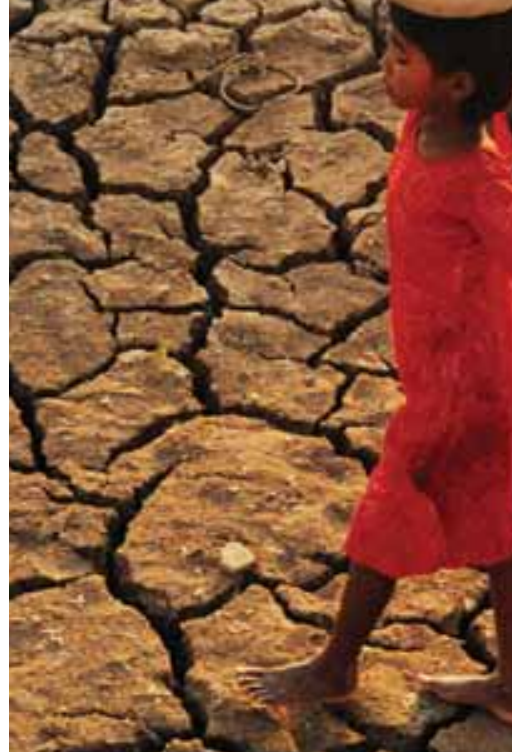

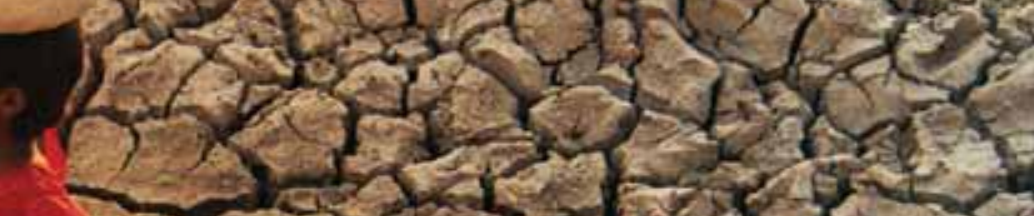

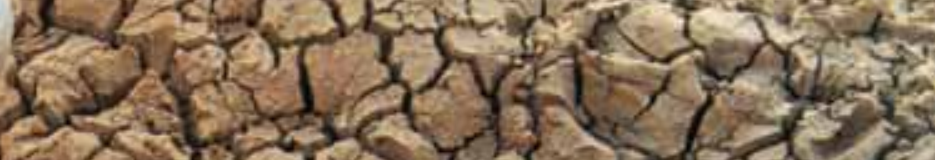
(c)
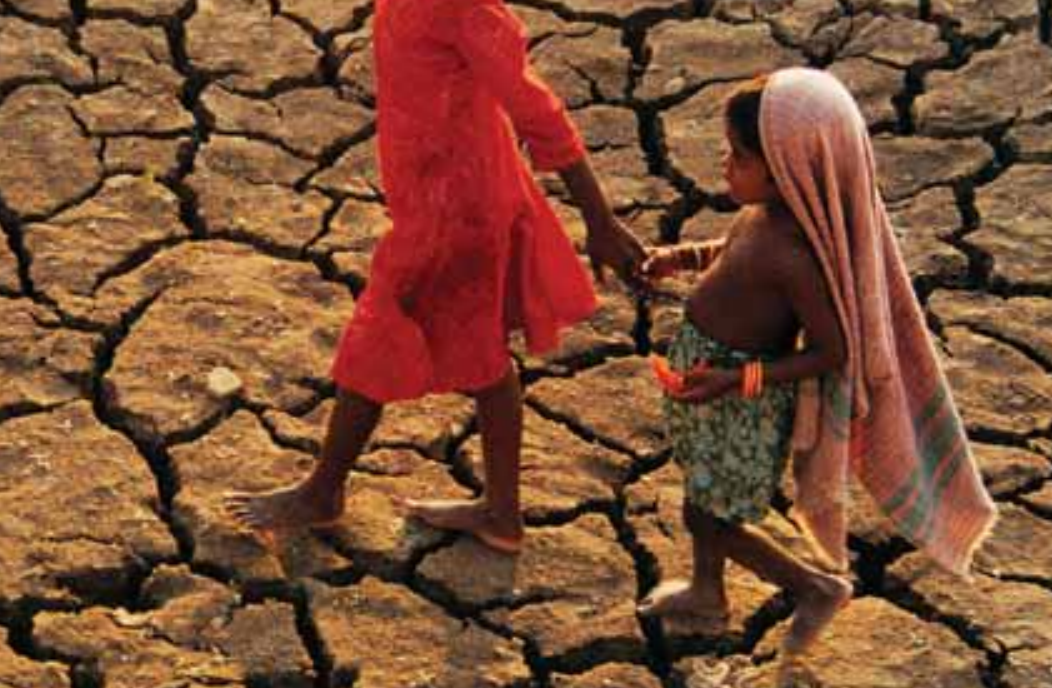

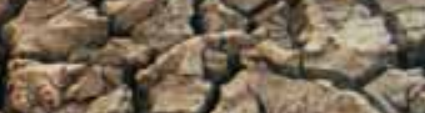

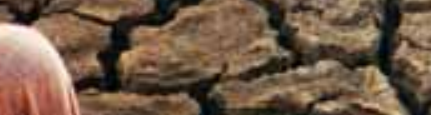

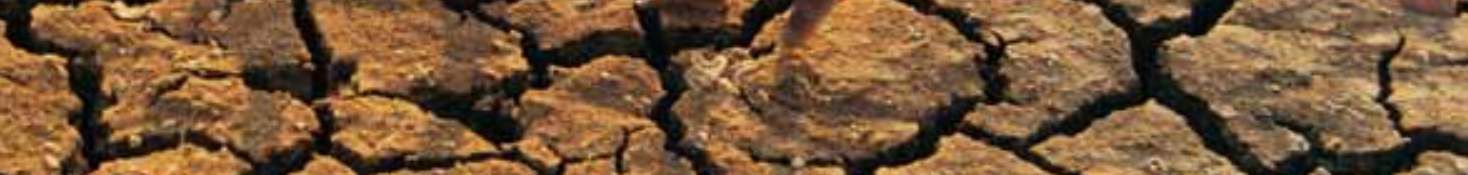

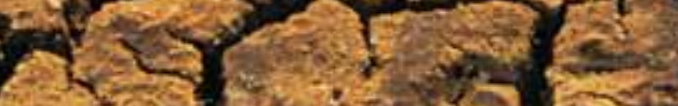
25.

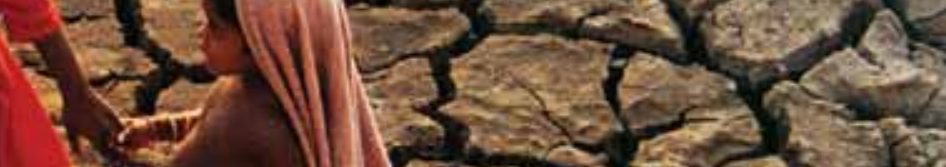

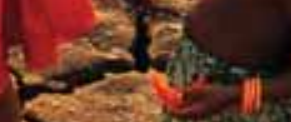

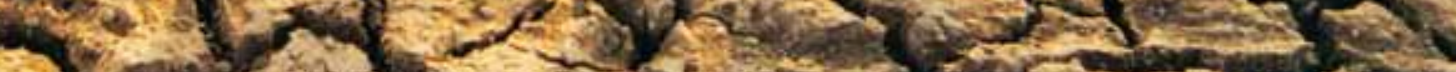

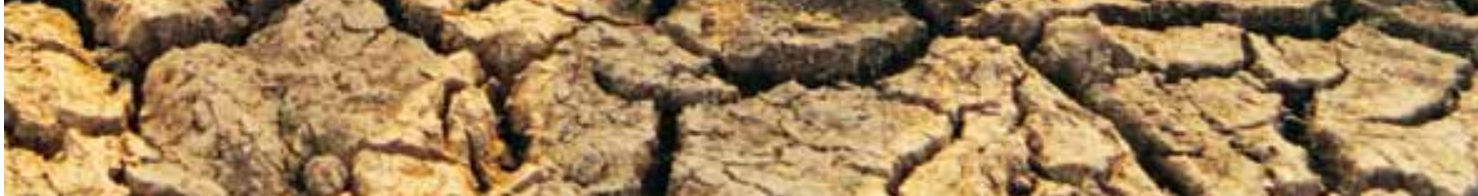

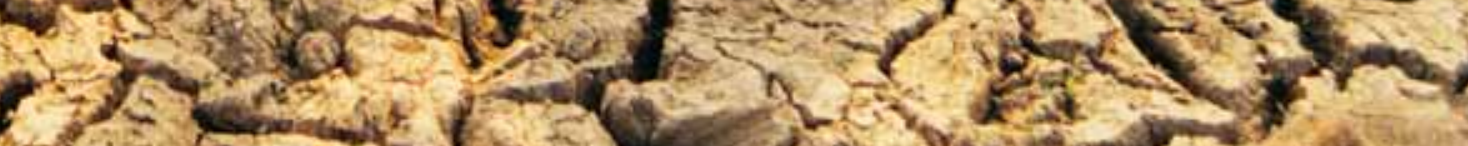
6.25
63 
15. Interacción con el Sector Privado

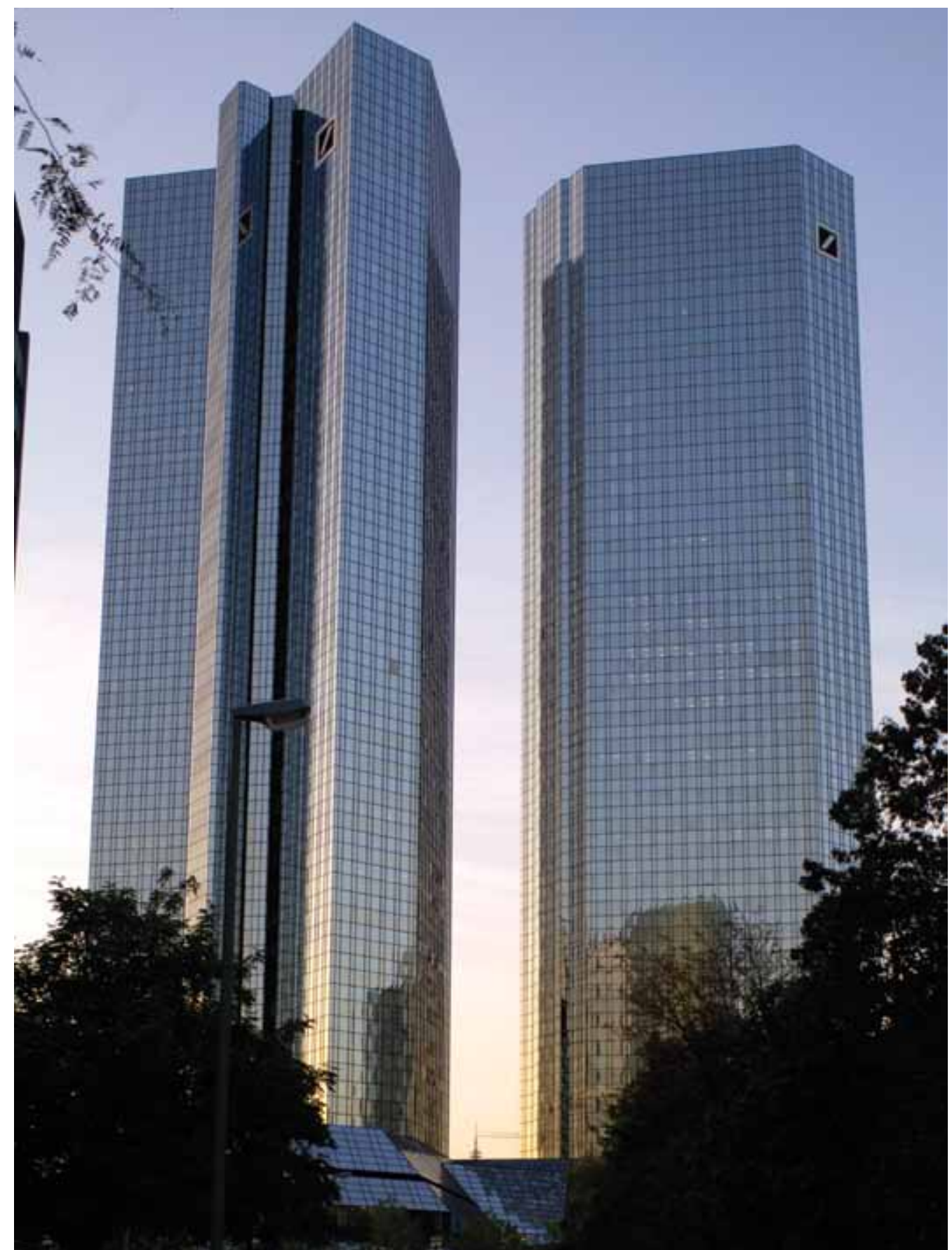


A medida que fracasan los bancos, se congelan los mercados monetarios, y los políticos discuten sobre los términos de un rescate (o adquisición financiera), más y más personas se están centrando en los resultados financieros y la estabilidad económica de su propio futuro y menos en perspectivas tales como el papel de los mercados y los negocios en la conservación de la biodiversidad. Sin embargo, cada vez resulta más evidente que los mercados y las empresas, que habían sido percibidos por los ambientalistas como un "problema" de la conservación, tendrán que ser una parte importante de la solución.

Las empresas que son especialmente proclives a tener impactos en la biodiversidad se clasifican dentro de las siguientes cuatro categorías:

- Industrias con una gran huella ambiental (minería, petróleo y gas, construcción, proveedores automotrices y de energía)

- Industrias dependientes de la biodiversidad (agricultura, silvicultura, pesca, caza, y comercio de vida silvestre)

- Servicios financieros (banca, seguros de inversión y otros intermediarios financieros)

- Empresas "verdes" (agricultura orgánica, explotación forestal de bajo impacto, energía renovable, turismo ecológico, comerciantes éticos).

Hoy en día, son varios los enfoques que están siendo adoptados por diversas partes, tanto profesionales como no profesionales, en un intento para transformar las prácticas comerciales, los mercados de productos básicos y las relaciones entre empresas y asociaciones de productores, como parte de los esfuerzos encaminados hacia una mayor sostenibilidad ambiental.

Durante el Foro de Barcelona, varios sectores empresariales proporcionaron un enfoque para los debates incluyendo la pesca (capítulo 17), la energía (capítulo 7), la agricultura (capítulo 20), las industrias extractivas y el turismo.

El nexo entre las industrias extractivas y la conservación es muy emotivo y ha sido objeto de intensa preocupación por parte de los Miembros de la UICN a lo largo de los años, especialmente con respecto a los impactos sobre las comunidades indígenas y locales. El Consejo Internacional de Minería y Metales (ICMM) (2006) ha desarrollado una Guía de Buenas Prácticas para la minería y la biodiversidad que ofrece información en todas las etapas operacionales, e incluye orientación concreta sobre consultas de los interesados directos. Varias Resoluciones (CMN 4.084, 4.087, 4.088, 4.089 y 4.090) fueron adoptadas en Barcelona con relación a los impactos de la minería sobre la biodiversidad 
a nivel regional y mundial y específicamente los efectos sobre las áreas protegidas y las comunidades locales e indígenas.

La Organización Mundial del Turismo de las Naciones Unidas (UNWTO) informó de que 924 millones de turistas hicieron viajes internacionales en 2008 y se prevé 1600 millones de llegadas de turistas internacionales en 2020 (UNWTO, 2009). La Alianza para los Criterios Mundiales de Turismo Sostenible (Alianza GSTC), una coalición de 32 organizaciones, incluida la UICN, ha llegado a cerca de 100.000 negocios turísticos, ha analizado más de 4500 criterios de más de 60 criterios de certificación y otros criterios voluntarios, y recibió los comentarios de más de 1500 personas para desarrollar los Criterios Mundiales de Turismo Sostenible (Alianza GSTC, 2008). Estos representan las normas mínimas a las que cualquier empresa turística debería aspirar para proteger y mantener los recursos naturales y culturales del mundo al tiempo que aseguran que el turismo cumpla con su potencial como herramienta para aliviar la pobreza (http://www.sustainabletourismcriteria. org). La UICN, en cooperación con los hoteles Accor y la Asociación Internacional de Hoteles y Restaurantes, también ha puesto en marcha las directrices Biodiversity: My Hotel in Action para la utilización sostenible de los recursos biológicos en este sector (UICN, 2008a).

Además, un sector emergente de "empresas pro biodiversidad" -empresas comerciales que generan ganancias a través de actividades que conservan la biodiversidad, utilizan los recursos biológicos en forma sostenible, y comparten equitativamente los beneficios derivados de este uso -también está recibiendo atención. Bishop et al., (2008) sostienen que el desafío actual de la biodiversidad es reorientar los incentivos económicos que impulsan la inversión privada, la producción y el consumo, y hacer de la conservación de la biodiversidad una propuesta empresarial viable por derecho propio.
Entre los desafíos que presenta la degradación ambiental se incluye la escasez de agua, el cambio climático, el cambio de hábitat, las especies invasoras, la sobreexplotación de los océanos y la sobrecarga de nutrientes. La agitación actual del mercado, junto con los acuciantes problemas ambientales, hace que sea más pertinente que nunca promover la colaboración entre los sectores público y privado y los gobiernos en la protección de la biodiversidad y los servicios de los ecosistemas que son parte integral de muchas operaciones comerciales (recuadro 15.1). Las organizaciones de conservación pueden contribuir a poner en marcha planes de acción y gestión sobre biodiversidad para las empresas con una gran huella ambiental, tales como la rehabilitación permanente de minas. Este enfoque no solo minimiza los impactos de la minería en la biodiversidad, sino que también

Recuadro 15.1 WWF y Coca-Cola - una asociación para la conservación del agua

En 2006, la compañía Coca-Cola y sus embotelladores autorizados utilizaron aproximadamente 290 mil millones de litros de agua para la producción de bebidas, de los cuales aproximadamente 114 mil millones de litros componían las bebidas que se vendieron en todo el mundo y otros 176 mil millones de litros se utilizaron en los procesos de fabricación de las bebidas como el lavado, limpieza, calefacción y refrigeración.

Coca Cola y WWF establecieron en 2007 una asociación que trabaja en aras de mejorar la eficiencia del agua y reducir las emisiones de carbono de las operaciones mundiales de la compañía, y ayudar a la empresa a promover prácticas agrícolas sostenibles. Además, CocaCola y WWF colaborarán en proyectos para la conservación de cuencas hidrográficas.

Fuente: WWF, 2007 
ayuda a las empresas en sus esfuerzos tendientes a la obtención de una licencia de operación para su siguiente desarrollo.

El objetivo primordial de las empresas es obtener beneficios, pero el sector privado es cada vez más consciente de los impactos perjudiciales sobre el medio ambiente de algunas de sus actividades y el hecho de que a largo plazo estos efectos suponen un factor de riesgo para su propio éxito. Las empresas están descubriendo que una mayor atención al "reverdecimiento" también puede aumentar la eficiencia, en tanto que las prácticas empresariales inteligentes pueden hacer sus operaciones más verdes y con más probabilidades de éxito. Ciertamente, las empresas centradas en la sostenibilidad han obtenido mejores resultados durante la reciente crisis financiera (AT Kearney, 2009). Los posibles beneficios de las empresas con una filosofía de desarrollo sostenible es uno de los temas que actualmente explora el Consejo Empresarial Mundial para el Desarrollo Sostenible (WBCSD - www.wbcsd.org), una asociación mundial formada por unas 200 empresas que están estudiando el papel de las empresas en el desarrollo sostenible.

Existen tanto fundamentos de demanda como de oferta para que las empresas desarrollen y apliquen programas de Responsabilidad Social Empresarial (RSE). Tal como lo señalan Lyon y Maxwell (2008), desde la perspectiva de la demanda, los productos ecológicos son un negocio en crecimiento, los inversores están impulsando a las empresas a adoptar "prácticas verdes" y los empleados prefieren trabajar para empresas que "hacen del mundo un lugar mejor". Desde la perspectiva de la oferta, los esfuerzos ambientales a menudo pueden ser más rentables que otras opciones y también mejorar a largo plazo el acceso a los recursos necesarios para la producción. Por ejemplo, convencer a los huéspedes de los hoteles a utilizar menos agua como un beneficio para la conservación representa también un ahorro en la factura de agua del hotel. Sin embargo, Margolis et al. (2007) examinaron la relación entre el desempeño social empresarial y el desempeño financiero empresarial y encontraron una asociación que, si bien muy pequeña, es positiva.

Otra medida que pueden tomar las empresas consiste en participar en programas ambientales voluntarios. Su impacto en las empresas es muy variable dependiendo de si estos programas son automonitoreados o evaluados externamente (Darnall y Sides, 2008).

Las empresas multinacionales más grandes pueden tener mayores incentivos para "reverdecerse" debido a la influencia de la atención pública sobre sus actividades y los riesgos asociados con su reputación, en adición a su capacidad para hacer cambios. Una gran empresa con malas prácticas ambientales puede ser objeto de críticas públicas. Las empresas multinacionales tienen normas mundiales que deben acatar. Como líderes del sector las grandes empresas tienen un papel positivo que desempeñar. Pueden ofrecer procedimientos y directrices, capacitación y concientización.

Un desafío para las organizaciones de conservación es cómo lograr la participación de las pequeñas y medianas empresas (Pymes). A menudo, las Pymes no disponen de los recursos o la capacidad para llevar a cabo los esfuerzos de conservación, o carecen de la reputación internacional, o incluso nacional, para que se justifique o para que sea políticamente necesario.

Entre las nuevas herramientas y mecanismos para ayudar a las empresas a participar de manera constructiva en la conservación cabe mencionar tanto la participación en las acciones de mitigación como el apoyo activo a la conservación. En el capítulo 12 se pueden encontrar más herramientas para la discusión sobre una economía verde incluyendo compensaciones, pagos por los servicios de los ecosistemas (PSE), incentivos y subvenciones. 


\section{FOMENTANDO LAS RELACIONES CON LAS EMPRESAS}

La UICN ha elaborado directrices operacionales para trabajar con el sector privado (UICN, 2009a) $\mathrm{y}$ tiene a su haber historias de compromiso en este sentido. Las organizaciones de conservación no pueden ignorar ni olvidar al sector privado y su enorme impacto sobre la biodiversidad y los servicios de los ecosistemas. En tanto que el apoyo tiene un papel de concientización y la creación de presión para el cambio, la participación constructiva es otra estrategia complementaria. La UICN y otras organizaciones conservacionistas pueden influir, alentar y ayudar a mejorar las prácticas empresariales, con la finalidad de mejorar las políticas y prácticas de industrias enteras. La UICN y muchos de sus Miembros hacen esto mediante la colaboración con los actores del sector para mejorar las normas ambientales y, en última instancia, las reglamentaciones gubernamentales. $\mathrm{Al}$ interactuar con una empresa, la UICN puede crear un punto de entrada a todo un sector.

Al contemplar la posibilidad de colaborar con las empresas, los conservacionistas debemos primero entender que las empresas actúan de manera diferente a las organizaciones no gubernamentales (ONG) y a los gobiernos. Para construir una relación es preciso entender cómo ha de crear un beneficio mutuo para ambas partes. Las preguntas que se plantean las empresas al considerar la colaboración con una organización de conservación son qué son las asociaciones verdes, por qué reverdecerse, y cómo hacerlo.

$\mathrm{Al}$ igual que con cualquier otra organización de conservación que establece una relación con una empresa, la UICN debe ser un amigo crítico y no un sello de goma. Como organización de membresía, la UICN obedece al mandato de sus Miembros, que van desde gobiernos hasta ONG. Muchos Miembros han expresado preocupación por estas asociaciones en razón de una supuesta falta de transparencia. Estas relaciones se prestan también para que una ONG corra el riesgo

de desviarse de su misión y propósito. El principal temor de los conservacionistas con respecto a estos acuerdos es que serán parte del "lavado verde", en el que una empresa utiliza a la organización conservacionista para

implicar acciones conservacionistas positivas que no reflejan la realidad. Para evitar que esto ocurra, es esencial que el profesionalismo, la objetividad y la transparencia del asociado "verde" imperen en sus relaciones con los socios del sector privado. Desde la perspectiva del sector privado, esto también es vital, ya que garantiza la credibilidad de su socio; si el socio "verde" no es de fiar la relación pierde su valor.

El trabajo con el sector privado puede ser objeto de controversia y exige cautela, pero muchas de las ONG miembro de la UICN ya han establecido relaciones productivas con el sector privado, en todas partes del mundo. Los miembros gubernamentales de la UICN generalmente apoyan la colaboración de las ONG porque creen que ambas partes se pueden beneficiar, lo que a su vez se traduce en una mejor conservación y mejores prácticas empresariales. El beneficio inicial que las ONG perciben al involucrarse en estos tipos de acuerdos es el poder de las empresas para influir en los interesados directos y así contribuir a la conservación a gran escala. Este poder e 


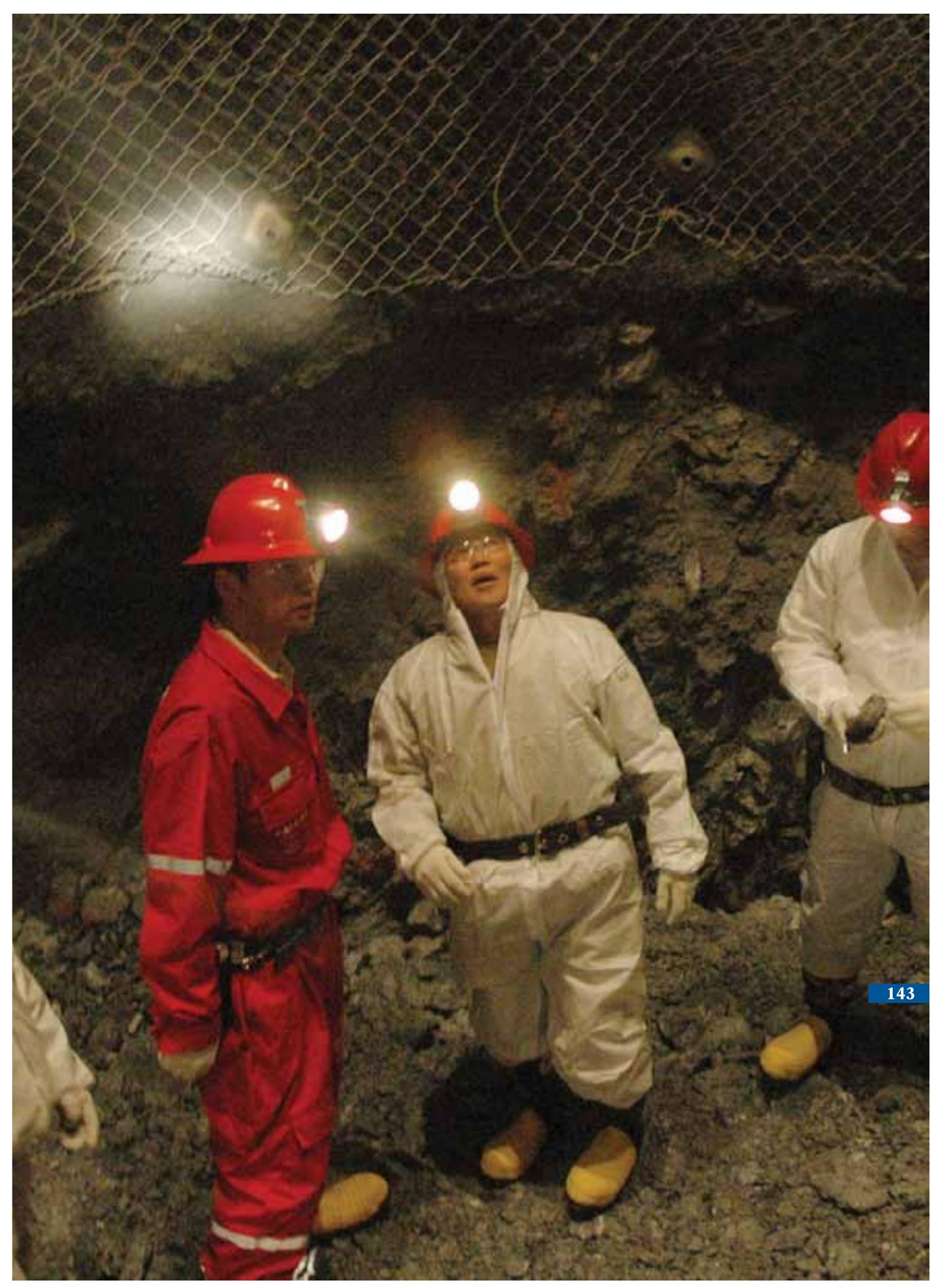


influencia puede ser seductor y la relación puede decaer fácilmente si la ONG y la empresa no mantienen rigurosos lineamientos. Si no lo hacen, se perderán los beneficios a largo plazo de la colaboración, lo cual también devaluará la reputación de ambas partes.

El tipo más fácil de relaciones que pueden emprender las organizaciones de conservación con las empresas suelen asociarse con los acuerdos de patrocinio, incluyendo los logotipos, pero la participación en tales relaciones supone

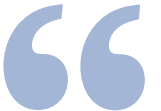
sector privado y las organizaciones de conservación puede promover la innovación en el diseño y soluciones técnicas para las empresas y la conservación.

vulnerabilidad al

“lavado verde”. Del mismo modo, el apoyo de las organizaciones conservacionistas a los programas de RSE (es decir, acciones autogeneradas más allá de los requisitos legales para la protección social y ambiental), ha sido criticado en el sentido de que esas organizaciones contribuyen al "lavado verde" de la empresa porque la RSE es un programa voluntario centrado en prácticas sostenibles y no implica necesariamente la integración de la conservación en el negocio ni en las prácticas comerciales o decisiones empresariales en general.

Las relaciones que implican una mayor participación pueden ir desde proyectos de conservación conjuntos hasta apoyo técnico y evaluación de las actividades de las empresas. Por ejemplo, desde 2004 la UICN ha trabajado con Sakhalin Energy de Rusia, un consorcio de Gazprom, Shell, Mitsui y Mitsubishi, para brindar asesoramiento y recomendaciones sobre la manera de minimizar el riesgo que suponen las explotaciones de petróleo y gas para las ballenas y al menos una parte de su hábitat. Una parte importante de este trabajo ha sido la creación en 2006 del Grupo consultivo occidental de la ballena gris (WGWAP), un grupo de científicos independientes que ofrecen asesoramiento científico sobre los planes operativos de la empresa. La asociación resultó de gran provecho para convencer a la empresa a modificar el trazado de los oleoductos submarinos para esquivar las zonas de alimentación de las ballenas con base en el asesoramiento de la

UICN. Más recientemente, las recomendaciones del WGWAP en relación con la alarmante actividad sísmica que perturba las poblaciones de ballenas se han traducido en la detención de los estudios sísmicos en la zona (comunicado de prensa de la UICN, 24 de abril de 2009 - http://www.iucn. org/about/work/programmes/marine/marine_ news/?3069/Stop-all-oil-and-gas-activities-thatcould-harm-Western-Gray-Whales-says-panel).

\section{LOS BENEFICIOS DE LA COLABORACIÓN ENTRE EL SECTOR PRIVADO Y LA CONSERVACIÓN}

La colaboración entre el sector privado y las organizaciones de conservación puede promover la innovación en el diseño y soluciones técnicas para las empresas y la conservación. Las organizaciones conservacionistas pueden ayudar a las empresas a mejorar su desempeño operacional desde una perspectiva medioambiental. Esto podría acometerse a través del diseño biomimético de productos o edificios, el asesoramiento sobre la reducción de las emisiones, la eficiencia operativa, o de fuentes alternativas de energía y tecnologías. La creación de una cadena de suministro más verde (y más eficiente) puede reportar muchos beneficios secundarios positivos, especialmente para las grandes corporaciones. Una cadena de suministro sostenible traslada las normas 
y criterios ambientales de la empresa a los proveedores, como parte de los criterios en sus solicitudes de propuestas y normas de los proveedores de materias primas. Las normas ambientales permiten a las empresas crear relaciones más sólidas con los proveedores, sumado a salud, seguridad y calidad. La integración de consideraciones de naturaleza conservacionista en las etapas tempranas del diseño del proyecto o sitio se verá recompensada en el largo plazo.

Por otra parte, las organizaciones conservacionistas se pueden beneficiar del asesoramiento del sector privado en la gestión de proyectos, relaciones públicas, gestión financiera, y diseño de operaciones complejas. Para las organizaciones de conservación, el reto, en términos de las cadenas de suministro, consiste en determinar dónde pueden ser más útiles sus consejos para lograr la conservación y hasta qué punto en la cadena pueden las normas de conservación trasladarse de un subcontratista a otro, y en qué nivel de la cadena de suministro es una sociedad responsable.

\section{DESAFÍOS FUTUROS}

Una vez que una empresa ha decidido hacer sus operaciones más verdes, ¿qué cambios operativos son necesarios y cómo puede una organización conservacionista contribuir a ello? ¿Cómo se pueden reconciliar los intereses privados con el bien público?

La necesidad de una mayor responsabilidad social y ambiental y regulaciones gubernamentales para orientar el sector privado está ampliamente aceptada tanto en el ámbito medioambiental como en los mercados financieros del mundo. La verdadera cuestión es qué tipo de iniciativas voluntarias o reglamentos garantizarán que los resultados cumplan con el doble requisito de la conservación y la rentabilidad.
Muchas empresas están interesadas en asociarse con las organizaciones de conservación para lograr un mayor impacto ambiental, o por razón de ahorro de costos. Pocas, sin embargo, están interesadas en emprender cambios fundamentales y potencialmente perturbadores en sus prácticas empresariales. Las empresas están dispuestas a entrar en alianzas con organizaciones ambientales para mejorar sus prácticas, pero la mayoría de los debates están más centrados en mejores prácticas que en nuevas prácticas.

Las asociaciones entre las organizaciones de conservación y el sector privado pueden ayudar a reverdecer a las empresas. Pero hasta que los negocios verdes se conviertan en la norma y la competencia entre las empresas se base en criterios ecológicos que obliguen a las empresas a acometer cambios profundos y fundamentales, el número de empresas que son verdaderamente “verdes” seguirá siendo modesto. Para apoyar la transición a la "empresa verde", las organizaciones de conservación y el sector privado tendrán que desarrollar un lenguaje común para la valoración de las numerosas funciones que la biodiversidad puede desempeñar en las empresas. A largo plazo habrá una creciente necesidad de reconocimiento de los problemas por parte de las empresas; y el liderazgo será necesario dentro de la comunidad empresarial. Al mismo tiempo, habrá necesidad de un mayor diálogo entre las empresas, la sociedad civil y las autoridades reguladoras. 


\section{Los bosques contienen la mayoría de las especies de cualquier}

ecosistema terrestre y el $75 \%$ de los centros de diversidad de plantas se encuentran en los bosques. Si bien según la Organización para la Agricultura y la Alimentación (FAO), la cubierta forestal mundial está aumentando muy ligeramente (3950 millones de hectáreas en 2005 frente a 3860 millones de hectáreas en 2000), las cifras incluyen plantaciones y regeneración de bosques templados. Si se excluyen las plantaciones, la tasa de deforestación ha continuado a unos 13 millones de hectáreas por año durante el período 1990-2005, con pocos indicios de una disminución significativa en el tiempo (FAO, 2005). Mientras tanto, a nivel de las especies, la Lista Roja de Especies Amenazadas de 2008 informa de que 172 de las 620 especies (28\%) de coníferas están en peligro de extinción (UICN, 2008d).

El Estado de los Bosques del Mundo 2009 (FAO, 2009a) pinta un panorama diverso de problemas relacionados con los bosques a nivel mundial. Mientras se estima que la superficie boscosa se estabilizará en los países desarrollados de Asia, de América del Norte y de algunas partes de Asia Occidental y Central, una pérdida de bosques se espera en gran parte de África y América del Sur, aunque para este último se prevé que aumentarán los bosques plantados. El aumento de conciencia sobre la gran variedad de servicios prestados por los bosques, especialmente los relativos a la mitigación y adaptación al cambio climático, está atrayendo nuevos adeptos y nuevas inversiones para la gestión forestal sostenible (GFS). El informe da cuenta de la continua innovación en el sector forestal pero también de una brecha en los países desarrollados y en desarrollo en cuanto al acceso a dichas innovaciones. Por último, el informe cuestiona los impactos que la crisis económica de 2008/2009 tendrá sobre los bosques a nivel mundial y si se adoptará o no una “orientación verde" hacia el desarrollo que apoye la gestión forestal sostenible para el futuro.

Esta disminución en los bosques a nivel mundial es un problema para todos, especialmente para los pobres de las zonas rurales. En 2004, Vedeld et al. informaron de que los bosques proporcionaban el 22\% de los ingresos para las familias rurales en 17 países de tres continentes. La mayoría de los ingresos provino de alimentos silvestres, y la leña junto con el forraje, la madera, paja y medicinas silvestres también ocupan un lugar importante. Los bosques, y los numerosos servicios que ofrecen, son realmente una parte importante de la riqueza de los pobres. 
La conservación de los bosques está centrada hoy día en la gestión a escala del paisaje, apoyando una mejor aplicación y gobernanza de los bosques, aplicando enfoques por ecosistemas y promoviendo diálogos y asociaciones que mejoren el papel de los bosques en el apoyo de los medios de subsistencia para las comunidades locales. Cada uno de estos temas ha ocupado un lugar destacado en el programa forestal y fue objeto de gran atención en el CMN de Barcelona.

\section{BOSQUES FUNCIONALES MEDIANTE LA} RESTAURACIÓN DEL PAISAJE FORESTAL

Los bosques, con su rica biodiversidad, proporcionan gran cantidad de bienes y servicios en apoyo del bienestar humano. Sin embargo, para mantener esos servicios es preciso un enfoque que vaya más allá de los árboles a una visión más amplia del uso del suelo que apoye beneficios ambientales, sociales, culturales y económicos para las personas. En el mundo de la conservación,

\section{Recuadro 16.1 Diez principios de buenas prácticas para la gestión sostenible de los bosques}

1. No existe un enfoque único, sino múltiples enfoques basados en los ecosistemas que deben ser adaptados y aplicados con pragmatismo en cada situación.

2. Las personas son parte de los ecosistemas -los puestos de trabajo, los medios de subsistencia y la generación de riqueza son tan importantes como las aves y los monos.

3. Toda gestión ambiental debe ser adaptable: gestionamos, aprendemos, adaptamos y gestionamos de nuevo.

4. Los enfoques por ecosistemas requieren herramientas que miden el rendimiento del sistema en su conjunto, incluidas las ventajas ambientales y las mejoras en los medios de subsistencia de las personas.

5. En un entorno propicio para los enfoques por ecosistemas son tan importantes los derechos de tenencia claros y defendibles como las instituciones democráticas y el imperio de la ley.

6. Los profesionales de la silvicultura deben ser eclécticos, con excelentes habilidades interpersonales, y deben ganarse el respeto de todos los grupos de interesados directos.
7. La ciencia no ofrece las respuestas pero nos ayuda a aprender de los errores y a adaptar y explorar opciones innovadoras.

8. La parte flexible de los enfoques por ecosistemas es más importante que la parte inflexible. Estos enfoques no son solo una fórmula más -suponen nuevas actitudes, enfoques, competencias y una amplia gama de habilidades.

9. Muchos elementos de los enfoques por ecosistemas no están directamente bajo el control de los departamentos forestales, por lo que estos organismos tienen que aprender a ejercer influencia y hacer arreglos con otros interesados directos.

10. Los enfoques por ecosistemas no harán desaparecer los conflictos; pueden hacer las concesiones más explícitas, pero siempre habrá ganadores y perdedores. Los enfoques por ecosistemas pueden ayudar a reducir las diferencias de poder entre los interesados directos y dar lugar a resultados más equitativos, asegurando que la sociedad en general y los grupos de interesados directos en particular ganen más y pierdan menos. 
la gestión forestal sostenible ha sido ampliamente adoptada. Sayer y Maginnis (2005) han propuesto diez principios de buenas prácticas para la GFS (recuadro 16.1).

Los enfoques por ecosistemas, la gestión forestal sostenible y la restauración del paisaje forestal han evolucionado más allá de las características biofísicas e incluyen componentes sociales, políticos y otros componentes del sistema (Sayer et al., 2007). La restauración del paisaje forestal opera en una escala que incorpora todos los tipos de tierra circundantes, creando un mosaico de bosques, tierras agrícolas, áreas protegidas y asentamientos dentro de los cuales ocurre la planificación y la implementación, e incorporando la participación de todos los interesados directos con base en los múltiples usos de dicho paisaje para el apoyo de los medios de subsistencia (Fisher et al., 2008).

El concepto unificador de estos enfoques es la idea de integrar la conservación y el desarrollo. Para los conservacionistas suele ser difícil convencer a las comunidades locales de que los beneficios a largo plazo de la conservación superarán los beneficios a corto plazo de la explotación de los bosques. Sayer et al. (2007) proponen proyectos de planificación que incluyan indicadores basados en los cinco bienes de capital (económico, social, físico, humano y capital natural) como medio para garantizar que las perspectivas de la población local y las de la conservación estén vinculadas entre sí.

La integración de los conocimientos tradicionales en el diseño y la ejecución de los proyectos es crucial para mantener el interés en los proyectos a corto y mediano plazo. Los conservacionistas deben considerar muy cuidadosamente las repercusiones sociales y ambientales de los proyectos, tales como los derechos de tenencia, las necesidades de buena gobernanza, los derechos de los pueblos indígenas, y la corrupción.
Recuadro 16.2 Los bosques versus la agricultura -el caso de la reserva forestal Mabira

La reserva forestal Mabira, en las costas del Lago Victoria en Uganda, alberga una valiosa vida silvestre, proporciona madera, presta servicios de los ecosistemas para el equilibrio del agua, y los bosques lluviosos representan un destino turístico. Tras un plan propuesto para el despeje de una tercera parte de la reserva para fines agrícolas, investigadores locales estimaron los valores del bosque. Esta valoración económica de los bosques muestra que, desde una perspectiva de corto plazo, el cultivo de la caña de azúcar produciría más beneficios económicos que si se mantuviera la reserva forestal, con una ganancia de US\$3.6 millones por año frente a US\$1.1 millones por año para conservación. Empero, la producción de caña de azúcar solo es óptima durante un corto período de cinco años. Al comparar las alternativas de uso del suelo a lo largo de los 60 años de vida de la reserva de madera, los beneficios del bosque y de los servicios de los ecosistemas que proporcionan, superan los de la siembra de caña de azúcar.

Fuente: Environment Times \#5, bttp://rerwe.grida.no/ publications/et/ep5/page/2351.aspx

Haber ignorado las causas fundamentales de la deforestación, que suelen ser causas sociales, fue una de las principales razones de los fracasos de los primeros planes de conservación de los bosques.

Así pues, ¿cuáles son las orientaciones futuras para las acciones de conservación en el desarrollo del paisaje forestal? Una de ellas es las nuevas oportunidades y amenazas impulsadas por la expansión agrícola y agroindustrial y la incertidumbre económica. Numerosos estudios 
recientes han tratado de determinar el umbral en el que resulta más rentable para los habitantes de los bosques despejar tierras para la agricultura que mantener los bosques en sus tierras (recuadro 16.2). Las condiciones que promueven este tipo de deforestación incluyen el aumento de los precios mundiales de los alimentos como la soja y la carne de vacuno, así como el aumento en la accesibilidad a los bosques a medida que mejora la infraestructura de transporte. Además de la evaluación de los costos/beneficios a través de un período de tiempo lo suficientemente largo, otras técnicas que pueden apoyar la gestión forestal sostenible incluyen sistemas de certificación, la tala de impacto reducido, e instrumentos financieros tales como los pagos por los servicios de los ecosistemas (PSE).

\section{APLICACIÓN DE LA LEGISLACIÓN FORESTAL Y LA GOBERNANZA}

La principal causa de los problemas relacionados con la GFS yace en los mecanismos de gobernanza para los recursos forestales. El Banco Mundial (2006) estima que las pérdidas de los gobiernos a causa de la tala ilegal ascienden a US\$10 mil millones por año, cifra que excede por mucho la Asistencia Oficial para el Desarrollo (ODA) invertida en la GFS. Por otra parte, se estima que a causa de la corrupción anualmente se pierde US\$5 mil millones por concepto de regalías e impuestos no recaudados de las cosechas legalmente autorizadas. Los millones de personas que dependen de los recursos forestales para sus medios de subsistencia son los principales perdedores.

En el Congreso Mundial de la Naturaleza (CMN) celebrado en Ammán en 2000, los Miembros de la UICN reconocieron los impactos de la corrupción en el sector forestal y la necesidad de apoyar una mejor gobernanza (Resolución CMN 2.039) (UICN, 2000a). Muchos países y regiones están tratando de abordar el tema de los crímenes forestales y sus consecuencias mediante su participación en procesos de Aplicación de las leyes y gobernanza sobre los bosques (FLEG).

El Plan de Acción sobre Bosques del G8 (1998) identificó la tala ilegal como uno de los principales obstáculos para la gestión forestal sostenible. El Programa proporcionó un importante incentivo para incrementar las acciones contra la tala ilegal. Como resultado de ello, se han organizado tres conferencias ministeriales regionales sobre Aplicación de las leyes y gobernanza sobre los bosques; a saber, FLEG Asia Oriental (FLEG AO) en setiembre de 2001 en Bali, Indonesia; FLEG África en Yaoundé, Camerún, en octubre de 2003; y FLEG Europa y Norte de Asia en San Petersburgo, Federación Rusa, en noviembre de 2005. Las tres conferencias FLEG congregaron a gobiernos, industrias, organizaciones no gubernamentales (ONG) e investigadores de países dentro y fuera de la región para mejorar la gobernanza y promover el diálogo internacional sobre actividades ilícitas en el sector forestal, así como para establecer marcos que permitan a los gobiernos de los países productores trabajar juntos para mejorar las relaciones y armonizar las regulaciones, y a los gobiernos de los países consumidores atacar de frente la tala y las prácticas comerciales ilícitas. Las conferencias se tradujeron en una mayor atención política para la tala ilegal y en una serie de iniciativas nacionales e internacionales por parte de los gobiernos, el sector privado y ONG para abordar el problema.

Una importante iniciativa provino de la Comisión Europea (CE) al aprobar un Plan de Acción para la aplicación de las leyes, gobernanza y comercio forestales (FLEGT) en 2003. El plan fue aprobado ese mismo año por los países miembros. Este Plan de Acción tiene por objeto excluir la tala ilegal del ingreso a los mercados de la Unión Europea (UE) mediante estrategias que incluyen la implementación de acuerdos de cooperación voluntaria (VPA) con los países productores. Estos 
acuerdos aplicarán en cada país un sistema de licencias para madera legal cuya importación sería permitida a los países de la UE para así garantizar que no ingrese al mercado de la UE productos sin licencia y posiblemente clandestinos. A partir de mayo de 2009 se suscribió un VPA con Ghana y otros están a punto de concretarse con el Congo (Brazzaville) y Camerún. Las negociaciones con Malasia e Indonesia están en marcha, y con Gabón darán inicio a finales de 2009. La CE también está trabajando con China, Vietnam y otros países para que se aborde la tala ilegal de otras maneras.

Otras estrategias empleadas o en discusión incluyen políticas de aprovisionamiento y legislación adicional para evitar que la madera clandestina llegue a los mercados consumidores.

Entre las lecciones aprendidas de estas iniciativas cabe mencionar las siguientes:

- La tala ilegal es tanto un resultado como un síntoma de una deficiente gobernanza forestal, y es necesario que las acciones tendientes a promover la aplicación de la ley se acompañen de una reforma más fundamental de la gobernanza forestal para abordar las causas subyacentes de la tala ilegal.

- La tala "legal" no es necesariamente parte de una gestión forestal "sostenible y equitativa”. La meta de la UICN es la implementación de acuerdos de gobernanza que promuevan la gestión forestal sostenible y equitativa.

- Es necesario que las acciones para abordar la tala ilegal y una reforma forestal más amplia se basen en procesos efectivos con múltiples interesados directos para aumentar la calidad de las decisiones y el apoyo de la sociedad para su implementación.

- Los procesos efectivos con múltiples interesados directos que acompañan las iniciativas tendientes a abordar la tala ilegal, como los VPA, tienen el potencial para convertirse en un trampolín para abordar una reforma más amplia a la gobernanza forestal.
- Las experiencias recientes con la reforma de la gobernanza forestal en el contexto de FLEG(T) y los procesos con múltiples interesados directos están aportando información valiosa a las discusiones sobre los acuerdos de gobernanza forestal para apoyar los planes de Reducción de Emisiones por Deforestación y Degradación (REDD).

\section{ASOCIACIONES FORESTALES EN APOYO DE LOS} MEDIOS DE SUBSISTENCIA

Los bosques proporcionan múltiples bienes y servicios a múltiples interesados directos. Esto debe reflejarse en la forma como se gestionan y conservan los paisajes forestales, pero solo puede hacerse equitativamente cuando se escucha a todos los interesados. Las asociaciones son, por tanto, cruciales para compartir necesidades y perspectivas, y para encontrar sinergias. En este contexto, el enfoque a la gobernanza y gestión de los bosques basado en una sola perspectiva resultaría contraproducente -si quienes tienen un interés legítimo en los bosques no tienen opinión en lo que toca al futuro de los paisajes forestales, con toda probabilidad minarán los intentos para avanzar. No se puede permitir que la suposición de que los bosques son "para secuestración de carbono" o "para la conservación de la biodiversidad" desvíe la atención de los bienes y servicios que proporcionan a las poblaciones rurales, que en cantidades desmedidas cuentan con dichos recursos para apoyar sus medios de subsistencia básicos. Tampoco será suficiente asumir que en tales circunstancias podría lograrse acciones de conservación y desarrollo en las que todos ganan. Para satisfacer las múltiples y contradictorias voces, es preciso recurrir a las concesiones, lo cual se facilita bajo un entorno de colaboración.

El Diálogo sobre los Bosques Tropicales, cuya secretaría está en la Universidad de Yale, ha estado promoviendo procesos de diálogo desde 
su inicio en 1998. Su premisa se basa en que se debe crear confianza entre los diferentes grupos que participan en los diálogos y facilitarles las herramientas e ideas y un entorno en el que puedan formar sus propias asociaciones. Estas asociaciones no tienen necesariamente que resultar en una concesión absoluta; la creación de consenso en sí puede ser radical. La UICN ha contribuido al Manejo intensivo de los bosques plantados: bacia mejores prácticas y más allá de REDD - la función de los bosques en el cambio climático, una declaración de consenso sobre los bosques y el cambio climático.

\section{La Asociación de Colaboración en Materia de} Bosques (CPF) es un acuerdo voluntario entre 14 organizaciones y secretarías internacionales con importantes programas sobre bosques (CIFOR, FAO, OIMT, IUFRO, CDB, FMAM, UNCCD, UNFF, UNFCCC, PNUD, PNUMA, ICRAF, $\mathrm{BM}, \mathrm{UICN})^{3}$. La misión de CPF es promover la gestión, conservación y desarrollo sostenible de todos los tipos de bosques y fortalecer el compromiso político a largo plazo a este efecto. Los miembros de CPF trabajan juntos cada vez más en proyectos y movilizan recursos para ayudar a los países en la consecución de sus metas relacionadas con los bosques y apoyar la implementación de la gestión forestal sostenible (FAO, 2009b).

En 2007, el Banco Mundial propuso la creación de una Alianza Growing Forests (GFP) que vincula los procesos a nivel local y mundial y promueve procesos de toma de decisiones en la escena internacional a fin de reflejar las opiniones y necesidades de los habitantes de los bosques. El Banco Mundial solicitó al Instituto Internacional para el Medio Ambiente y Desarrollo (IIED) llevar a cabo una evaluación independiente de su propuesta con una amplia gama de interesados directos. Más de 600 expertos forestales respondieron a la evaluación del IIED o participaron en grupos de concentración en Brasil, China, Ghana, Guyana, India, Rusia y Mozambique, así como en reuniones internacionales. La UICN también ha tenido un papel destacado en la GFP. Esta iniciativa, apoyada por la FAO y el Banco Mundial, apunta a hacer verdaderamente sostenible la silvicultura mediante la creación y el fortalecimiento de nuevas asociaciones que reflejen las necesidades locales y protejan los bienes públicos mundiales. A la vez que complementa la CPF, se diferencia de ella en su enfoque específico de abajo hacia arriba. El enfoque inmediato de la UICN sobre GFP está centrado en el desarrollo de asociaciones en Mozambique, Ghana y Guatemala.

Un interesante avance logrado por algunas ONG consiste en ayudar a fomentar la capacidad de las comunidades locales en el desarrollo empresarial. Forest Trends, un Miembro de la UICN, ha creado un Fondo de Desarrollo de Negocios para prestar asistencia técnica a los operadores forestales en la evaluación, identificación y desarrollo de oportunidades para ingresos no madereros para maximizar el valor de los bosques, incluyendo la secuestración de carbono, la conservación de cuencas hidrográficas, y la conservación de la biodiversidad. Los conservacionistas pueden apoyar a los habitantes de los bosques en el cambio de un "enfoque hacia un solo activo", en el que la madera cortada se ve como el único valor real de los bosques, a un "enfoque de activos múltiples" que diversifica las oportunidades de mejoramiento de los medios de subsistencia

\footnotetext{
${ }^{3}$ Las siglas corresponden a los siguientes nombres: CIFOR - Centro Internacional de Investigación Forestal; FAO - Organización de las Naciones Unidas para la Agricultura y la Alimentación; OIMT - Organización Internacional de Maderas Tropicales; IUFRO - Unión Internacional de Organizaciones de Investigación Forestal; CDB - Convenio sobre la Diversidad Biológica; FMAM - Fondo para el Medio Ambiente Mundial; UNCCD - Convención de las Naciones Unidas de Lucha Contra la Desertificación; UNFF - Foro de las Naciones Unidas sobre Bosques; UNFCCC - Convención de las Naciones Unidas sobre el Cambio Climático; PNUD - Programa de Naciones Unidas para el Desarrollo; ICRAFCentro Mundial de Agroforestería; BM - Banco Mundial.
} 
aprovechando los productos y servicios no madereros y apoyando el acceso a los mercados.

\section{LOS BOSQUES Y EL CAMBIO CLIMÁTICO}

El capítulo 5 pone de relieve el papel de los bosques en la mitigación del cambio climático a través de REDD. Además de REDD, los bosques presentan otra oportunidad para el cambio climático. Las tierras forestales degradadas cubren actualmente un estimado de 800 millones de hectáreas. Si bien sus reservas de carbono están significativamente agotadas, a menudo estas tierras conservan suficiente cubierta forestal para excluirlas de ser clasificadas como deforestadas $\mathrm{y}$, por tanto, accesibles a fondos de reforestación en virtud de los mecanismos de Kioto. El Cuarto Informe de Evaluación del Grupo
Intergubernamental de Expertos sobre el Cambio Climático (IPCC) estima que la restauración de estas tierras podría ser responsable de cerca de 117 millones de toneladas equivalentes de dióxido de carbono (ajustando otros gases de efecto invernadero a dióxido de carbono) hasta 2030. Esto equivale a una y media veces el potencial estimado disponible de evitar la deforestación hasta 2030. La restauración de las tierras forestales degradadas ofrece un triple beneficio climático: evitar las emisiones deteniendo la degradación en curso; secuestración adicional de carbono a través de la restauración, y beneficios de adaptación climática a nivel del paisaje con respecto a la prestación de los servicios de los ecosistemas restaurados, como por ejemplo, una mejor regulación del ciclo hidrológico.

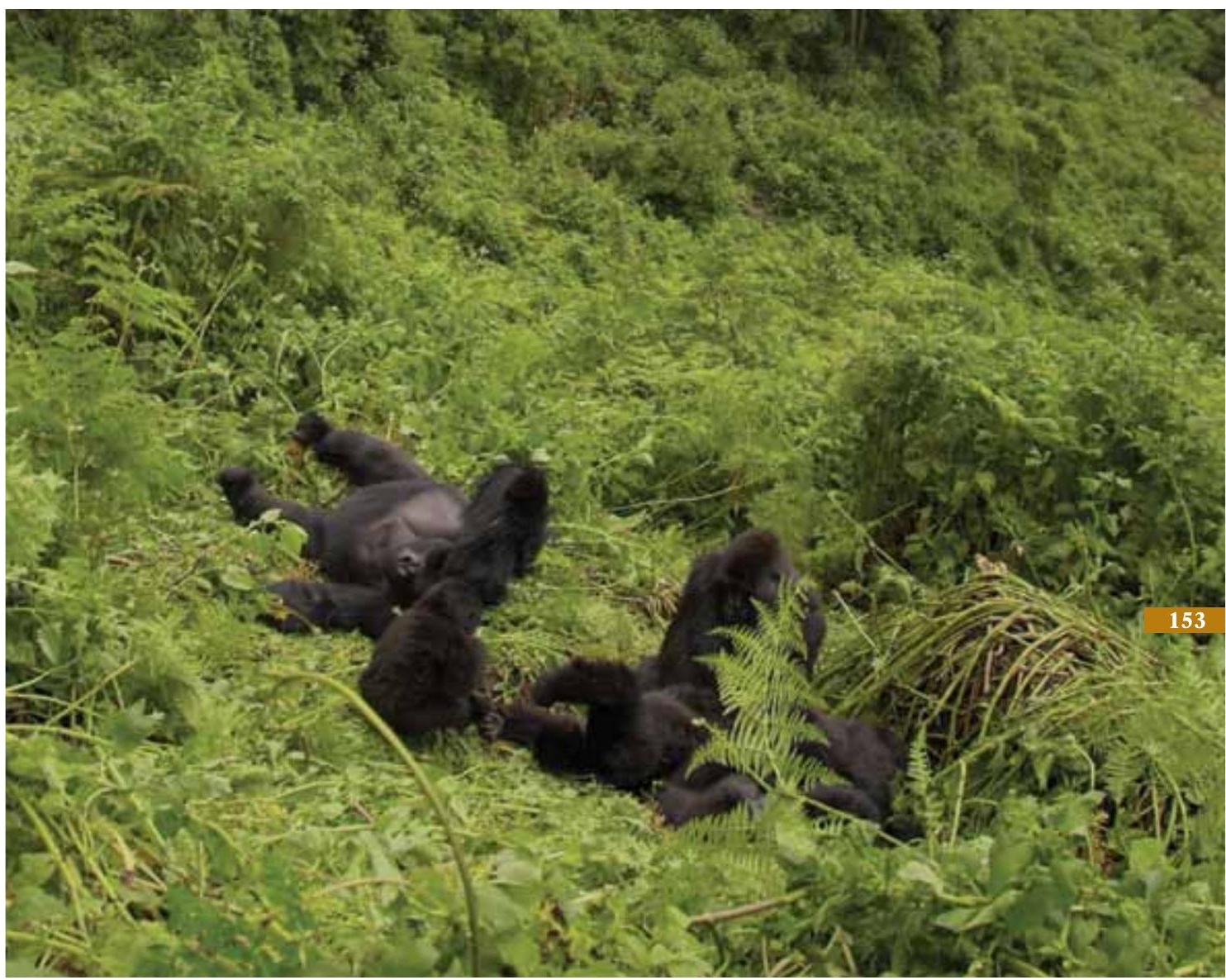




\section{Sistemas Marinos: Encauzando 1. la Conservación hacia el Mar}

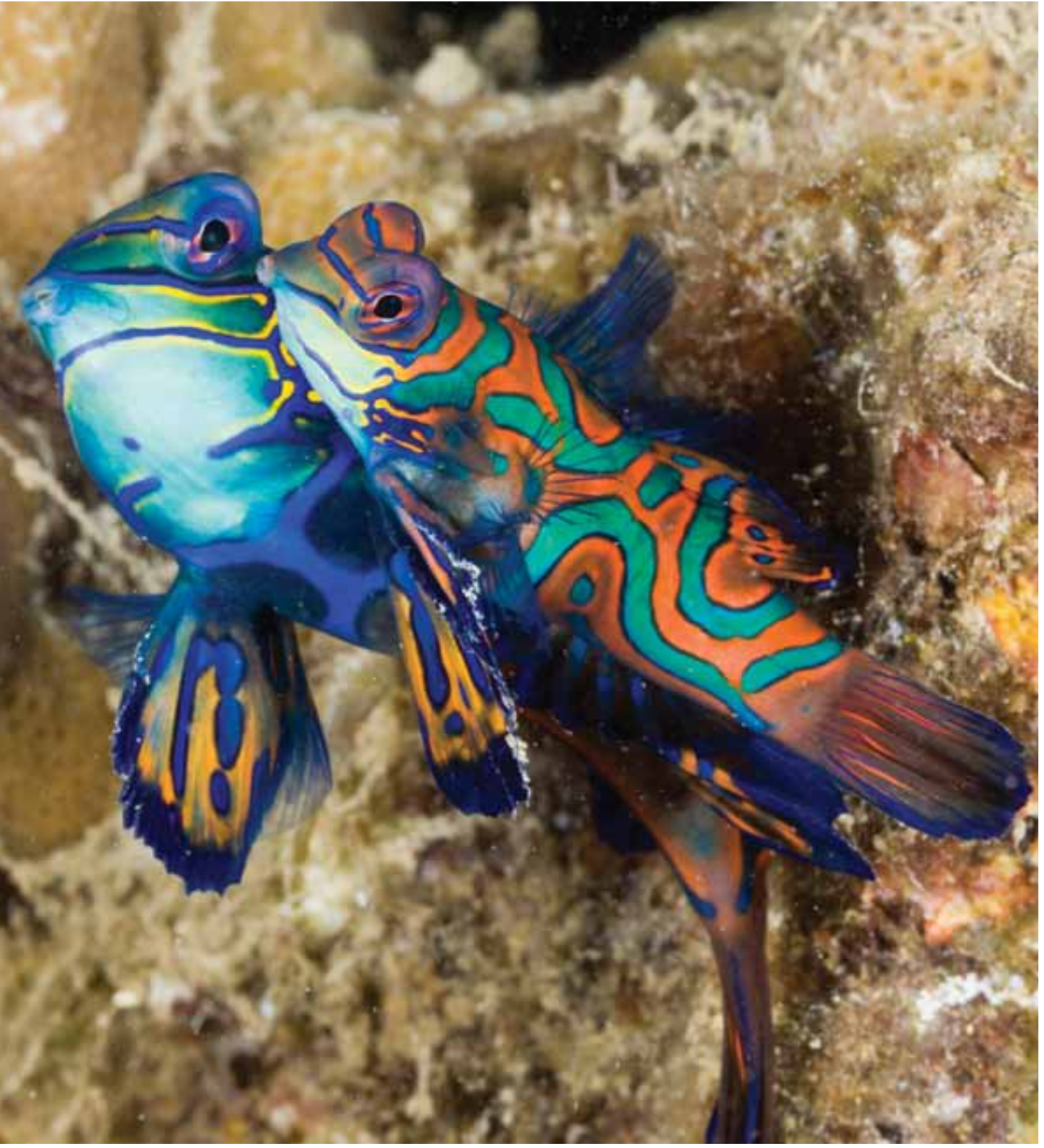


Tras muchos años de ser ignorado, pese a representar la vasta mayoría de la superficie del planeta, el reino marino es ahora objeto de atención. A medida que escasean los recursos terrestres, el mundo dirige su mirada hacia el mar en busca de soluciones. A medida que las soluciones terrestres para la mitigación del cambio climático se tornan más y más difíciles, los responsables de la formulación de políticas se preguntan cómo pueden ayudar los océanos.

Entre las cuestiones más urgentes de abordar desde la perspectiva marina son los impactos de las crecientes concentraciones de $\mathrm{CO}_{2} \mathrm{y}$ otros gases de efecto invernadero (GHG) y la sobrepesca. En nuestra lucha para hacer frente a estos problemas, dos herramientas clave que deben ser perfeccionadas y adaptadas a los océanos incluyen la gobernanza de los recursos marinos en zonas fuera de la jurisdicción nacional y la planificación espacial, incluidas las áreas marinas protegidas (AMP).

\section{LOS OCÉANOS Y EL CAMBIO CLIMÁTICO}

Los océanos desempeñan un papel crucial en la regulación del clima del mundo y en el suministro de alimentos e ingresos para miles de millones de personas en todo el mundo. A medida que el clima mundial cambia a un ritmo sin precedentes debido en gran parte a las emisiones antropógenas de GHG, las pruebas de los impactos en los medios marinos y costeros ya no puede seguir ignorándose. Ya se están observando efectos tales como el calentamiento de los océanos, el aumento de la acidez del agua, el blanqueo del coral y el aumento del nivel del mar, con consecuencias graves para la biodiversidad marina y las sociedades humanas. Una mejor comprensión del cambio climático y la forma en que interactúa y exacerba muchos efectos directos como la contaminación y la sobrepesca y la aplicación de este conocimiento a la mitigación y adaptación al cambio climático, se han convertido en prioridades para la comunidad internacional.

Los océanos serán la víctima y la posible solución a los impactos del cambio climático. Los arrecifes de coral son uno de los ecosistemas más vulnerables al cambio climático, y pueden ser considerados como los "canarios en la mina de carbón del cambio climático”. El informe de 2008 sobre la situación de los arrecifes de coral del mundo determinó que el 19\% de los arrecifes de coral se han perdido con el consiguiente impacto sobre 500 millones de personas cuya subsistencia depende de ellos (Wilkinson, 2008). Pero no son solo los arrecifes los que están mostrando signos de los impactos del cambio climático. Los manglares y otros ecosistemas costeros son 
particularmente vulnerables a la elevación del nivel oceánico. Temperaturas más altas y cambios en la acidez del mar están afectando los pastos marinos que se utilizan para medicina tradicional, mobiliario y techos de viviendas, y proveen hábitats esenciales para numerosas especies, desde peces hasta dugongos.

La pesca, y las comunidades que dependen de ella también sentirán los efectos del cambio climático. Alison et al. (2009) compararon la vulnerabilidad de 132 economías nacionales a los posibles efectos del cambio climático en la pesca de captura y determinaron que Malawi, Guinea, Senegal, Perú, Colombia, Bangladesh, Camboya, Pakistán y Yemen son los más vulnerables. Esta vulnerabilidad se debe al efecto combinado del calentamiento previsto, la importancia relativa de la pesca para las economías nacionales y las dietas, y la limitada capacidad de la sociedad para adaptarse a los posibles impactos y oportunidades.

En términos de soluciones sosas a las amenazas que plantea el cambio climático, una que está atrayendo gran atención es la geoingeniería de los océanos. El fitoplancton desempeña un papel clave en hacer de los océanos el sumidero de dióxido de carbono más grande del mundo, y las propuestas para la "geoingeniería" de los océanos y para aumentar la absorción de carbono incluyen estimular la proliferación de algas mediante la adición de hierro y otros nutrientes para capturar $\mathrm{CO}_{2}$ o para "inyectar" $\mathrm{CO}_{2}$ directamente en las estructuras geológicas en el subsuelo marino, un proceso conocido como captura y almacenamiento de carbono (CCS) (Victor et al., 2009). Muchos de los debates sobre el potencial de los océanos para ayudar con la mitigación del cambio climático no pueden superar el hecho de que aún sabemos muy poco sobre los procesos bioquímicos oceánicos y la capacidad para absorber $\mathrm{CO}_{2}$. Si bien algunos estudios muestran que la fertilización de los océanos estimula la floración del plancton, no está claro si el transporte de carbono al sedimento de los océanos es eficaz, y los efectos de esas actividades sobre el entorno marino, sobre los que se alimentan de plancton como las ballenas, y sobre el clima mundial siguen siendo desconocidos e impredecibles. Antes de considerar la venta de contrapartidas a la fijación de carbono para los proyectos de fertilización, se necesitan más investigaciones para evaluar los riesgos para nuestros océanos y las actividades de fertilización en gran escala requieren extrema cautela. Del mismo modo, tampoco están probadas la eficacia en función de los costos y la energía de CCS, y las posibles implicaciones de las fugas. Por último, los actuales marcos normativos para la fertilización del océano o para CCS no son suficientes, ni tampoco contribuye efectivamente la actividad a reducir la producción del $\mathrm{CO}_{2}$ generado por las actividades humanas.

\section{SOBREEXPLOTACIÓN PESQUERA}

El informe Estado de la Pesca Mundial de la Organización para la Agricultura y la Alimentación (FAO, 2008a) repite las conclusiones de su informe de 2007, pero, si bien una situación estable en los últimos dos años es una señal positiva, el hecho sigue siendo que la mayoría de la pesca mundial ya está totalmente explotada y un $28 \%$ está sobreexplotada. El informe confirma que, en 2006, la pesca y la acuicultura proporcionaron más alimentos que nunca, con una proporción creciente de peces procedentes de la acuicultura. El progreso ha sido mínimo para hacer frente a los principales factores que han incidido en la sobreexplotación pesquera; incluyendo el manejo de la pesca incidental, la sobre capitalización de las flotas pesqueras del mundo, el control de la pesca ilegal, y la mitigación de los daños causados a través de algunos métodos de pesca como la pesca de arrastre de fondo y la pesca con cianuro. 
El informe de la FAO no menciona algunos de los graves resultados que salieron a la luz en los últimos años. Aproximadamente el 26\% de los tiburones y rayas del Atlántico Nororiental están en peligro de extinción debido a la pesca excesiva de estas especies de crecimiento lento (Gibson, et al., 2008). Muchas aves marinas, en particular los albatros, están amenazadas por la actividad pesquera ya que pueden ser parte de las capturas incidentales, si bien los cambios en los métodos hawaianos de pesca del atún con palangre han resultado en una disminución del $67 \%$ en las capturas incidentales de aves marinas (Gilman $e t$ al. 2008). Otra consecuencia preocupante de años de sobreexplotación pesquera, especialmente para los peces como el bacalao, es el hecho de que algunas poblaciones de peces, a una década de una caída de la población por razones de la sobrepesca, están ahora madurando en tamaños más pequeños y a edades más tempranas (Fudge y Rose, 2008). Las prácticas modernas de pesca están dando lugar a cambios evolutivos mucho más rápidamente de lo que podríamos haber imaginado.

La voluntad política para gestionar la pesca parece ser escasa. Uno de los eventos recientes más decepcionantes fue la decisión adoptada en noviembre de 2008 por la Comisión Internacional para la Conservación del Atún Atlántico (ICCAT) de aprobar una cuota para el atún del Atlántico Norte que supera en casi un $50 \%$ el nivel de pesca recomendado, propuesto por sus propios asesores científicos (UICN, 2008c). La población del atún aleta azul ha llegado a un nivel críticamente bajo, con todos los dictámenes científicos coincidiendo en la necesidad de una drástica reducción de los niveles de pesca y una veda a la pesca durante la época de desove para permitir la recuperación de la población. Los objetivos económicos y de empleo a corto plazo están superando las necesidades a más largo plazo de los ecosistemas que sustentan dichos objetivos. Pone en tela de juicio el papel de las organizaciones regionales de gestión pesquera y su capacidad para administrar los recursos en alta mar para un rendimiento sostenible. En menor escala, sin embargo, se han documentado algunos éxitos en la gestión pesquera a través de la asignación de "cuotas de captura" para los pescadores particulares, esencialmente un enfoque basado en los derechos para la gestión de los recursos (Costello et al., 2008).

Como si no fuera suficiente ocuparse de los efectos de decisiones miopes, ya se cuenta con nuevos descubrimientos sobre los cambios inducidos por el cambio climático en la distribución y abundancia de peces e invertebrados de interés comercial, los cuales sugieren que las especies de aguas más cálidas están cambiando a latitudes más altas y la productividad de peces es probable que disminuya en las latitudes más bajas (es decir, la mayoría de las zonas tropicales y subtropicales de los océanos, mares y lagos) (FAO, 2008b). $\mathrm{Si}$ bien esos cambios ecológicos pueden tener impactos positivos en los países del Norte, obviamente, reducirán el potencial de captura de peces en los países tropicales. Además, se prevé que los océanos tropicales y polares y los mares semicerrados son los más vulnerables a la invasión de especies no nativas y cambios en la distribución de las especies. Debido a su alta dependencia de la pesca de subsistencia y su limitada capacidad para adaptarse al cambio climático, las naciones pobres costeras en los trópicos, en particular en África, Asia y el noroeste de América del Sur, serán las más afectadas por los impactos del cambio climático en la pesca. Se requieren respuestas de gestión, pero estas deben ser cuidadosamente consideradas para equilibrar las concesiones entre la gestión de la pesca, la conservación de la biodiversidad y la gestión de otras actividades 
humanas en el mar para el beneficio a largo plazo de todos los interesados.

\section{GOBERNANDO DONDE NO GOBIERNA}

\section{GOBIERNO ALGUNO}

Las necesidades de los océanos de todo el mundo deben considerarse como un todo y la construcción de puentes entre los múltiples interesados directos de los océanos y los recursos oceánicos -en tanto que representa un reto importante- es también el único camino razonable hacia adelante. Los sistemas de gobernanza y gestión descoordinados y sectoriales no son adecuados para atender debidamente las múltiples amenazas para el medio marino, o para evaluar los impactos acumulativos de las actividades o los efectos de una actividad sobre otra. Y no están adaptados para hacer frente a la espinosa cuestión de la gobernanza más allá de la jurisdicción nacional -es decir, en alta mar.

No obstante lo anterior, las cuestiones marinas están recibiendo una buena dosis de atención política cada año en las Naciones Unidas y presentan una oportunidad tangible de corto plazo para obtener resultados sobre políticas de conservación. La Asamblea General de las Naciones Unidas se ocupa de la pesca ilegal, no declarada y no reglamentada (IUU), la pesca de arrastre de fondo, la conservación de los montes marinos y otros ecosistemas marinos vulnerables, los recursos genéticos del fondo marino, y las medidas de gestión de áreas más allá de la jurisdicción nacional, mientras que el Convenio sobre la Diversidad Biológica (CDB) se ocupa de cuestiones de la conservación del medio marino dentro de la jurisdicción nacional incluyendo las zonas marinas protegidas y la prestación de asesoramiento científico y técnico con respecto a las AMP fuera de la jurisdicción nacional, incluida la identificación de áreas de importancia ecológica y biológica y el diseño de redes representativas de AMP.
Recuadro 17.1 Diez principios para la gobernanza en alta mar

1. Libertad condicional de las actividades en alta mar

2. Protección y preservación del medio marino

3. Cooperación internacional

4. Enfoque basado en la ciencia para la gestión

5. Disponibilidad pública de información

6. Procesos de toma de decisiones transparentes y abiertos

7. Enfoque de precaución

8. Enfoques por ecosistemas

9. Uso sostenible y equitativo

10. Responsabilidad de los Estados como guardianes del medio marino mundial Fuente: http://cmsdata.iucn.org/downloads/10_principles_for_ high_seas_governance_final.pdf

\section{La Organización Mundial del Comercio (OMC)} también está negociando la reforma de los subsidios a la pesca, principalmente en respuesta a las preocupaciones acerca de la explotación no sostenible y los impactos ambientales (por ejemplo, la captura incidental). Estas cuestiones seguirán siendo política y técnicamente importantes para el futuro previsible. El Convenio de Londres (LC) ha desarrollado normas en relación con el subsuelo marino y la secuestración de $\mathrm{CO}_{2}$ y está desarrollando un marco de evaluación de las actividades de investigación científica para las actividades relativas a la fertilización de los océanos. Las partes del LC han exhortado a los Estados a abstenerse de actividades de fertilización oceánica, habiendo emitido una resolución declarando que las actividades de fertilización 
de los océanos, salvo "la investigación científica legítima”, son contrarias a los objetivos del LC, actualmente no califican para exenciones, y no deben permitirse.

Para estimular el debate internacional sobre la reforma, en el Congreso Mundial de la Naturaleza en Barcelona, se enunciaron 10 Principios para la gobernanza moderna de alta mar que reflejan los principios fundamentales que las naciones han adoptado en diversos tratados y declaraciones, pero cuya implementación ha fracasado en casi el 50\% del planeta que está más allá de cualquier jurisdicción nacional (recuadro 17.1). Estos enfoques están diseñados para estimular el progreso mediante la identificación de directrices comunes para la acción.

\section{ÁREAS MARINAS PROTEGIDAS (AMP)}

Aunque la cobertura mundial de áreas protegidas terrestres se encuentra en $\sim 12 \%$, para el reino marino la cobertura es inferior al 1\% - una medida insignificante teniendo en cuenta que el 71\% del planeta está cubierto por océanos. Cuando son eficazmente diseñadas, gestionadas y ejecutadas, las AMP pueden proporcionar muchos beneficios ecológicos y socioeconómicos, además de aumentar la resiliencia de los ecosistemas marinos frente a las crecientes presiones globales, especialmente el cambio climático. Sin embargo, al ritmo actual, el objetivo acordado a nivel mundial de proteger el 10\% de los océanos del mundo para el año 2010 no se alcanzará antes de 2060 -un momento en el que muchas especies marinas, especialmente las de alto valor comercial- podrían haber desaparecido. La Comisión Mundial de Áreas Protegidas (CMAP) incluirá un enfoque basado en la mejora de las listas indicativas de los sitios marinos del Patrimonio Mundial así como el desarrollo de enfoques para mejorar la eficacia de la gestión de los espacios marinos.
Varias evaluaciones mundiales han llegado a la conclusión de que la buena gestión de las zonas marinas protegidas, basada en un profundo conocimiento del contexto local, puede ser de gran beneficio para las comunidades locales, además de alcanzar las metas de conservación. Las AMP eficaces han demostrado ayudar a mejorar la productividad para las explotaciones pesqueras circundantes, incrementar y diversificar las oportunidades económicas para la población local, apoyar el reconocimiento de los derechos de la pesca tradicional y otros derechos de los usuarios, y resolver los conflictos locales. Las redes de AMP también desempeñan un papel importante en el aumento de la resiliencia de los ecosistemas y pueden promover la adaptación al cambio climático.

Para ser eficaces, las redes de áreas marinas protegidas deben ser ecológicamente coherentes y deben incluirse en los marcos de gestión integrada de los océanos que se ocupan de la gama de actividades humanas e impactos tanto dentro como fuera de las áreas protegidas. Una red eficaz y representativa de AMP requiere de información espacial y temporal sobre el mundo marino. El lanzamiento de la capa de AMP en Google Earth, accesible a cientos de millones de usuarios, así como un portal global de fácil utilización sobre AMP en www. protectplanetocean.org deberían generar interés y apoyar el intercambio de información entre gobiernos, conservacionistas, profesionales y público en general para ahondar en ese conocimiento. Las decisiones sobre dónde establecer nuevas zonas marinas protegidas deben basarse en información pertinente sobre las especies, los hábitats y los medios de subsistencia en los océanos. Ya se han dado los primeros pasos para reunir información sobre especies y hábitats para optimizar la planificación de AMP, marcando una nueva e innovadora asociación de expertos para la conservación. 


\section{EL FUTURO DE NUESTROS MARES Y OCÉANOS}

Es evidente que el aumento de las concentraciones de $\mathrm{CO}_{2}$ y otros gases de efecto invernadero (GHG) y los cambios en el clima de la Tierra, así como la química de los océanos, suponen una importante amenaza para los océanos y los ecosistemas costeros. Esta amenaza debe abordarse en el contexto de los numerosos impulsores directos del cambio, incluyendo la sobreexplotación y la contaminación, la mayoría de los cuales se ven exacerbados por el cambio climático.

Si bien las amenazas que enfrenta el medio marino son similares en algunos aspectos a los que enfrentan los hábitats terrestres, las soluciones deben basarse en una comprensión y atención a las diferencias del trabajo sobre el entorno marino. Además, existe una urgente necesidad de un acuerdo global sobre estrategias de gestión en áreas fuera de la jurisdicción nacional, así como la necesidad de aplicar enfoques basados en los derechos para la gestión de la pesca y para cumplir las metas convenidas internacionalmente sobre redes de AMP eficazmente gestionadas y ecológicamente coherentes. 


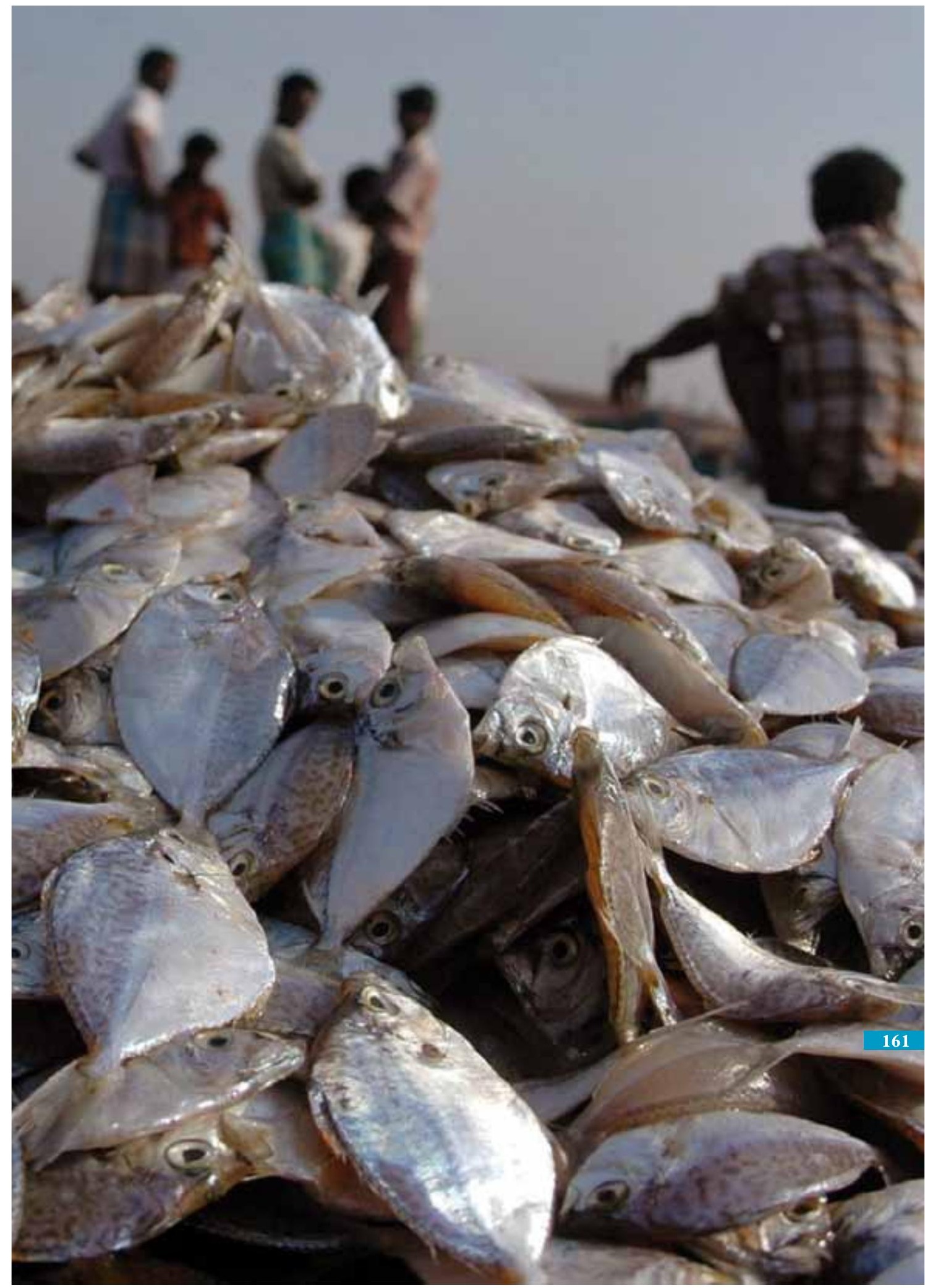


18. Sistemas de Tierras Secas:

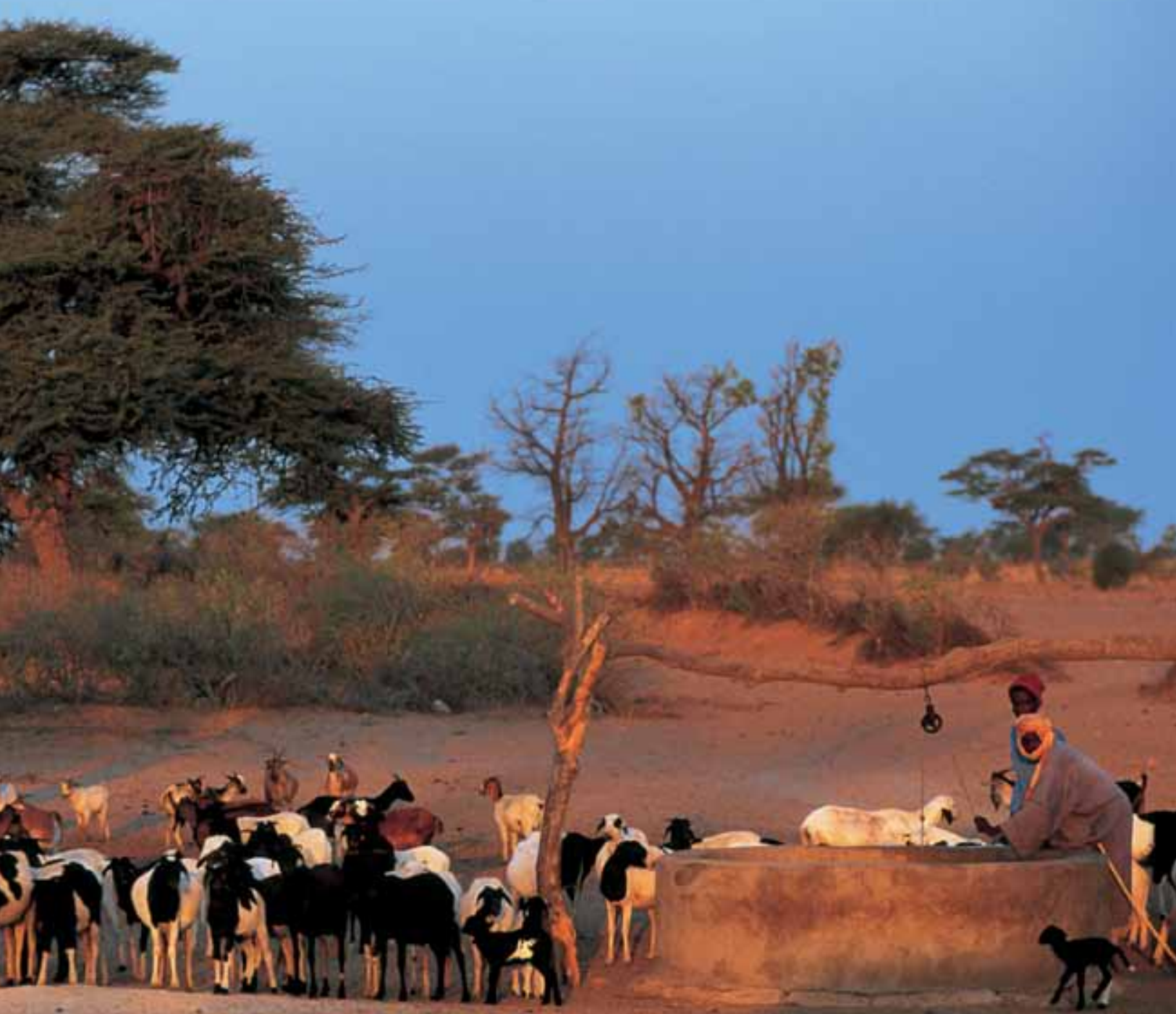


La UICN considera las tierras secas como paisajes y regiones tropicales y templadas y regiones con un índice de aridez inferior a 0,65, que incluye los siguientes subtipos de tierras secas: subhúmedas secas, semiáridas, áridas, e hiperáridas (desiertos) (UICN, 2008b). Esas tierras secas constituyen cerca del $40 \%$ de la superficie terrestre del planeta y se pueden encontrar tanto en países desarrollados con en países en desarrollo. Al menos el 30\% de las plantas cultivadas del mundo tienen su origen en las tierras secas, y estas son el hogar del 47\% de las áreas de aves endémicas y el 26\% de las áreas protegidas de todo el mundo.

La UICN aplica un enfoque global hacia los paisajes de tierras secas, que comprende las zonas urbanas y los humedales en las regiones y paisajes de tierras secas. Sin embargo, para los efectos de los programas de trabajo de la UICN en las tierras áridas, se excluyen las zonas secas del Ártico y el Antártico, ya que estas son zonas donde la temperatura más que la disponibilidad de agua limita la productividad biológica. Además, la UICN también incluye las tierras secas estacionales en el ámbito de su trabajo con tierras secas, especialmente los pastizales donde

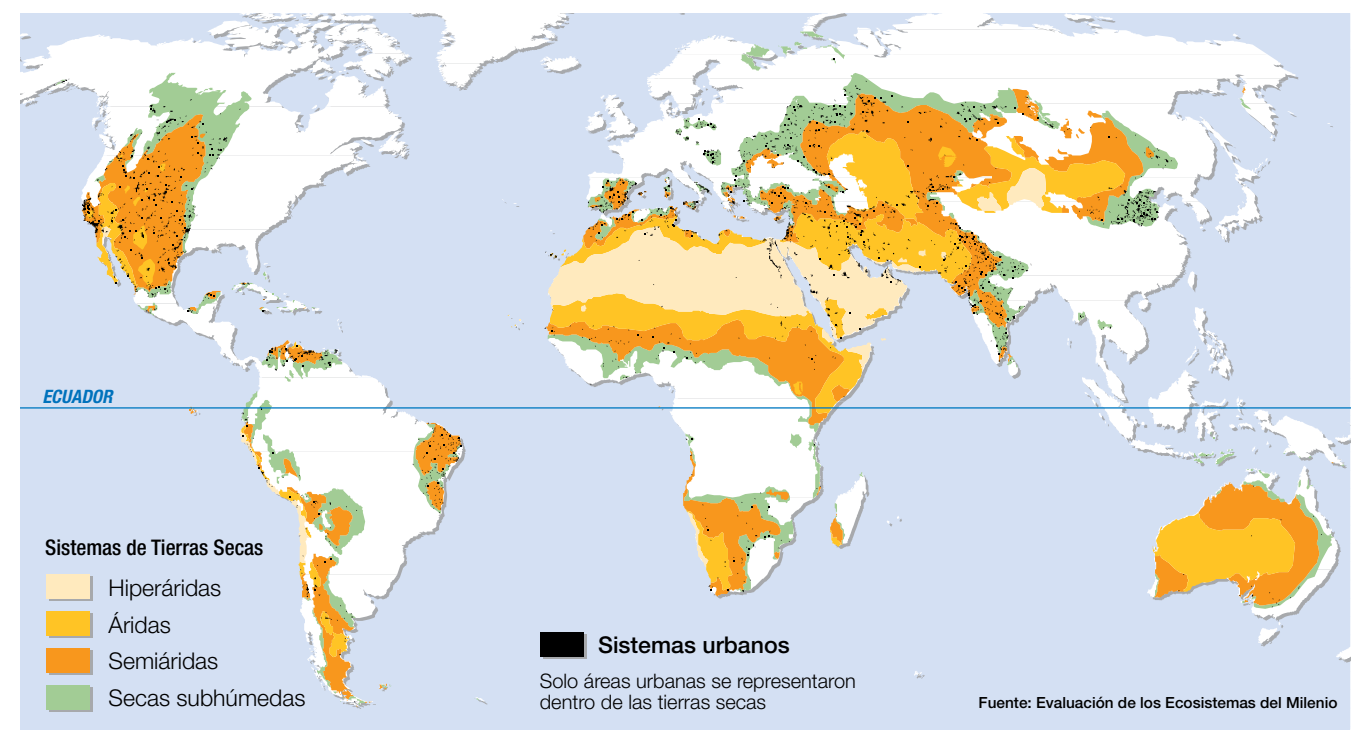

Figura 18.1 Distribución de las tierras secas en el mundo (EM, 2005a) 
el área de distribución y la composición de las especies están determinadas por la escasez de agua.

La biodiversidad en las tierras secas se adapta bien a las duras condiciones imperantes en ellas; las tierras secas son sitios importantes para el endemismo de todo el mundo. Las estrategias de adaptación de las especies van desde la maravilla arquitectónica de los montículos de termitas que aíslan las colonias de las temperaturas extremas del desierto hasta los anfibios del desierto que cavan madrigueras en la arena y permanecen aletargados hasta la llegada de las lluvias. De hecho, algunas de estas estrategias han sido la fuente de descubrimientos importantes para mejorar los medios de subsistencia de los seres humanos. Sin embargo, con el cambio climático y el aumento de la demanda humana sobre estos sistemas de tierras secas, la biodiversidad especial que aquí habita está bajo creciente amenaza.

Las tierras secas son el hogar de algunas de las especies más carismáticas, apoyan un alto endemismo de especies y comprenden muchos biomas y ecosistemas únicos, incluyendo los ecosistemas de tipo mediterráneo, pastizales, sabanas, bosques secos, zonas costeras, desiertos, montes bajos y el karoo suculento (estos dos últimos son tipos de vegetación muy peculiares y característicos del Sur de África) (Zeidler y Mulongoy, 2003; White et al., 2000; Bonkoungou y Niamir-Fuller, 2001). Además, muchos otros ecosistemas, como los bosques ribereños o los ecosistemas boscosos se encuentran dentro de los paisajes de tierras secas y están en riesgo por la degradación de las tierras secas.

Los ecosistemas de tierras secas proporcionan muchos servicios de los ecosistemas incluyendo cultivos para la alimentación y medicamentos, forraje para los animales, recursos genéticos, agua para las personas y los animales, y materiales para vivienda y vestimenta. También pueden ser importantes fuentes de ingresos (por ejemplo, turismo) o para apoyo cultural y espiritual. El valor potencial de algunos de estos servicios puede expresarse en términos del porcentaje de la producción agrícola en los países compuestos en gran parte de tierras secas. Por ejemplo, la agricultura representa más del 30\% del PIB en Afganistán, Kenia y Sudán. Las porciones de tierras secas de la India contribuyen el 45\% de la producción agrícola del país. Las tierras secas de China son el hogar de 78 millones de cabras de cachemir que abastecen el 65-75\% de la oferta del mercado mundial, y Mongolia genera el 30\% del PIB del pastoralismo de tierras secas.

El pastoralismo, que suele ser más rentable en las tierras marginales para cultivos, es una fuente importante de medios de subsistencia en las tierras secas. El pastoreo nómada permite una mejor utilización de las tierras de pastoreo que están sujetas a variaciones en las precipitaciones y la temperatura. La agricultura o los rebaños sedentarios no tienen la flexibilidad para movilizarse cuando las condiciones dejan de ser adecuadas. No obstante, algunas prácticas tradicionales apoyan la agricultura a través de la plantación de árboles y otros mecanismos de apoyo a la regeneración natural.

Las especies adaptadas a las tierras secas tienden a ser ecológicamente resilientes y capaces de hacer frente a los extremos del medio ambiente. Sin embargo, según la Evaluación de los Ecosistemas del Milenio (EM), el 10-20\% de las tierras secas se está degradando, amenazando miles de millones de hectáreas de pastizales y tierras de cultivo, con el consiguiente impacto sobre los más de 2000 millones de personas que viven en estos ecosistemas (datos de 2000).

\section{LAS TIERRAS SECAS Y LA DESERTIFICACIÓN}

La desertificación adquiere cada vez más relevancia más allá de la Convención de las Naciones Unidas de Lucha contra la 
Desertificación (UNCCD). Si bien la

desertificación es un tema importante para

las tierras secas, la mayoría de ellas no están desertificadas. La desertificación ha sido definida, a través de la UNCCD, como "la degradación de las tierras en zonas áridas, semiáridas y secas subhúmedas”. A su vez, la degradación se expresa como una persistente reducción de productividad biológica y económica y puede medirse monitoreando los productos de los servicios de los ecosistemas incluyendo el suministro de cultivos y agua.

Las causas de la desertificación incluyen:

- Políticas sociales y económicas

- Obligar a los pastores nómadas a aplicar estilos de cultivo sedentarios

- Promover o imponer prácticas de tenencia de la tierra que dan lugar a la sobreexplotación de los recursos

- Prácticas no sostenibles de gestión de la tierra, que a menudo resultan de los tres puntos anteriores.

La desertificación se produce en todos los continentes excepto en la Antártida y tiene especial impacto sobre los pobres en las tierras secas, que dependen en gran medida de los servicios de los ecosistemas que estos sistemas proporcionan.

Si bien muchos efectos de la desertificación en las tierras áridas son locales, también hay consecuencias regionales y globales. Desde una perspectiva medioambiental, la pérdida de vegetación lleva a la pérdida de suelos, erosión e inundaciones aguas abajo. Desde la perspectiva social, quienes habitan en tierras secas degradadas pueden verse obligados a emigrar a otras zonas que ya están saturadas y que no pueden hacer frente a las crecientes demandas.

Otros impactos de la degradación de las tierras secas en los estilos de vida asociados incluyen:
- Pérdida de conocimiento indígena (nativo) $\mathrm{y}$ tradicional;

- Mayor vulnerabilidad de las comunidades por su incapacidad para adaptarse a variaciones y cambios en las condiciones;

- Marginación de los pueblos indígenas (nativos);

- Conflictos en las tierras áridas y semiáridas; y

- Desaparición de las instituciones tradicionales de gestión que han demostrado su eficacia durante muchas generaciones.

\section{PÉRDIDA DE BIODIVERSIDAD}

Los habitantes de las tierras secas son quienes más sienten la pérdida de biodiversidad, de importancia crítica en estos entornos difíciles. La biodiversidad de las tierras secas, sin embargo, proporciona apoyo no solo a los habitantes locales, sino que también es la fuente de muchos servicios para las partes más ricas del mundo. Tenemos, por ejemplo, la planta medicinal Harpagophytum sp., o Hoodia sp. que se utiliza para tratar padecimientos occidentales como la artritis y la obesidad. Sin una adecuada gestión de las tierras secas, las soluciones a los problemas de salud de hoy y mañana podrían desaparecer antes de descubrirlas (recuadro 18.1).

\section{ASUNTOS APREMIANTES}

La desertificación está siendo inducida por un conjunto de factores, entre ellos la escasez de agua, el uso intensivo de los servicios de los ecosistemas, y el cambio climático. Estos factores están estrechamente ligados dado que el cambio climático probablemente llevará a un aumento de la escasez de agua en muchas tierras secas, con la consiguiente disminución de los servicios pese al aumento de la demanda. Estos cambios también tienden a incrementar el riesgo de conflictos. 
Recuadro 18.1 Goma arábiga - un estudio de caso sobre los servicios de los ecosistemas en tierras secas

\section{La goma arábiga en las tierras secas de Sudán}

El tipo de bosque más importante en el Sudán puede ser el cinturón de la goma arábiga, que se encuentra dentro de la zona poco lluviosa de la sabana. Los servicios de los ecosistemas proporcionados por los árboles de hashab (Acacia senegal) en este cinturón son:

- Actúan como una barrera natural para proteger más del 40\% de la superficie total de Sudán contra la invasión del desierto.

- Apoyan la economía familiar mediante el suministro de goma arábiga de los árboles de hashab, un árbol que tiene un papel importante en la generación de ingresos y la provisión de leña y forraje.

- Enriquecen la fertilidad del suelo, posiblemente también a través de la fijación biológica del nitrógeno.

En tiempos faraónicos, la goma arábiga se utilizaba también para la momificación de los cuerpos y la fabricación de acuarelas, tintes y pinturas.

Normalmente, el uso de la tierra en Sudán incluía un sistema de descanso arbustivo que apoyaba tanto el cultivo como la recolección de goma arábiga. Este ciclo se inicia con la limpieza de un antiguo sembradío de goma (15-20 años de edad) para la siembra de cultivos agrícolas. Los árboles se cortan a $10 \mathrm{~cm}$ del nivel del suelo, dejando los tocones para iniciar el crecimiento de nuevos rebrotes laterales mientras el área despejada es cultivada por un período de 4-6 años. Cuando disminuye la fertilidad del suelo, cesa el cultivo y la zona se deja en barbecho con excepción de los árboles restantes cuya goma arábiga es aprovechada hasta la edad de 15-20 años. El ciclo puede repetirse. Este enfoque ha sido reconocido y considerado como una de las formas más exitosas de gestión de bosques naturales en las tierras secas tropicales y consideradas como sostenibles en términos de sus beneficios ambientales, sociales y económicos.

\section{Los retos actuales de la producción de goma arábiga en las tierras secas de Sudán}

La importancia de la goma arábiga en los medios de subsistencia de las personas que habitan en el cinturón de la goma es de sobra conocida. Más de cuatro millones de personas en el cinturón de la goma de Sudán están involucradas en la explotación, cosecha, limpieza y comercio de la goma arábiga. Sudán domina el 70-80\% del mercado mundial de goma arábiga. Sus exportaciones anuales oscilan entre 20.000-50.000 toneladas métricas con un promedio anual durante la última década de 25.000 toneladas métricas.

En las últimas décadas, el sistema de descanso arbustivo se ha interrumpido y el tradicional ciclo de cultivo con descanso arbustivo se ha acortado drásticamente o ha sido totalmente abandonado, con los consiguientes impactos en la producción de cultivos y de goma arábiga. La gestión sostenible de las plantaciones de goma se ve amenazada a causa de las severas sequías y el despeje indiscriminado de $A$. senegal para la producción de carbón vegetal y leña. Sumado a estas amenazas, las comunidades productoras de goma sufren de la falta de marcos reguladores y de información sobre el mercado para planificar la distribución y venta de la goma producida. A esto se suma la falta de financiación y facilidades de transporte. Como resultado de ello, un informe ha señalado que las utilidades reales para los productores de goma no exceden el $40 \%$ de los costos de producción. Para tratar de abordar estas cuestiones, se formaron asociaciones de productores de goma (APG) en varias provincias a manera de caso de prueba y luego se ampliaron. En la actualidad, 1650 APG tienen dos millones de miembros, de los cuales $30 \%$ son mujeres

Fuente: A.G. Mohammed, 2008 


\section{Uso intensivo de los servicios de los ecosistemas, especialmente el agua}

Es probable que el continuo crecimiento de la población y el consiguiente aumento de la demanda de alimentos acentúen la presión en términos de disponibilidad de tierra para cultivar que podría llevar a una mayor degradación y conflictos entre grupos étnicos. Las regiones de tierras secas pasan por episodios cíclicos de escasez de agua durante los cuales la población local es más vulnerable a sus efectos, es decir, a la escasez de alimentos y crisis sanitarias por falta de agua.

\section{Cambio climático}

Los impactos del cambio climático presentan un complejo panorama de posibilidades para las tierras secas. Para algunos, las sequías más intensas y prolongadas podrían eliminar toda la productividad de un paisaje de tierras secas. Para otros, un aumento significativo en las precipitaciones (tanto en intensidad como en volumen y distribución temporal) podría transformar las tierras secas en sistemas más húmedos. Si bien esto podría ser beneficioso, también podría inducir a conflictos entre agricultores y pastores.

La desertificación contribuye al cambio climático a través de la pérdida de suelos y vegetación que disminuyen la capacidad de almacenamiento de carbono de la tierra. Se estima que anualmente se pierden a la atmósfera 300 millones de toneladas de carbono de las tierras secas como resultado de la desertificación (aproximadamente el 4\% del total de las emisiones globales procedentes de todas las fuentes combinadas) (EM, 2005a).

\section{LA GESTIÓN DE LAS TIERRAS SECAS EN LA PREVENCIÓN DE LA DESERTIFICACIÓN}

\section{Mayor conocimiento}

Uno de los esfuerzos más importantes es la necesidad de un mayor conocimiento sobre las tierras secas, los factores que intervienen y la consiguiente vulnerabilidad de la población local. Los responsables de la toma de decisiones y los técnicos encargados de la conservación y la concepción de medios de subsistencia alternativos deben tener un conocimiento adecuado de las potencialidades, limitaciones y oportunidades que ofrecen las tierras áridas y semiáridas y una mejor comprensión de los impactos urbanos y externos en dichas zonas. En respuesta, la Organización para la Agricultura y la Alimentación (FAO), junto con muchos asociados, ha desarrollado la Evaluación de la Degradación de las Tierras Secas, que incluye mapeos, indicadores y estudios piloto a nivel de país para ayudar a aumentar nuestro conocimiento de las tierras secas. La UNCCD y la Organización Meteorológica Mundial (OMM) están colaborando en un proyecto para ayudar en la prevención, advertencia y monitoreo de las sequías.

Debe darse también una mejor comprensión del valor de las tierras secas y los servicios que proporcionan. Hasta la fecha, las tierras secas se han caracterizado por la falta de inversión al ignorarse oportunidades potenciales en favor de las tierras agrícolas, los bosques tropicales o los ecosistemas marinos.

\section{GESTIÓN INTEGRADA DE LAS TIERRAS SECAS}

\section{Gestión de los recursos hídricos}

La gestión integrada de los recursos hídricos es un medio fundamental para prevenir la desertificación, asegurando que las políticas de gestión de la tierra se adapten a las tradiciones y necesidades locales. Estas políticas deben y el mantenimiento de los conocimientos tradicionales, evitando la transición innecesaria a cultivos con un uso más intensivo del agua. La gestión de las tierras secas implica la gestión del agua y para ser eficaz se requiere la cooperación 
intersectorial. La reducción del estrés en las tierras secas puede a veces requerir el desarrollo y la promoción de medios de subsistencia alternativos, incluyendo los medios de subsistencia en zonas cercanas que no son secas.

\section{Restauración de las tierras secas degradadas}

$\mathrm{Al}$ igual que con otros ecosistemas degradados, la restauración de las tierras secas debe llevarse a cabo con base en el paisaje, utilizando los principios de los enfoques por ecosistemas.

\section{Las políticas y la gobernanza de las tierras secas}

La definición dogmática de lo que son las tierras secas no es de utilidad en términos de políticas.

De hecho, la definición de las tierras secas en la UNCCD difiere de la del Convenio sobre la Diversidad Biológica (CDB), en cuanto a que la primera es más precisa en términos de niveles de precipitación y la segunda incluye una zona más amplia mediante la inclusión de determinados tipos de vegetación (recuadro 14.1). El resultado es un problema en potencia para las partes que tratan de implementar programas de trabajo sobre tierras secas en ambos convenios, y este es un típico problema que refuerza la necesidad de armonizar los acuerdos multilaterales sobre el medio ambiente (AMMA).

Sin embargo, independientemente de la definición, los problemas de gobernanza que enfrenta la gestión de las tierras secas siguen siendo los mismos, a saber:

- Corrección de la privación de los derechos de los pobladores de las tierras secas, incluyendo la garantía de los derechos de tenencia locales, así como las cuestiones relacionadas con la libre determinación, la educación y la salud;

- Descentralización de la gestión de los recursos naturales, incluyendo el establecimiento de "convenios locales" (acuerdos comunitarios) y permitir que la población local pueda ser recompensada por los beneficios que se disfrutan a nivel nacional y global (a través de los pagos por los servicios de los ecosistemas provistos por las tierras secas); y

- Fortalecimiento de la resiliencia de los residentes de las tierras secas, incluyendo los pastores en las tierras secas, a través de adecuados marcos de políticas y acciones.

Tal como se destaca en los capítulos anteriores, estas cuestiones de gobernanza deben también ocuparse de las preocupaciones relativas al cambio climático (capítulo 5) y la reducción de la pobreza (capítulo 1).

Las tierras secas son ecosistemas productivos que apoyan a un gran número de personas, pero estas personas son vulnerables a los cambios climáticos, a los mercados y a los derechos (Mortimore et al., 2008). La gestión eficaz de las tierras secas -y, por ende, la prevención de la desertificación- será un paso importante hacia la reducción de la pobreza y la conservación de la biodiversidad en una parte importante de nuestro mundo. 


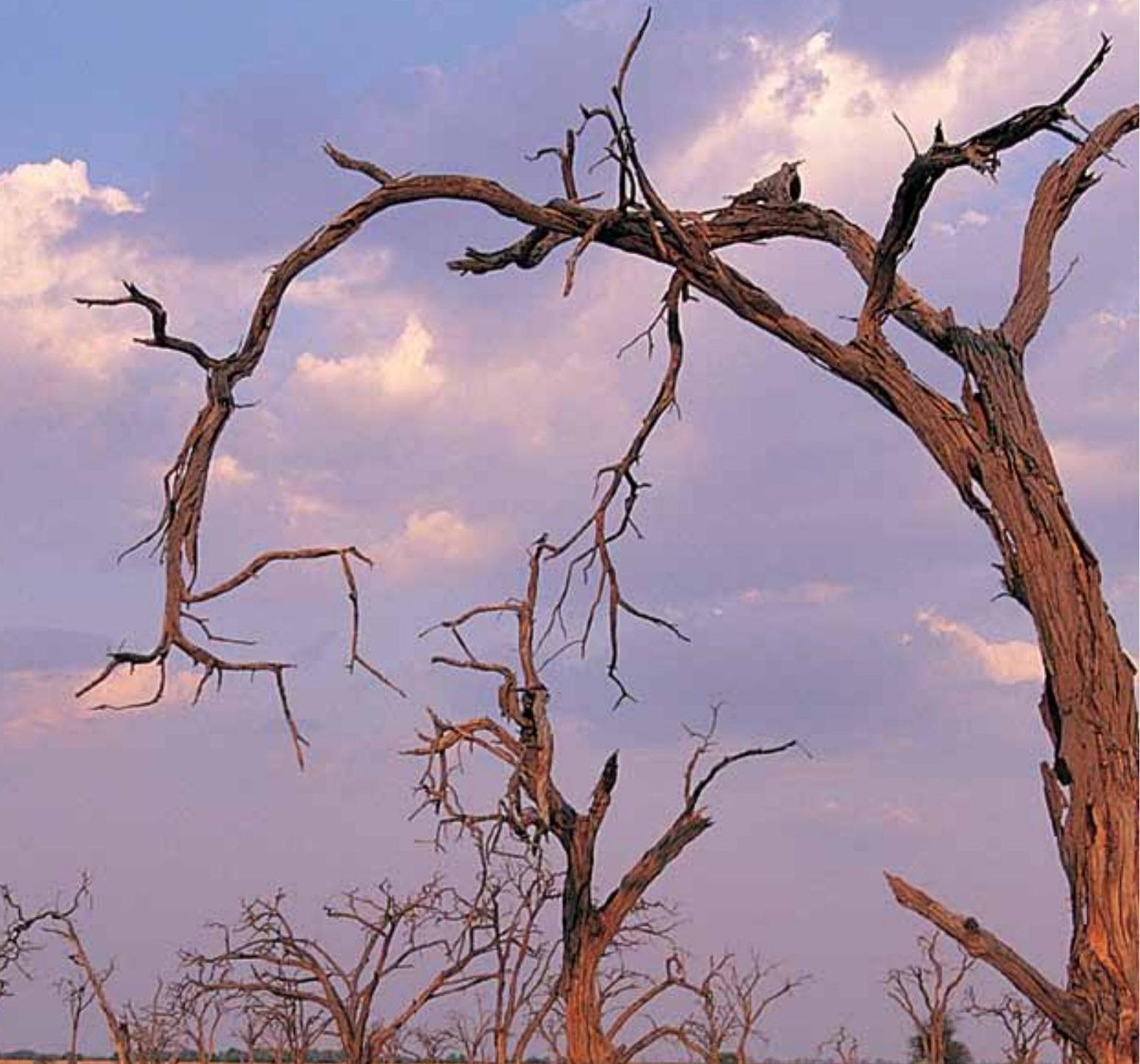

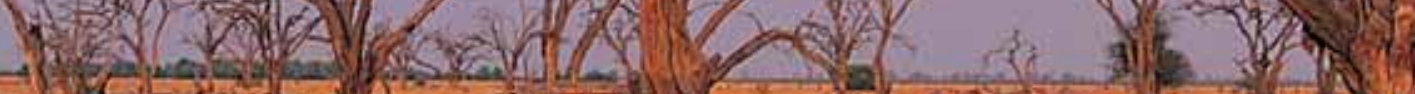

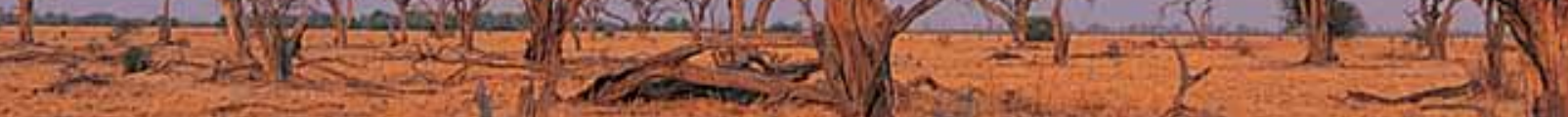

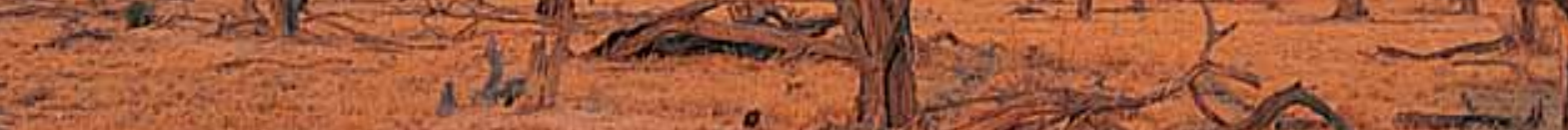

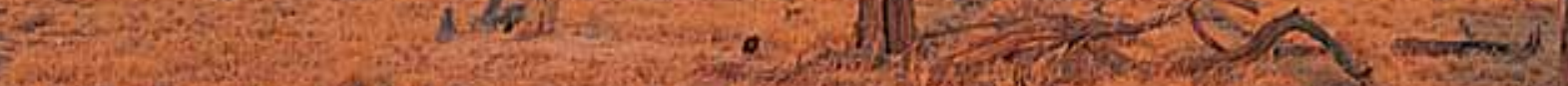

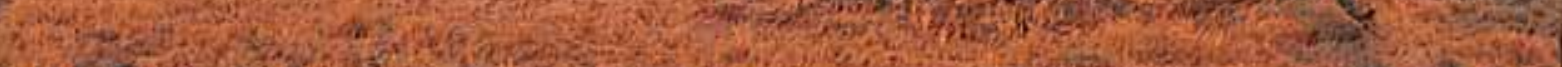

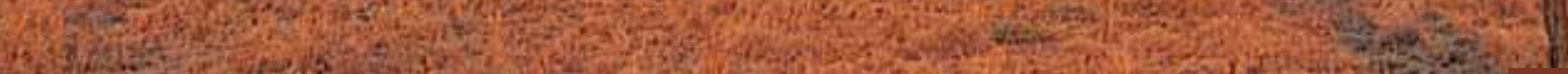
6.t. 2.

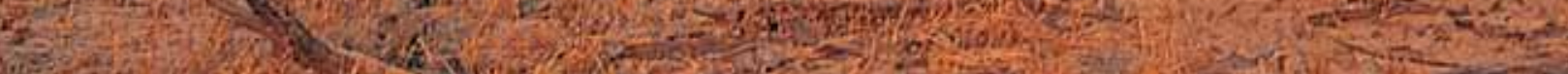

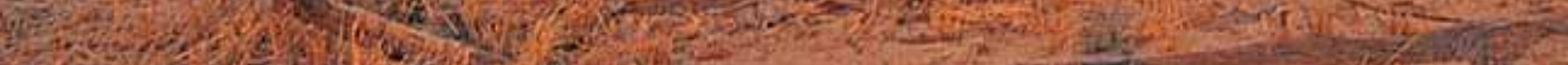

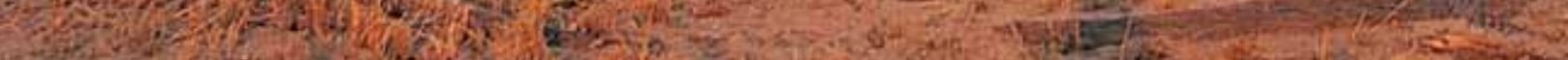

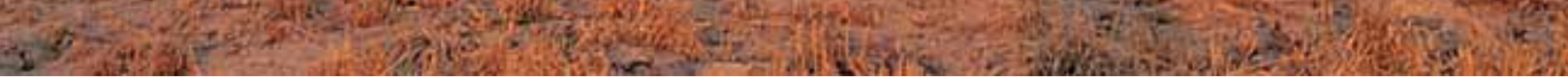




\section{Sistemas de Agua Dulce: \\ 19. Gestión de Caudales para Beneficio de las Personas y la Naturaleza}

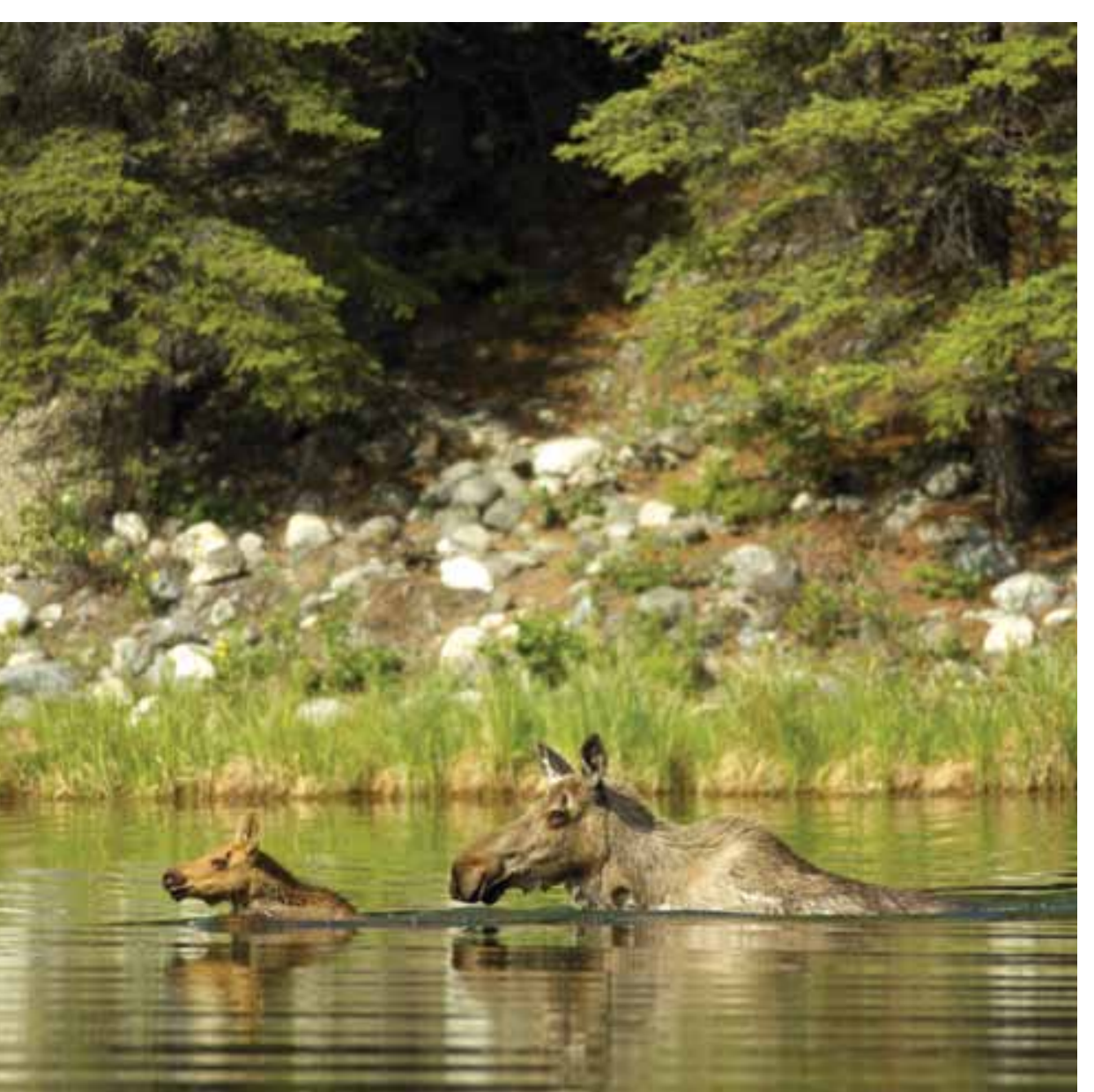


Si bien los sistemas de agua dulce cubren menos del 1\% de la superficie de la Tierra, son vitales para sustentar la vida. La calidad del agua apoya la salud de las personas y los ecosistemas. Los ríos y las aguas subterráneas requieren de un enfoque global basado en el paisaje para abordar una comprensión completa de las presiones sobre los recursos aguas arriba y aguas abajo, reconociéndose la importancia de los valores estéticos, religiosos, históricos, y arqueológicos que el agua contribuye al patrimonio de una nación.

Los hábitats de agua dulce albergan 126.000 especies, o el 7\%, de los 1,8 millones de especies estimadas descritas, incluyendo una cuarta parte de los 60.000 vertebrados estimados (Balian $e t$ al., 2008). También tienen un valor económico. Según una estimación, el valor de los bienes y servicios provistos por los humedales del mundo es de US\$70 mil millones por año (Schuyt y Brander, 2004).

Tanto la biodiversidad como el bienestar humano se ven afectados por los cambios en el agua dulce. En general, las poblaciones de las especies de agua dulce se redujeron a la mitad entre 1970 y 2005, un descenso mayor que en otros biomas (Programa mundial de evaluación de los recursos hídricos, 2009). El Índice de la Lista Roja para aves que viven en hábitats de agua dulce muestra uno de los más graves descensos de todos los hábitats, después de los hábitats marinos (Butchart et al., 2004). Una evaluación global de la Lista Roja para cangrejos de agua dulce dio cuenta de que de las especies para las cuales se dispone de datos suficientes para llevar a cabo una evaluación, el 32\% estaba amenazado (Cumberlidge et al., 2009). Los estudios sobre la situación de los peces de agua dulce en determinadas regiones, reportan cifras que van desde un $11 \%$ en peligro en el Sur de África (Darwall et al., 2008) hasta un 56\% de peces de agua dulce endémicos del Mediterráneo que están amenazados (Smith y Darwall, 2006).

Más del 60\% de los 227 ríos más grandes están fragmentados por represas, desvíos o canales (Revenga et al., 2000) lo que conduce a una degradación generalizada de los ecosistemas de agua dulce. La sobrepesca y las prácticas de pesca destructivas, la contaminación, las especies invasoras y el cambio climático, se suman a las preocupaciones en torno a la mayoría de los sistemas de agua dulce. Darwall et al., (2008) informan de que el $85 \%$ de los peces amenazados en el Sur de África, el 55\% de las especies amenazadas de peces de agua dulce en Europa y algo menos del $45 \%$ de los peces de agua dulce en peligro en Madagascar, se ven afectados por las especies invasoras. En este último caso, ello 
es en gran parte resultado de la implementación de un plan para restablecer las pesquerías locales mediante la introducción de 24 especies de peces no nativos (Benstead et al., 2003). El cambio climático provocará más vulnerabilidad y dará lugar a un mayor impacto sobre los sistemas de agua dulce. Por último, en muchos países las políticas y las leyes sobre los recursos hídricos se encuentran en proceso de reforma y deben implementarse efectivamente si ha de conservarse los recursos hídricos.

En un mundo con un acceso descendente al agua, la solución de los retos de conservación requiere de soluciones que combinen las necesidades de las personas y de la naturaleza. La Visión del agua y la naturaleza (2000) promueve un enfoque por ecosistemas para el manejo integrado de los recursos hídricos (IWRM), incluyendo la mejora de la gobernanza del agua, el empoderamiento de los interesados directos, la creación de conocimientos y la valoración de los recursos hídricos.

La UICN ha desarrollado una serie de herramientas para apoyar la implementación de una adecuada gestión de los recursos hídricos para fortalecer la seguridad del abastecimiento de agua, incluyendo Cambio, Caudales, Pagos, Compartir y Rule. Todos ellos son accesibles en línea, y están disponibles en varios idiomas, en: http:// www.iucn.org/about/work/programmes/water/ wp_resources/wp_resources_toolkits/.

\section{LOS SERVICIOS DE LOS ECOSISTEMAS Y LA SEGURIDAD DEL AGUA}

Las personas necesitan un mínimo de 20 litros de agua al día para beber, bañarse y mantener la higiene básica (ONU-Agua, 2007). Imagínese lo que es sobrevivir con una cuarta parte de esa cantidad, 5 litros al día -la cantidad con la que vivía la gente durante la sequía en África Oriental (2005-2006). La ONU afirma que en 2025 dos tercios de nosotros sufriremos escasez de agua, con una severa falta de agua afectando la vida y los medios de subsistencia de 1800 millones de personas (ONU-Agua, 2007).

Los retos que enfrentamos se refieren tanto a la cantidad como a la calidad del agua. En 2006, la Evaluación Mundial de Aguas Internacionales confirmó que la escasez de agua dulce era un problema en la mayor parte del mundo, pero especialmente en el África subsahariana, donde la escasez de agua dulce afecta a nueve de 19 sistemas de agua dulce evaluados por la Evaluación Mundial de Aguas Internacionales y la contaminación (incluida la contaminación transfronteriza) afecta a cinco sistemas. En 2025, se prevé que en muchas regiones del Sur del mundo se enfrentarán a la escasez de agua (figura 19.1). Sin embargo, la escasez de agua no es coherente en el tiempo y el espacio. La escasez física de agua se produce cuando el acceso físico es limitado y, por lo tanto, el desarrollo de los recursos hídricos se aproxima a o ya ha excedido los límites sostenibles. La escasez económica de agua existe cuando la población carece de los recursos humanos, institucionales y económicos para acceder al agua aunque ella esté disponible en la naturaleza a nivel local para satisfacer las demandas humanas. La escasez económica de agua derivada de la distribución desigual de los recursos tiene muchas causas, entre ellas los conflictos políticos y étnicos. Gran parte de África subsahariana sufre los efectos de este tipo de escasez de agua (Evaluación general del agua en la agricultura, 2007).

La crisis del agua se debe a la creciente demanda, la disminución de la calidad y, por tanto, la disminución de la disponibilidad por habitante. La distribución y la gestión son también parte del problema. La diferencia en la fiabilidad del agua entre el Japón y Camboya -que tienen prácticamente la misma precipitación media de $160 \mathrm{~cm}$ al año- es que Japón ha sido capaz de crear la infraestructura para aprovechar y 


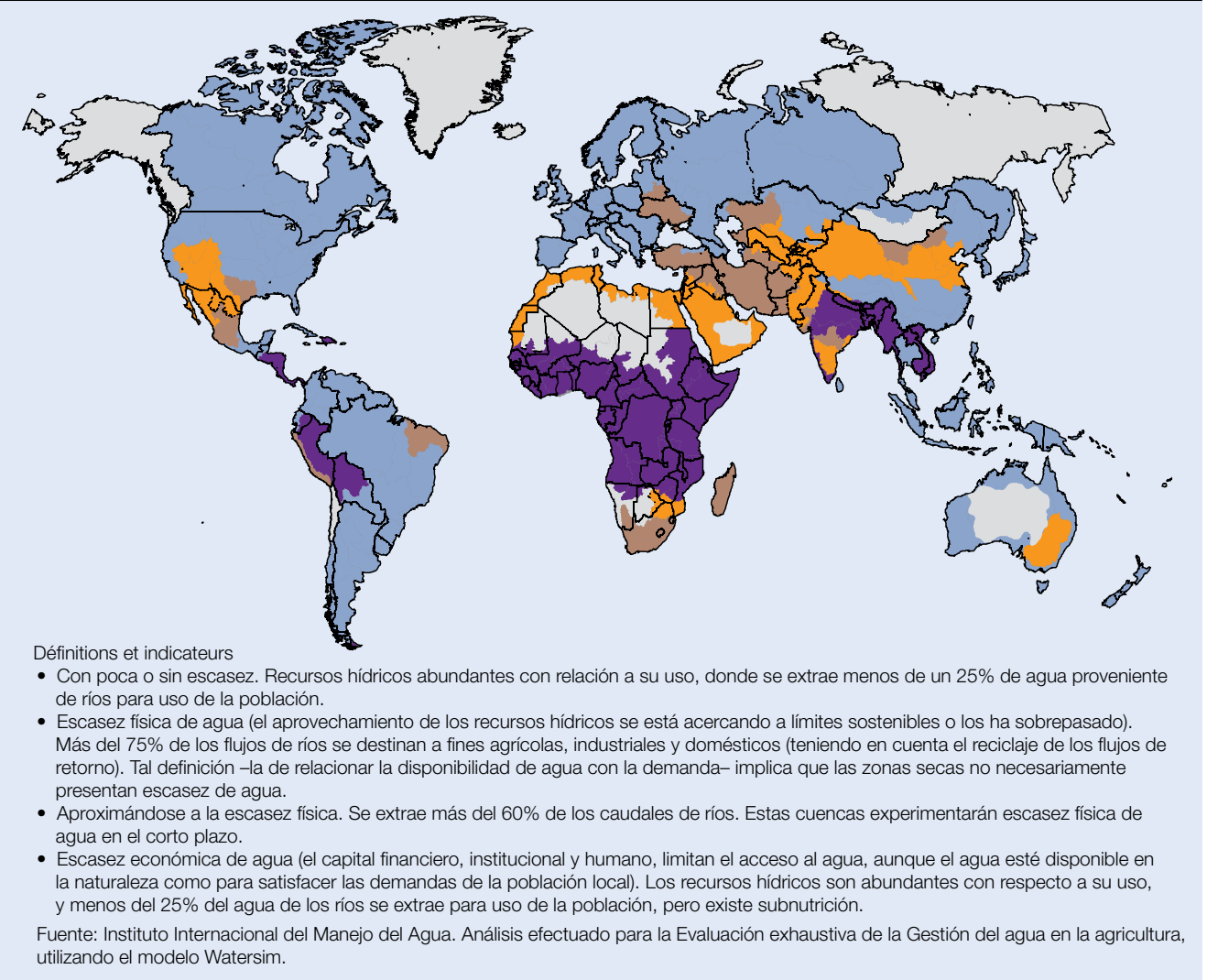

Figura 19.1 Escasez de agua prevista en 2025 (IWMI, 2009)

almacenar agua. En los países con fuertes lluvias, como Bangladesh y Myanmar, la mayor parte de las precipitaciones monzónicas no es capturada para uso productivo y se escurre hacia el océano.

Si bien el mínimo de agua necesaria puede ser de 20 litros por día, el promedio de uso diario en los EE. UU. y en los países europeos es de 200-600 litros por día (ONU-Agua, 2007). La gestión de su propio consumo de agua puede ser tan fácil como cerrar el grifo mientras se cepilla los dientes. Una herramienta que puede utilizarse para determinar el consumo de agua es la herramienta de la huella hídrica (recuadro 19.1). La huella hídrica de una persona, comunidad o empresa se define como el volumen total de agua dulce que se utiliza para producir los bienes y servicios consumidos por
Recuadro 19.1 Caminando sobre el agua: ¿Cuán grande es su huella hídrica?

Si bien muchos de nosotros hemos escuchado hablar de nuestra huella de carbono, pocos somos conscientes de que también dejamos una huella hídrica. Usted puede calcular la cantidad de agua que requiere para sus hábitos diarios -ya sea la ducha, la cocina, la cantidad de agua ocupada para sus alimentos, o el tipo de electricidad que utiliza. Para mayor información visite la web de la red Water Footprint: http://www.waterfootprint. org/?page=files/home 
el individuo o comunidad o producidos por la empresa. La huella hídrica y otras herramientas pueden utilizarse como herramientas para la implementación de IWRM.

\section{LA GESTIÓN DEL AGUA Y LOS CAUDALES AMBIENTALES}

IWRM "es un proceso que promueve el desarrollo y la gestión coordinada del agua, la tierra y los recursos conexos, a fin de maximizar el resultado económico y el bienestar social de manera equitativa sin comprometer la sostenibilidad de los ecosistemas vitales” (GWP, 2009). Integra la gestión a escala del paisaje que actúa en una escala lo suficientemente amplia como para reconocer el papel crítico de todos los factores que influyen y los interesados directos que dan forma a las decisiones relativas al uso de la tierra. IWRM se basa en los Principios de Dublín (GWP, 2000), a saber:

Principio I: El agua es un recurso finito y vulnerable

Principio II: Enfoque participativo

Principio III: El papel central de la mujer

Principio IV: El agua como un

bien económico

\section{En la Resolución 4.063 (La nueva cultura del} agua - gestión integrada de los recursos hídricos), los Miembros de la UICN exhortaron a los gobiernos a adoptar el IWRM y apoyar los marcos para su implementación.

La cuestión clave en la gestión de la asignación del agua es "¿Cómo podemos asegurar que haya suficiente agua para la naturaleza?” Esto puede ser contestado aplicando caudales ambientales. Los caudales ambientales describen la cantidad, el tiempo y la calidad de los cursos de agua necesarios para mantener los ecosistemas estuarinos y de agua dulce y los medios de subsistencia y el bienestar humano de quienes dependen de estos ecosistemas (Declaración de Brisbane, 2007). Las evaluaciones se llevan a cabo para determinar la cantidad de caudal necesario para mantener un río saludable y apoyar los servicios vitales de los ecosistemas. Esta información se utiliza para tomar decisiones informadas sobre la asignación de agua a todos los sectores, incluido el medio ambiente.

Para aumentar la integración de los caudales ambientales en las políticas y prácticas para la gestión del agua, es necesaria la comunicación, el aprendizaje y la demostración de los beneficios de los caudales para las personas y la naturaleza. La red sobre Caudales Ambientales (www. eflownet.org) es un punto de referencia central para la información sobre caudales y también es una herramienta para compartir experiencias, desarrollar el concepto y establecer un enlace con un público multisectorial.

La UICN apoya la aplicación de los caudales ambientales para mitigar los efectos del desarrollo de infraestructura en los ríos, incluyendo las represas y el riego en gran escala. Los caudales ambientales se implementan cambiando la operación de la infraestructura de manera que recupere la cantidad, la calidad y el ritmo estacional de los caudales de los ríos para sostener los ecosistemas y los servicios que prestan a las personas. La aplicación de los caudales ambientales tiene lugar mediante la negociación de la asignación del agua por parte de los interesados directos, lo cual fomenta la integración de las necesidades de las personas y la naturaleza en las decisiones sobre gestión de los recursos hídricos. Fortaleciendo el apoyo para la aplicación de los caudales ambientales en las políticas y la legislación se impulsa el desarrollo de los conocimientos, las capacidades e instituciones necesarias para la implementación de IWRM. 


\section{LA GOBERNANZA DEL AGUA Y LA PARTICIPACIÓN DE LOS INTERESADOS DIRECTOS}

Para una gestión eficaz del agua es preciso contar con políticas y leyes que permitan la definición transparente de los derechos, funciones y responsabilidades, incluyendo la asignación de suficiente agua para sostener ecosistemas sanos. Para la implementación exitosa de políticas y leyes hídricas adecuadamente estructuradas también se requiere de las instituciones necesarias para la implementación y de un entorno caracterizado por la transparencia, la certidumbre, la rendición de cuentas y la ausencia de corrupción.

Esto fue reconocido a nivel internacional en la Asamblea del Milenio de las Naciones Unidas 2000, que acordó “detener la explotación insostenible de los recursos hídricos mediante el desarrollo de estrategias de gestión de agua en los planos regional, nacional y local, que promuevan un acceso equitativo y un abastecimiento adecuado”. En la Cumbre Mundial sobre el Desarrollo Sostenible (WSSD) en 2002, los Jefes de Estado acordaron un objetivo específico para preparar el Manejo Integrado de los Recursos Hídricos (IWRM) y planes eficientes para la gestión del agua para el año 2005 -un objetivo que no se cumplió.

La gestión del agua sigue siendo un reto importante en muchos países debido, por ejemplo, a la falta de coherencia entre sectores y políticas y leyes en conflicto formuladas en diferentes momentos por diferentes administraciones y grupos de interés. La reforma de las políticas y leyes nacionales en un paquete coherente es una tarea difícil que demanda muchos recursos, pero los países que lo han abordado han comprobado que sus planes de implementación aguas abajo funcionan mejor. Por ejemplo, Brasil ha emprendido una larga reforma de la estructura de la gobernanza del agua que, como consecuencia de la reorganización sistemática de las políticas, la legislación y las instituciones, condujo a una mejora sustancial de su régimen de gestión hídrica. Además, Iza y Stein (2009) sugieren que las reformas de la gobernanza del agua que reducen la pobreza y hacen las economías más resilientes deben basarse en principios de equidad y sostenibilidad. Por ejemplo, Sudáfrica ha puesto en marcha ambiciosas reformas hídricas en la última década. La Ley Nacional de Aguas garantiza una "reserva de agua" para garantizar un abastecimiento básico de agua y la salud de los ecosistemas acuáticos.

\section{En la Resolución 3.006 del CMN (Protección del} agua de la Tierra para el beneficio público y ecológico), los Miembros de la UICN instaron a apoyar la consecución de la meta de WSSD, así como la plena participación en la toma de decisiones acerca de la conservación, protección, distribución y uso del agua. La comunidad internacional está también promoviendo enfoques basados en los derechos para la gestión del agua con base en la necesidad fundamental de agua limpia y potable. En el plano nacional, el Estado ha de llevar a la práctica las obligaciones y compromisos adquiridos en el contexto internacional.

La transformación de la política y la gestión hídricas proviene de la creación de consenso en las plataformas de múltiples interesados directos. Estas plataformas empoderan a los interesados directos a nivel local, de cuencas o transfronterizo para llegar a un acuerdo sobre los derechos, funciones y responsabilidades y para negociar reformas a la legislación hídrica.

Además, un buen sistema de gobernanza debe "pensar en términos de la cuenca, pero actuar a nivel local”. Cuando las asociaciones comunitarias de usuarios del agua participan en el proceso de planificación, ejecución y mantenimiento de los sistemas tradicionales de captación de agua, son más resilientes y permiten a las comunidades adaptarse al cambio climático. La participación 
de la sociedad civil en todos los niveles fomenta la conciencia y la responsabilidad hacia el agua y facilita la aceptación del sistema jurídico.

Esto, a su vez, presenta una plataforma útil para resolver los posibles conflictos entre los derechos consuetudinarios y tradicionales, facilitando la implementación de la legislación hídrica a través de una participación activa de los usuarios en la fase final de distribución del agua. Por último, pueden desempeñar un papel muy importante en el monitoreo de su parte en el sistema hídrico.

El éxito de la gobernanza y la gestión del agua dependen de la inclusión de las mujeres. Un estudio realizado en 1988 por el Centro Internacional de Agua Potable y Saneamiento sobre proyectos de abastecimiento de agua y saneamiento en 88 comunidades en 15 países, determinó que los proyectos diseñados y ejecutados con la plena participación de las mujeres son más sostenibles y eficaces que aquellos que excluyen a las mujeres como partes interesadas de pleno derecho (IWSC, 1988).

La gobernanza de las aguas transfronterizas es un tema complejo con varios desafíos para el cumplimiento de sus objetivos medioambientales. Hay más de 260 ríos internacionales en el mundo, que abarcan el 45\% de la superficie terrestre de la Tierra, y constituyen aproximadamente el $80 \%$ de los cuerpos de agua a nivel global. Cerca del 90\% de la población del mundo vive actualmente en los países que comparten estos ríos (Banco Mundial, 2009). Estos recursos esenciales están sometidos a una creciente presión a medida que crecen las poblaciones y se desarrollan las economías. Es importante identificar mecanismos e instrumentos para apoyar el uso del agua como catalizador para la cooperación regional en lugar de una posible fuente de conflicto. La gestión y el desarrollo en colaboración de estos ríos exigen gran habilidad, instituciones sólidas, una importante inversión, y una fuerte cooperación transfronteriza. Entre los ejemplos de iniciativas que lo hacen se incluyen el Diálogo de la Cuenca del Nilo, la Comisión del Río Mekong, y la recién creada Autoridad de la Cuenca del Volta.

La búsqueda de un enfoque común para la gestión de las aguas transfronterizas se complica aún más por la diversidad de la legislación, las prácticas de gestión del agua, las estructuras institucionales, y las lenguas y culturas de los países limítrofes. Sin embargo, la cooperación en la gestión de la calidad y cantidad de los cuerpos de agua transfronterizos también ofrece una oportunidad de la que todas las partes implicadas pueden beneficiarse (Aguilar e Iza, 2006). Las negociaciones, el consenso y los acuerdos concertados entre dos o más partes de una cuenca hidrográfica compartida forman parte del sistema de gobernanza del agua, pero es la voluntad política de los Estados soberanos la que determina si se apoyará con éxito la gestión sostenible del agua.

\section{PAGOS POR LOS SERVICIOS DE LAS CUENCAS HIDROGRÁFICAS}

Los recursos hídricos apuntalan la economía, y los dividendos de la inversión en los servicios de las cuencas hidrográficas deben dar cuenta de los beneficios y la seguridad del agua para los medios de subsistencia y el desarrollo empresarial y económico. En el sector empresarial hay diversos intereses en torno al agua; el interés de los servicios hídricos (las personas que hacen dinero a costa del agua); las empresas que venden productos que necesitan agua; las empresas de energía hidroeléctrica; las empresas que producen biocarburantes; las empresas de energía que utilizan el agua para la refrigeración; las industrias que requieren agua para la transformación, etc. Antes de asociarse con las empresas, sin embargo, es importante que los usuarios tengan un conocimiento cabal de todas las pérdidas potenciales de los servicios de los ecosistemas que pueden ser ocasionadas por el desarrollo. Los incentivos basados en el mercado, incluido 
el pago por los servicios de los ecosistemas (PSE), son parte de la financiación sostenible para el IWRM. En Ecuador, el Fondo del Agua de Quito (FONAG) ha desarrollado un prospecto de inversión para atraer contribuciones de los sectores público y privado a un fideicomiso a largo plazo que tiene por objeto garantizar la cantidad y calidad del agua suministrada a Quito por la cuenca del río Guayllabamba.

El agua es un recurso vital para los sectores agrícola y energético. La agricultura es el principal usuario de agua. La ganadería y el riego representan el $70 \%$ de la extracción de agua, que puede elevarse a más de $80 \%$ en algunas regiones, por lo que los conservacionistas necesitan conectarse más con el sector agrícola para fortalecer los conocimientos sobre temas relacionados con el agua (EM, 2005c; Programa Mundial de Evaluación de los Recursos Hídricos, 2009). Sin un acceso seguro en cuanto a la cantidad y calidad del agua, falla la generación de energía hidroeléctrica, especialmente cuando se reduce el caudal o la refrigeración de las centrales eléctricas. El uso sostenible del agua, incluyendo la inversión en la gestión sostenible de cuencas hidrográficas, debe ser prioritario para estos sectores, incluido el creciente número de productores de biocombustibles. Las políticas hídricas y energéticas deben coordinarse tanto a nivel de estrategia como de operación.

Los beneficios de la inversión en la gestión del agua y en los servicios de los ecosistemas suelen no tomarse en cuenta o subestimarse. La gestión basada en los servicios de los ecosistemas puede proporcionar un marco para apoyar la toma de decisiones relativas a los servicios prestados por los sistemas naturales y determinar las concesiones que pudieran ser necesarias en las decisiones (Farber et al., 2006). Las inversiones en la sostenibilidad de las cuencas hidrográficas estimula el "crecimiento verde" y la resiliencia económica. El agua y los servicios proporcionados por las cuencas hidrográficas, incluyendo el almacenamiento de agua, la purificación, la regulación de inundaciones y la seguridad alimentaria, suponen beneficios para toda la economía, desde el nivel local hasta el nacional. Las inversiones destinadas a asegurar la continuación o renovación de la seguridad hídrica y los servicios de las cuencas hidrográficas sostienen los medios de subsistencia locales, crean oportunidades para el desarrollo de las empresas y apuntalan el crecimiento económico nacional. Las inversiones en la sostenibilidad de cuencas hidrográficas pueden, por ende, estimular un crecimiento ambientalmente sólido a favor de los pobres, a la vez que se fortalece la resiliencia de las comunidades y las economías nacionales.

\section{EL AGUA Y EL CAMBIO CLIMÁTICO}

Se prevé que el cambio climático causará impactos significativos sobre los recursos hídricos y una vulnerabilidad generalizada. Estos efectos se harán sentir en primer lugar en lo relativo al agua -a través de sequías, inundaciones, tormentas, derretimiento del hielo y aumento del nivel del mar. La rápida disminución de los glaciares de los Himalayas, que para 2030 pueden perder las cuatro quintas partes de su superficie, significa que podría perderse una enorme reserva natural que almacena agua para más de mil millones de personas.

Hacer frente a tales efectos implica la necesidad de elaborar estrategias de adaptación al cambio climático. Aunque el agua es el eje central de los impactos del cambio climático, también lo es de las políticas de adaptación, planificación y acción. Las cuencas hidrográficas y las costas, y sus ecosistemas, son infraestructuras naturales para hacer frente a estos impactos. Ofrecen almacenamiento de agua, control de inundaciones y defensa costera, todos ellos vitales para reducir la vulnerabilidad de las comunidades y las economías al cambio climático. La inversión en el IWRM, como "crítica infraestructura natural nacional", debe ser parte integral de los programas de adaptación al cambio climático (Barchiesi y Smith, 2008). 


\section{Sistemas Agrícolas: La Biodiversidad 20. en Paisajes Domesticados}


A medida que la población mundial se expande, al parecer inexorablemente, hacia 9 mil millones, es de amplia aceptación que la producción mundial de alimentos tendrá que aumentar al menos en un 50\% para alimentar a la creciente población y mejorar el nivel de vida de miles de millones de personas. Y lo que es peor, esto tendrá que hacerse de cara al cambio climático, que hace que la productividad agrícola sea altamente impredecible. La demanda de alimentos puede crecer aún más rápido que la población humana, como resultado de la creciente urbanización, el aumento de los ingresos, y mayores esfuerzos para reducir el hambre entre los aproximadamente 950 millones de personas desnutridas (FAO, 2008c). El consumo mundial de productos pecuarios se prevé que superará los 650 millones de toneladas en 2020. Seguramente se necesitará más tierra para cultivar y pastorear el ganado, más aún cuando se espera que los biocombustibles se conviertan en un importante impulsor de energía. Solo en África, se prevé que las tierras dedicadas a la producción de cereales experimentarán un aumento de más de 100 millones de hectáreas en 1997 a unos 135,3 millones de hectáreas en 2025, que inevitablemente supondrá concesiones entre la tierra dedicada a cultivos, a la ganadería y a otros propósitos.

Alimentar a una población de 9 mil millones utilizando los métodos actuales podría implicar la conversión de otros mil millones de hectáreas de hábitat natural para la producción agrícola, principalmente en el mundo en desarrollo, junto con una duplicación o triplicación de los insumos de nitrógeno y fósforo, un aumento del doble en el consumo de agua y del triple en el uso de plaguicidas. Se prevé que el agua será un grave factor limitante, dado que el 70\% del agua dulce utilizada por la gente ya está dedicado a la agricultura. Los escenarios preparados por la Evaluación de los Ecosistemas del Milenio $(\mathrm{EM})$, sugieren que la producción agrícola en el futuro tendrá que centrarse más explícitamente en sistemas de gestión más ecológicos que se ocupen más de la biodiversidad (Carpenter et al., 2005).

Ya sea que el aumento de la producción agrícola se realice a través de un uso más intensivo de las tierras agrícolas o de un uso más extenso de las tierras que actualmente están siendo 
utilizadas para otros fines, la biodiversidad se verá inexorablemente sometida a una mayor presión.

La agricultura puede definirse como el arte, la ciencia y el negocio de criar ganado y cultivar la tierra para producir cosechas. Depende en su totalidad de los genes, las especies y los ecosistemas y la variabilidad que contienen. Esta biodiversidad también proporciona a la agricultura la capacidad para adaptarse a condiciones cambiantes.

El movimiento conservacionista está estudiando la forma en que desea relacionarse con la agricultura de la manera más productiva. Después de todo, los agricultores, pastores y cazadores-recolectores son los ocupantes de los paisajes rurales donde sobrevive la mayor parte de la biodiversidad del mundo. Si aspiramos a mantener la biodiversidad mundial y un equilibrio razonable entre las personas y el resto de la naturaleza, entonces la agricultura debe ser parte del debate.

Por otro lado, la conservación tiene mucho que aportar a la agricultura sostenible. Esa agricultura debe ser muy diversa, con ecosistemas de apoyo que conforman una gran riqueza de especies silvestres de beneficio para la agricultura.

Estas incluyen parientes silvestres de plantas domesticadas, polinizadores, especies útiles para el control de plagas, microorganismos del suelo, y muchos otros.

Casi un tercio de la tierra de nuestro planeta está dominado por cultivos agrícolas o pasturas sembradas, con el consiguiente efecto ecológico en todo el paisaje. Otro $10-20 \%$ de la tierra está sometido a la ganadería extensiva de pastoreo, y alrededor del 1-5\% de los alimentos se producen en los bosques naturales (Cassman y Wood, 2005). De ahí que la biodiversidad y los servicios de los ecosistemas son fundamentales para garantizar un futuro sostenible para nuestros agricultores.

\section{CÓMO APOYA LA BIODIVERSIDAD LA CRECIENTE DEMANDA DE PRODUCCIÓN AGRÍCOLA}

Prácticamente todas las especies domesticadas de plantas y animales tienen todavía parientes silvestres cuya diversidad genética puede ser valiosa para propiciar la adaptación de las especies domesticadas a condiciones cambiantes. Si bien los bancos de semillas nacionales e internacionales contienen mucho material genético valioso, los parientes silvestres son especialmente importantes porque viven y se adaptan a la evolución de las condiciones climáticas, en competencia con otras especies, depredadores y enfermedades nuevas. Los esfuerzos para la conservación de los parientes silvestres de plantas y animales domesticados han aumentado considerablemente en los últimos decenios, los acuerdos internacionales reconocen su valor, numerosos proyectos se han puesto en marcha en diversos países, y se está ampliando la colaboración institucional (Meilleur y Hodgkin, 2004). Dentro de la UICN, la Comisión de Supervivencia de Especies (CSE) cuenta ahora con un Grupo de especialistas que trabajan con los parientes silvestres de plantas domesticadas, y algunos de sus otros Grupos de especialistas trabajan con los parientes silvestres de los animales domésticos (por ejemplo, ganado salvaje, camélidos, cerdos y pecaríes y faisanes) .

Un servicio de apoyo prestado por la biodiversidad de especial importancia para la agricultura es la protección de las plantas. Las plantas responden a los insectos que se alimentan de las hojas sintetizando y liberando complejas mezclas de compuestos volátiles, que atraen a los insectos que son enemigos naturales de los insectos que se alimentan de las hojas, contribuyendo así a defender la planta. Si las defensas naturales de las plantas basadas en la biodiversidad pudieran ser movilizadas de manera más eficaz, segura y efectiva, se podría diseñar estrategias de protección de los cultivos 
que reducirían significativamente los efectos secundarios negativos de la actual generación de fertilizantes químicos.

Muchas de las cuencas más importantes del mundo están densamente pobladas y bajo un uso predominantemente agrícola, y la mayoría del resto se encuentra bajo distintos usos agrícolas, en los que los cultivos, la ganadería y la producción forestal influyen en los sistemas hidrológicos. En esas regiones, es posible gestionar la agricultura y a la vez mantener las funciones críticas de las cuencas, tales como el mantenimiento de la calidad del agua, la regulación del caudal hídrico, la recarga de los acuíferos subterráneos, la mitigación de los riesgos de inundación, la moderación de los flujos de sedimentos, y el mantenimiento de las especies y los ecosistemas de agua dulce. Una gestión eficaz del agua incluye la opción de aplicar mezclas de cultivos favorables a la conservación del agua, la gestión del suelo y el agua (incluyendo el riego), barreras de vegetación para frenar el escurrimiento del agua en las laderas, cubierta vegetal del suelo durante todo el año y mantenimiento de la vegetación natural en las zonas ribereñas, los humedales y otras áreas estratégicas de la cuenca. La buena gestión de los paisajes agrícolas ricos en biodiversidad también puede proporcionar protección contra fenómenos naturales extremos. Con el aumento previsto de escasez de agua y fenómenos meteorológicos extremos en los próximos decenios en muchas partes del mundo, es probable que la contribución de la biodiversidad para mejorar la capacidad de los sistemas agrícolas para mantener las funciones de la cuenca sea una de las consideraciones más importantes en la inversión y la gestión agrícola.

Los paisajes agrícolas pueden conservar una amplia gama de especies terrestres nativas, especialmente aquellas que se adaptan bien a la fragmentación del hábitat y al uso de la tierra agrícola. Las perspectivas para la conservación de la biodiversidad en paisajes agrícolas depende del grado de fragmentación y la conectividad funcional de los espacios naturales, la calidad del hábitat de estas zonas, la calidad del hábitat de la matriz productiva, y la medida en que los agricultores gestionan sus tierras para la conservación de la biodiversidad. Las formas de agricultura que equilibran con éxito la productividad, la mejora de los medios de subsistencia, y la conservación de la biodiversidad a escala del paisaje se han denominado “agricultura ecológica” (McNeely y Scherr, 2003).

Los esfuerzos para mantener los hábitats naturales en las zonas agrícolas son de larga data, principalmente a través de regímenes de segregación de tierras agrícolas, rotación de cultivos, dejando algunas tierras en barbecho, e incluyendo árboles en las granjas. Las tierras segregadas de la producción convencional de cultivos han demostrado de forma inequívoca que mejoran la biodiversidad en América del Norte y Europa (Van Buskirk y Willi, 2004). Para muchos monocultivos comerciales, el dejar franjas de tierra sin cultivar para la protección del hábitat no reduce el rendimiento total por cuanto los insumos se aplican más económicamente en el resto (Clay, 2004).

Sin embargo, las intervenciones basadas en el paisaje terrestre específicamente diseñadas para proteger los hábitats para la biodiversidad son mucho más eficaces que un enfoque a nivel de granjas individuales. Una reciente revisión de pruebas de América del Norte sobre cuánta cantidad de hábitat de vida silvestre es "suficiente" en los paisajes agrícolas (Blann, 2006) llegó a la conclusión de que las necesidades de hábitat deben ser consideradas dentro de la historia y el contexto del paisaje. Los parches de hábitat deben ser lo suficientemente grandes y estar conectados con otros parches, por ejemplo, a lo largo de ríos y quebradas o tierras empinadas o montañosas cubiertas de vegetación nativa. Los 
parches de hábitat natural más pequeños pueden ser suficientes si los parches agrícolas adyacentes son gestionados de manera ecológica. Un número creciente de investigaciones muestra que la conectividad del paisaje entre los grandes parches de bosque puede mantenerse de manera eficaz a través de la retención de la cubierta forestal en la granja, tales como cercas vivas, rompevientos y setos en las tierras de pastoreo y campos agrícolas (Harvey et al., 2004) . Los esfuerzos de conservación de la biodiversidad encaminados a la adaptación a los cambios en los paisajes agrícolas, por lo tanto, deben centrarse en la protección (o restauración) de las grandes áreas de hábitat natural en la matriz agrícola y la retención de elementos (tales como setos, árboles aislados, bosques ribereños y otras zonas no cultivadas) que mejoren la conectividad del paisaje. Estas medidas garantizarán la heterogeneidad tanto a nivel del campo como del paisaje, mejorando así la capacidad de adaptación de los ecosistemas agrícolas frente al cambio climático, a nuevas demandas de nuevos cultivos, a la demografía y a otros factores dinámicos.

\section{EL FUTURO DE LA BIODIVERSIDAD Y LA AGRICULTURA}

Desde una perspectiva de conservación de la biodiversidad silvestre, el ideal de los sistemas de producción agrícola imita la estructura y función de los ecosistemas naturales (Blann, 2006, Jackson y Jackson, 2002). En ecosistemas forestales húmedos y subhúmedos las explotaciones agrícolas se asemejarían a los bosques, con cultivos productivos de árboles, cultivos que crecen a la sombra, y mezclas agrosilvícolas; en los ecosistemas de pastizales, los sistemas de producción dependerían más de los granos y pastos perennes, junto con arbustos económicamente útiles y especies arbóreas de tierras secas. Los cultivos anuales podrían ser cultivados en tales sistemas, pero como intercultivos, o parcelas de monocultivo intercaladas en mosaicos de producción perenne y zonas de hábitat natural. Se fomentaría la diversidad de cultivos domesticados y especies de ganado a escala del paisaje, y se conservaría in situ la diversidad genética dentro de las especies en una gran escala del ecosistema, para asegurar la resiliencia del sistema y la diversidad ecológica necesarias para adaptarse a condiciones cambiantes.

Los sistemas agroforestales de sombra, los árboles en barbecho y los huertos familiares complejos son especialmente ricos en biodiversidad silvestre. Por ejemplo, la altura del dosel y la diversidad de árboles, epifitas, lianas y especies de aves, la complejidad estructural de la vegetación, el porcentaje de tierra cubierta por hojarasca y el calcio del suelo, los niveles de nitrógeno de 
nitrato y de materia orgánica en la capa superior del suelo, son significativamente mayores en las granjas con cultivos de sombra que en los que crecen al sol, mientras que las temperaturas del aire y del suelo, la diversidad de malezas y el porcentaje de cubierta vegetal por la maleza son significativamente mayores en las explotaciones sin árboles. En Centroamérica, las complejas combinaciones de policultivos y sistemas de gestión mejoran la productividad del café, cacao, banano, madera y otros productos comerciales de árboles.

Mientras que el café cultivado en plantaciones de monocultivos con plena exposición al sol tiene un mayor rendimiento, el café cultivado a la sombra es mucho más beneficioso para la agricultura sostenible y la conservación de la biodiversidad (a menudo apoya más del doble de especies de aves). Los sistemas con muchas

Recuadro 20.1 Cabrucas: la conservación de murciélagos en la producción de cacao

En el Estado de Bahía, Brasil, las plantaciones tradicionales de cacao de sombra (conocidas localmente como "cabrucas") también proporcionan hábitat para muchas especies que habitan en los bosques, incluyendo una rica y abundante comunidad de murciélagos que se alimentan de muchas especies de insectos y ayudan a polinizar especies de plantas que florecen por la noche. Pero cuando las cabrucas están ubicadas a más de un kilómetro de los bosques nativos, las comunidades de murciélagos son menos diversas que las que se encuentran en los bosques. Por lo tanto, debe considerarse todo el paisaje para la gestión, teniendo en cuenta que el mantenimiento de cabrucas junto con la preservación y restauración del bosque es esencial para la conservación de la diversidad de murciélagos.

Fuente: Schroth y Harvey, 2007 especies de árboles de sombra también ayudan a proporcionar apoyo para insectos beneficiosos, orquídeas, mamíferos y otras especies, así como a proteger los suelos tropicales frágiles contra la erosión, proporcionando nutrientes y suprimiendo malezas, reduciendo o eliminando así la necesidad de herbicidas y fertilizantes químicos y, por tanto, reduciendo los costos de producción. Los agricultores también están en condiciones de cosechar diferentes especies de frutos, leña, madera y medicamentos de los árboles de sombra.

Para sustituir los cultivos que deben ser replantados cada año (normalmente en forma de monocultivos, en donde una sola especie se planta en una zona extensa), nuevos y mejores cultivos perennes como frutas, verduras, especias, y aceites vegetales, son cada vez más populares. Los cultivos perennes pueden ser más resilientes y causar menos perturbación del suelo y del ecosistema que los cultivos anuales, y ofrecer mayor valor del hábitat, especialmente cultivándose en mezclas y mosaicos (Jackson y Jackson, 2002).

La planificación estratégica para el desarrollo agrícola ha empezado a centrarse en la adaptación de los sistemas al cambio climático, la previsión del aumento de las temperaturas y otros fenómenos meteorológicos extremos. Con cada aumento de un grado Celsius en la temperatura durante la temporada de cultivo, los rendimientos del arroz, el trigo y el maíz disminuyen en cerca del 10\% (Brown, 2004). Los cultivos como el café y el té, que requieren entornos más frescos, también se verán afectados, obligando a los productores de estos cultivos a desplazarse más arriba en las colinas, despejando nuevas tierras a medida que suben. Los bosques montanos importantes para la biodiversidad es probable que se vean sometidos a una creciente amenaza como consecuencia de ello. Las respuestas eficaces al cambio climático exigirán cambios en 
las variedades, modificación en torno a la gestión de los suelos y el agua, y el desarrollo de nuevas estrategias para el manejo de plagas, conforme se modifiquen las especies de plagas silvestres, sus depredadores naturales, y sus ciclos de vida en respuesta a los cambios climáticos. Es probable que el incremento de la diversidad a escala del paisaje y de las explotaciones agrícolas sea una respuesta importante para la reducción de riesgos y la adaptación al cambio.

Desde el decenio de 1960, tanto la agricultura industrial en los países desarrollados como la revolución verde en los países en desarrollo han dependido de semillas mejoradas, fertilizantes químicos y pesticidas, además del riego. Este modelo de producción implicó un número reducido de cultivos, generalmente en masas de monocultivos (para aumentar la eficiencia en el uso de insumos externos y mecanización). La flora y fauna silvestres se consideraban competidores directos de los recursos o productos recolectados, en tanto que se desvió el agua de los humedales y de los hábitats naturales para el riego. Pero en las últimas dos décadas, la investigación ha demostrado el valor de la biodiversidad agrícola en todas sus formas, incluida la diversidad genética agrícola y ganadera, las especies asociadas de importancia para la producción (por ejemplo, los polinizadores, los microorganismos del suelo, los insectos beneficiosos y los depredadores de las plagas) y las especies silvestres que encuentran su hogar en los paisajes agrícolas (Uphoff et al., 2006).

De las diversas disciplinas, filosofías o condiciones geográficas ha surgido una variedad de enfoques modernos que fomentan la biodiversidad. Las alternativas favorables a la biodiversidad para la agricultura industrial incluyen la agroecología (Altieri, 1995), la agricultura de conservación (FAO, 2001a), la agricultura orgánica (IFOAM, 2000) y la agricultura sostenible (Pretty, 2005). Todas han tendido a centrarse en el mantenimiento de la base de los recursos para la producción, a través de la gestión de los ciclos de nutrientes, la protección de los polinizadores y los microorganismos beneficiosos, la salud de los suelos y la conservación del agua. Pretenden reducir la "huella" ecológica de las zonas cultivadas y el daño a la biodiversidad silvestre de los productos químicos tóxicos, la alteración del suelo y la contaminación del agua. En muchos aspectos, se asemejan a las formas preindustriales de la agricultura, pero se benefician de los enfoques modernos que mejoran los rendimientos y la productividad laboral, a la vez que se mantiene la biodiversidad.

La agricultura orgánica ayuda a la biodiversidad mediante el uso de menos pesticidas y fertilizantes inorgánicos, y mediante la gestión favorable del hábitat silvestre que se mantiene sin cultivar, incluyendo estrategias para no desyerbar cerca de los setos y combinando la agricultura de labranza con la ganadería. La agricultura combinada es particularmente beneficiosa para algunas especies de aves, incluidas las que anidan en los cultivos. Algunas granjas que adoptan prácticas orgánicas seleccionadas, tales como la sustitución de la escarda química con métodos mecánicos, puede fomentar la biodiversidad tanto como las explotaciones completamente ecológicas.

El futuro de la agricultura dependerá en gran medida de la contribución de las mujeres. Las mujeres son las principales productoras de cultivos básicos del mundo (arroz, trigo, maíz) que proporcionan hasta un $90 \%$ de la ingesta de alimentos de la población rural pobre y producen el 60-80\% de los alimentos en la mayoría de los países en desarrollo. En la India, las mujeres aportan el 75\% de la mano de obra para la escarda y el transplante de arroz, el 60\% para la cosecha, y el 33\% para la trilla. (Comunicados 
de prensa del Centro de Información de las Naciones Unidas en Sydney para Australia, Nueva Zelanda y el Pacífico Sur, 1995, citado en Mata y Sasvari, 2009).

Según la Organización para la Agricultura y la Alimentación (FAO), las mujeres producen, seleccionan y ahorran hasta un $90 \%$ de las semillas y el germoplasma que utilizan los pequeños agricultores como material de plantación. En Ruanda, las mujeres producen más de 600 variedades de frijoles, y las mujeres aguaruna del Perú cultivan más de 60 variedades de yuca (FAO, 2001b).

Según la Estrategia y plan de acción nacional para la diversidad biológica (EPANDB) de Yemen, las mujeres también tienen un papel clave en el cultivo y preservación de las especies subutilizadas, que no satisfacen una gran proporción de las necesidades alimentarias del mundo, sino que son utilizadas por comunidades específicas para complementar su dieta. En Yemen, las mujeres siembran cultivos diferentes a los hombres, que se identifican como "los cultivos de las mujeres", tales como maní, calabazas, hortalizas de hoja, guisantes, pepinos y batatas, que tienen el efecto de aumentar la biodiversidad y la seguridad alimentaria (EPANDB Yemen, 2005). La EPANDB de Bután reconoce que las especies subutilizadas contribuyen sustancialmente a la subsistencia y seguridad alimentaria de los hogares; y suelen ser administradas o recolectadas por las mujeres. El conocimiento sobre los usos y la gestión de estas especies es también localizado y especializado (EPANDB de Bután, 2002).

En la próxima década, la comunidad de la conservación, en estrecha colaboración con las organizaciones agrícolas, debe buscar formas sostenibles y adaptables de uso de la tierra que den prioridad a la conservación de los parientes silvestres de plantas y animales domésticos (cabe señalar que muchas de ellas son especies amenazadas). La incorporación de formas compatibles de agricultura con estrategias y planes de acción para la conservación de la biodiversidad a escala del paisaje requerirá el desarrollo del conocimiento de los agricultores como gestores de los ecosistemas y la difusión de los múltiples valores de la biodiversidad en el apoyo a la agricultura, creando así apoyo para la conservación.

La biodiversidad y los servicios de los ecosistemas deben incorporarse en la investigación y el desarrollo agrícola para garantizar que las nuevas tecnologías agrícolas apoyen la conservación de la biodiversidad en lugar de amenazarla. Por último, el desarrollo de nuevos enfoques para compensar a los agricultores por su contribución a la conservación de la biodiversidad y el mantenimiento de los servicios de los ecosistemas, ayudará a proporcionar los incentivos necesarios para la consolidación de actividades de conservación y agricultura.

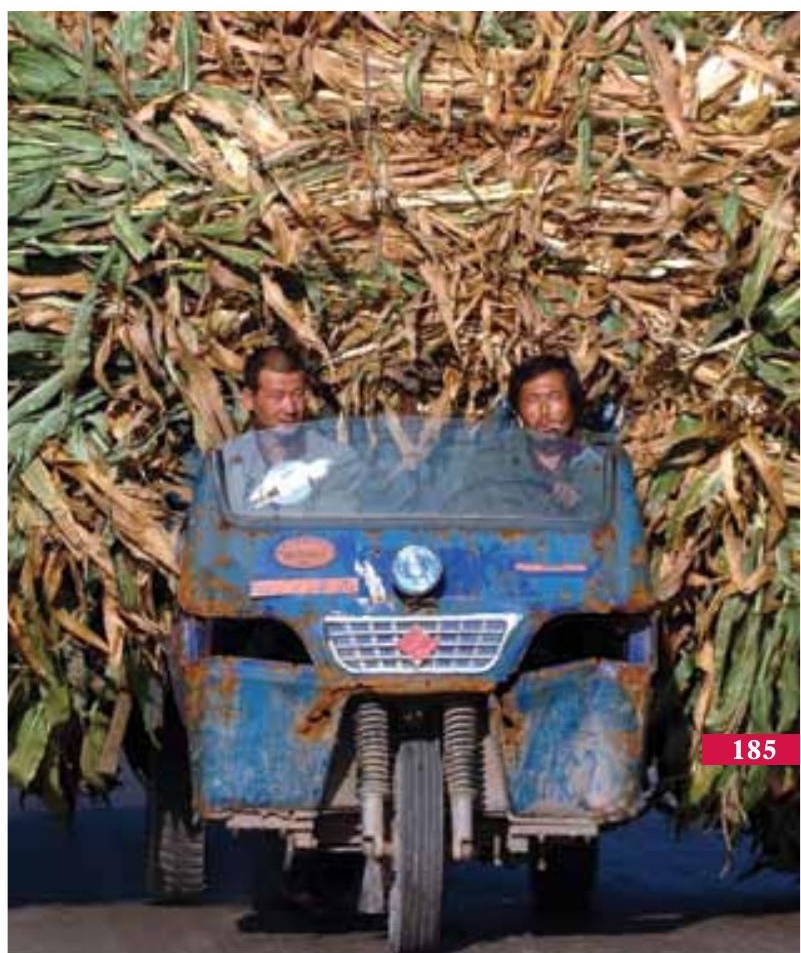




\section{Sistemas Urbanos: \\ 21. La Conservación en las Ciudades}


En 1900, unos 160 millones de personas vivían en las ciudades, el equivalente a aproximadamente el 10\% de la población mundial de 1600 millones en ese entonces. En 2000, alrededor de la mitad de los 6 mil millones de personas vivían en las zonas urbanas, y el porcentaje ha seguido aumentando (capítulo 1). Si la conservación ha de ser un fenómeno universal, deben encontrarse nuevas vías que permitan a las personas que viven en las ciudades tomar parte activa en la conservación.

La conservación de la naturaleza en las ciudades puede ser abordada desde muchas direcciones. Benton-Short y Short (2007) ofrecieron una perspectiva social, mientras que Shiro (2004) tomó un enfoque de planificación basado en la consideración de las ciudades como organismos gigantescos, e Isenberg (2006) se basó en una perspectiva más histórica, con ejemplos de los Estados Unidos, Europa y África.

Si bien la conversión de bosques o tierras agrícolas en ciudades provoca inevitablemente una pérdida de biodiversidad, los habitantes urbanos utilizan menos cantidad de algunos recursos por persona que quienes residen en el campo. Los apartamentos en edificios altos son más eficientes en cuanto a consumo de energía que las casas individuales, y las ciudades tienden a contar con medios más eficientes para el suministro de agua, energía y transporte que las zonas rurales. En Londres, las emisiones de dióxido de carbono por habitante son apenas un poco más de la mitad de la media para todo el país, mientras que los habitantes de la ciudad de Nueva York produjeron menos de un tercio de la media de emisiones per cápita para la totalidad de los Estados
Unidos. Las emisiones de dióxido de carbono por habitante también son sustancialmente más bajas en São Paulo y Río de Janeiro, pero ciudades como Pekín y Shanghai, que contienen muchas fábricas que producen un alto grado de emisiones, están muy por encima de la media nacional. Pero a nivel mundial, las ciudades emiten el 50-60\% de los gases de efecto invernadero (GHG), llegando a alrededor del 80\% si se incluyen las emisiones indirectas, según cifras de ONU-Hábitat.

Por supuesto, las ciudades también plantean problemas para los ecosistemas. Las ciudades ocupan el 2\% de la superficie terrestre y, sin embargo, consumen el 75\% de sus recursos naturales. Con un mayor número de personas concentradas en pequeñas superficies de tierra, las enfermedades infecciosas pueden ser transmitidas con más facilidad. La biodiversidad en las ciudades, especialmente a nivel de ecosistemas y especies, está particularmente amenazada por las especies exóticas invasoras. Ello es de esperarse porque las ciudades tienden a ser el centro del comercio internacional que lleva consigo especies invasoras (Schwartz et al., 2006). Este efecto se extiende también a las 
aves, y la avifauna de las zonas urbanas tiende a ser cada vez más homogeneizada, y las especies poco comunes tienden a retirarse, $\mathrm{y}$ las especies cosmopolitas como las palomas y gorriones tienden a dominar (Clergeau et al., 2006). Y las personas que viven en las ciudades deben recurrir a la campiña circundante para obtener muchos de sus recursos esenciales, especialmente alimentos, agua y energía.

También necesitan de áreas protegidas, que proporcionan importantes beneficios a las ciudades, incluyendo el suministro de agua, recreación, y diversos valores económicos y de otra índole.

Muchas personas que viven en las ciudades buscan áreas protegidas para obtener bienestar psicológico; una semana en la selva de un parque nacional les brinda un respiro estimulante de las presiones de vivir en ciudades hacinadas e impersonales. Las áreas protegidas dependen también de las ciudades, para apoyo político, como fuente de visitantes, y para garantizar un vínculo cultural entre la población urbana y su entorno.

Muchas organizaciones conservacionistas han reconocido la importancia de la incorporación de los espacios naturales como parte de la infraestructura urbana. Esto se extiende mucho más allá de simples parques de vecindad, aunque, por supuesto, estos desempeñan un papel importante. Algunas ciudades han sido bastante ambiciosas en la integración de la biodiversidad en la planificación urbana. Londres, por ejemplo, ha adoptado una estrategia formal de biodiversidad, con cinco elementos principales: permitir que aquellos que viven o trabajan en Londres tengan mayor contacto con la naturaleza en su propia localidad; proteger los importantes hábitats de vida silvestre de Londres y identificar más de 1500 de esos lugares; mejorar los hábitats de los parques públicos y espacios abiertos o crear nuevos hábitats para la fauna silvestre para el disfrute público y la educación ambiental; fomentar la provisión de instalaciones para educación ambiental y oportunidades para todos los sectores de la sociedad para participar activamente en proyectos ambientales; y lograr la participación de una amplia gama de organizaciones y personas en el apoyo de una asociación para la estrategia de biodiversidad (Goode, 2005). Muchas ciudades tienen parques nacionales dentro de sus fronteras, o inmediatamente adyacentes a ellas, incluyendo grandes metrópolis como Los Ángeles, Río de Janeiro y Sydney. Las áreas protegidas dentro de las ciudades pueden ayudar a proteger los recursos hídricos, proveer oportunidades de recreación, ayudar a promover la educación ambiental, y crear puestos de trabajo locales.

La UICN ha tratado de coordinar las acciones de conservación dentro de las ciudades, dirigidas por el Grupo de tareas de la Comisión Mundial de Áreas Protegidas (CMAP) sobre las ciudades y las áreas protegidas, que a su vez ha contribuido a la Asociación Mundial sobre Ciudades y Biodiversidad, que comenzó en 2006. Y más de 300 gobiernos locales se han unido en una red de apoyo a la Cuenta hacia atrás 2010 de la UICN, que busca revertir la tasa de pérdida de biodiversidad antes de esa fecha.

\section{LOS VALORES DE LA NATURALEZA EN LAS CIUDADES}

Cabe esperar que las zonas urbanas presten más apoyo a las áreas protegidas cuando las personas que viven en las ciudades reconocen los beneficios que ellas ofrecen. Por ejemplo, Dudley y Stolton (2005) determinaron que cerca de un tercio (33 de 105) de las principales ciudades del mundo obtienen una parte importante de su agua potable directamente de las áreas protegidas, incluyendo Barcelona, Bogotá, Brasilia, Caracas, Yakarta, Johannesburgo, Karachi, Los Ángeles, Madrid, Melbourne, Bombay, Nairobi, Nueva York, Perth, Río de Janeiro, São Paulo, Singapur, Sydney, Tokio y Viena.

Muchas otras ciudades gestionan los bosques específicamente para la protección de cuencas hidrográficas, incluidas las de Seúl, Tokio, Pekín, 
Rangún, Santiago, Nueva York, Estocolmo, Munich y Minsk. Alrededor del 90\% del suministro de agua de Melbourne (Australia) proviene de las deshabitadas cuencas de montaña boscosa al norte y al este de la ciudad. Si bien la mayoría de estas cuencas se encuentra fuera de las áreas protegidas, la gestión de la empresa pública de agua de Melbourne se basa en la protección de dichas cuencas. Al vincular una contribución muy práctica de las áreas protegidas u otras zonas de gran biodiversidad a las ciudades, se contribuye a crear un mayor apoyo para ellas.

El acceso a los espacios verdes dentro de las ciudades ofrece muchos beneficios para las personas, especialmente en lo que respecta a la salud, seguridad y bienestar (Kuo et al., 1998). Fuller y Gaston (2009) han evaluado los espacios verdes dentro de 386 ciudades en 31 países europeos, que contienen más de 170 millones de personas (más de un tercio de la población de Europa). Encontraron una gran variación en términos de espacios verdes, desde 1,9\% en Reggio di Calabria, Italia, hasta 46\% en Ferrol, España, tendiendo las ciudades al norte de Europa a tener una mayor proporción de espacios verdes en comparación con los del sur. Así pues, no es de extrañar que hayan determinado que la proporción de espacios verdes por persona tiende a disminuir a medida que aumenta la densidad poblacional. La creciente densidad poblacional en las ciudades supone ciertamente una amenaza para el resto de las zonas verdes. Por ejemplo, la Ciudad de México está perdiendo hasta 500 hectáreas de parques y bosques al año debido a la ocupación ilegal de la tierra y el desarrollo, representando esto casi la mitad de las restantes áreas protegidas abiertas en la capital durante la última década.

Algunos expertos consideran que los combustibles fósiles son esenciales para el enfoque moderno de la vida urbana (Girardet, 1999). Hasta hace muy poco, la mayoría de las ciudades tenía lo que podría considerarse como un metabolismo lineal,

\section{Recuadro 21.1 Las aves en las ciudades}

Las aves en los paisajes urbanos ocupan principalmente los parques (que pueden ser vistos como fragmentos de bosque), calles arboladas (franjas lineales que conectan fragmentos), o la matriz urbana; las palomas, por ejemplo, tratan los edificios como los acantilados artificiales de sus antepasados, y los halcones han encontrado un hogar en Manhattan, donde las palomas son abundante presa. Fernández-Juncic (2000) estudió los efectos de la ubicación de las calles en el paisaje, la estructura de la vegetación y la perturbación humana (la carga peatonal y vehicular) en las calles arboladas con respecto a la riqueza de especies de aves, la persistencia temporal, y la densidad de anidación y alimentación de los grupos, y sobre la probabilidad de ocupación de las calles por parte de especies individuales en Madrid, España. El número de especies registradas aumentó desde el hábitat menos adecuado (calles sin vegetación) hasta el más adecuado (parques urbanos), siendo las calles arboladas los elementos intermedios del paisaje. Las calles arboladas que conectaban parques urbanos influyeron positivamente en el número de especies dentro de las calles arboladas, la persistencia de especies, la densidad de grupo y la probabilidad de ocupación de las calles por las distintas especies. La perturbación humana ejerció una influencia negativa sobre las mismas variables. Las calles arboladas podrían funcionar potencialmente como corredores, permitiendo a ciertas especies prosperar mediante el apoyo al hábitat para la alimentación, anidación y reposo (para las especies migratorias). Las mejoras locales en la calidad de los corredores, a través de una mayor complejidad de vegetación y reducción de la perturbación humana, podría influir positivamente en la conectividad regional del sistema y, por ende, su idoneidad como 
con los recursos fluyendo en el sistema sin que los consumidores se preocuparan de su origen o de la eliminación de sus desechos. Un modelo más adecuado para las ciudades sería el de imitar el metabolismo circular de la naturaleza, en el que cada producto es también un producto que ayuda a mantener y renovar todo el sistema -la esencia de los servicios de los ecosistemas. El reciclaje ya se está convirtiendo en norma de comportamiento en muchas ciudades, y la actual crisis financiera ha demostrado que es perfectamente posible llevar una vida urbana decente sin altos niveles de consumo de recursos. Una ciudad sostenible será capaz de satisfacer sus propias necesidades sin poner en peligro el mundo natural o las condiciones de vida de sus ciudadanos.

\section{UNA NUEVA VISIÓN DE LAS CIUDADES Y LA NATURALEZA}

Muchas ciudades ya son relativamente verdes, como por ejemplo Pekín, que ya produce casi todas sus hortalizas dentro de su región metropolitana. Otras están tratando de reverdecerse.

\section{Recuadro 21.2 Chicago Wilderness}

Concebido junto con la UICN como un modelo, Chicago Wilderness es una alianza de colaboración regional ampliamente comprometida con la conservación de la biodiversidad en la región metropolitana de Chicago, que conecta a la gente con la naturaleza. Más de 240 miembros de diversas organizaciones trabajan juntos en los programas y estudios científicos para proteger y restaurar los espacios naturales dentro de una región urbana que se extiende a través de cuatro estados. La alianza busca aumentar la conciencia y el conocimiento de la biodiversidad nativa y los valores de la naturaleza en la región, incrementar y diversificar la participación ciudadana en el cuidado del medio ambiente, fomentar relaciones de colaboración entre las diversas circunscripciones de toda la región para promover una relación sostenible con la naturaleza, facilitar la aplicación de investigaciones naturales y sociales en la restauración y el mantenimiento de la diversidad de entornos en la zona, fomentar el desarrollo de mejores prácticas de gestión y el intercambio de información, y generar una base amplia de apoyo público y privado con el objetivo final de mantener la biodiversidad nativa -las zonas selváticas- en la región metropolitana de Chicago $\mathrm{y}$, en el proceso, volver a conectar a muchas personas con la naturaleza y los restantes lugares silvestres de la región.

El nombre de Chicago Wilderness se aplica también al mosaico regional de áreas naturales en más de 145.000 hectáreas de tierras y aguas protegidas. Las comunidades naturales de Chicago Wilderness incluyen praderas de hierba alta, bosques de madera dura, roble sabana, praderas de juncia, pantanos y ciénagas. Se mantiene menos de una décima parte del $1 \%$ de las praderas originales de hierba alta de Illinois, pero Chicago Wilderness contiene algunos de los mejores ejemplares, con varias especies amenazadas a nivel regional.

\section{La alianza Chicago Wilderness se formó en 1996} para mejorar la gestión de las numerosas áreas protegidas en y alrededor de Chicago, que se extienden desde el sudoeste de Michigan a través del noroeste de Indiana y el noreste de Illinois, hasta el sureste de Wisconsin. La alianza produjo primero un Atlas de la biodiversidad, luego un Plan de recuperación de la biodiversidad y, posteriormente, un Informe sobre el estado de la biota y los ecosistemas en la región. También publica una revista trimestral y ha publicado una guía familiar para promover las actividades de los jóvenes en la naturaleza. La revista contiene 
A pesar de algunos esfuerzos importantes en términos del reverdecimiento de las ciudades, la mayoría de las ciudades del mundo está concentrada en barrios pobres en biodiversidad (Turner et al., 2004). Miles de millones de personas pueden perder la oportunidad de desarrollar aprecio por la naturaleza y los beneficios que pueden obtenerse de ello. Esto sugiere la necesidad y conveniencia de emprender un esfuerzo importante para proporcionar oportunidades para vincular a las personas a la biodiversidad dentro de las ciudades.
Algunas ciudades han reconocido esta necesidad imperiosa. Jinan, capital de la provincia de Shandong de China Oriental, plantará hasta 7100 hectáreas de nuevos bosques en los próximos tres años. La ciudad tiene previsto responsabilizar a toda persona mayor de 11 años de la siembra de tres a cinco árboles por año, como parte del proyecto "Cielo azul" de la ciudad que tiene por objeto crear un medio ambiente limpio y verde en esta contaminada ciudad en el término de cinco años. artículos sobre especies nativas, reconoce a profesionales y laicos que participan activamente en la conservación, y describe una variedad de lugares protegidos de la región. También ha publicado números especiales sobre las principales preocupaciones, tales como los recursos hídricos y la construcción de carreteras. La membresía de la alianza Chicago Wilderness incluye organismos gubernamentales federales, estatales y locales, municipalidades, distritos de parques; grandes ONG de conservación, pequeños grupos de voluntarios, organizaciones de educación e investigación, e instituciones culturales. Se ha creado un Consejo Corporativo con unas 35 empresas que han comprometido su apoyo y participación en los esfuerzos de la alianza. El apoyo financiero proviene de las organizaciones afiliadas y del Consejo Corporativo, de fuentes filantrópicas, y de los abonados de la revista, pero gran parte de la financiación programática ha llegado a través de dos agencias federales, el Servicio de Pesca y Vida Silvestre de los EE. UU. y el Servicio Forestal de los EE. UU., que se ha utilizado para motivar a otras organizaciones miembro a no quedarse atrás.

\section{El programa de la alianza Chicago Wilderness} tiene ahora cuatro ejes de interés: un grupo de expertos sobre los efectos del cambio climático sobre la biodiversidad regional; un visionario plan para quintuplicar las áreas protegidas para la continuación de la existencia de la diversidad de la biota nativa; el programa "Ningún niño adentro" que tiene por objeto desarrollar el interés de los niños en la naturaleza y crear capacidades para el cuidado del medio ambiente, y una iniciativa a largo plazo para adquirir más conocimientos en la ecología de restauración y su aplicación en la gestión.

El éxito de Chicago Wilderness se debe a que se construyó sobre un siglo de historia de conservación local, tenía un diverso grupo fundador de líderes institucionales que ya estaban dedicados a la misión de la conservación de la biodiversidad, tenía el apoyo de la opinión pública a través de sus publicaciones, y permitió a los miembros de la alianza lograr sus propias misiones institucionales. Incluso en ausencia de tales condiciones, Chicago Wilderness ofrece un poderoso modelo que muestra cómo un enfoque de colaboración para la conservación de la biodiversidad puede ser implementado en un entorno urbano, el cual ya se ha incorporado en Curitiba, Brasil y en Houston, Texas. 
Un programa innovador para vincular la juventud urbana a la naturaleza en el campo es el Programa de Santuario de Tigres Kids for Tigers, que se inició en la India en 2001, con la finalidad de alentar a los niños urbanos de Asia Meridional a visitar la naturaleza. Aunque los tigres eran el fin primordial, muchas de las cuestiones más importantes se centraron en el agua (Sahgal, 2005). En el programa han participado más de un millón de niños, de 700 escuelas en 12 ciudades de la India.

En los últimos años, la "ecología urbana” se ha desarrollado como una iniciativa para integrar las ciencias naturales y sociales para estudiar el medio ambiente de las ciudades y sus efectos globales $\mathrm{y}$ regionales, con base en el principio de que las ciudades presentan tanto los problemas como las soluciones a los retos de la sostenibilidad de un mundo cada vez más urbanizado (Grimm et al., 2008). Chicago Wilderness Area (recuadro 21.2) es un ejemplo notable.

Si bien las especies invasoras de plantas suelen aumentar en las zonas urbanas, esto puede aumentar la riqueza de las especies en las ciudades en relación a las zonas rurales, incluso las áreas protegidas. Las ciudades se caracterizan por un mosaico muy heterogéneo de hábitats, y la gente introduce en los jardines urbanos especies no nativas de plantas con un número relativamente reducido de individuos de cada una de estas especies.

Muchas ciudades tienen parques zoológicos y jardines botánicos que sirven como valiosos depósitos de especies nativas silvestres, y ofrecen una oportunidad para que la población urbana tenga un contacto más cercano con especies de plantas y animales de todo el mundo.

Los ecosistemas urbanos suelen tener poca similitud con los ecosistemas rurales, y las comunidades de aves a menudo cambian a especies que se alimentan de granos a costa de las que se alimentan de insectos; y muchas comunidades de insectos pueden perder sus especies especialistas al tiempo que obtienen cada vez más especies generalistas. Muchas ciudades tienden a tener especies bastante similares adaptadas al entorno urbano, lo que lleva a la homogeneización en contraposición a la diversidad (Grimm et al., 2008). Por otra parte, caracterizándose las ciudades en general por temperaturas más cálidas y mucha más luz en la noche, muchas especies nocturnas resultan comparativamente desfavorecidas. Grimm y sus colegas defienden "la ecología de reconciliación", en la que los hábitats que son muy alterados para el uso humano se conciben, organizan y gestionan espacialmente para aumentar al máximo la biodiversidad y ofrecer a la vez beneficios económicos y servicios de los ecosistemas. Sugieren que la ecología de reconciliación ofrece importantes oportunidades para que los ecologistas contribuyan al diseño y la gestión de las nuevas ciudades y la reconstrucción de las antiguas.

Dado que las comunidades biológicas en las ciudades son las que la mitad de la población humana normalmente experimenta, es cada vez más importante garantizar que se aproveche al máximo los últimos reductos de "naturaleza" que se encuentran en las zonas urbanas para fomentar el apoyo a la conservación en un sentido más amplio.

Los habitantes de las ciudades deben promover y votar por estrategias basadas en la ciudad que sean más eficientes en términos de recursos, que promuevan programas de educación sobre la naturaleza para los centros urbanos y fomenten una cultura de sostenibilidad y conservación urbana.

Los responsables de la toma de decisiones en las zonas urbanas deben ser alentados a participar más en cuestiones relativas a biodiversidad y áreas protegidas y a incluir estos temas en las reuniones pertinentes, tanto a nivel nacional como internacional. Una importante oportunidad podría ser la Conferencia de Alcaldes en 2010 en Nagoya, 
Japón, en paralelo con la Conferencia de las Partes del Convenio sobre la Diversidad Biológica (COP del CDB). También deben establecer y reconocer las áreas de conservación municipal como una contribución significativa a la red mundial de áreas protegidas y el esfuerzo internacional para conservar la biodiversidad y tratar de incorporar componentes de biodiversidad y áreas protegidas en la planificación de importantes acontecimientos deportivos urbanos, como los Juegos Olímpicos (tanto de verano como de invierno) y la Copa Mundial de Fútbol. Por último, la vinculación con el Centro de las Naciones Unidas para los Asentamientos Humanos y otras partes interesadas podría mejorar el flujo de información entre los administradores urbanos y los líderes empresariales sobre cuestiones ambientales pertinentes a las ciudades.

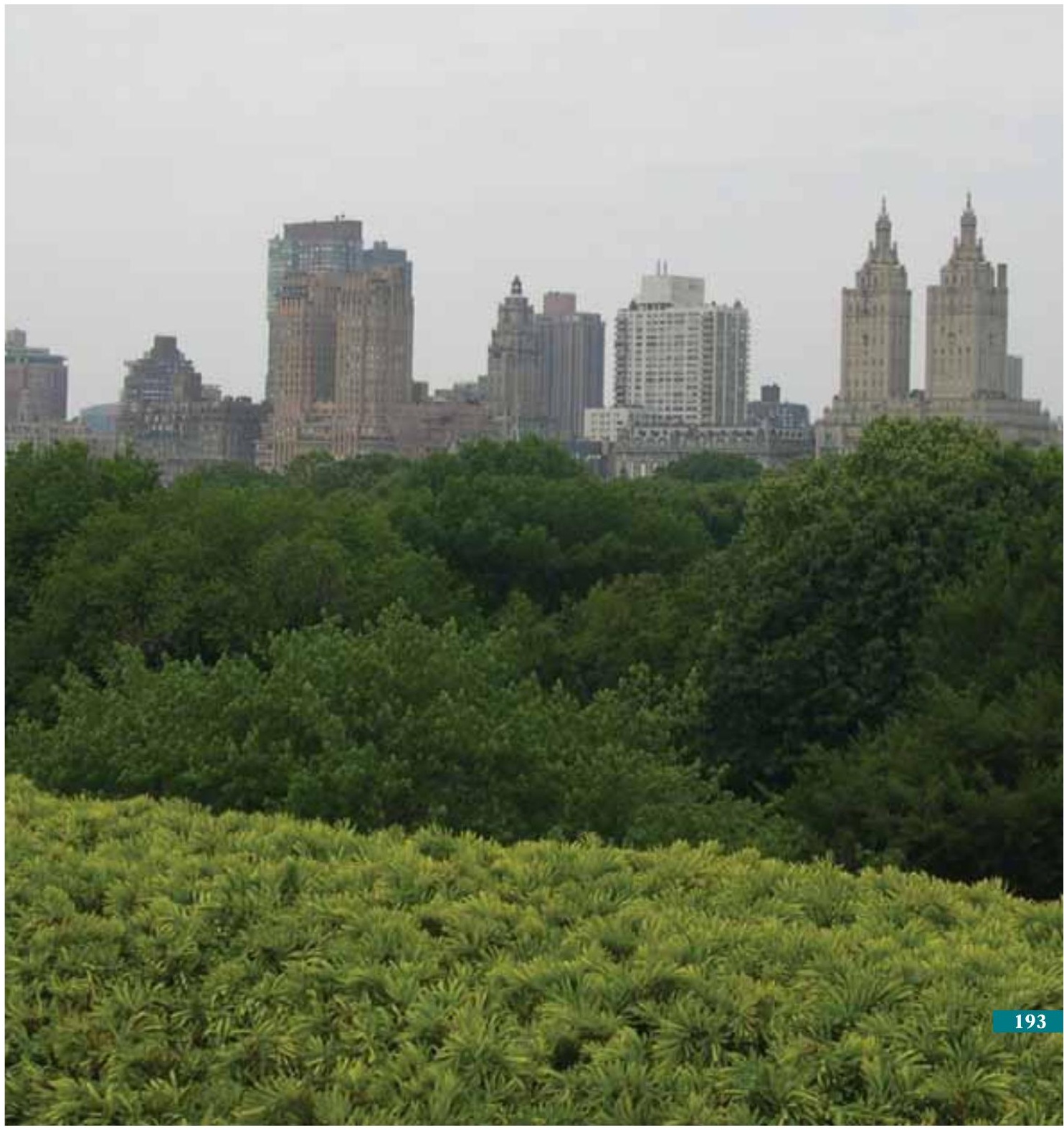


22. Puntos Centrales para la 
Este libro, y el Foro Mundial de la Naturaleza que lo inspiró, han puesto de relieve muchas cuestiones y preocupaciones, así como oportunidades. Aplaudimos la llegada de enfoques incluyentes y basados en la ética para la conservación de la biodiversidad en general. Reconocemos la primacía del cambio climático como una amenaza, pero también señalamos que cuestiones "de más larga data" como la degradación de los hábitats, la sobreexplotación y las especies invasoras, no han desaparecido y, de hecho, están entrelazadas con el cambio climático. Vemos el potencial de oportunidades que ofrece la biodiversidad para ayudar a resolver muchos de los problemas más acuciantes de la humanidad. Este libro ha confirmado que la naturaleza es importante no solo por la naturaleza misma, sino también por el bienestar humano.

Conforme se iban analizando los posibles enfoques de la conservación iban surgiendo varios elementos comunes. La conservación actual tendrá que tener en cuenta las particularidades de las diversas cuestiones, pero algunos puntos son válidos para todos los ámbitos de aplicación -puntos centrales para el futuro de la conservación. Estos incluyen:

1) Integración de la biodiversidad y los servicios de los ecosistemas en todos los sectores

2) Adaptación al cambio a través de la diversidad, la creatividad y el respeto por la naturaleza

3) Promoción de políticas que apoyan la equidad y los derechos como parte integral de la conservación.
INTEGRACIÓN DE LA BIODIVERSIDAD EN TODOS LOS SECTORES

El paradigma de los servicios de los ecosistemas cristaliza la interdependencia de nuestras vidas y nuestro medio ambiente. También proporciona los medios por los que podemos medir y monitorear el impacto de nuestras acciones y establecer con más facilidad los costos y beneficios de dichas acciones. Los servicios de los ecosistemas también ofrecen un punto de entrada a muchas áreas que en apariencia no tienen relación con el medio ambiente, la más visible de las cuales han sido los esfuerzos para incorporar el medio ambiente como parte esencial del desarrollo.

Una medida importante en dicha integración es 
disciplinas. La Comisión Mundial de Áreas Protegidas (CMAP) de la UICN reconoce la necesidad de "hablar un lenguaje común" para llegar a un amplio espectro de público y ayudar a esas audiencias a comprender el sistema de clasificación de la UICN para las áreas protegidas (Bishop et al., 2004). El uso de la jerga médica se ha identificado como un factor que interfiere con la salud de los pacientes, porque simplemente no entienden lo que su médico les dice (Zeng y Tse, 2006). Si los conservacionistas realmente quieren ver cambios para un mejor mundo en las próximas décadas, tendremos que llegar a nuevos públicos y hablarles en un lenguaje que tenga sentido para ellos. Los capítulos sobre la energía (capítulo 8), conflictos armados (capítulo 9), desastres (capítulo 10), salud humana (capítulo 11), tecnología (capítulo 13), sector privado (capítulo 15), agricultura (capítulo 20) y ciudades (capítulo 21) son intentos en esta dirección. Hablar de los servicios de los ecosistemas en lugar de la biodiversidad es otro paso en esa dirección y el estudio La Economía de los Ecosistemas y la Biodiversidad(TEEB) se está apoyando en ello para conectar a la comunidad económica con la biodiversidad. También será necesario hacer uso de las nuevas herramientas de comunicación y concientización a nuestra disposición. Atrás han quedado los días en que el conocimiento podía ser transmitido solo a través de la interacción personal o los libros. Wikis, blogs, cursos en línea en lugar de una aula de clase, y quién sabe qué otra cosa, serán los medios del futuro para el intercambio de información sobre la conservación.

Con el creciente reconocimiento del papel que la naturaleza puede desempeñar en el apoyo a la reducción de la pobreza y al desarrollo, los gobiernos disponen de la evidencia necesaria para apoyar inversiones en la naturaleza como un medio fundamental para apoyar el desarrollo sostenible en todos los sectores. Además, muchas agencias donantes están tomando medidas para "integrar" el medio ambiente como un tema transversal. Por integración se entiende "los procesos mediante los cuales se llama la atención de las organizaciones y personas involucradas en la toma de decisiones relativas al desarrollo económico, social y físico de un país (a nivel nacional, subnacional o local) sobre consideraciones ambientales, y los procesos mediante los cuales el medio ambiente es considerado en esas decisiones" (IIED, 2009). La integración del medio ambiente en el desarrollo requiere que los países receptores incluyan el medio ambiente en sus solicitudes y que los países donantes garanticen que el medio ambiente se incluya en sus proyectos. Los gobiernos que buscan un futuro mejor están dirigiendo su mirada hacia el papel del medio ambiente en su planificación nacional y concluyendo que este es importante (recuadro 22.1). Siendo fundamental la función de la biodiversidad en esos procesos, la integración, por consiguiente, se refiere a la biodiversidad.

Pero la integración -o lo que es lo mismo- la sostenibilidad, también influye en el sector privado. Las cuestiones ambientales, que antes se consideraron irrelevantes para la actividad económica, hoy día están reescribiendo dramáticamente las reglas para los negocios, los inversores y los consumidores. Las empresas que están tomando en serio la sostenibilidad han salido mejor paradas que otras en la reciente crisis económica (AT Kearney, 2009).

Sin embargo, para una sostenibilidad a más largo plazo, será preciso integrar el medio ambiente en todas partes -especialmente en los estilos de vida de las personas. Las elecciones que hacemos -desde los alimentos que comemos hasta los vehículos que conducimos hasta la forma en que nos relajamos- todas afectan la naturaleza. A medida que adquirimos conciencia con respecto a la naturaleza de esos efectos, debemos asumir la responsabilidad de nuestras propias acciones $\mathrm{y}$ unirnos a gobiernos y empresas en un esfuerzo mundial en favor de un medio ambiente más saludable y productivo. 
Recuadro 22.1 Actualización del PRSP de Tanzania: Integración del medio ambiente a nivel nacional para la reducción de la pobreza

La nueva Estrategia Nacional para el Crecimiento y la Reducción de la Pobreza (NSGRP) o Mkukuta representa un nuevo enfoque más amplio para la reducción de la pobreza. En particular, presta una mayor atención a cuestiones como la sostenibilidad ambiental que contribuyen tanto a la reducción de la pobreza como al crecimiento. Esto es producto de la realización por parte del gobierno de Tanzania, de los interesados directos nacionales y de los asociados para el desarrollo, de que el primer PRSP no abordó adecuadamente el medio ambiente y otras importantes cuestiones, esenciales para lograr la sostenibilidad en términos de reducción de la pobreza y crecimiento. Quince de los 108 objetivos de la NSGRP en el Mkukuta están directamente relacionados con el medio ambiente y los recursos naturales, y se prevé que las intervenciones sobre el medio ambiente contribuirán a otras metas. Se prevé que las acciones sobre el medio ambiente ayudarán a lograr los objetivos de gobernanza y rendición de cuentas. Una característica clave de la revisión que condujo a la NSGRP fue el sentido de pertenencia nacional. Fue coordinada por la oficina del Vicepresidente y la implementación se basó en una consulta sobre contenido y enfoque con una amplia gama de partes interesadas.

Fuente: PNUMA 2008b, The Environment Times, http:// wrere.grida.no/publications/et/ep4/page/2641.asp $x$
Tan necesarios para un futuro sostenible son los esfuerzos tendientes a la integración de la conservación a nivel institucional como la gestión del comportamiento individual. En este libro se incluyen muchos ejemplos de acciones que cualquiera puede llevar a cabo para integrar el medio ambiente en su propia vida.

1. Empeñarse en un estilo de vida carbono neutral a través de opciones energéticas conscientes.

2. Comprobar las huellas hídricas y gestionar el consumo de agua en el hogar.

3. Consumir en una forma favorable al medio ambiente -apoyar los programas de certificación, ajustarse a las $3 \mathrm{R}$ - reducir, reciclar y reutilizar.

4. Apoyar y votar por políticas gubernamentales que apoyan la conservación del medio ambiente.

\section{ADAPTACIÓN AL CAMBIO}

Tal como lo hemos descrito a lo largo de este libro, la sociedad humana se está desarrollando más rápidamente que en cualquier otro momento de su historia y se enfrenta constantemente a la escala y las consecuencias sociales y económicas de los cambios ambientales. En términos de afrontar los retos de conservación en las próximas décadas, una constante debe integrarse en nuestro pensamiento y planificación -la necesidad de hacer frente al cambio constante.

A medida que la población humana sigue creciendo y concentrándose en las zonas urbanas, los impactos sobre la capacidad de los recursos naturales para proporcionar alimentos, fibras y combustible son cada vez más evidentes. La pesca mundial está colapsando, los bosques están desapareciendo y las opciones agrícolas se ven ahora influidas por las necesidades energéticas mundiales, además de las necesidades alimentarias. Las zonas urbanas de rápido crecimiento están impulsando un aumento sostenido y, quizás, insostenible, en el comercio 
minería, lo que a su vez resulta en deforestación y cambios en el uso del suelo. Y como la migración podría ser una estrategia importante en la planificación de la adaptación al cambio climático, especialmente para los pobladores de las zonas costeras, la gestión de ese cambio en cuanto a la población y su repercusión será crítica.

Pero no solo la prestación de servicios se verá afectada. También están en peligro los servicios de apoyo y regulación que garantizan unas condiciones óptimas para la salud humana. Existen pruebas abrumadoras que apuntan hacia los cambios demográficos humanos como el principal factor directo e indirecto que contribuye al incremento de las enfermedades infecciosas (capítulo 11).

Nuestro cambiante mundo también está teniendo un profundo efecto en los servicios culturales asociados con la naturaleza. La cultura humana está indisolublemente ligada al medio ambiente en que vivimos y los desafíos que enfrenta nuestro medio ambiente también están amenazando las culturas de todo el mundo. Los estudiosos han estimado que el 60-90\% de los 6900 idiomas actuales puede desaparecer en el próximo siglo (Romaine, 2007), una tasa de extinción incluso superior a la citada por la Lista Roja de Especies Amenazadas de la UICN para cualquiera de los principales taxones. La pérdida de idiomas significa también pérdida de conocimientos y prácticas tradicionales, algunos de las cuales pueden ser de vital importancia para nuestro futuro en la adaptación a los cambios climáticos. Por otra parte, la pérdida de biodiversidad significa la pérdida de la base fundamental para muchas creencias y prácticas culturales.

Todos los servicios están siendo también afectados por los cambios ambientales resultantes del cambio climático, en particular. Uno de los ejemplos mencionados con frecuencia a lo largo de este libro, son las especies exóticas invasoras, que ya han sido reconocidas como una fuente importante de pérdidas económicas y bióticas, y que son especies que se adaptan bien al cambio $\mathrm{y}$ es probable que demuestren una mayor propagación y efectos.

La gestión de los impactos del cambio requiere un doble enfoque -mitigación y adaptación- que es igualmente aplicable en los otros aspectos del cambio que estamos viviendo.

Siempre que sea posible, debemos mitigar la magnitud de los impactos del cambio en el medio ambiente -ya sea disminuyendo las emisiones de gases de efecto invernadero (GHG) o gestionando la migración de la población, o cambiando las mezclas energéticas. Pero también debemos reconocer que los impactos de los cambios ya se están sintiendo, y por la secuencia observada en estos impactos, es probable que veremos impactos más intensos antes de que cualquier medida de mitigación pueda surtir efecto. Por lo tanto, la adaptación es tan necesaria como la mitigación. Y la adaptación debe ser dinámica por cuanto estamos viviendo en un entorno en constante adaptación, no en uno estático.

Lo ideal sería que toda planificación se basara en procesos y no en estados por lo que la planificación basada en la prestación de los servicios de los ecosistemas ofrece un modelo útil que promueve la gestión adaptable. La gestión y el monitoreo adaptables son elementos esenciales de este enfoque. La gestión adaptable es un enfoque que integra el monitoreo y la actualización periódica de los planes y estrategias basadas en los resultados de dicho monitoreo. Es un medio por el cual se garantiza que cualquier uso de los recursos sea sostenible; también es un mecanismo importante para hacer frente a las incertidumbres inherentes a la planificación de la gestión de los recursos naturales. Los planes deben centrarse en abordar los cambios, las amenazas y las respuestas. Tecnologías tales como las herramientas para la modelización 


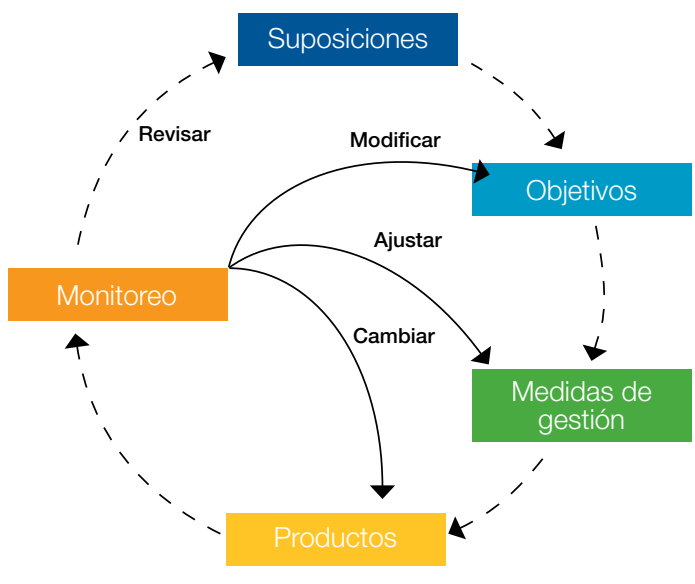

Figura 22.1 Ciclos de retroalimentación asociados con la gestión adaptable (CDB, 2003)

por computadora están disponibles para este propósito (Pressey et al., 2007).

La base fundamental de las acciones tendientes a la mitigación y adaptación al cambio es la necesidad de una mejor comprensión de los procesos por los cuales estas influencias están creando cambios en el medio ambiente. ¿Qué es lo que apoya la resiliencia ecológica y la solidez y dónde están los puntos de inflexión para la extinción? Además, si bien se reconoce que el medio ambiente tiene un valor de existencia intrínseco, mejorando la comprensión de los diversos valores económicos de la naturaleza ayudará a reforzar el argumento a favor de la inversión en el medio ambiente. Como la comunidad mundial se está centrando ahora en los Objetivos de Desarrollo del Milenio (ODM) y, potencialmente, en un marco post 2015 para la acción, una mejor comprensión de la función del medio ambiente, especialmente para la reducción de la pobreza y el desarrollo, contribuirá, sin duda, a asegurar una adecuada inversión en la conservación. La Economía de los Ecosistemas y la Biodiversidad (TEEB), una revisión del valor de la naturaleza que se divulgará en la Conferencia de las Partes en el Convenio sobre la Diversidad Biológica (COP10 del CDB) en el año 2010, será un gran paso adelante en este sentido. Asimismo, la aplicación de la teoría económica a la gestión de los ecosistemas puede proporcionar nuevas perspectivas en torno a la gestión de los recursos y una mejor comprensión de las concesiones que tienen lugar cuando se toman decisiones acerca del uso o no uso de dichos recursos (Perrings, 2006).

Además de una mejor comprensión de los impactos y opciones para la acción, la implementación de decisiones eficaces requiere también el establecimiento de asociaciones entre sectores y filosofías. Tanto las empresas, como los programas gubernamentales, la asistencia al desarrollo y las comunidades locales, tendrán que unirse en torno a objetivos comunes. Las estructuras institucionales evolucionan, cambian las percepciones y las nuevas tecnologías abren nuevas oportunidades. El desarrollo de una sociedad cada vez más global genera problemas y oportunidades. Para abordarlos de forma que se garantice la calidad de vida para las generaciones presentes y futuras se requieren nuevas visiones y nuevos enfoques.

La innovación es fundamental para el mundo de hoy y un ingrediente clave en la respuesta y adaptación a los cambios que se derivan de un mundo cada vez más complejo que se caracteriza por el aumento de la población humana y la disminución de la base de los recursos. De ahí que la innovación seguirá siendo el imperativo y la esperanza para un mundo sostenible que muchos visualizan para el futuro.

¿Cómo puede la conservación estimular la innovación? ¿Cuáles son las ideas más innovadoras que emergen del CMN? ¿Quiénes son los nuevos asociados? Este libro señala la ruta hacia algunas de las respuestas.

El pragmatismo puede ser la clave para todo, reconociendo que quizás no es posible lograr soluciones en las que todos ganen y haya que aceptar concesiones en las que "se gane más - se pierda menos". 


\section{PROMOCIÓN DE UNA GOBERNANZA EFICAZ}

La gobernanza es la interacción entre estructuras, procesos y tradiciones que determinan cómo se ejerce el poder y las responsabilidades, cómo se toman las decisiones, y cómo participan los ciudadanos u otros interesados directos en la gestión de los recursos naturales. La gobernanza es un medio para alcanzar un resultado y no el resultado en sí mismo. La gobernanza tiene lugar en múltiples niveles (local a mundial) en múltiples sectores (público y privado) y en múltiples culturas. Lo ideal sería que toda esta actividad se reforzara mutuamente para que las decisiones adoptadas a nivel internacional permitieran la acción a nivel local. Si la gobernanza falla, las consecuencias pueden ir más allá de la pérdida de los recursos naturales. Como Milledge et al. (2007) señalan, "el déficit en términos de gobernanza [en el sector de la silvicultura] puede acabar afectando las perspectivas de lograr el crecimiento económico nacional y los objetivos de reducción de la pobreza”.

Las definiciones sobre qué es "buena gobernanza" han sido objeto de muchas revisiones (Bosselman et al., 2008). El Convenio sobre la Diversidad Biológica ha reconocido, a través de la Decisión VII/11, que la buena gobernanza es esencial para la aplicación de su enfoque por ecosistemas.

A través de varias resoluciones (CMN 3.012 y CMN 4.037) y del Programa de la UICN, la UICN ha reconocido la importancia de una gobernanza eficaz y definió los principios que sustentan la buena gobernanza como:

- Transparencia - franqueza en la toma de decisiones

- Acceso a la información y a la justicia comunicación precisa, efectiva y abierta

- Participación pública - verdadera participación en la toma de decisiones

- Coherencia - un enfoque consecuente

- Subsidiariedad - decisiones tomadas al nivel más bajo más apropiado
- Respeto a los derechos humanos - entretejido con la "buena" gobernanza ambiental

- Rendición de cuentas - respecto del desempeño económico, social y ambiental

- Estado de derecho - cumplimiento justo, transparente y consecuente de las disposiciones legales a todo nivel.

La visión de la UICN, "un mundo justo que valore y conserve la naturaleza”, simplemente no será posible si estos principios no son el fundamento de nuestra labor de conservación. No solo es un imperativo ético sino que también tiene sentido: la conservación eficaz se logra cuando estos principios fundamentales se integran en nuestro trabajo.

\section{EQUIDAD, ESPECIALMENTE IGUALDAD DE GÉNERO}

La UICN está comprometida con la equidad, tanto a través de su visión y misión, como a través de numerosas declaraciones de política, incluida la política de género y las políticas sobre enfoques basados en los derechos. La labor realizada dentro de la UICN para promover la igualdad de género se basa en dos principios:

(1) la equidad de género es un requisito previo para la conservación, puesto que las mujeres constituyen aproximadamente la mitad de los usuarios de los recursos biológicos y sin su apoyo ninguna política de conservación puede ser eficiente y sostenible;

(2) la conservación de la diversidad biológica es una oportunidad para promover la igualdad de género, ya que promueve la revisión de las prácticas existentes y la introducción de nuevas prácticas que ofrecen la posibilidad de empoderamiento para las mujeres.

Tal como se reconoce a lo largo de este volumen, las mujeres se encuentran entre las personas más vulnerables a los cambios de las circunstancias (clima, desastres, pobreza). Por otra parte, la 
UICN promueve un enfoque que va más allá de considerar a las mujeres meramente como un grupo marginado, poniendo de relieve el importante papel que ellas desempeñan en la gestión de los recursos naturales, y reconociéndolas como recursos de conocimientos y aptitudes esenciales para la conservación.

La investigación muestra que los proyectos de gestión ambiental que incluyen la participación de las mujeres (y, por tanto, su experiencia y conocimientos tradicionales en la gestión de los recursos) son más eficaces (IRC, 1988). Un estudio del Banco Mundial sobre 121 proyectos rurales de abastecimiento de agua determinó que la participación de las mujeres fue una de las variables más fuertemente asociadas a la eficacia de los proyectos. Se constató, asimismo, que el hecho de no contemplar las diferencias de género y las desigualdades podría dar lugar a proyectos fallidos (Narayan, 1995).

En el libro hemos visto que la equidad y la igualdad de género son motivo de preocupación en muchas de las cuestiones debatidas, desde la reducción de la pobreza hasta el cambio climático hasta la energía hasta la gestión del agua. La participación de las mujeres en la gobernanza como actores principales y la integración de sus conocimientos pueden mejorar significativamente la eficiencia y la sostenibilidad de las iniciativas de conservación. El tema de la equidad y su importancia suele expresarse en términos del costo de no incorporarlo versus los beneficios de hacerlo. Tomemos el caso de la igualdad de género. En ninguna región las mujeres y los hombres tienen iguales derechos sociales, económicos y legales y el resultado de esa desigualdad se explora en un informe del Banco Mundial (2001). Los resultados muestran que los costos de la desigualdad de género pueden incluir una mayor incidencia de SIDA, mala nutrición, mayor fertilidad y mortalidad infantil. Todos ellos pueden tener efectos posteriores sobre el medio ambiente.
En un informe sobre la gestión comunitaria de los bosques en India, Agarwal (2002) señaló que varias desigualdades básicas (por ejemplo, la división desigual del trabajo entre hombres y mujeres, el acceso desigual a los recursos, las normas sociales y las percepciones respecto del papel de la mujer) resultaron en una disminución de la participación de las mujeres en la gestión de los recursos de los que dependen, así como en una disminución de los beneficios para las mujeres ya que estos suelen distribuirse a nivel del hogar y los hombres reciben el beneficio en nombre de la familia. Como se señala más adelante, la participación plena es un factor importante en la gestión eficaz de la conservación y la utilización sostenible de los recursos.

\section{ENFOQUES BASADOS EN LOS DERECHOS}

Para la UICN, los enfoques de la conservación basados en los derechos se refieren a una conservación que incorpora la consideración y el respeto por los derechos humanos, los derechos de tenencia y acceso a los recursos y los derechos tradicionales de los pueblos indígenas y las comunidades locales (UICN, 2008e). La UICN ha adoptado esta política en reconocimiento del hecho de que algunas prácticas de conservación como la sedentarización o el reasentamiento forzoso, pueden tener efectos perjudiciales para el bienestar humano, y la UICN, a través de su Centro de Derecho Ambiental (CDA), ha definido un conjunto de principios relativos a los derechos humanos en la conservación (recuadro 22.2).

Scherr (1999) informa de que se ha comprobado que el reconocimiento de los derechos de propiedad respecto de recursos como la tierra, el agua y los árboles, como importantes activos domésticos para la población local, desempeña un papel fundamental en el nexo entre pobreza y medio ambiente. En su revisión sobre los agricultores del Sur de África, Gbetibouo (2009) 
Recuadro 22.2 Principios relativos a los derechos humanos en la conservación elaborados por el Centro de Derecho Ambiental:

1. Promover la obligación de todos los Estados y los actores no estatales que planifican o participan en políticas, proyectos, programas o actividades con implicaciones para la conservación de la naturaleza, a asegurar a todas las personas y poblaciones potencialmente afectadas los derechos substantivos y de procedimiento que están garantizados en el derecho nacional e internacional;

\section{Asegurar la evaluación previa del alcance de las} políticas, proyectos, programas o actividades de conservación, de tal manera que se identifiquen todas las conexiones entre derechos humanos y medio ambiente, y que todas las personas potencialmente afectadas sean informadas y consultadas;

\section{Asegurar que la planificación e implementación} de las políticas y las acciones de conservación reflejan esa evaluación previa, están basadas en decisiones razonadas y, por lo tanto, no dañan a los que son vulnerables sino que apoyan, en la medida de lo posible, la satisfacción de sus derechos dentro del contexto de la naturaleza y la utilización de los recursos naturales;

4. Incorporar directrices y herramientas en la planificación de proyectos y programas para asegurar el monitoreo y la evaluación de todas las intervenciones y de sus repercusiones sobre los derechos humanos de las personas involucradas o potencialmente afectadas para apoyar así una mejor rendición de cuentas y lanzar un sistema de retroalimentación; y

5. Apoyar la mejora de los marcos de gobernanza en los asuntos relativos a los marcos jurídicos y de políticas, las instituciones y los procedimientos que puedan asegurar el respeto de los derechos de las poblaciones locales dentro del contexto de la conservación y la utilización sostenible de los recursos.

Fuente: CMN 4.056 uno de los factores que afectan la capacidad de adaptación al cambio climático. Fisher y Oviedo (2008) apuntan que "los derechos ambientales a veces pueden interpretarse en formas que menoscaban los derechos humanos”, e instan a que la discusión sobre los enfoques de la conservación basados en los derechos vayan más allá de los derechos de propiedad y acceso a los recursos a fin de incluir un conjunto más amplio de cuestiones, entre ellas los derechos humanos y la justicia.

La delegación de autoridad a la población local ha tenido éxito en la conservación de los bosques en Tanzania (Barrow et al., 2003), Etiopía (IIRR, 2000), y China (Oviedo, 2006). Los enfoques basados en los derechos han sido vitales en el apoyo a los medios de subsistencia y la cultura de los pueblos indígenas. Ejemplos incluyen el otorgamiento a los wai wai de título y derechos sobre los bosques en el Sur de Guyana, como resultado de lo cual crearon la primera y única área protegida amerindia (Janki y Sose, 2008), y la cogestión en Waza Logone, Camerún. En el decenio de 1990, la UICN inició el desarrollo de organizaciones de cogestión, incluyendo el reconocimiento y la ampliación de los derechos de la comunidad local al uso de la tierra dentro del parque, y la delegación de la autoridad de gestión a las comunidades dentro de "la zona periférica del parque dio lugar al mejoramiento de la salud de los ecosistemas, y los miembros de las comunidades participantes reportaron resultados positivos en términos del acceso a los recursos y la reducción de los conflictos” (Scholte et al., 2006). 
PARTICIPACIÓN, TRANSPARENCIA Y RENDICIÓN DE CUENTAS

El Principio 10 de Río establece que "Las cuestiones ambientales se manejan mejor con la participación de todos los ciudadanos interesados, en el nivel que corresponda”. La conservación participativa como parte de la gestión de los recursos naturales ha demostrado que resulta en la mejora de la condición de dichos recursos -como por ejemplo, los bosques en Tanzania (Blomley et al., 2008).

Los enfoques incluyentes también apoyan la integración de muchos elementos independientes pero relevantes en la gestión sostenible de los recursos. Por ejemplo, el Gobierno de Terranova y Labrador quería fortalecer la gestión de la subespecie de oso polar del estrecho de Davis creando un documento incluyente que combinara el conocimiento local, indígena y científico en un plan de gestión que es un “documento vivo" que seguirá actualizándose a medida que se disponga de nueva información. El plan de gestión de Terranova y Labrador va más allá de la mayoría de los planes de gestión de especies mediante la inclusión no solo del conocimiento científico y local, sino también del conocimiento tradicional de los ancianos nain sobre el hábitat del oso polar, el cambio climático, los encuentros con los humanos, y la caza tradicional (MacLeod, 2008).

\section{LA ÚLTIMA PALABRA}

La configuración de un futuro sostenible requerirá los esfuerzos concertados de toda la sociedad. Transición a la Sostenibilidad: hacia un mundo humanitario y diverso, Adams y Jeanrenaud (2008) describen la necesidad de "una economía del planeta", un "rejuvenecido movimiento ambiental mundial", y una "arquitectura institucional que apoya el cambio”. De no actuar de inmediato, ello supondrá elevados costos, no solo monetarios, para el futuro. Si bien la conservación de los genes, las especies y los ecosistemas redundará en considerables ahorros económicos a largo plazo, en este momento exige importantes inversiones. ¿Qué será preciso para que la gente se decida a emprender esas inversiones?

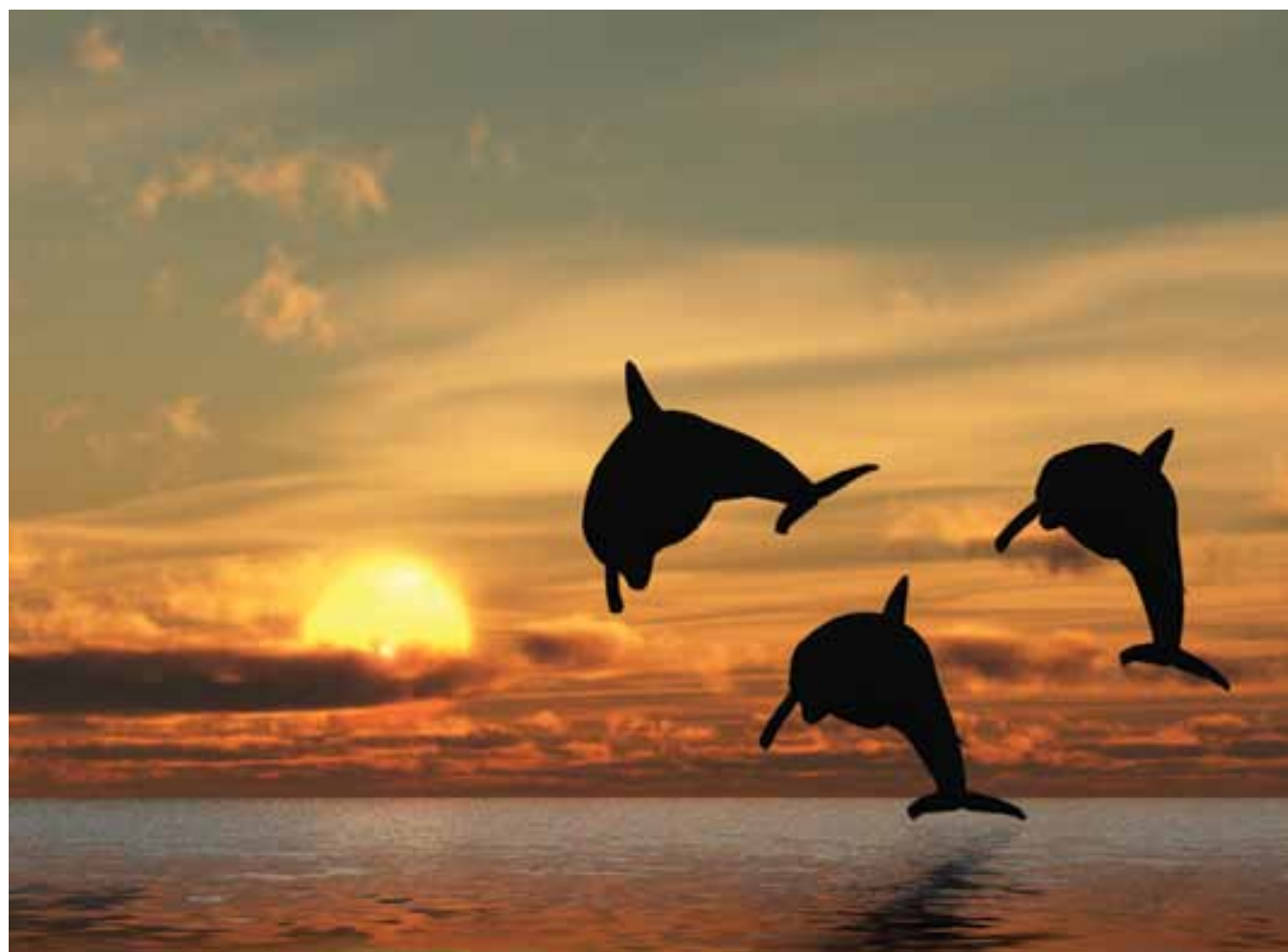




\section{Bibliografía}

Adams, W.M. and S.J. Jeanrenaud. 2008. Transición a la Sostenibilidad: hacia un mundo humanitario y diverso. IUCN, Gland, Switzerland.

Agarwal, B. 2002. Gender Inequality, Cooperation and Environmental Sustainability. http:// www.santafe.edu/research/publications/ workingpapers/02-10-058.pdf

Aguilar, G. and A. Iza. 2006. Gobernanza de aguas compartidas: aspectos juridicos e institucionales. UICN Mesoamerica, San Jose, Costa Rica. http://data. iucn.org/dbtw-wpd/edocs/EPLP-058.pdf

Allison, E.H., A.L. Perry, M. Badjeck, W.N. Adger, K. Brown, D. Conway, A.S. Halls, G.M. Pilling, J.D. Reynolds, N.L. Andrew and N.K. Dulvy. 2009. Vulnerability of national economies to the impacts of climate change on fisheries. Fish and Fisheries $4 \mathrm{Feb}$ 2009. doi: 10.1111/j.14672979.2008.00310.x

Altieri, M. 1995. Agroecology: The Science of Sustainable Agriculture. Westview Press, Boulder, CO, USA.

Amend, S. and T. Amend (eds.). 1995. ¿Espacios sin habitantes? Parques nacionales de América del Sur. IUCN, Gland, Switzerland.

Anon. 1994. The Earth Charter. www.earthcharter.org

Asahi Glass Foundation. 2008. Summary of the 17th Questionnaire on Environmental Problems and the Survival of Humankind. http://www.af-info.or.jp/ en/questionnaire/doc/2008jresult_fulltext.pdf

Asian Development Bank (ADB). 2005. Assessment of tsunami recovery implementation in Hambantota district. http://www.adb.org/Documents/ Reports/Rebuilding-Sri-Lanka/Hambantotateam.pdf
AT Kearney. 2009. Green Winners. http://www. atkearney.com/images/global/pdf/Green_ winners.pdf

Badman, T., B. Bomhard, A. Fincke, J. Langley, P. Rosabal and D. Sheppard. 2009. World Heritage in Danger. IUCN, Gland, Switzerland.

Baillie, J., C. Hilton-Taylor and S.N. Stuart. 2004. 2004 IUCN Red List of Threatened Species: a global species assessment. IUCN, Gland, Switzerland. $191 \mathrm{pp}$.

Baker, C.S., J.C. Cooke, S. Lavery, M.L. Dalebout, Y.U. Ma, N. Funahashi, C. Carraher and R.L. Brownell Jr. 2007. Estimating the number of whales entering trade using DNA profiling and capture-recapture analysis of market products. Molecular Ecology. doi: 10.1111/j.1365294X.2007.03317.x

Balian, E.V., H. Segers, C. Lévêque and K. Martens. 2008. The freshwater animal diversity assessment: an overview of the results. Hydrobiologia 595: 627-637.

Balmford, A., A. Bruner, P. Cooper, R. Costanza, S. Farber, R.E. Green, M. Jenkins, P. Jefferiss, V. Jessamy, J. Madden, K. Munro, N. Myers, S. Naeem, J. Paavola, M. Rayment, S. Rosendo, J. Roughgarden, K. Trumper and R.K. Turner. 2002. Economic Reasons for Conserving Wild Nature. Science 297: 950-953.

Barrow, E. and W. Mlenge. 2003. Trees as Key to Pastoralist Risk Management in Semi-Arid Landscapes in Shinyanga, Tanzania, and Turkana, Kenya. International Conference on Rural Livelihoods, Forest and Biodiversity. CIFOR, Bonn, Germany. 
Baskin, Y. 2002. A Plague of Rats and Rubber Vines: the growing threat of species invasions. Island Press, Washington DC, USA. 377 pp.

Benstead, J.P., P.H. De Rham, J.-L. Gattoliat, F.-M. Gibon, P.V. Loiselle, M. Sartori, J.S. Sparks and M.L.J. Stiassny. 2003. Conserving Madagascar's freshwater biodiversity. Bioscience 53(11): 1101-1111.

Benton-Short, L. and J. Rennie-Short. 2007. Cities and Nature. Routledge, London, UK.

Benyus, J. 1997. Biomimicry: Innovation inspired by nature. Perennial, New York, USA.

Bergstrom, D., A. Lucieer, K. Kiefer, J. Wasley, L. Belbin, T.K. Pedersen and S.L. Chown. 2009. Indirect effects of invasive species removal devastate World Heritage Island. Journal of Applied Ecology 46: 73-81.

Bishop, J., S. Kapila, F. Hicks, P. Mitchell and F. Vorhies. 2008. Building Biodiversity Business. Shell International Limited, London, UK and IUCN, Gland, Switzerland. 164 pp. http://data.iucn.org/dbtw-wpd/ edocs/2008-002.pdf

Bishop, J., S. Kapila, F. Hicks, P. Mitchell and F. Vorhies. 2009. New Business Models for Biodiversity Conservation. Journal of Sustainable Forestry 28: 285-303. doi: $10.1080 / 10549810902791481$

Bishop, K., N. Dudley, A. Phillips and S. Stolton. 2004. Speaking a common language. Cardiff University, Cardiff, UK, IUCN, Gland, Switzerland and UNEP-WCMC, Nairobi, Kenya. 191 pp. http://data.iucn.org/dbtwwpd/edocs/2004-049.pdf

Blann, K. 2006. Habitat in Agricultural Landscapes: How Much is Enough? A Stateof-the-Science Literature Revieze. Defenders of Wildlife, West Linn, OR, USA.

Blomley, T., K. Pfliegner, J. Isango, E. Zahabu, A. Ahrends and N. Burgess. 2008. Seeing the wood for the trees: an assessment of the impact of participatory forest management on forest condition in Tanzania. Oryx 42: 380-391.

Bojo, J., K. Green, S. Kishore, S., Pilapitiva and R.C. Reddy. 2004. Environment in Poverty Reduction Strategies and Poverty Reduction Support Credits. World Bank Environment Department Paper No. 102.

Bonkoungou, E.G. and M. Naimir-Fuller. 2001. Biodiversity in Drylands: challenges and opportunities for conservation and sustainable use. The Global Drylands Partnership, UNDP, New York, USA.

Borrini-Feyerabend, G., A. Kothari and G. Oviedo. 2004. Indigenous and Local Communities and Protected Areas: Toweards Equity and Enhanced Conservation. IUCN, Gland, Switzerland and Cambridge, UK.

Bosselmann, K., R. Engel and P. Taylor. 2008. Governance for Sustainability - Issues, Challenges, Successes. IUCN, Gland, Switzerland. xvi +260 pp.

Boucher, J. and W.F. Doolittle. 2002. Something new under the sea. Nature 417: 27-28.

Bowen, G., J. Leonard, I. Wassenaar and K.A. Hobson. 2005. Global application of stable hydrogen and oxygen isotopes to wildlife forensics. Oecologia 143: 337-348. doi: 10.1007/ s00442-004-1813-y

Braby C.E. and G.N. Somero. 2006a. Ecological gradients and relative abundance of native (Mytilus trossulus) and invasive (Mytilus galloprovincialis) blue mussels in the California hybrid zone. Marine Biology 148: 1249-1262.

Brashares, J.C., P. Arcese, M.K. Sam, P.B. Coppolillo, A.R.E. Sinclair and A. Balmford. 2004. Bushmeat Hunting, Wildlife Declines, and Fish Supply in West Africa. Science 306: 1180-1183.

Bräuer, I., R. Müssner, K. Marsden, F. Oosterhuis, M. Rayment, C. Miller et al. 2006. The use of market incentives to preserve biodiversity. (Final Report A project under the Framework Contract for Economic Analysis ENV.G.1/FRA/2004/0081.) 
Bray, M. 2006. Reviere of Computer Energy Consumption and Potential Savings. White Paper. Sponsored by Dragon Systems Software Limited (DssW). http://www.dssw.co.uk/research/computer_ energy_consumption.pdf

Brown, L. 2004. Outgrowing the Earth: The Food Security Challenge in an Age of Falling Water Tables and Rising Temperatures. W.W. Norton, New York, USA.

Bruner, A.G., R.E. Gullison and A. Balmford. 2004. Financial Costs and Shortfalls of Managing and Expanding Protected-Area Systems in Developing Countries. Bioscience 54: 1119-1126.

Burns, C.E., K.M. Johnston and O.J. Smitz. 2003. Global climate change and mammalian species diversity in U.S. national parks. Proceedings of the National Academy of Sciences 100: 11474-11477.

Burrowes, P.A., R.L. Joglar and D.E. Green. 2004. Potential causes for amphibian declines in Puerto Rico. Herpetologica 60: 141.

Business and Biodiversity Offsets Programme (BBOP). 2009. Business, Biodiversity Offsets and BBOP: An Overview. BBOP, Washington DC, USA. http://www.forest-trends.org/ biodiversityoffsetprogram/guidelines/overview. pdf

Butchart, S. 2008. Red List Indices to measure the sustainability of species use and impacts of invasive alien species. Bird Conservation International 18: S245-S262. doi: 10.1017/ S095927090800035X

Butchart, S.H.M., A.J. Stattersfield, J. Baillie, L.A. Bennun, S.N. Stuart, H.R. Akcakaya, C. HiltonTaylor and G.M. Mace. 2005. Using Red List Indices to measure progress towards the 2010 target and beyond. Phil. Trans. R. Soc. B 360: 255-268.

Carbon Footprint. http://www.carbonfootprint.com/ energyconsumption.html

Carpenter, S.R., P. Pingali, E. Bennett and M. Zurek (eds.). 2005. Ecosystems and Human Well-being: Scenarios. Island Press, Washington DC, USA.
Cassman, K.G. and S. Wood. 2005. Cultivated Systems. Ecosystems and Human Well-being: Current State and Trends, Volume 1. 745-794. In Hassan, R., R. Scholes and N. Ash (eds.). Island Press, Washington DC, USA.

Cello, J., A.V. Paul and E. Wimmer. 2002. Chemical synthesis of polio virus cDNA: Generation of infectious virus in the absence of natural template. Science 297: 1016-1018.

Chan, K.M., M.R. Shaw, D.R. Cameron, E.C. Underwood and G.C. Daily. 2006. Conservation Planning for Ecosystem Services. PLoS Biology 4: e379.

Chivian, E. and A. Bernstein (eds). 2008. Sustaining Life: How Human Health Depends on Biodiversity. Oxford University Press, New York, USA.

Clay, J. 2004. World Agriculture and the Environment: A Commodity-By-Commodity Guide to Impacts and Practices. Island Press, Washington DC, USA.

Clergeau, P., S. Croci, J. Jokimäki, M.-L. Kaisanlahti-Jokimäki and M. Dinetti. 2006. Avifauna homogenization by urbanization: Analysis at different European latitudes. Biological Conservation 127: 336-244.

Coad, L., A. Campbell, L. Miles, K. Humphries. 2008. The Costs and Benefits of Protected Areas for Local Liveliboods: a review of the current literature. Working Paper. UNEP World Conservation Monitoring Centre, Cambridge, UK. http://www.unep-wcmc. org/climate/pdf/Coad_et_al_2008_Working_ Paper.pdf

Cohen, J.E. 2005. Human Population Grows Up. Scientific American Sept 2005: 48-55.

Collier, P. 2003. Breaking the Conflict Trap: Civil war and development policy. Oxford University Press, London, UK.

Comprehensive Assessment of Water Management in Agriculture. 2007. Water for Food, Water for Life: A Comprehensive Assessment 
of Water Management in Agriculture. Earthscan,

London, UK, International Water Management Institute, Colombo, Sri Lanka.

Convention on Biological Diversity (CBD). 2003.

Report of the Fourth open-ended WORKSHOP

ON Sustainable Use of Biological Diversity UNEP/

CBD/WS Sustainable Use 4/4. http://www.

cbd.int/doc/meetings/suse/wssuse-04/official/

wssuse-04-04-en.doc

Convention on Biological Diversity (CBD). 2004a.

Guidelines on biodiversity and tourism development. http://www.biodiv.org/doc/publications/tougdl-en.pdf

Convention on Biological Diversity (CBD). 2004b. Programme of Work on Protected Areas. http:// www.cbd.int/protected/pow.shtml

Convention on Biological Diversity Secretariat (CBD). 2006. Global Biodiversity Outlook 2.

Montreal, Canada. 81 + vii pp. http://www.cbd. int/gbo2/

Convention on Biological Diversity (CBD). 2008. Report of the first meeting of the second ad hoc technical expert group on biodiversity and climate change. UNEP/CBD/AHTEG/BD-CC-2/2/5. http://www.cbd.int/doc/meetings/cc/ahtegbdcc-02-02/official/ahteg-bdcc-02-02-05-en.doc

Convention on Biological Diversity (CBD). Principles of the Ecosystem Approach. http://www.cbd.int/ ecosystem/principles.shtml

Convention on Trade in Endangered Species (CITES). 2001. Multi-lateral agreements for conservation of hawessbill turtles. International Instruments Relevant to the Conservation of Hareksbill Turtles [And Their Habitats]. Background document prepared by IUCN/ ELC for CITES hawksbill turtle dialogue meetings held in 2001 and 2002. http:// www.cites.org/eng/prog/HBT/bg/multi_ agreement 1. shtml

Costello, C., S.D. Gaines and J. Lynham. 2008. Can catch shares prevent fisheries collapse? Science 321: 1678-1681.
Crawford, J.A. and R.V. Fiorentino. 2005. The Changing Landscape of Regional Trade Agreements. WTO Discussion paper No. 8. http://www.wto.int/english/res_e/booksp_e/ discussion_papers8_e.pdf

Cumberlidge, N. et al. 2009. Freshwater crabs and the biodiversity crisis: Importance, threats, status, and conservation challenges. Biol. Conserv. doi: 10.1016/j.biocon.2009.02.038. In press.

Daily, G.C. (ed.). 1997. Nature’s Services: Societal Dependence on Natural Ecosystems. Island Press, Washington DC, USA.

Dalton, R. 2003. Mock turtles. Nature. 219-220.

Darnall, N. and S.R. Sides. 2008. Assessing the Performance of Voluntary Environmental Programs: Does Certification Matter? Policy Studies Journal 36(1). http://ssrn.com/ abstract $=1030622$

Darwall, W., K. Smith, D. Allen, M. Seddon, G. McGregor Reid, V. Clausnitzer and V. Kalkman. 2008. Freshwater biodiversity - a hidden resource under threat. The 2008 Reviewe of the IUCN Red List of Threatened Species. In Vié, J.C., C. Hilton-Taylor and S.N. Stuart (eds.). IUCN, Gland, Switzerland.

Darwall, W.R.T., K.G. Smith and D. Tweddle (eds.). 2008. The Status and Distribution of Freshwater Biodiversity in Southern Africa. IUCN, Gland, Switzerland.

Deffeyes, K.S. 2005. Beyond Oil: The Vieze from Hubbard's Peak. Hill and Wang, New York, USA.

Derocher, A.E., N.J. Lunn and I. Stirling. 2004. Polar Bears in a warming climate. Integrative and Comparative Biology 44(2): 163-176.

DFID, EC, UNDP and World Bank. 2002. Linking Poverty Reduction and Environmental Management: Policy Challenges and Opportunities. DFID, London, UK.

Distefano, E. 2005. Human-Wildlife Conflict worldwide: collection of case studies, analysis of management strategies and good practices. http://www.fao.org/ sard/common/ecg/1357_en_HWC_final.pdf 
Dolman, S.J., M.P. Simmonds and S. Keith. 2002. Marine wind farms and cetaceans. International Whaling Commission IWC/SC/55/E4.

Dudley, N. (ed.). 2008. Directrices para la aplicación de las categorías de gestión de áreas protegidas. IUCN, Gland, Switzerland. $x+86$ pp. http://data.iucn. org/dbtw-wpd/edocs/PAPS-016-es.pdf.

Dudley, N. and S. Stolton. 2005. The Role of forest protected areas in supplying water to the world's biggest cities. The Urban Imperative. 27-33. In Tryzna, T. (ed.). California Institute of Public Affairs, Sacramento, CA, USA.

Dukes, J.S. and H.A. Mooney. 2004. Disruption of ecosystem processes in western North America by invasive species. Revista Chilena de Historia Natural 77: 411-437.

Dyson, M., G. Bergkamp and J. Scanlon (eds.). 2003. Caudal: Elementos esenciales de caudales ambientales. IUCN, Gland, Switzerland and Cambridge, UK. xiv +118 pp.

Earthtrack. 2008. Subsidies are an expensive way to remove greenhouse gases from the economy. http://www.earthtrack.net/earthtrack/library/ Carbon $\% 20$ efficiency $\% 20$ of $\% 20$ Subsidies.pdf

Ehrenfeld, J.G. 2003. Effects of exotic plant invasions on soil nutrient cycling processes. Ecosystems 6(6): 503-523.

Ehrlich, P. and A. Ehrlich. 2008. The Dominant Animal. Island Press, Washington DC, USA.

Eken, G., L. Bennun, T.M. Brooks, W. Darwall, L.D.C. Fishpool, M. Foster, D. Knox, P. Langhammer, P. Matiku, E. Radford, P. Salaman, W. Sechrest, M.L. Smith, S. Spector and A. Tordoff. 2004. Key biodiversity areas as site conservation targets. BioScience 54: 1110-1118.

Eliasch, J. 2008. The Eliasch Revierw: Climate Change: Financing Global Forests. United Kingdom Office of Climate Change (OCC), London, UK. http://www.occ.gov.uk/activities/eliasch.htm.

Ellis W.N., J.H. Donner and J.H. Kuchlein. 1997. Recent shifts in phenology of Microlepidoptera, related to climatic change (Lepidoptera). Entomologische Berichten 57: 66-72.

Elsayed, S. 2009. Energy Access for Development. EarthTrends Update May 2009.

Emerton, L., J. Bishop and L. Thomas. 2006. Sustainable Financing of Protected Areas: A global revieze of challenges and options. IUCN, Gland, Switzerland and Cambridge, UK. $x+97$ pp. http://app.iucn.org/dbtw-wpd/edocs/ PAG-013.pdf

Engelhard, G.H. and M. Heino. 2006. Climate Change and Condition of Herring (Clupea Harengus) Explain Long-Term Trends in Extent of Skipped Reproduction. Interim report 06-008. International Institute for Applied Systems Analysis, Laxenburg, Austria.

Engler, M. 2008. The Value of International wildlife Trade. TRAFFIC Bulletin 22(1): 4-5.

Ervin, D.E., R. Welsh, S.S. Batie and C. Line Carpentier. 2003. Towards an ecological systems approach in public research for environmental regulation of transgenic crops. Agriculture, Ecosystems and Environment 99: 1-14. doi: 10.1016/S0167-8809(03)00145-2

European Commission (EC) and German Ministry for the Environment, BMU. 2008. TEEB - The Economics of Ecosystems and Biodiversity: An interim report. European Communities, Brussels, Belgium. http://ec.europa.eu/environment/nature/ biodiversity/economics/pdf/teeb_report.pdf

European Commission (EC). 2008. Commission Recommendation of 07/02/2008 on a code of conduct for responsible nanosciences and nanotechnologies research. http://ec.europa.eu/nanotechnology/ pdf/nanocode-rec_pe0894c_en.pdf

European Environment Agency (EEA). 2005. The European Environment: State and Outlook 2005. http://www.eea.europa.eu/publications/state_ of_environment_report_2005_1

Farber, S., R. Costanza, D.L. Childers, J. Erickson, K. Gross, M. Grove, C.S. Hopkinson, J. Kahn, S. Pincetl, A. Troy, P. Warren and M. Wilson. 2006. 
Linking Ecology and Economics for Ecosystem Management. BioScience 56(2): 121-133.

Fernández-Juricic, E. and J. Jokimäki. 2001. A habitat island approach to conserving birds in urban landscapes: case studies from southern and northern Europe. Biodiversity and Conservation 10: 2023-2043.

Fisher, R. and G. Oviedo. 2008. Rights-based approaches to forest conservation. Arborvitae 36. http://cmsdata.iucn.org/downloads/av_36_ english.pdf

Fisher, R.J., S. Maginnis, W.J. Jackson, E. Barrow and S. Jeanrenaud. 2005. Poverty and Conservation: Landscapes, People and Power. IUCN, Gland, Switzerland and Cambridge, UK. xvi + 148 pp.

Fisher, R., S. Maginnis, W. Jackson, E. Barrow and S. Jeanrenaud. 2008. Linking Conservation and Poverty Reduction. Earthscan, London, UK. 146 pp.

Food and Agriculture Organization (FAO). 2001a. Conservation Agriculture: Case Studies in Latin America and Africa. FAO, Rome, Italy.

Food and Agriculture Organization (FAO). 2001b. Women - users, preservers and managers of agrobiodiversity. SD dimensions. http://www.fao.org/ sd/2001/PE1201a_en.htm

Food and Agriculture Organization (FAO). 2005. Evaluación de los recursos forestales mundiales. $\mathrm{ftp} / / \mathrm{ftp}$. fao.org/docrep/fao/008/A0400E/A0400E00.pdf

Food and Agriculture Organization (FAO). 2008a. El estado mundial de la pesca y la acuicultura. http:// www.fao.org/docrep/011/i0250e/i0250e00.htm

Food and Agriculture Organization (FAO). 2008b. Algunas problemas de la pesca y la acuicultura. Part 2. ftp://ftp.fao.org/docrep/fao/011/i0250e/ i0250e2.pdf

Food and Agriculture Organization (FAO). 2008c. El estado mundial de la agricultura y la alimentación. http://www.fao.org/sof/sofa/index_en.html

Food and Agriculture Organization (FAO). 2008d. El estado de la inseguridad alimentaria en el mundo 2008. http://www.fao.org/docrep/011/i0291e/ i0291e00.htm
Food and Agriculture Organization (FAO). 2009a. Situación de los bosques del mundo 2009. http:// www.fao.org/docrep/011/i0350e/i0350e00.HTM

Food and Agriculture Organization (FAO). 2009b. Asociación de colaboración en materia de bosques. http://www.fao.org/forestry/44935/en/

Food and Agriculture Organization (FAO). AQUASTAT database. http://www.fao.org/nr/ water/aquastat/data/query/index.html

Ford, J. 2007. Emerging trends in climate change policy: the role of adaptation. Journal of Climate 3: 2. 12 pp. http://www.ucl.ac.uk/ippr/ download/volume-3-2/Ford.pdf

Fudge, S. and G.A. Rose. 2008. Life history covariation in a fishery depleted Atlantic cod stock. Fisheries Research 92(1): 107-113.

Fuller, R.A. and K.J. Gaston. 2009. The scaling of green space coverage in European cities. Biological Letters. doi: 10.1098/RSBI.2009.0010.

Funk, C., M.D. Dettinger, J.C. Michaelsen, J.P. Verdin, M.E. Brown, M. Barlow and A. Hoell. 2008. Warming of the Indian Ocean threatens eastern and southern African food security but could be mitigated by agricultural development. Proceedings of the National Academy of Sciences 105: 11081-11086.

Gadgil, M. and F. Berkes. 1991. Traditional Resource Management Systems. Resource Management and Optimization 8(3-4): 127-141.

Gardner, G. 2002. Invoking the Spirit: Religion and Spirituality in the Quest for a Sustainable World. Worldwatch Institute, Washington DC, USA.

Gazeau, F., C. Quiblier, J.M. Jansen, J.-P. Gattuso, J.J. Middelburg and C.H.R. Heip. 2007. Impact of elevated $\mathrm{CO} 2$ on shellfish calcification. Geophysical Research Letters 34: L07603. doi: 10.1029/2006GL028554

Gbetibouo, G.A. 2009. Understanding Farmers' Perceptions and Adaptations to Climate Change and Variability: The Case of the Limpopo Basin, South Africa. IFPRI Discussion Paper 00849. http:// www.ifpri.org/pubs/dp/IFPRIDP00849.pdf 
Gibson, C., S. Valenti, S. Fowler and S. Fordham. 2008. The Conservation Status of Northeast Atlantic Chondrichthyans: Report of the IUCN Shark Specialist Group Northeast Atlantic Regional Red List Workshop. http://cmsdata.iucn.org/ downloads/shark_report_1.pdf

Gilman, E., D. Kobayashi and M. Chaloupka. 2008. Reducing seabird bycatch in the Hawaii longlinetuna fishery. Endangered Species Research. http://cmsdata.iucn.org/downloads/reducing seabird_bycatch.pdf

Girardet, H. 1999. Greening Urban Society. Imagine Tomorrow's World. 110-120. In McNeely, J.A. (ed.). IUCN, Gland, Switzerland.

Global Environment Facility (GEF). 2009. Biodiversity. http://www.gefweb.org/interior_ right.aspx?id=224

Global Footprint Network. 2008. http://www. footprintnetwork.org/en/index.php/GFN/page/ world_footprint/

Global Sustainable Tourism Criteria Partnership. 2008. Global sustainable tourism criteria. http:// www.sustainabletourismcriteria.org/index. php?option $=$ com_content $\&$ task $=$ view $\&$ id $=58 \&$ Itemid $=188$

Global Transboundary Protected Area Network (GTPAN). 2009. UNEP-WCMC Transboundary Protected Area Network Inventory - 2007. http:// www.tbpa.net/tpa_inventory.html

Global Water Partnership (GWP). 2000. Integrated Water Resource Management. Global Water Partnership Technical Advisory Committee Paper 4. http://www.cepis.ops-oms.org/bvsarg/i/ fulltext/tac4/tac4.pdf

Global Water Partnership (GWP). 2009. Toolbox - Integrated Water Resources Management. http://www.gwptoolbox.org/index. php?option $=$ com_content $\&$ view $=$ article\&id $=8$ \&Itemid $=3$

Goldin, O. 1997. The Ecology of the Critias and Platonic Metaphysics. The Greeks and the Environment. 73-82. In Westra, L. and
T.M. Robinson (eds.). Rowman \& Littlefield Publishers, Lanham, MD, USA.

Goode, D. 2005. Connecting with Nature in a Capital City: The London Biodiversity Strategy. The Urban imperative. 75-85. In Tryzna, T. (ed.). California Institute of Public Affairs, Sacramento, CA, USA.

Green Indian States Trust (GIST). 2003-2008. Green Accounting for India's States and Union Territories Project Reports. GIST, Chennai, India.

Grimm, N.B., S.H. Faeth, N.E. Golubiewski, C.L. Redman, J. Wu, X. Bai and J.M. Briggs. 2008. Global change and the ecology of cities. Science 319: 756-760.

Hamann, A. and T. Wang. 2006. Potential Effects of Climate Change on Ecosystem and Tree Species Distribution. British Columbia Ecology 87(11): 2773-2786.

Hamilton, K., M. Sjardin, A. Shapiro and T. Marcello. 2009. Fortifying the Foundation: State of the Voluntary Carbon Markets 2009. Ecosystem Marketplace, New Carbon Finance. http://ecosystemmarketplace. com/documents/cms_documents/ StateOfTheVoluntaryCarbonMarkets_ 2009.pdf

Hansen, J., M. Sato, R. Ruedy, K. Lo, D.W. Lea and M. Medina-Elizade. 2006. Global temperature change. Proceedings of the National Academy of Sciences 103: 14288-14293. doi: 10.1073/ pnas.0606291103

Hansen, S. 2007. The Economic Case for investing in the Environment: A Review of Policies, Practice and Impacts of Relevance to Norwegian Partner Countries. Norad Report 6a/2007 Discussion. http://norad.no/en/ Tools+and+publications/Publications/ Publication+Page?key=109662

Hanson, T., T.M. Brooks, G.A.B. da Fonseca, M. Hoffmann, J.F. Lamoreux, G. Machlis, C.G. Mittermeier, R.A. Mittermeier and J.D. Pilgrim. 2009. Warfare in Biodiversity Hotspots. Conservation Biology 23: 578-587. 
Harvey C., F. Alpizar, M. Chacon and R. Madrigal. 2004. Assessing Linkages between Agriculture and Biodiversity in Central America: Historical Overvieze and Future Perspectives. The Nature Conservancy, San Jose, Costa Rica.

Hausman, R., L. Tyson and S. Zahidi. 2007. The Global Gender Gap Report 2007. World Economic Forum. Ref 112007. http://www.weforum.org/ pdf/gendergap/report2007.pdf

Hockings, M., S. Stolton, F. Leverington, N. Dudley and J. Courrau. 2006. Evaluating Effectiveness: A framezork for assessing management effectiveness of protected areas. 2nd edition. IUCN, Gland, Switzerland and Cambridge, UK. xiv + 105 pp.

Howard, G. and S. Ziller. 2008. Alien alert - plants for biofuel may be invasive. Bioenergy Business. July/August 2008: 14-16.

Howarth, R.W. and S. Bringezu (eds.). 2009. Biofuels: Environmental Consequences and Interactions with Changing Land Use. Proceedings of the Scientific Committee on Problems of the Environment (SCOPE) International Biofuels Project Rapid Assessment, 22-25 September 2008, Gummersbach, Germany. http://cip.cornell. edu/biofuels/

Huntley, B., R.E. Green, Y.C. Collingham and S.G. Willis. 2007. A Climatic Atlas of European Breeding Birds. Lynx Edicions, Barcelona, Spain.

Hutton, J.M. and N. Leader-Williams. 2003. Sustainable use and incentive-driven conservation: realigning human and conservation interests. Oryx 37: 215-226.

IIED. 2009. Environmental Mainstreaming. http:// www.environmental-mainstreaming.org

Intergovernmental Panel on Climate Change (IPCC). 2007a. IPCC 4th Assessment ReportSummary for Policy Makers. http://www.ipcc.ch/ pdf/assessment-report/ar4/syr/ar4_syr_spm.pdf

Intergovernmental Panel on Climate Change (IPCC). 2007b. Summary for Policymakers. Climate Change 2007: Impacts, Adaptation and Vulnerability. Contribution of Working Group II to the Fourth Assessment Report of the
Intergovernmental Panel on Climate Change. 7-22. In Parry, M.L., O.F. Canziani, J.P. Palutikof, P.J. van der Linden and C.E. Hanson (eds.). Cambridge University Press, Cambridge, UK. http://www.ipcc.ch/pdf/assessment-report/ ar4/wg2/ar4-wg2-spm.pdf

International Council on Mining and Minerals (ICMM) 2006. Good Practice Guidance for Mining and Biodiversity. http://www.icmm.com/ page/1182/good-practice-guidance-for-miningand-biodiversityInternational Federation of Organic Agriculture Movements (IFOAM). 2000. Organic Agriculture and Biodiversity. IFOAM, Bonn, Germany.

International Institute of Rural Reconstruction (IIRR). 2000. Sustainable Agriculture Extension Manual. IIRR, Cavite, Philippines.

International Risk Governance Council (IRGC). 2007. Nanotechnology Risk Governance. IRGC White Paper. http://www.irgc.org/IMG/pdf/ PB_nanoFINAL2_2_.pdf

International Risk Governance Council (IRGC). 2008a. Risk governance guidelines for bioenergy policy. http://www.irgc.org/IMG/pdf/IRGC_ PB_Bioenergy_WEB-2.pdf

International Risk Governance Council (IRGC). 2008b. Synthetic Biology: Risks and Opportunities of an Emerging Field. IRGC, Geneva, Switzerland.

International Water and Sanitation Centre (IWSC). 1988. Community Participation and Women's Involvement in Water Supply and Sanitation Projects: a compendium paper. IWSC, The Hague, Netherlands.

Isenberg, A.C. (ed.). 2006. The Nature of Cities: Culture, Landscape and Urban Space. University of Rochester Press, Rochester, NY, USA.

IUCN SSC Medicinal Plant Specialist Group. 2007. International Standard for Sustainable Wild Collection of Medicinal and Aromatic Plants (ISSCMAP). Version 1.0. Bundesamt für Naturschutz (BfN), Bonn, Germany, MPSG/SSC/IUCN, Gland, Switzerland, WWF Germany, Frankfurt, Germany, and TRAFFIC, Cambridge, UK. 
BfN-Skripten 195. http://www.floraweb.de/ MAP-pro/Standard_Version1_0.pdf

IUCN, UNEP and WWF. 1980. Estrategia mundial para la conservación: La conservación de los recursos vivos para el logro de un desarrollo sostenido. IUCN, Gland, Switzerland.

IUCN, UNEP and WWF. 1991. Ciudar la Tierra.

IUCN. 2000a. Resoluciones y Recomendaciones. IUCN, Gland, Switzerland and Cambridge, UK. vii +76 pp.

IUCN. 2000b. Declaración de política de la UICN acerca del uso sostenible de los recursos vivos silvestres. Resolución 2.29 adoptada al Congreso Mundial de la Naturaleza de la UICN, Amman, Octubre 2000. http://intranet.iucn.org/webfiles/doc/ SSC/SSCwebsite/SUSG_policy_esp.pdf

IUCN. 2001. Transboundary Protected Areas for Peace and Cooperation. IUCN, Gland, Switzerland.

IUCN. 2003. Acuerdo de Durban. http://cmsdata. iucn.org/downloads/durbanaccordes.pdf

IUCN. 2008a. Biodiversity: My hotel in action: A guide to sustainable use of biological resources IUCN, Gland, Switzerland. 128 pp.

IUCN. 2008b. Drylands - an economic asset for rural livelihoods and economic growth. Drylands Challenge Paper. http://cmsdata.iucn.org/ downloads/draft_drylands_challenge_ paper_29sept08.pdf

IUCN. 2008c. Failure to act will push bluefin tuna fishery to extinction says IUCN. http://cms.iucn. org/about/work/programmes/marine/marine news/?uNewsID $=2343$

IUCN. 2008d. The 2008 IUCN Red List of Threatened Species. www.iucnredlist.org

IUCN. 2008e. WCC Resolución 4.056 - Enfoques de la conservación basados en los derechos. IUCN Resolutions and Recommendations, World Conservation Congress, Barcelona 5-14 October 2008.

IUCN. 2009a. Directrices Operativas para Intervenciones con el Sector Privado. http://cmsdata.iucn.org/ downloads/ps_20guidelines.pdf
IUCN. 2009b. The Future of the World Heritage Convention, Challenges for the next twenty years: An IUCN Perspective. IUCN, Gland, Switzerland.

IWMI. 2009. Projected water scarcity in 2025. http:// www.lk.iwmi.org/Press/map0.htm (last accessed on 30 April 2009).

Iza, A. and R. Stein (eds.). 2009. Rule: reforming water governance. IUCN, Gland, Switzerland.

Jackson, D.L. and L.L. Jackson (eds.). 2002. The Farm as Natural Habitat: Reconnecting Food Systems with Ecosystems. Island Press, Washington DC, USA.

Jacobson, M.F. 2004. Liquid candy: How soft drinks are harming Americans' health. Center for Science in the Public Interest, Washington DC, USA. 15 October 2004. www.cspinet.org/sodapop/ liquid_candy.htm

James, A.N., K.J. Gaston and A. Balmford. 2001. Can we afford to conserve biodiversity? BioScience 51: 43-52.

Janki, M. and C. Sose. 2008. The Wai Wai Protected Area - Our Land: Our Life. Governance for Sustainability - Issues, Challenges, Successes. 123-132. In Bosselmann, K., R. Engel and P. Taylor (eds). IUCN, Gland, Switzerland. xvi +260 pp.

Jianchu, X. (ed.). 2000. Links between Cultures and Biodiversity. Yunnan Science and Technology Press, Kunming, China.

Kearney, M., R. Shine and W.P. Porter. 2009. The potential for behavioral thermoregulation to buffer "cold-blooded" animals against climate warming. Proceedings of the National Academy of Sciences 106: 3835-3840. doi: 10.1073/ pnas.0808913106

Kelly, A.E. and M.L. Goulden. 2008. Rapid shifts in plant distribution with recent climate change. Proceedings of the National Academy of Sciences 105: 11823-11826. doi: 10.1073/pnas.0802891105

Klare, M.T. 2001. Resource Wars: The New Landscape of Global Conflict. Metropolitan Books, New York, USA. 
Klee, G.A. (ed.). 1980. World Systems of Traditional Resource Management. Edward Arnold, London, UK.

Kousky, C. 2005. Choosing from the policy toolbox. Ecosystem Marketplace. http:// ecosystemmarketplace.com/pages/ article.opinion.php?component_ id $=4002 \&$ component_version id $=5679 \&$ language_id $=12$

Kunz, T.H., E.B. Arnett, B.M. Cooper, W.P. Erickson, R.P. Larkin, T. Mabee , M.L. Morrison, M.D. Strickland and J.M. Szewczak. 2007a. Assessing Impacts of Wind-Energy Development on Nocturnally Active Birds and Bats: A Guidance Document. Journal of Wildlife Management 71(8): 2449-2486. doi: 10.2193/2007-270

Kunz, T.H., E.B. Arnett, W.P. Erickson, A.R. Hoar, G.D. Johnson, R.P. Larkin, M.D. Strickland, R.W. Thresher and M.D. Tuttle. 2007b.

Ecological impacts of wind energy development on bats: questions, research needs, and hypotheses. Frontiers in Ecology and Environment 5(6): 315-324.

Kuo, F.E., M. Bacaicoa and W. Sullivan. 1998. Transforming inner-city landscapes: Trees, sense of safety and preference. Environment and Behavior 30(1): 28-59.

Laffoley, D. d'A. (ed.). 2008. Towards Networks of Marine Protected Areas. IUCN, Gland, Switzerland.

Langhammer, P.F., M.I. Bakarr, L.A. Bennun, T.M. Brooks, R.P. Clay, W. Darwall, N. De Silva, G.J. Edgar, G. Eken, L.D.C. Fishpool, G.A.B. da Fonseca, M.N. Foster, D.H. Knox, P. Matiku, E.A. Radford, A.S.L. Rodrigues, P. Salaman, W. Sechrest and A.W. Tordoff. 2007. Identification and Gap Analysis of Key Biodiversity Areas: Targets for Comprehensive Protected Area Systems. IUCN, Gland, Switzerland.

Lavorel, S. 1998. Mediterranean terrestrial ecosystems: research priorities on global change effects. Global Ecology and Biogeography 7: 157-166.
Liu, J., G.C. Daily, P.R. Ehrlich and G.W. Luck. 2003. Effects of household dynamics on resource consumption and biodiversity. Nature 421 : 530-533.

Louisiana Department of Agriculture and Forestry. 2005. Imposition of Quarantine. Office of Agricultural and Environmental Sciences. http:// www.ldaf.state.la.us/portal/Portals/0/AES/ Horticulture/katrinaquarantine.pdf

Louv, R. 2005. The Last Child in the Woods: Saving our children from nature-deficit order. Algonguin Books, New York, USA.

Lyon, T.P. and J.W. Maxwell. 2008. Corporate Social Responsibility and the Environment: A Theoretical Perspective. Review of Environmental Economics and Policy 1: 1-22. doi: 10.1093/reep/ren004

Mace, G.M. and E.J. Hudson. 1999. Attitudes toward Sustainability and Extinction. Conservation Biology 13: 242-246.

Mack, R.N., D. Simberloff, W.M. Lonsdale, H. Evans, M. Clout and F.A. Bazzaz. 2000. Biotic invasions: Causes, epidemiology, global consequences, and control. Ecological Applications 10: 689-710.

MacLeod, C.E. 2008. It Takes a Village to Save the Polar Bear. Governance for Sustainability - Issues, Challenges, Successes. 141-148. In Bosselmann, K., R. Engel and P. Taylor (eds). IUCN, Gland, Switzerland. xvi +260 pp.

Maffi, L. 2005. Linguistic, Cultural, and Biological Diversity. Annual Revieze of Anthropology 29: 599-617, doi: 10.1146/annurev. anthro.34.081804.120437

Magrin, G., C. Gay García, D. Cruz Choque, J.C. Giménez, A.R. Moreno, G.J. Nagy, C. Nobre and A. Villamizar. 2007. Latin America. Climate Change 2007: Impacts, Adaptation and Vulnerability. Contribution of Working Group II to the Fourth Assessment Report of the Intergovernmental Panel on Climate Change. 581-615. In Parry, M.L., O.F. Canziani, J.P. Palutikof, P.J. van der Linden and C.E. Hanson (eds.). Cambridge University Press, Cambridge, UK. 
Malthus, T. 1798. An Essay on the Principle of Population. J. Johnson, London, UK.

Margolis, J.D., H.A. Elfenbein and J.P. Walsh. 2007. Does it pay to be good? A meta-analysis and redirection of research on the relationship between corporate social performance and financial performance. (Mimeograph). http://stakeholder. bu.edu/2007/Docs/Walsh,\%20Jim\%20Does\%20 It $\% 20$ Pay $\% 20$ to $\% 20 B e \% 20$ Good.pdf

Massachusetts Institute of Technology (MIT). 2007. The future of geothermal energy. http://geothermal. inel.gov/publications/future_of_geothermal_ energy.pdf

Matthews, H.D. and K. Caldeira. 2007. Transient climate-carbon simulations of planetary geoengineering. Proceedings of the National Academy of Sciences 104: 9949-9954.

May, R.M. 1999. Conservation: Dealing with Extinction. Imagine Tomorrow's World. 57-76. In McNeely, J.A. (ed.). IUCN, Gland, Switzerland.

McCann, K. 2000. The Diversity-Stability Debate. Nature 405: 228-233.

McCauley, D. 2006. Selling out on Nature. Nature 443: 27-28.

McDonough, W. and M. Braungart. 2002. Cradle to cradle: remaking the way we make things. North Point Press, New York, USA. 194 pp.

McKibben, B. 2007. Deep Economy: The Wealth of Communities and the Durable Future. Henry Holt, New York, USA.

McNeely, J.A. 1988. Economics and Biological Diversity: Developing and Using Economic Incentives to Conserve Biological Resources. IUCN, Gland, Switzerland.

McNeely, J.A. and P. Wachtel. 1988. Soul of the Tiger. Doubleday, New York, USA.

McNeely, J.A., H.A. Mooney, L.E. Neville, P. Schei and J.K. Waage (eds.). 2001. A Global Strategy on Invasive Alien Species. IUCN, Gland, Switzerland.

McNeely, J.A. 2002. The role of taxonomy in conserving biodiversity. Journal of Nature Conservation 10(3): 145-154.
McNeely, J.A. and S.J. Scherr. 2003. Ecoagriculture: Strategies for Feeding the World and Conserving Wild Biodiversity. Island Press, Washington DC, USA.

McNeely, J. 2008. Applying the Diversity of International Conventions to Address the Challenges of Climate Change. Michigan State Journal of International Law 17: 123-137.

McNeely, J. et al. 2009. The Wealth of Nations. Conservation International, Arlington, VA, USA, and Cemex, San Pedro Garza García, Mexico.

McNeely, J.A. In press. Conservation and conflict. State of the Wild 2010. Wildlife Conservation Society, New York, USA.

Meadows, D.H., D.L. Meadows, J. Randers and I. Behrens. 1972. The Limits to Growth. Universe Books, New York, USA.

Meffe, G.K., C.R. Carroll and M.J. Groom. 2005. What is Conservation Biology? Principles of Conservation Biology. In Meffe, G.K., C.R. Carroll and M.J. Groom (eds). Sinauer Associates, Sunderland, MA, USA.

Meilleur, B. and T. Hodgkin. 2004. In situ conservation of crop wild relative: status and trends. Biodiversity and Conservation 13: 663-684.

Melnick, D., J.A. McNeely, Y. Kakabadse Navarro, G. Schmidt-Traub and R.R. Sears. 2005. Environment and Human Well-Being: A Practical Strategy. UN Millennium Project. Task Force on Environmental Sustainability. Earthscan, London, UK and Sterling, VA, USA.

Merode, de E. and G. Cowlishaw. 2006. Species protection, the changing informal economy, and the politics of access to the bush meat trade in the Democratic Republic of Congo. Conservation Biology 20(4): 1262-1271.

Milledge, S.A.H., I.K. Gelvas and A. Ahrends. 2007. Forestry, Governance and National Development: Lessons Learned From a Logging Boom in Southern Tanzania. TRAFFIC East /Southern Africa, Dar Es Salaam, Tanzania. 
Millennium Ecosystem Assessment (MA). 2003. Ecosystems and Human Well-Being: A Framework for Assessment. Island Press, Washington DC, USA.

Millennium Ecosystem Assessment (MA). 2005a. Desertification synthesis. www.maweb.org/ documents/document.355.aspx.pdf

Millennium Ecosystem Assessment (MA). 2005b. Ecosystems and Human Well-Being: Biodiversity Synthesis. World Resources Institute, Washington DC, USA.

Millennium Ecosystem Assessment (MA). 2005c. Ecosystems and Human Well-Being: Wetlands and Water Synthesis. World Resources Institute, Washington DC, USA. http:// www.millenniumassessment.org/documents/ document.358.aspx.pdf

Millennium Ecosystem Assessment (MA). 2005d. Synthesis. http://www.millenniumassessment. org/documents/document.356.aspx.pdf

Milner-Gulland, E.J., E.L. Bennett and SCB 2002 Annual Meeting Wild Meat Group. 2003. Wild meat: the bigger picture. Trends in Ecology \& Evolution 18: 351-357.

Mohammed, A.G. 2008. Gum Arabic Belt Potential in the Livelihood improvement of Central Sudan Drylands. 4th World Conservation Congress. Barcelona. Alliances Workshop.

Mortimore, M., S. Anderson, L. Cotula, K. Faccer, C. Hesse, A. Mwangi, W. Nyangena and J. Skinner. 2008. Drylands - An Economic Asset for Rural Livelihoods and Economic Growth. Draft Challenge Paper of IUCN, IIED and UNDP/ DDC. http://cmsdata.iucn.org/downloads/ draft_drylands_challenge_paper_29sept08.pdf

Myers, N. and J.L. Simon. 1994. Scarcity or Abundance? A debate on the environment. W.W. Norton, New York, USA. xix + 254 pp.

Naidoo, R., A. Balmford, R. Costanza, B. Fisher, R.E. Green, B. Lehner, T.R. Malcolm and T.H. Ricketts. 2008. Global Mapping of Ecosystem Services and Conservation Priorities. Proceedings of the National Academy of Sciences of the United States 105: 9495-9500.
Narayan, D. 1995. Contribution of People's Participation: Evidence from 121 Rural Water Supply Projects. The World Bank, Washington DC, USA.

National Geographic. 2009. Greendex 2009: Consumer Choice and the Environment - $A$ Worldwide Tracking Survey Highlights Report. http://www.nationalgeographic.com/greendex/ assets/Greendex_Highlights_Report_ May09.pdf

National Research Council (NRC). 2007. Environmental Impacts of Wind Energy Projects. http://books.nap.edu/openbook.php?record_ $\mathrm{id}=11935 \&$ page $=7$

Navarro, E., A. Baun, R. Behra, N.B. Hartmann, J. Filser, A.J. Miao, A. Quigg, P.H. Santschi, and L. Sigg. 2008. Environmental behavior and ecotoxicity of engineered nanoparticles to algae, plants, and fungi. Ecotoxicology 17: 372-386. doi: 10.1007/s10646-008-0214-0

NBSAP Bhutan. 2002. Biodiversity Action Plan for Bhutan. Government of Bhutan, Thimphu, Bhutan.

NBSAP Yemen. 2005. National Biodiversity Strategy and Action Plan, 16. Ministry of Environment and Water, Yemen.

Nuñez-Iturri, G. and H.F. Howe. 2007. Bushmeat and the Fate of Trees with Seeds Dispersed by Large Primates in a Lowland Rain Forest in Western Amazonia. Biotropica 39(3): 348-354. doi: 10.1111/j.1744-7429.2007.00276.x

Oates, J.F. 1998. Myth and Reality in the Rain Forest. University of California Press, Berkeley, USA.

Organisation for Economic Co-operation and Development (OECD). 2008. Natural Resources and Pro-Poor Growth: the Economics and Politics. DAC Guidelines and Reference Series. OECD, Paris, France.

Organisation for Economic Co-operation and Development (OECD). 2009. Development aid at its highest level ever in 2008. http:// www.oecd.org/document/35/0,3343, en_2649_34487_42458595_1_1_1_1,00.html 
Organisation for Economic Co-operation and Development/International Energy Agency (OECD/IEA). 2006. World Energy Outlook 2006. OECD, Paris, France.

Orr, D. 2005. Armageddon versus extinction. Conservation Biology 19: 290-292.

Osofsky, S.A., S. Cleaveland, W.B. Karesh, M.D. Kock, P.J. Nyhus, L. Starr and A. Yang (eds.). 2005. Conservation and Development Interventions at the Wildlife/Livestock Interface: Implications for Wildlife, Livestock and Human Health. IUCN, Gland, Switzerland and Cambridge, UK. xxxiii + 220 pp. http://data. iucn.org/dbtw-wpd/edocs/SSC-OP-030.pdf

Oviedo, G. 2006. Land Ownership Issues in Forest Restoration. Forest Restoration in Landscapes Beyond Planting Trees. 84-94. In Mansourian, S., E. Vallauri and N. Dudley (eds). Springer WWF, New York, USA.

Palsbøll, P.J., M. Berube, H.J. Skaug and C. Raymakers. 2006. DNA Registers of Legally Obtained Wildlife and Derived Products as Means to Identify Illegal Takes. Conservation Biology 20: 1284-1293. doi: 10.1111/j.15231739.2006.00429

Parmesan, C. and G. Yohe. 2003. A globally coherent fingerprint of climate change impacts across natural systems. Nature 421: 37-42.

Patz, J., P. Daszak, G.M. Tabor, A. Alonso Aguirre, M. Pearl, J. Epstein, N.D. Wolfe, A. Marm Kilpatrick, J. Foufopoulos, D. Molyneux, D.J. Bradley and Members of the Working Group on Land Use Change and Disease Emergence. 2004. Unhealthy Landscapes: Policy Recommendations on Land Use Change and Infectious Disease Emergence. Environmental Health Perspectives 112(10): 1092-1098. doi: 10.1289/ehp.6877

Perrings, C. 2006. Resilience and sustainable development. Environment and Development Economics 11: 417-427.

Perry, A.L., P.J. Low, J.R. Ellis and J.D. Reynolds. 2005. Climate Change and Distribution Shifts in Marine Fishes. Science 308: 1912-1915.
Pinter, L. 2006. International Experience in Establishing Indicators for the Circular Economy and Considerations for China. Report for the Environment and Social Development Sector Unit, East Asia and Pacific Region, The World Bank. http://www.iisd.org/pdf/2006/measure circular_economy_china.pdf

Pirages, D. and T. De Geest. 2003. Ecological Security: An Evolutionary Perspective on Globalization. Rowman and Littlefield, Lanham, MD, USA.

Poertner, H.O. and R. Knust. 2007. Climate change affects marine fishes through the oxygen limitation of thermal tolerance. Science 315: 95-97.

Polasky, S., E. Nelson, J. Camm, B. Csuti, P. Fackler, E. Lonsdorf, C. Montgomery, D. White, J. Arthur, B. Garber-Yonts, R. Haight, J. Kagan, A. Starfield and C. Tobalske. 2008. Where to Put Things? Spatial Land Management to Sustain Biodiversity and Economic Returns. Biological Conservation 141: 1505-1524.

Posey, D.A. (ed.). 1999. Cultural and Spiritual Values of Biodiversity. United Nations Environment Programme, Nairobi, Kenya.

Pounds J.A., M.P.L. Fogden and J.H. Campbell. 1999. Biological response to climate change on a tropical mountain. Nature 398: 611-615.

Pounds, J.A., M.R. Bustamante, L.A. Coloma, J.A. Consuegra, M.P.L. Fogden, P.N. Foster, E. La Marca, K.L. Masters, A. Merino-Viteri, R. Puschendorf, S.R. Ron, G.A. Sanchez-Azofeifa, C.J. Still and B.E. Young. 2006. Widespread amphibian extinctions from epidemic disease driven by global warming. Nature 469: 161-167.

Poverty Environment Partnership (PEP). 2005. Case studies on pro-poor growth: Diamond-based growth in Botswana. http://povertyenvironment.net/files/ CASE\%20Botswana.pdf

Pressey, R.L., M. Cabeza, M.E. Watts, R.M. Cowling and K.A. Wilson. 2007. Conservation planning in a changing world. Trends in Ecology $\bullet$ Evolution 22: 583-592. 
Pretty, J.N. (ed). 2005. The Earthscan Reader in Sustainable Agriculture. Earthscan, London, UK.

Redford, K. and E. Fearn (eds.). 2007. Protected Areas and Human Livelihoods. Wildlife Conservation society, New York, USA.

Reid, Walter, et al. 2006. Nature: the many benefits of ecosystem services. Nature 443: 749.

Rivalan, P., V. Delmas, E. Angulo, L.S. Bull, R.J. Hall, F. Courchamp, A.M. Rosser and N. LeaderWilliams. 2007. Can bans stimulate wildlife trade? Nature 447: 529-530.

Rodrigues, A.S.L., S.J. Andelman, M.I. Bakarr, L. Boitani, T.M. Brooks, R.M. Cowling, L.D.C. Fishpool, G.A.B. da Fonseca, K.J. Gaston, M. Hoffmann, J.S. Long, P.A. Marquet, J.D. Pilgrim, R.L. Pressey, J. Schipper, W. Sechrest, S.N. Stuart, L.G. Underhill, R.W. Waller, M.E.J. Watts and X. Yan. 2004. Effectiveness of the global protected area network in representing species diversity. Nature 428: 640-643.

Rodriguez, G., M. Blanco and F. Azofeifa. 2004. Diversity Makes the Difference. IUCN, San Jose, Costa Rica.

Rodrigues, G., M. Blanco and F. Azofeifa. 2004. La diversidad hace la diferencia. IUCN, San Jose, Costa Rica.

Roe, D. 2008. The origins and evolution of the conservation-poverty debate: a review of key literature, events and policy processes. Oryx 42(4): 491-503.

Romaine, S. 2007. Preserving Endangered Languages. Languages and Linguistics Compass 1/1-2: 115-132. doi: 10.1111/j.1749-818X.2007.00004.x

Ron, S.R., W.E. Duellman, L.A. Coloma and M.R. Bustamante. 2003. Population decline of the Jambato Toad Atelopus ignescens (Anura: Bufonidae) in the Andes of Ecuador. J. Herpetol 37: 116-126.

Roundtable for Sustainable Biofuels (RSB). 2008. Global principles and criteria for sustainable biofuels production Version Zero. http://cgse.epfl.ch/
webdav/site/cgse/shared/Biofuels/VersionZero/ Version\%20Zero_RSB_Std_en.pdf

Royal Society of Chemistry (RSC). 2008. China quake hits chemical industry. http://www.rsc.org/ chemistryworld/News/2008/May/ 16050802.asp

Rubinoff, D. 2006. Utility of Mitochondrial DNA Barcodes in Species Conservation. Conservation Biology 20: 1026-1033. doi: 10.1111/j.15231739.2006.00372.x

Sahgal, B. 2005. Kids for Tigers: A globally replicable school contact programme to win support for wildlife and protected areas. The Urban Imperative. 121-123. In Tryzna, T. (ed.). California Institute of Public Affairs, Sacramento, CA, USA.

Sala O.E., F.S. Chapin, J.J. Armesto et al. 2000. Global biodiversity scenarios for the year 2100 . Science 287: 1770-1774.

Sandwith, T., C. Shine, L. Hamilton and D. Sheppard. 2001. Transboundary Protected Areas for Peace and Co-operation. IUCN, Gland, Switzerland and Cambridge, UK.

Sayer, J., B. Campbell, L. Petheram, M. Aldrich, M.R. Perez, D. Endamana, Z.N. Dongmo, L. Defo, S. Mariki, N. Doggart and N. Burgess. 2007. Assessing environment and development outcomes in conservation landscapes. Biodiversity Conservation 16: 2677-2694.

Sayer, J.A. and S. Maginnis. 2005. Forests in landscapes: expanding horizons for ecosystem forestry. Forests in Landscapes: ecosystem approaches to sustainability. In Sayer, J. and S. Maginnis (eds.). Earthscan, London, UK. 257 pp.

Scherl, L., A. Wilson, R. Wild, J. Blockhus, P. Franks, J. McNeely and T. McShane. 2004. Can Protected Areas Contribute to Poverty Reduction? Opportunities and Limitations. IUCN, Gland, Switzerland.

Scherr, S. 1999. Poverty-Environment Interactions in Agriculture: Key Factors and Policy Implications. Poverty and Environment Initiative Background Paper 3. UNDP, New York, USA. 
Scherr, S.J. and J.A. McNeely (eds.). 2007. Farming with Nature: The Science and Practice of

Ecoagriculture. Island Press, Washington DC, USA

Schippmann, U., D. Leaman and A.B. Cunningham. 2006. A comparison of cultivation and wild collection of medicinal and aromatic plants under sustainability aspects. Medicinal and Aromatic Plants. In Bogers, R.J., L.E. Craker and D. Lange (eds.). Springer, Dordrecht, The Netherlands. pp. 75-95.

Scholte, P., S. Kari, M. Moritz and H. Prins. 2006. Pastoralist Responses to Floodplain Rehabilitation in North Cameroon. Human Ecology 34: 27-51. doi: 10.1007/s10745-0059001-1

Schroth, G. and C.A. Harvey. 2007. Biodiversity conservation in cocoa production landscapes: An overview. Biodiversity and Conservation 16(8): 2237-2244.

Schuyt, K. and L. Brander. 2004. Living Waters Conserving the source of life. The economic value of the world's wetlands. WWF, Gland, Switzerland.

Schwanz, L.E. and F.J. Janzen. 2008. Climate Change and Temperature-Dependent Sex Determination: Can Individual Plasticity in Nesting Phenology Prevent Extreme Sex Ratios? Physiological and Biochemical Zoology 81(6): 826-834. doi: 10.1086/590220

Schwarz, M.W., J. Thorne and J. Viers. 2006. Biotic homogenization of the California flora in urban and urbanizing regions. Biological Conservation 127: 282-291.

Sheil, D. and D. Murdiyarso. 2009. How Forests Attract Rain: An Examination of a New Hypothesis. BioScience 59: 341-347. doi: 10.1525/bio.2009.59.4.12.

Shiro, W. 2004. Enclose cities in nature-developing new technologies to build cities within nature. City Planning Reviezw 249: 49-54.

Smith, D.M. and S. Barchiesi. 2008. Environment as infrastructure: Resilience to climate change impacts on water through investments in nature. Perspectives on water and climate change adaptation. http:// cmsdata.iucn.org/downloads/iucnperspap_ environment_as_infrastructure_1.pdf

Smith, H.O., C.A. Hutchison, C. Pfannkoch and J.C. Venter. 2003. Generating a synthetic genome by whole genome assembly: X174 bacteriophage from synthetic oligonucleotides. Proceedings of the National Academy of Sciences 100: 15440-15445. doi: 10.1073/pnas.2237126100

Smith, K.G. and W.R.T. Darwall (compilers). 2006. The Status and Distribution of Freshreater Fish Endemic to the Mediterranean Basin. IUCN Red List of Threatened Species - Mediterranean Regional Assessment No.1. IUCN, Gland Switzerland and Cambridge, UK.

Smith, M., D. de Groot and G. Bergkamp. 2006. Pago: Establecer pagos por servicios de cuencas. IUCN, Gland, Switzerland.

Sobrevila, C. 2008. The Role of Indigenous Peoples in Biodiversity Conservation: The Natural but Often Forgotten Partners. A report for the World Bank. http://siteresources.worldbank. org/INTBIODIVERSITY/Resources/ RoleoflndigenousPeoplesinBiodiversity Conservation.pdf.

Solomon, S., G.K. Plattner, R. Knutti and P. Friedlingstein. 2009. Irreversible climate change due to carbon dioxide emissions. Proceedings of the National Academy of Sciences 106: 1704-1709. doi: 10.1073/pnas.0812721106

Srinivasan, U.T., S.P. Carey, E. Hallstein, P.A.T. Higgins, A.C. Kerr, L.E. Koteen, A.B. Smith, R. Watson, J. Harte and R.B. Norgaard. 2008. The debt of nations and the distribution of ecological impacts from human activities. Proceedings of the National Academy of Sciences 105(5): 1768-1773. doi: 10.1073/ pnas.0709562104

Stern, N. 2006. Stern Review on the Economics of Climate Change. Cambridge University Press, Cambridge, UK. http://www.hm-treasury.gov. uk/stern_review_report.htm 
Stiling, P. 2002. Potential non-target effects of a biological control agent, prickly pear moth, Cactoblastis cactorum (Berg) (Lepidoptera: Pyralidae) in North America and possible management actions. Biological invasions 4: 273-281.

Stuart S.N., G.W. Archibald, J. Ball, R.J. Berry, S.D. Emmerich, D.M. Evans, J.R. Flenley, K.J. Gaston, D.R. Given, A.G. Gosler, P. Harris, J. Houghton, E.D. Lindquist, D.C. Mahan, M.D. Morecroft, D.C. Moyer, D. Murdiyarso, B.W.W. Musiti, C. Nicolson, A. Oteng-Yeboah, A.J. Plumptre, G. Prance, V. Ramachandra, J.B. Sale, J.K. Sheldon, S. Simiyu, R. Storey, L.G. Underhill, J. Vickery and T. Whitten. 2005. Conservation theology for conservation biologists - A reply to David Orr. Conservation Biology 19: 1689-1692.

Sumaila, U.R. and D. Pauly. 2006. Catching More Bait: A Bottom-Up Re-Estimation Of Global Fisheries Subsidies (2nd edition). Fisheries Centre Research Reports Volume 14 Number 6. http:// www.fisheries.ubc.ca/archive/publications/ reports/14-6.pdf

Sutherland, W.J. et al. 2008. Future novel threats and opportunities facing UK biodiversity identified by horizon scanning. Journal of Applied Ecology 45: 821-833. doi: 10.1111/j.13652664.2008.01474.x

ten Brink, P. 2008. Loss of ecosystem services from land-based ecosystems. COPI Study. In Braat, L. and P. ten Brink (eds.)

The Economics of Ecosystems and Biodiversity (TEEB). 2008. Interim report on The Economics of Ecosystems and Biodiversity (2008). http:// ec.europa.eu/environment/nature/ biodiversity/economics/

The Economist. 2009. Charlemagne: Fishy Tales: 25 April 2009.

The Trust for Public Land. (2009). http://www.tpl.org/

Thomas, C.D. and J.J. Lennon. 1999. Birds extend their ranges northwards. Nature 399: 213.
Thomas, L. and J. Middleton. 2003. Guidelines for Management Planning of Protected Areas. IUCN, Gland, Switzerland and Cambridge, UK. ix +79 pp.

Thouless, C. 2008. Human Wildlife Conflict-Biology and Beyond. World Conservation Forum Workshop Report, Event 1537. http://intranet. iucn.org/webfiles/ftp/public/ForumEvents/ E1537/Final\%20Document/1537_REPORT_ Thouless_C_Human $\% 20$ Wildlife $\% 20$ Conflict $\% 20$ Biology $\% 20$ and $\% 20$ Beyond.pdf

TRAFFIC. 2008. What's Driving the Wildlife Trade? A Review of Expert Opinion on Economic and Social Drivers of the Wildlife Trade and Trade Control Efforts in Cambodia, Indonesia, Lao PDR and Vietnam. East Asia and Pacific Region Sustainable Development Discussion Papers. East Asia and Pacific Region Sustainable Development Department, World Bank, Washington, DC, USA.

Tumpey, T.M. et al. 2005. Characterization of the reconstructed 1918 Spanish influenza pandemic virus. Science 310: 77-80.

Turner, W., T. Nakamura and M. Dinetti. 2004. Global urbanization and the separation of humans from nature. Bioscience 54(6): 1-6.

Turner, W.R., K. Brandon, T.M. Brooks, R. Costanza, G.A.B. da Fonseca and R. Portela. 2007. Global Conservation of Biodiversity and Ecosystem Services. BioScience 57: 868-873.

UN Convention to Combat Desertification (UNCCD). www.unccd.int/knowledge/ menu.php

UN Water. 2007. Coping with water scarcity: challenge of the twenty-first century. Prepared for World Water Day 2007. http://www.unwater.org/wwd07/ downloads/documents/escarcity.pdf

UN. 1982. The World Charter for Nature. UN GA RES 37/7. http://sedac.ciesin.columbia.edu/entri/ texts/world.charter.for.nature.1982.html

UNESCO. 2006. Decisions of the 30th Session of the World Heritage Committee. http://whc.unesco. org/archive/2006/whc06-30com-19e.pdf 
UNESCO. 2009. List of World Heritage Sites in Danger. http://whc.unesco.org/en/danger/

United Nations (UN). 2008. The Millennium

Development Goals Report 2008. UN, New York, USA.

United Nations Department of Economic and Social Affairs (UN DESA). 2009. World Population Prospects-The 2008 Revision. http://www. un.org/esa/population/publications/wpp2008/ wpp2008_highlights.pdf

United Nations Development Programme (UNDP). 2002. Poverty and Environment Initiative. UNDP, New York, USA.

United Nations Development Programme (UNDP). 2004. Gender \& Energy for sustainable development: a Toolkit and Resource Guide. http://www.undp. org/energy/genenergykit/

United Nations Development Programme (UNDP). 2005. Concept paper: High-Level Commission on Legal Empowerment of the Poor: Poverty Reduction through Improved Asset Security, Formalisation of Property Rights and the Rule of Law. http://www. undp.org/legalempowerment/pdf/Concept_ Paper.pdf

United Nations Economic Commission for Europe (UNECE) and FAO. 2008. UNECE/FAO Forest Products Annual Market Reviere, 20072008. Executive Summary. http://timber.unece. org/fileadmin/DAM/publications/executivesummary-2008.pdf

United Nations Environment Programme (UNEP). 2003. Perspectivas del medio ambiente mundial. http://www.unep.org/GEO/geo3/

United Nations Environment Programme (UNEP). 2005. After the Tsunami: Rapid Environmental Assessment. UNEP, Nairobi, Kenya. 140 pp.

United Nations Environment Programme (UNEP). 2006. Global International Waters Assessment: Challenges to International Waters: Regional Assessments in a Global Perspective. UNEP, Nairobi, Kenya. http://www.unep.org/dewa/ giwa/publications/finalreport/executive_ summary.pdf

United Nations Environment Programme (UNEP). 2008a. Environment key to poverty reduction in Tanzania. The Environment Times \#4. http:// www.grida.no/publications/et/ep4/page/ 2641.aspx

United Nations Environment Programme (UNEP). 2008b. Environmental change and new infectious diseases. The Environment Times \#4. http://www.grida.no/publications/et/ep4/ page/2631.aspx

United Nations Millennium Project. 2005. Environment and Human Wellbeing: A practical strategy. Summary version of the report of the Task Force on Environmental Sustainability. The Earth Institute at Columbia University, New York, USA.

United Nations World Tourism Organisation (UNWTO). 2009. Rapidá visión global de las tendencias clave. Barométro OMT del turismo mundial: January 2009. http://www.unwto. org/facts/eng/pdf/barometer/UNWTO_ Barom09_1_en_excerpt.pdf

United Nations. 2008. Promotion and Protection of All Human Rights, Civil, Political, Economic, Social and Cultural Rights, Including the Right to Development: Human Rights and Climate change. Document A/ HRC/7/L.21/Rev.1. http://daccessdds.un.org/ doc/UNDOC/LTD/G08/121/52/PDF/ G0812152.pdf?OpenElement

Uphoff, N., A.S. Ball, E. Fernandes, H. Herren, O. Husson, M. Laing, C. Palm, J. Pretty, and P. Sanchez (eds.). 2006. Biological Approaches to Sustainable Soil Systems. CRC Press, Boca Raton, USA.

US Environmental Protection Agency (EPA). 2005. The Formosan Subterranean Termite in Georgia. http://www.caes.uga.edu/departments/ent/ upmp/termites.html

Valencia Declaration, a plea for the protection of marine biodiversity. http://www.marbef.org/ worldconference/declaration.php 
Van Buskirk, J. and Y. Willi. 2004. Enhancement of Farmland Biodiversity within Set-Aside Land. Conservation Biology 18: 897-994. Based on a meta-analysis of 127 published studies.

Vasconcelos, P.F., A.P. Travassos da Rosa, S.G. Rodrigues, E.S. Travassos da Rosa, N. Dégallier, J.F. Travassos da Rosa. 2001. Inadequate management of natural ecosystem in the Brazilian Amazon region results in the emergence and reemergence of arboviruses. Cad Saude Publica 17 Suppl:155-64.

Vedeld, P., A. Angelsen, E. Sjaastad and G.K. Berg. 2004. Counting on the Environment: Forest Incomes and the Rural Poor. Environmental economics series PAPER NO. 98. http://www-wds. worldbank.org/servlet/WDSContentServer/ WDSP/IB/2004/09/30/000090341_200409301 05923/Rendered/PDF/300260PAPER0Countin g0on0ENV0EDP0198.pdf

Veitch, C.R. and M.N. Clout. 2002. Turning the Tide: The eradication of invasive species. IUCN SSC Invasive Species Specialist Group. IUCN, Gland, Switzerland and Cambridge, UK. viii + 414 pp.

Victor, D., G. Morgan, J. Apt, J. Steinbrunner and K. Riche. 2009. The geoengineering option. Foreign Affairs 88(2): 69-76.

Vié, J.-C., C. Hilton-Taylor and S.N. Stuart. 2009. Wildlife in a Changing World: An analysis of the 2008 IUCN Red List of Threatened Species. IUCN, Gland, Switzerland.180 pp.

Wackernagel, M., N.B. Schulz, D. Deumling, A. Callejas Linares, M. Jenkins, V. Kapos, C. Monfreda, J. Loh, N. Myers, R. Norgaard and J. Randers. 2002. Tracking the Ecological Overshoot of the Human Economy. Proceedings of the National Academy of Sciences 99: 9266-9271.

Walther, G., E. Post, P. Convey, A. Menzel, C. Parmesan, T.J.C. Beebee, J.M. Fromentin, O. Hoegh-Guldberg and F. Bairlein. 2002. Ecological responses to recent climate Change. Nature 416: 389-395.
Wang, S.W. and D.W. McDonald. 2006. Livestock predation by carnivores in Jigme Singye Wangchuck National Park, Bhutan. Biological conservation 129: 558-565. doi: 10.1016/j. biocon.2005.11.024

Warren, M.S., J.K. Hill, J.A. Thomas, J. Asher, R. Fox, B. Huntley, D.B. Royk, M.G. Telferk, S. Jeffcoate, P. Hardingk, G. Jeffcoate, S.G. Willis, J.N. Greatorex-Daviesk, D. Mossk and C.D. Thomas. 2001. Rapid responses of British butterflies to opposing forces of climate and habitat change. Nature 414: 65-69.

Watson, A.M. 1983. Agricultural Innovation in the Early Islamic World. Cambridge University Press, Cambridge, UK.

Weizsäcker, E. and A. Lovins. 1995. Factor Four: Doubling Wealth, Halving Resource Use. Earthscan, London, UK.

White, R.P., S. Murray and M. Rohweder. 2000. Pilot analysis of global ecosystems: Grassland Ecosystems. World Resources Institute, Washington DC, USA.

\section{WHO/IUCN/WWF. 1993. WHO/IUCN/WWF}

Directrices sobre conservación de plantas medicinales. IUCN, Gland, Switzerland.

Wild, R. and C. McLeod (eds.). 2008. Sacred Natural Sites: Guidelines for Protected Area Managers. IUCN, Gland, Switzerland.

Wilkinson, C. 2008. Status of the Coral Reefs of the World 2008. Global Coral Reef Monitoring Network and Rainforest Research Centre, Townsville, Australia. 296 pp.

Willer, H. and M. Minou Yussefi. 2006. The world of organic agriculture: Statistics and emerging trends. International Federation of Organic Agriculture Movements, Bonn, Germany and Research Institute of Organic Agriculture, Frick, Switzerland. http://orgprints.org/2555/01/willeryussefi-2004-world-of-organic.pdf

Wilson, E.O. 1984. Biophilia. Harvard University Press, Cambridge, MA, USA. 
Wittenberg, R. and M.J.W. Cock. 2001. Invasive alien species. How to address one of the greatest threats to biodiversity: a toolkit of best prevention and management practices. $\mathrm{CAB}$ International, Wallingford, Oxon, UK.

Woiwod, I.P. 1997. Review. Journal of Insect Conservation 1: 149-158.

World Bank. 2006. Strengthening Forest Law Enforcement and Governance: Addressing a Systemic Constraint to Sustainable Development. Report No. 36638-GLB. August 2006. http:// siteresources.worldbank.org/INTFORESTS/ Resources/ForestLawFINAL_HI_ RES_9_27_06_FINAL_web.pdf

World Bank. 2008. World Development Report 2008 Overview: Agriculture for Development. 2000/2001 World Development Report, World Bank, Washington DC. http:// www-wds.worldbank.org/external/default/ WDSContentServer/WDSP/IB/2007/11/13 /000020953_20071113102401/Rendered/PD F/414560ENGLISH018082137297501PUBL IC1.pdf

World Bank. 2009. Water Resources management: transboundary waters. http://web.worldbank. org/WBSITE/EXTERNAL/TOPICS/EXTW AT/0,,contentMDK:21633352 menuPK:48 28556 pagePK:148956 piPK:216618 theSi tePK:4602123,00.html (last accessed on 30 April 2009).

World Commission on Environment and Development (WCED). 1987. Our Common Future. WCED, New York, USA.

World Health Organization (WHO). 2002. Informe sobre la salud en el mundo. www.who.org

World Health Organization (WHO). 2003. Directrices de la OMS sobre Buenas Prácticas Agrícolas y de Recolección (BPAR) de Plantas Medicinales. WHO, Geneva, Switzerland. http://whqlibdoc.who.int/ publications/2003/9241546271.pdf

World Resources Institute (WRI), IUCN and United Nations Environment Programme
(UNEP). 1992. Estrategia Global para la Biodiversidad. World Resources Institute, Washington DC, USA.

World Resources Institute (WRI). 2008. Environmental Challenges after China's Sichuan Earthquake. http:// earthtrends.wri.org/updates/node/316

World Water Assessment Programme. 2009. El Informe de las Naciones Unidas sobre el desarrollo de los recursos hídricos en el mundo 3: El agua en un mundo en constante cambio. UNESCO Publishing, Paris and Earthscan, London, UK.

World Wide Fund for Nature (WWF). 2007. WWF and Coca-Cola announce partnership to conserve freshreater resources. http://www.panda.org/ wwf_news/news/?uNewsID=104940

World Wide Fund for Nature (WWF). 2008. Living Planet Report 2008. http://assets.panda.org/ downloads/living_planet_report_2008.pdf

WorldWatch Institute. 2008. State of the World 2008: Innovations for a Sustainable Economy. WorldWatch Institute, Washington DC, USA. http://www.worldwatch.org/node/5568

Wunder, S. 2005. Payments for Ecosystem Services: Some nuts and bolts. CIFOR Occasional Paper 42: 1-24.

Zeidler, J. and J.K. Mulongoy. 2003. Dry and Sub-Humid Lands Programme of Work of the Convention on Biological Diversity: Connecting the CBD and the UN Convention to Combat Desertification. Reviewe of European Community and International Environmental Law 12: 164-175. http://www.unccd.int/workshop/ docs/ZeidlerArticle.pdf

Zeng, Q.T. and T. Tse. 2006. Exploring and Developing Consumer Health Vocabularies. Journal of the American Medical Informatics Association 13(1): 24-29. doi: 10.1197/jamia. M1761 
acuicultura, 156

Actualización sobre la situación de los arrecifes de coral del mundo, 54

Acuerdo multilateral sobre el medio ambiente (AMMA), 129, 168

Acuerdos comerciales regionales (ACR), 133

acuerdos internacionales

acción colectiva, 31-32

aplicar los compromisos existentes, 132

armonización, 130-31

ayuda internacional, 131-33

cambios climáticos, 58

acuerdos regionales, 133, 134-35

Adaptación basada en el ecosistema (EbA), 57-58

África subsahariana, 20, 84-85, 172

África, hambre y ecoagricultura, 22

Agencia Europea de Medio Ambiente, 116

agricultura

agua, 177, 179, 181

y biodiversidad, 180, 182-85

y bosques, 150

cambios climáticos, 183-84

ecoagricultura, 22, 181

especies, 180, 185

medio ambiente y recursos, 21-22

métodos alternativos, 184

mujeres, 184-85

OGM, 124-25

reflección de los ecosistemas naturales, 182-85

servicios de los ecosistemas, 45

tierras secas, 164

Ver también sistemas agrícolas

agua

agricultura, 177, 179, 181

cambios climáticos, 177

caudales, 82, 100, 174

ciudades, 188-89

consumo, 173

y economía, 82-83, 176-77 escaseces previstas, 172, 173

gestión, 174, 176, 177

gobernanza, 175-76

necesidades de la naturaleza, 174

tierras secas, 167-68

transfronteriza, 176

Ver también sistemas de agua dulce

Alianza Growing Forests (GFP), 152

Alianza para los Criterios Mundiales de Turismo

Sostenible (GSTC), 140

Alianza 2010 sobre Indicadores de Biodiversidad (BIP), 17-18

alimentación, seguridad, 22

alimentos, producción y demanda, 179

Amazonia brasileña, arbovirus, 105

animales, y salud humana, 105

Aplicación de las leyes y gobernanza sobre los bosques (FLEG), 150, 151

árboles, tala ilegal, 151

Áreas Clave para la Biodiversidad (KBA), 62

Áreas marinas protegidas (AMP), 62, 158, 159

áreas protegidas, 61-66

cambios climáticos, 55, 59

ciudades, 188-89

comunidades locales, 39, 62-63

directrices, 62, 64

especies no nativas e invasoras, 63

financiación y capacidad, 64-65

futuro, 65-66

gestión 62-64

representatividad, 62

áreas protegidas transfronterizas, 92-94, 107-9

arrecifes de coral, 155

Asamblea del Milenio de las Naciones Unidas 2000, 175

Asamblea General de las Naciones Unidas, 46

Asia, 20, 85

Asociación de Colaboración en Materia de Bosques (CPF), 152

Asociación Internacional de Hoteles y Restaurantes, 140 
Asociación Mundial sobre Ciudades y Biodiversidad, 188 asociaciones, $142-45,151-52$

Atlas Climático de las Aves Reproductoras de Europa, 52 aves, 75, 83, 187-88, 189

ayuda al desarrollo, 23, 131-33, 134

Banco Asiático de Desarrollo (ADB), 98

Banco Mundial, 20, 152, 201

Barcelona, Foro de. Ver Foro Mundial de la Naturaleza

Base de Datos sobre Áreas Protegidas de 2008, 62

bienestar humano, dinámica del, 19-20

biocarburantes, 81

biodiversidad

y comunicaciones, 195-96

conservación, 18-19

ejes temáticos del Foro de Barcelona, 16

importancia económica, 112-13

indicadores, 17-18

lugares críticos, 27, 89

meta de Biodiversidad 2010, 17-20

pérdida de, 18-19

como propuesta empresarial, 140

Biodiversidad 2010, 134

biodiversidad cultural, 37

Biodiversity: My Hotel in Action, 140

bioética. Ver ética de la conservación

biología sintética, 126

biomasa, $81-82$

biomimética, 123-24

biotecnología, 122-27

bosques

y agricultura, 149

cambios climáticos, 56, 153

deforestación mundial, 147

gestión sostenible, 148, 150, 151

gobernanza, 150-51

recuperación, 148-50, 153

uso sostenible, 90

Ver también sistemas forestales

Botsuana, 115

Brasil, 175, 183

Buenas prácticas agrícolas y de recolección de plantas medicinales (BPAR), 107

cacao, 183

cadenas de suministro, 113

cadenas de suministro sostenibles, 144-45

cambios ambientales, 19

cambios climáticos, 51-59

acuerdos internacionales, 58-59 adaptación basada en el ecosistema, 57-58

agricultura, 183-84

agua, 177

áreas protegidas, 55, 59

biodiversidad, 52-55

bosques, 56, 153

desastres naturales, 101

ecosistemas, 54-55

especies, 52-54, 157-58

impacto sobre el hombre, $57-58$

islas, $55-56$

océanos, 155-56

REDD, 56-57

servicios de los ecosistemas, 55

temperaturas, 52-53

tierras secas, 167

cambios generales, 16, 25-26, 197-99

capacidad de carga de nuestro planeta, 33, 116

capacidad y financiación, 64-65, 132

capital natural, 115

Captura y almacenamiento de carbono (CCS), 156, 167

carbono

bosques, 153

ciudades, 187

y economía, 58-59, 113

océanos, 156

secuestración, 125

tierras secas, 167

carne de animales silvestres, 91

Carta de la Tierra, 29, 32, 33

Carta Mundial de la Naturaleza, 29-31

caudales ambientales, 174

caudales de agua, 82, 100, 174

caza furtiva, 91, 92

Centro de Derecho Ambiental (CDA), 130-31, 201, 202

Centro Internacional de Agua Potable y Saneamiento (IRC), 176

certificación, programa de, 114

Chicago Wilderness, 190-91

China, 80, 116

ciudades. Ver sistemas urbanos

clima, 51-52, 126

Coca-Cola y WWF, 140

combustibles fósiles, alternativas, 80

comercio, 72, 73, 107, 133

Comisión Brundtland, 130

Comisión de Política Ambiental, Económica y Social de la UICN (CPAES), 119

Comisión de Supervivencia de Especies (CSE), 54, 180

Comisión Económica de las Naciones Unidas para 
Europa (UNECE), 114

Comisión Europea (CE), 122, 150

Comisión Internacional para la Conservación del Atún Atlántico (ICCAT/CICAA), 157

Comisión Mundial de Áreas Protegidas (CMAP) armonización de comunicación, 195 autogobernanza de las comunidades indígenas, 39 ciudades, 188

cultura y biodiversidad, 37

gestión, 64

hábitats marinos, 62, 159

jóvenes, 66

Comisión Mundial de Represas, 82

Comisión sobre el Desarrollo Sostenible (CSD), 129

Comité del Patrimonio Mundial de la UNESCO, 55

compensaciones, 113

comunidades locales

áreas protegidas, $39,62-63$

cambios climáticos, 57-58

y conservación, 35, 38-41, 202

desertificación, 165

gestión, 37-38, 203

Ver también indígenas, pueblos

conectividad, 64, 182

Conferencia de Estocolmo, 130

Conferencia de las Naciones Unidas sobre Comercio y Desarrollo (UNCTAD), 132-33

Conferencia de las Naciones Unidas sobre el Medio

Ambiente y el Desarrollo. Ver Cumbre de la Tierra conflicto entre el hombre y la vida silvestre, 74-75

conflictos armados y conservación, 89-95

áreas protegidas transfronterizas, $92-94$

biodiversidad, 89-90

impacto sobre la vida silvestre, 90-92

período post conflicto, problemas, 92, 95

recursos naturales, 89-90

Congreso Mundial de la Naturaleza (CMN), 10n1

Congreso Mundial de la Naturaleza (CMN) 2000, 150

Congreso Mundial de la Naturaleza (CMN) 2008

bosques, 148-49

Centro de Recursos 10

ejes temáticos, 15-16

especies, 69

océanos, 158, 159

Ver también Foro Mundial de la Naturaleza

Congreso Mundial de Parques de la UICN, 38, 61, 66, 107

conocimientos

especies, 69-71

océanos y conservación, 159-60

recuperación post desastre, 99 salud humana, 104-5

tierras secas, 167

conocimientos tradicionales, $38,104-5$

Consejo Empresarial Mundial para el Desarrollo

Sostenible (WBCSD), 141

Consejo Internacional de Gobernabilidad del Riesgo

(IRGC), 82, 123

Consejo Internacional de Minería y Metales (ICMM), 139

Consejo Mundial de Energía Eólica, 83

conservación

prácticas tradicionales y modernas, 38-39

puntos centrales, 195-203

puntos centrales para el futuro, 195

consumo y consumidores

clasificación Greendex, 112

consecuencias ambientales, 36

no sostenibilidad, 111

programas de certificación, 114

Convención de la Naciones Unidas de Lucha contra la

Desertificación (UNCCD), 164-65, 167, 168

Convención de las Naciones Unidas sobre el Derecho

del Mar (UNCLOS), 58

Convención de Londres, 158-59

Convención del Patrimonio Mundial, 65, 130

Convención Marco de las Naciones Unidas sobre el

Cambio Climático (CMMUCC/UNFCCC), 52, $56-57,58,59,130$

Convención sobre el comercio internacional de especies amenazadas de fauna y flora silvestres (CITES), 73,130

Convención sobre las Especies Migratorias (CMS), 58-59, 130

Convención de las Naciones Unidas de Lucha contra la Desertificación (UNCCD/CNULD), 58

Convenio sobre la Diversidad Biológica (CDB) acuerdos, armonización, 130

adopción de la, 32

apoyo financiero, 132

áreas protegidas, 63,65

biodiversidad, valor de, 31

cambios climáticos, 58-59

Conferencia de las Partes, 129, 193, 199

conflictos armados, 94

conocimientos y modos de vida tradicionales, 37

conservación marina, 158

enfoque de los ecosistemas, 36

especies, 71-72

gobernanza, 200

meta de Biodiversidad 2010, 17

OGM, 124-25 
servicios de los ecosistemas, 46-47

tierras secas, 168

cooperación internacional, 129-36

acuerdos, 130-31, 134-35

cuerpos de agua, 176

futuro, 135-36

implementación, 132-33

opinión pública, 133-34

voluntad política, 133-35

Costa Rica, 47, 49

Cradle to Cradle (McDonough y Braungart), 116-17

Cristal, 58

Criterios Mundiales de Turismo Sostenible, 140

Cuenta hacia atrás 2010, 188

Cuidar la Tierra, 29, 31-32

cultura

diversidad, 37

servicios de los ecosistemas, 44,46

valor de la biodiversidad, 48-49

vinculada al medio ambiente, 198

Cumbre de la Tierra, 32, 33, 46

Cumbre Mundial sobre el Desarrollo Sostenible

(WSSD), 17, 46, 134, 175

Declaración de Estocolmo, 29, 31, 58

Declaración de las Naciones Unidas de los Derechos de los Pueblos Indígenas de 2007, 38

Declaración de Río, 33

Declaración del Milenio, 23

deforestación, 56-57, 147, 159-50

demografía. Ver población

derechos humanos, principios del CDA, 202

derechos, 38, 58, 201-2

desarrollo

y bosques, $149-50$

y medio ambiente, 20-25, 134, 196

objetivos, 21-22, 23-26

recursos naturales, 115

zonas post conflicto, 92

desarrollo sostenible, energía, 84-86

desastres naturales y ecosistemas, 97-101

apoyo de políticas, 100

cambios climáticos futuros, 101

capacidades, 100

especies invasoras, 98-99

impacto, 99

plan ambiental, 97-98

planificación para la recuperación, 98-101

desertificación, 164-65, 167

Diálogo sobre los Bosques Tropicales, 151
Directrices para la aplicación de las categorías de gestión de áreas protegidas de la UICN, 62

Directrices sobre sitios naturales sagrados, 63

Durban, Acuerdo de, 38, 61, 64

ecoagricultura, 22, 181

ECOLEX, 130-31

economía

y agua, $82-83,176$

carbón, 59, 113

modelos sostenibles, 116-17

no sostenibilidad, 111, 115-16

recursos naturales, 112,115

valor de la naturaleza, 48

Ver también economía verde, desarrollo

Economía de los Ecosistemas y la Biodiversidad, La (TEEB), 48, 196, 199

economía verde, desarrollo, 111-17

gestión de recursos, 115

incentivos para la conservación, 113-14

medición de la sostenibilidad, 112

modelos económicos alternativos, 115-17

valoración del medio ambiente, 112-13

ecosistemas

cambios climáticos, 54-55

desastres naturales, 97-101

EbA, 57-58

necesidades humanas, 35-36

Ver también servicios de los ecosistemas

Edward, lago, 91-92

eficiencia energética, 80

ejércitos, y conservación, 94

empresas

desempeño ambiental, 144-45

impacto sobre la biodiversidad, 139

participación en la conservación, 141-45

preocupación por la sostenibilidad, 141

RSE, 136, 141, 144

"verde", 145

Ver también sector privada

energía, 79-86

agua, 177

alternativas, 80-84

biomasa, 81-82

conservación, 80, 86

consumo para TI, 120

costos y beneficios, 85

desarrollo sostenible, 84-86

eficiencia, 80

eólica, 83 
geotérmica, 84

hidroenergía, 82-83

nuclear, $80-81$

olas y mareas, 84

solar, 84

enfermedades

aparición y propagación, 105, 106, 107

áreas protegidas transfronterizas, 107-9

control y impacto sobre el medio ambiente, 106

Enfoque por ecosistemas del Convenio sobre la

Diversidad Biológica, 36

eólica, energía, 83

equidad, 200-201

escala del paisaje, 100, 147-48, 174, 181

espacios verdes, ciudades, 188-89

especies, 69-77

y agricultura, 180, 185

agua dulce, 171

cambios climáticos, 52-54, 157-58

ciudades, 187, 192

comercio internacional, 72, 73

conflicto entre el hombre y la vida silvestre, 74-75

conocimientos, faltas, 69-71

conservación de, 69

descubrimientos de, 92

estudios hechos por la TI, 121

futuro de la conservación, 76-77

información e identificación, 69-70

parientes silvestres, 180

pesca, 157

salud humana, 104-6

tierras secas, 164

uso sostenible, 71-74

especies amenazadas, 75-76

especies domesticadas, 180

especies invasoras, 54, 74-77

agua dulce, 171-72

áreas protegidas, 63

aves, 75

biocarburantes, 81

y biodiversidad, 74

ciudades, 187

desastres naturales, 98-99

erradicación y control, 76

y especies amenazadas, 75-76

especies no nativas, 63

especies protegidas, carne de animales silvestres, 91

especies silvestres, comercio de, 72, 73

Estado de los Bosques del Mundo 2009, El, 147

Estado de la Pesca Mundial, 156-57
Estándar Internacional para la Recolección Silvestre Sostenible

de Plantas Medicinales y Aromáticas (ISSC-MAP), 107

Estrategia Mundial para la Conservación, 29

Estrategias y planes de acción nacionales para la

diversidad biológica (EPANDB), 185

ética de la conservación, 29-33

acción colectiva, 31-33

herramientas, 33

responsabilidad individual, $32-33$

valores, 29-31

Evaluación de la Degradación de la Tierras Secas, 167

Evaluación de los Ecosistemas del Milenio (EM), 111

agricultura, 179

biodiversidad, 18

especies invasoras, 75

servicios de los ecosistemas, 20, 35, 43, 44

tierras secas, 164

FAO (Organización de las Naciones Unidas para la Agricultura y la Alimentación)

acuerdos internacionales, 131

agricultura, 185

bosques, 147, 152

hambre, 20-22

pesca, 73, 156-57

tierras secas, 167

fenómenos extremos. Ver desastres naturales y ecosistemas fertilización del océano, 125, 156, 158-59

Filipinas, 90

financiación y capacidad, 64-65, 132

Fondo de Desarrollo de Negocios, 152

Fondo del Agua de Quito, 177

Fondo para el Medio Ambiente Mundial (FMAM), 132

Forest Trends, 152

Foro de Barcelona. Ver Foro Mundial de la Naturaleza

Foro de Evaluación de la Energía Hidroeléctrica, 82

Foro Mundial de la Naturaleza

Centro de Recursos, 10

ejes temáticos, 15-16

especies, 69

sectores empresariales, 139

Ver también Congreso Mundial de la Naturaleza (CMN) 2008

fronteras, 176

Ver también áreas protegidas transfronterizas

Fundación Asahi Glass, 133

ganado, 107, 179

gases de efecto invernadero (GHG), 51-52, 120, 187

genética, 121-22 
Ver también organismos genéticamente modificados (OGM)

geoingeniería, 125-26, 156

geotérmica, 84

gestión

agua y caudales, 174, 176, 177

áreas protegidas, 62-64

enfoques incluyentes, 203

océanos, 159

pesca, $157-58$

programas de conservación, 39-41

recursos naturales, $73,114,115$

residuos post desastre, 99

resultados de la TI, 121

tierras secas, 167-68

gestión adaptable, 200, 200

Gestión forestal sostenible (GFS), 148, 150, 151

globalización, impacto ambiental, 36

GlobeScan, 111

gobernanza

agua, 174-76

áreas protegidas, 65

bosques, 150-51

eficaz, 200

océanos, 158-59

tierras secas, 168

gobiernos, 59, 92-93, 196

goma arábiga, 166

Google Earth y Google Ocean, 62, 159

Gran Limpopo, 107-8

Greendex, 111-12

Grupo consultivo occidental de la ballena gris (WGWAP), 144

Grupo de trabajo sobre la ética de la conservación, 29

Grupo especialista de la CSE/UICN en especies invasoras (ISSG), 75

Grupo especialista de la CSE/UICN sobre uso sostenible, 72

Grupo Intergubernamental de Expertos sobre el Cambio Climático (IPCC), 51, 153

guerra. Ver conflictos armados y conservación

hambre, 20-22

herramientas

áreas protegidas, 62

ética de la conservación, 33

recursos hídricos, 172

hidroenergía, 82-83, 177

hipopótamos, 91

huella hídrica, 173 humanidad, 31-33, 133

humo del fuego, impacto sobre la salud, $84-85$

idiomas, desaparición, 198

igualdad entre los sexos, 200-201

INB, y financiación de ODA, 132

India, 90

indicadores económicos de la conservación, 114

indicadores, biodiversidad, 17-18

Índice del Planeta Viviente, 33

indígenas, pueblos

conocimientos tradicionales, 37-38

y conservación, 38-41, 202

derechos, 38

desertificación, 165

participación en la gestión, 203

Informe sobre el Desarrollo Mundial 2008, 20

Infraestructura Mundial de Información en Biodiversidad (GBIF), 70

iniciativa Manglares para el futuro, 56-57

Iniciativa Mundial sobre Taxonomía, 71

Instituto Internacional para el Medio Ambiente y

Desarrollo (IIED), 152

Inventario de todos los taxones existentes, 70

Inversiones extranjeras directas (IED), 132-33

inversiones, gestión del agua, 177

islas, cambios climáticos, 55-56

jóvenes, áreas protegidas, 66

Katrina, huracán, 99

"lavado verde", 144

legislación ambiental, 136

leyes

agua, gestión, 175

bosques, $150-51$

leyes internacionales

conflictos armados, 94-95

medio ambiente, 136

Lista Roja de Especies Amenazadas 2008 de la UICN, 17, 70-71, 122, 147, 171

Londres, biodiversidad, 188

lugares críticos de la biodiversidad, 27, 89

Manejo Integrado de los Recursos Hídricos (IWRM), 172, 174, 175, 176, 177

Manejo intensivo de los bosques plantados: hacia mejores prácticas y más allá de REDD - la función de los bosques en el cambio climático, 152 
Marco de Acción de Hyogo 2005-2015, 59

Mecanismo para un desarrollo limpio (MDL), 113

medio ambiente

acuerdos internacionales, 130-31

cambios para el hombre, 198

capacidad de carga, 33

y desarrollo, 20-25, 134, 196

desastres naturales, 97-101

dinámica, 19-20

integración en todos los sectores, 196-97

leyes y regulaciones, 136

y mujeres, 200-201

opinión pública, 133

reuniones futuras, $134-35$

salud humana, 106

valoración económica, 112-13, 199

medios de subsistencia, bosques, 151-52

mercados alimentarios, carne de animales silvestres, 91

mercados del carbono, 113

mercados económicos

incentivos para la conservación, 113-14

madera, 150-51

servicios de los ecosistemas y PSE, 46-47, 49, 114

Mesa Redonda sobre Biocombustibles Sostenibles, 82

meta de Biodiversidad 2010, 17-20

microorganismos, 105-6, 126

migración animal, y conflictos armados, 92

monocultivo, 183-84

mujeres

agricultura, 184-85

gestión de agua, 176

igualdad de los sexos, 200-201

papel en la conservación, 201

murciélagos, 83, 183

Naciones Unidas, 158, 172

nanotecnología, 122-23

National Geographic, 111

naturaleza

modelo tecnológico, 122-23

valor, $48,188-90$

naxalitas, 90

Nepal, conflicto y conservación, 93

nuclear, energía, 80-81

Objetivos de Desarrollo del Milenio (ODM)

acuerdos internacionales, 134

agua, 100

cambios climáticos, 58

hambre, 21-22 medio ambiente, 23-25, 199

servicios de los ecosistemas, 46-47

océanos y mares

áreas marinas protegidas, 62, 158, 159-60

cambios climáticos, 155-56

fertilización, 125, 156, 158-59

gestión, 159

gobernanza, 158-59

olas y mareas, energía de, 84

Ver también sistemas marinos

Oficina del Alto Comisionado de Naciones Unidas para los Derechos Humanos, 58

olas y mareas, energía de, 84

ONU-Hábitat, 187

organismos genéticamente modificados (OGM), 124-25

Organización Meteorológica Mundial (OMM), 167

Organización Mundial de Comercio (OMC), 158

Organización Mundial de la Salud (OMS), 107

Organización Mundial del Turismo (UNWTO), 140

Organización para la Cooperación y el Desarrollo

Económicos (OCDE), 115

OCDE-CAD, 1932

Pagos por los servicios de los ecosistemas (PSE), 45

agua dulce y presas, $176-77$

bosques, $150-51$

colaboración internacional, 132

economía verde, 113-14

legislación, 136

países en desarrollo, 21-23, 84-85, 132

Parque Nacional de Garamba, 91

Parque Nacional de Virunga, 91-92

Parque Nacional Yala, 98

parques nacionales, 65, 92-93, 188

Ver también áreas protegidas

parques para promover la paz, 92-94

Partes en el CDB, áreas protegidas, 65

pastoralismo, 164

paz, y creación de áreas protegidas, 92-94

peces de agua dulce, situación, 171-72

Perspectiva Mundial sobre Diversidad Biológica 2 (GBO2), 17-19

Perspectivas de la energía en el mundo - 2008, 79-80

pesca

cambios climáticos, 156

caza furtiva, 91-92

energía eólica, 83

especies, 157

gestión, 157-58

sobrepesca, 73, 156-57 
subvenciones, 114-15

petróleo, alternativas, 79-80

planificación, 98-101, 198

plantas medicinales, 104, 107

plantas, y agricultura, 180-81

población

ciudades, 1997

y cuerpos de agua, 176

espacios verdes, 189

mundial, 24-27

salud humana, 103

pobreza

y bosques, 147

y cambios climáticos, 58

lugares críticos de la biodiversidad, 89

situación en 2008, 20

pobreza, reducción

y conservación de la biodiversidad, 20, 23

y medio ambiente, 197

y servicios de los ecosistemas, 20-23

Tanzania, 197

política

cooperación internacional, 133-35

gobernanza del agua, 175

recuperación post desastre, 100

reuniones futuros sobre el medio ambiente, 135

y servicios de los ecosistemas, 46-47

tierras secas, 168

política de equidad entre les sexos, 200-201

presas hidrográficas, 176-77, 181

Ver también ríos y presas

Principio de precaución, 33, 122, 127

Principios de Dublin, 174

Principios de Río 10, 203

Programa de Compensaciones de Negocios y

Biodiversidad (BBOP), 113

Programa de las Naciones Unidas para el Medio

Ambiente (PNUMA), 36, 98, 131

Programa de Restauración del Paisaje Forestal y la

Comisión Mundial de Áreas Protegidas, 37

Programa Marino, 62

Programa mundial sobre especies invasoras (GISP),

75-76, 81

Protocolo de Cartagena, 125

Protocolo de Kioto, 113

Protocolo de Montreal, 31-32

pueblo y individuos

derechos, 38

naturaleza y ciudades, 188, 191-92

papel en la conservación, 39-41 responsabilidad ambiental, 32-33

servicios de los ecosistemas, 35-36, 44

Ver también comunidades locales

Ramsar (Convención de), 58, 130

recuperación

bosques, 148-50, 153

desastres naturales, 97-101

recursos naturales

conflictos civiles, 89-90

y consumo, 36

y economía, 112, 115

gestión, 73, 114, 115

países en desarrollo, 21-23

Red Global de Áreas Protegidas Transfronterizas, 93

red sobre Caudales Ambientales, 174

Reducción de las Emisiones derivadas de la

Deforestación y la Degradación de los bosques

(REDD), 47, 56-57, 151, 152

reforestación, en Filipinas, 90

Registro de Partes Biológicas Estándar, 126

Reino Unido, 84, 120

República Democrática del Congo, 91

reserva forestal Mabira, 149

residuos, 99, 120

Responsabilidad Social Empresarial (RSE), 136, 141, 144

Revisión Eliasch, 56

ríos y presas, 82, 113-14

Sakhalin Energy, 144

Salud animal para el ambiente y el desarrollo (AHEAD), 107-9

salud humana, 103-8

afectaciones a los ecosistemas, 106

biodiversidad, importancia, 103-4, 106-7, 109

conocimientos tradicionales, 104-5

contribución de especies, 104-6

microorganismos, 105-6

OGM, 125

plantas medicinales, 104-5

y salud de los animales, 107-9

servicios de los ecosistemas, 106

sector privada, colaboración, 136, 139-45

asociaciones para la conservación, 142-45

establecimiento de relaciones, 142-44

sostenibilidad, 196

ventajas, 144-45

Servicio de Información sobre Especies de la UICN, 70

Servicio de Supervivencia de Especies, 69

servicios de los ecosistemas, 43-49 
agricultura, 43

agua dulce, 172-73

cambios climáticos, 55

clasificación, 44-46

concepto, 20

conservación, modelo para la, 195

cultura, 44, 46

dinámica, 19-20

inclusión en la economía, 46-47, 49, 114-15

y pobreza, 20-23

política y planificación, 46-47

recuperación post desastre, 99

ríos y presas, 113-14

salud humana, 106

tierras secas, 166-67

usos de la TI, 121

valor y beneficios, 45-46, 47-48

valoración, 47-49

Ver también pago por los servicios de los ecosistemas (PSE)

sistemas agrícolas, $179-85$

hábitats naturales, 181-82

imitación de ecosistemas naturales, 182-85

producción agrícola, 180-82

Ver también agricultura

sistemas áridas, 163-68

agricultura, 164

agua, gestión, 167-68

biodiversidad, 164, 165

cambios climáticos, 167

desertificación, 164-65, 167

distribución mundial, 163

gobernanza, 168

problemas, 165-67

servicios de los ecosistemas, 166-67

sistemas de agua dulce, 171-77

cambios climáticos, 177

especies invasoras, 171-72

gestión y caudales, 174, 177

gobernanza, 174-76

servicios de los ecosistemas y PSE, 172-73, 176-77

sistemas forestales, 147-53

cambios climáticos, 153

leyes y gobernanza, 150-51

medios de subsistencia, 151-52

recuperación, 148-50

tala ilegal, 150-51

Ver también bosques

sistemas marinos, 155-60

áreas marinas protegidas, $62,158,159-60$ cambios climáticos, 155-56

gobernanza, 158-59

sobrepesca, 73, 156-58

Ver también océanos y mares

sistemas urbanos, 187-93

espacios verdes y áreas protegidas, 188-89

especies, 187, 192

impacto, 197

naturaleza y biodiversidad, 190-93

valor de la naturaleza, 188-90

sitios del Patrimonio Mundial, 61

sitios sagrados, 63

sobrepesca, 73, 156-58

solar, energía, 84

sostenibilidad

y economía, 111, 115-16

innovaciones, 199

integración del medio ambiente, 197

preocupación de las empresas, 141

Species 2000, 71

Sri Lanka, 198

Stern, informe, 56, 57

subvenciones e incentivos fiscales, 114

Sudáfrica, 175

Sudán, 92, 166

Sudd, migración animal, 92

Tanzania, 197

taxonomía, 70-71

tecnología de la información (TI)

beneficios para la conservación, 121

y biodiversidad, 121, 122

impacto sobre el medio ambiente, 120

tecnologías tradicionales, 119

tecnología y conservación, 119-27

biología sintética, 126

biomimética, 123-24

biotecnología, 122-27

geoingeniería, 125-26

impacto, 119

nanotecnología, 122-23

OGM, 124-25

tecnología de la información, 120-22

Tematea, 130

temperatura, mayor, 53

termita subterránea de Formosa, 99

Terranova y Labrador, 203

territorios tradicionales, biodiversidad, 38-39

tierras secas. Ver sistemas áridas

tigres, 90 
tilapia, 91-92

TRAFFIC, 107

Transición a la Sostenibilidad: hacia un mundo bumanitario y diverso, 203

turismo sostenible, 140

Uganda, 91

Unión Europea (UE), 73

Unión Internacional para la Conservación de la Naturaleza (UICN)

acuerdos internacionales, 130-31

agua, 172, 174, 175

biodiversidad cultural, 37

cambios climáticos, 56

ciudades, 188

CMAP, 159

comunidades locales, 202-3

conflictos armados, 92, 94, 95

derechos, 38, 201

economía verde, 117

energía, 81-82, 85

equidad, 200-201

especies, 180

ética, posición, 31

GFP, 152

gobernanza, 151-52, 200

hidroenergía, 82

industrias extractivas, 139

necesidades humanas, 35

OGM, 124-25

plantas medicinales, 107

sector privada, 142, 144

tierras secas, 163-64

turismo sostenible, 140

visión y misión, 200

uso sostenible

especies, 71-74

gestión, 73

productos forestales, 90

valor

del medio ambiente, 112-13, 199

de la naturaleza, 48-49, 188-90

servicios de los ecosistemas, 45-46, 47-48

valores

y el consumo, 36

ética y conservación, 29-31

Venter, J. Craig y Instituto Venter, 126

Vía Campesina, 125

vida silvestre, 74-75, 90-92, 107-9
Visión del agua y la naturaleza, 172

Water footprint, 173

Wildlife Conservation Society, 92, 107

WWF (Fondo Mundial para la Naturaleza), 107, 140

Yemen, 185 


\section{Créditos fotográficos:}

Página 7 (C) UICN/Sue Mainka • Página 8 (C Daria Motorna/Dreamstime.com • Página 11 @ Martin Harvey/Still Pictures • Página 12 (C) Corbis • Página 14 (C) R. Gemperle/Still Pictures • Página 27 (C) Jack Dykinga/naturepl.com • Página 28 @ Flikr/daveblume • Página 34 @ Corbis • Página 40 @ Reuters/ Enrique Castro-Mendivil • Página 42 (C) Earl \& Nazima Kowall/Corbis • Página 50 @ Paul Marshall • Página 60 (C) Massimo Ripani/Grand Tour/Corbis • Página67 (C) Franck Charton/Corbis • Página 68 (C) Tim Davis/Corbis • Página 71 C UICN/Sue Mainka • Página 77 @ McPHOTO/Still Pictures • Página 78 @ Mirounga/Dreamstime.com • Página 87 @ Daniel Deitschel/Getty images • Página 88 @ Reuters/ Carlos Barria • Página 93 @ Reuters/Pool/Themba Hadebe • Página 94 @ Jung Yeon-Je/Getty images • Página 96 @ Reuters/Kamal Kishore • Página 102 @ UICN/Sue Mainka • Página 108 @ R. Gemperle/ Still Pictures • Página 110 (C) Corbis • Página 116 @ Nigel Dickinson/Still Pictures • Página 118 ( Dave Watts/naturepl.com • Página 124 (C) Uwe Wittbrock/Fotolia.com • Página 128 (C) Markus Seidel/iStockphoto • Página 135 (C) Alex Nikada/iStockphoto • Página 137 @ A. Ishokon-UNEP/Still Pictures • Página 138 @ Manfred Vollmer/Das Fotoarchiv/Still Pictures • Página 143 @ Reuters/Luke Distelhorst - Página 146 (C) Wild Wonders of Europe/Döerr/naturepl.com • Página 153 @ Andy Rouse/naturepl. com • Página 154 C Reinhard Dirscherl/WaterFrame/Still Pictures • Página 161 C Reuters/Babu Babu - Página 162 @ Iconotec • Página 169 @ Digital vision • Página 170 @ Biosphoto/Robert Valarcher/ Still Pictures • Página 178 @ Reuters/Sonam Wangdi • Página 185 @ Reuters/China Photos • Página 186 (C) El Fotopakismo/Flikr • Página 193 @ Elizabeth Brixton/Flikr • Página 194 @ Aflo/naturepl.com - Página 203 @ Galdzer/Dreamstime.com 


\section{UICN}

UNIÓN INTERNACIONAL PARA LA CONSERVACIÓN DE LA NATURALEZA

SEDE MUNDIAL

Rue Mauverney 28

1196 Gland, Suiza

Tél +41229990000

$\mathrm{Fax}+41229990020$

www.iucn.org

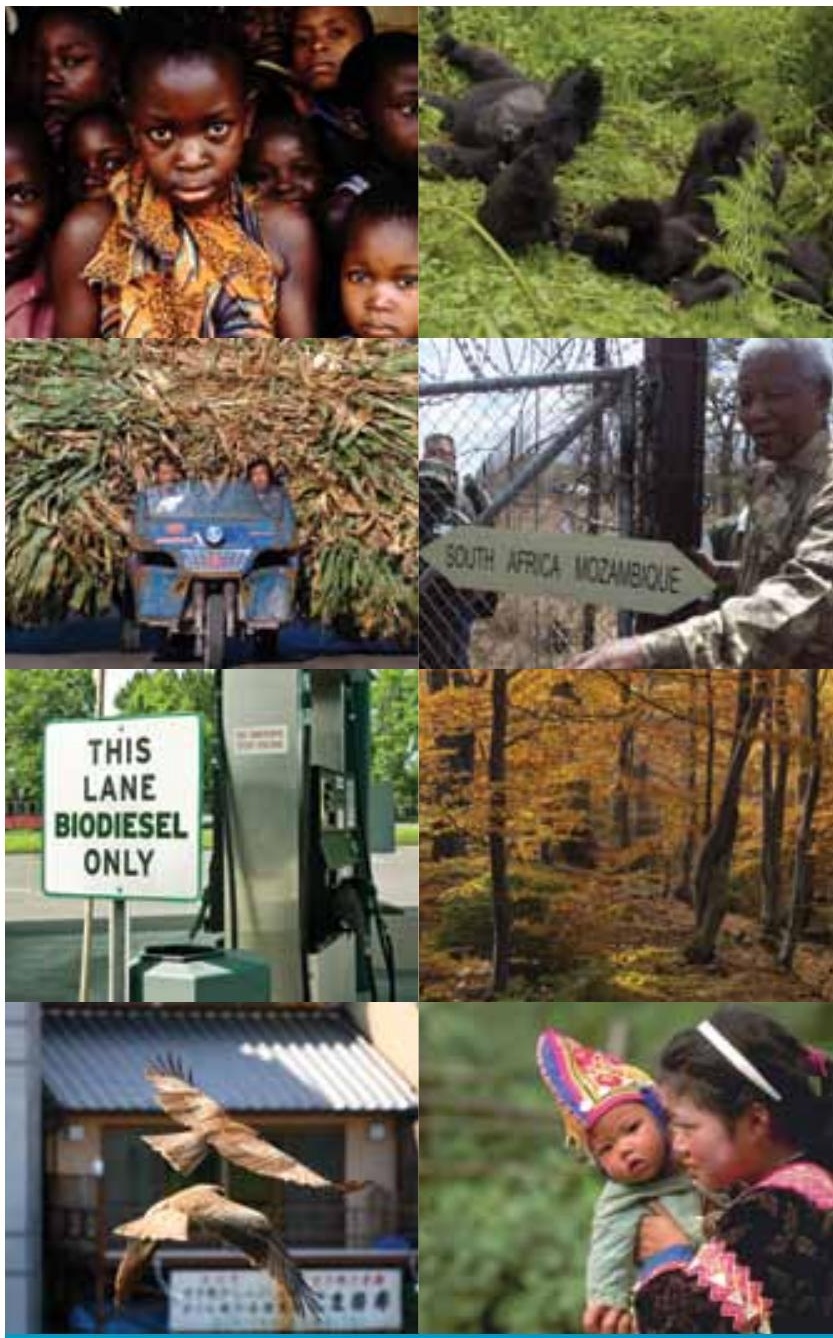

